\title{
Trick or treat?
}

Citation for published version (APA):

IJff, D. M. (2016). Trick or treat? cognitive side-effects of antiepileptic treatment. [Doctoral Thesis, Maastricht University]. Maastricht University. https://doi.org/10.26481/dis.20161209di

\section{Document status and date:}

Published: 01/01/2016

DOI:

10.26481/dis.20161209di

Document Version:

Publisher's PDF, also known as Version of record

\section{Please check the document version of this publication:}

- A submitted manuscript is the version of the article upon submission and before peer-review. There can be important differences between the submitted version and the official published version of record.

People interested in the research are advised to contact the author for the final version of the publication, or visit the DOI to the publisher's website.

- The final author version and the galley proof are versions of the publication after peer review.

- The final published version features the final layout of the paper including the volume, issue and page numbers.

Link to publication

\footnotetext{
General rights Owners
rights.

- You may freely distribute the URL identifying the publication in the public portal. please follow below link for the End User Agreement:

www.umlib.nl/taverne-license

Take down policy

If you believe that this document breaches copyright please contact us at:

repository@maastrichtuniversity.nl

providing details and we will investigate your claim.
}

Copyright and moral rights for the publications made accessible in the public portal are retained by the authors and/or other copyright owners and it is a condition of accessing publications that users recognise and abide by the legal requirements associated with these

- Users may download and print one copy of any publication from the public portal for the purpose of private study or research.

- You may not further distribute the material or use it for any profit-making activity or commercial gain

If the publication is distributed under the terms of Article $25 \mathrm{fa}$ of the Dutch Copyright Act, indicated by the "Taverne" license above, 


\section{TRICK or TREAT?}

Cognitive side-effects of antiepileptic treatment 
Printing and dissemination of this thesis was financially supported by the department of Research and Development Kempenhaeghe, School for Mental Health and Neurosciences (MHENS) Maastricht University, UCB Pharma BV, Eisai BV and Nutricia Advanced Medical Nutrition.

Cover: Xander Abbink, XAdesign.nl

Photo: iStock.com

Lay-out: Tiny Wouters

Printing: Ipskamp Drukkers

ISBN: 978-94-028-0401-0

(c) Dominique IJff, Maastricht 2016

No part of this these may be reproduced or transmitted in any form or by any means, electronic or mechanical, including photocopy, recording or otherwise without permission of the author. For all articles published or accepted the copyright has been transferred to the respective publisher. 


\section{TRICK or TREAT?}

\section{Cognitive side-effects of antiepileptic treatment}

\section{PROEFSCHRIFT}

Ter verkrijging van de graad van doctor aan de Universiteit Maastricht, op gezag van de Rector Magnificus, Prof. dr. Rianne M. Letschert, volgens het besluit van het College van Decanen,

in het openbaar te verdedigen op

vrijdag 9 december 2016 om 10:00 uur

door

Dominique Mistral IJff 


\section{Promotores}

Prof. dr. A.P. Aldenkamp

Prof. dr. H.J.M. Majoie

\section{Copromotores}

Dr. J.F.A. Jansen

Dr. R.H. Lazeron, Kempenhaeghe, Heeze

\section{Beoordelingscommissie}

Prof. dr. R.J. van Oostenbrugge (voorzitter)

Prof. Dr. G.A. Baker (Liverpool)

Dr. H.P. Bootsma (Gelderse Vallei)

Dr. R.P.W. Rouhl

Prof. dr. F. Verhey 


\section{Contents}

Chapter 1 General introduction

Part I Literature

Chapter 2 Cognitive side-effects of antiepileptic drugs.

Pediatric Epilepsy. New York: McGraw-Hill Professional;2012:424-36.

Handbook of clinical neurology. Oxford: Elsevier Science;2013:707-18.

Part II Bridging the gap of our knowledge

Chapter 3 Cognitive effects of lacosamide as adjunctive therapy in refractory

epilepsy.

Acta Neurol Scand. 2015;131:347-54.

Chapter 4 The cognitive profile of ethosuximide in children.

Pediatr Drugs 2016;18:379-85.

Chapter 5 Cognitive and behavioral impact of the ketogenic diet in children and adolescents with intractable epilepsy: a randomized controlled trial. Epilepsy Behav. 2016;60:153-7

Chapter 6 Long-term impact of antiepileptic drug treatment on cognitive development.

Submitted.

Part III Clinical relevance of subjective reports

Chapter 7 Subjectively perceived side-effects of antiepileptic drugs in chronic refractory epilepsy.

Adv Pharmacoepidemiol Drug Saf 2015;4:186.

Chapter 8 Cognitive adverse effects of antiepileptic drug treatment; how to recognize who is at risk.

Submitted.

Chapter 9 Effect of chronic high risk anti-epileptic drug use on functional status; a ten year follow-up study using the Barthel Index.

Submitted.

Part IV AEDs and the brain

Chapter 10 Glutamate concentrations vary with antiepileptic drug use and mental slowing.

Epilepsy Behav. 2016;64:200-205. 
Chapter 11 Chronic AED use and functional network efficiency.

Submitted.

Chapter 12 General discussion

Summary

183

Samenvatting

189

Valorisatie

195

Dankwoord

201

Curriculum Vitae

209

List of publications

213 



\section{Chapter 1}

General introduction 
Chapter 1 


\section{Introduction}

Epilepsy is a neurological disorder characterized by the occurrence of unprovoked epileptic seizures that may differ in their manifestation. Worldwide, about 70 million people are estimated to have epilepsy. ${ }^{1,2}$ The highest incidence is found in children ${ }^{3}$ and the prevalence of epilepsy among people with intellectual disabilities is much higher than in the general population, ${ }^{4}$ where one in five will have epilepsy (22\%).

Seizures can be divided into generalized seizures occurring in both hemispheres (bilaterally) such as tonic-clonic seizures or absences or focal, partial seizures which are limited to one hemisphere. ${ }^{5}$ Classification of type of epilepsy based on etiology has recently been replaced from idiopathic (no underlying cause, presumed genetic), symptomatic (known or suspected disorder of the central nervous system) and cryptogenic (no underlying etiology identified, unknown cause) to genetic, structuralmetabolic, and unknown. ${ }^{5}$

Cognitive impairment is a common comorbidity in patients with epilepsy. ${ }^{6}$ Different factors contribute to the development of cognitive impairment in people with epilepsy, such as age at onset, underlying etiology or the frequency and severity of seizures. Furthermore, treatment can adversely affect cognition.

In the majority of the patients, epilepsy is treated with antiepileptic drugs (AEDs) which have as primarily goal to control seizures without causing any side-effects. The accurate balance between efficacy of the drug in controlling the seizures and the tolerability (the avoidance of side-effects) is important for optimal treatment effects and compliance. Many AEDs are available and during the last 20 years, the list of new AEDs that have been developed, shows a steep increase (see Figure 1.1). Monotherapy is always preferred but after failure of one or more AEDs, a combination therapy is usually considered.

In literature, several synonyms are used for refractory of epilepsy such as intractability, drug-resistant or pharmaco-resistant which indicates that two AEDs have failed to achieve sustained seizure freedom. ${ }^{7}$ About one third of patients suffer from refractory epilepsy, both in children ${ }^{8}$ and in adults. ${ }^{9}$ These patients mostly have frequent seizures, are at risk for status epilepticus and often use high dosing polytherapy which will last for years. For these patients also alternative nonpharmacological treatment options are available, such as epilepsy surgery, vagus nerve stimulation and the ketogenic diet. Of all patients with epilepsy in the Netherlands, about $25 \%$ of the epilepsy patients is referred to a specialized (tertiary referral) center for further treatment considerations or uncertainty about the diagnosis.

One of the complications of AED treatment is the occurrence of side-effects. There seems to be agreement that polytherapy and high-dose treatment can produce cognitive side-effects. ${ }^{10,11}$ However, even in patients who are well-controlled and on monotherapy, ${ }^{12}$ cognitive side-effects are among the most commonly reported complaints in patients. ${ }^{13,14}$ Children are potentially more susceptible to the adverse 
effects of AEDs than adults because of the potential effects of AEDs on brain maturation and hence on neurodevelopment. Furthermore, children have a higher risk of learning disabilities and poor academic performance. ${ }^{15}$ Effective and timely control of the development of side-effects are therefore an important aspect of establishing overall treatment effectiveness.

\section{Antiepileptic drugs}

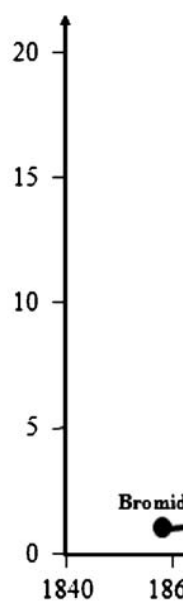

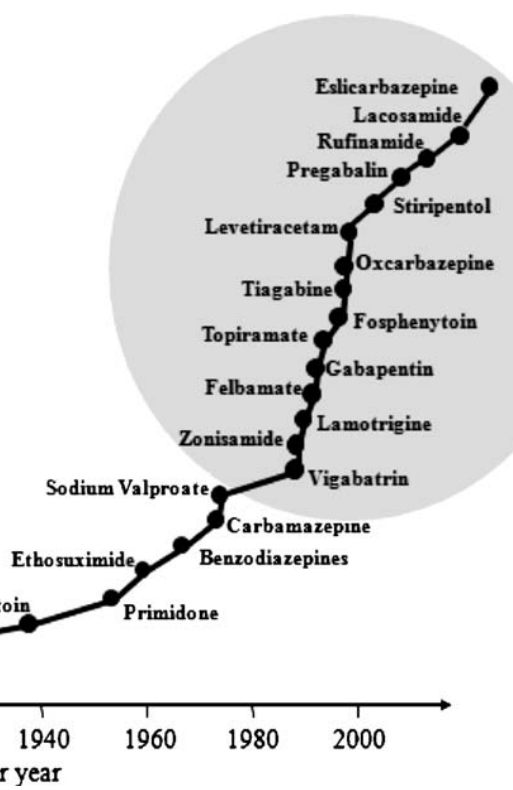

Figure 1.1 Adapted from Brodie \& Sills (2011). ${ }^{16}$ 


\section{Aim and outline of this thesis}

The aim of this thesis is to investigate the cognitive adverse effects of antiepileptic treatment in patients with refractory epilepsy. This thesis is divided in four parts. Part I starts with an overview of the available literature about the cognitive effects in adults and in children and also highlights the missing information (chapter 2). In part II, we discuss the cognitive functions that can be affected by antiepileptic treatment and some topics that will bridge the gap of our knowledge and thus fill the gaps identified in chapter 2. We focus on the cognitive profiles of two AEDs that have not been yet investigated; lacosamide, which is a relatively new drug (chapter 3) and ethosuximide which is an old, first-generation drug (chapter 4). Furthermore, we explore the behavioral and cognitive effects of an alternative antiepileptic treatment, the ketogenic diet (chapter 5) and focus on the absence of information of long-term chronic AED-use on cognitive development in children (chapter 6). In part III, the focus is on the clinical relevance of subjective reports. In this part, we not only discuss neuropsychological tests that are commonly used to assess cognition and cognitive side-effects, but we also focus on the subjectively perceived side-effects (chapter 7 ) and the profile of patients who are at risk for developing cognitive side-effects of antiepileptic drug treatment (chapter 8). Furthermore, we use a different method of assessment in a specific patient population, i.e. patients with intellectual disabilities (chapter 9). In part IV, we discuss our attempts identifying the neuronal substrates of cognitive side-effects, using MR spectroscopy and resting state fMRI (chapter 10 and 11). Chapter 12 provides a general discussion of this thesis and will elaborate on future implications of the results. 


\section{References}

1. Ngugi AK, Bottomly C, Kleinschmidt I, Sander JW, Newton CR. Estimation of the burden of active and life-time epilepsy: a meta-analytic approach. Epilepsia 2010;51:883-90.

2. Ngugi AK, Kariuki SM, Bottomley C, Kleinschmidt I, Sander JW, Newton CR. Incidence of epilepsy: a systematic review and meta-analysis. Neurology 2011;77:1005-12.

3. Kotsopoulos IA, van Merode T, Kessels FG, de Krom MC, Knottnerus JA. Systematic review and metaanalysis of incidence studies of epilepsy and unprovoked seizures. Epilepsia 2002;43:1402-9.

4. Bowley C, Kerr M. Epilepsy and intellectual disability. J Intellect Disabil Res 2000;44:529-43.

5. Berg AT, Berkovic SF, Brodie MJ, Buchhalter J, Cross JH, van Emde Boas W, et al. Revised terminology and concepts for organization of seizures and epilepsies: Report of the ILAE commission on classification and terminology, 2005-2009. Epilepsia 2010;51:676-85.

6. Aldenkamp AP, Krom MD, Reijs R. Newer antiepileptic drugs and cognitive issues. Epilepsia 2003:44; 21-9.

7. Kwan P, Arzimanoglou A, Berg AT, Brodie MJ, Hauser WA, Mathern G, et al. Definition of drug resistent epilepsy: consensus proposal by the ad hoc taks force of the ILAE commission on therapeutic strategies. Epilepsia 2010;51:1069-77.

8. Geerts A, Arts WF, Stroink H, Peeters E, Brouwer O, Peters B, et al. Course and outcome of childhood epilepsy: a 15-year follow-up of the Dutch Study of Epilepsy in Childhood. Epilepsia 2010;51:1189-97.

9. Kwan P, Sander JW. The natural history of epilepsy; an epidemiological view. J Neurol Neurosurg Psychiatry 2004;75:1376-81.

10. Mula M, Trimble MR. Antiepileptic drug-induced cognitive adverse effects: potential mechanisms and contributing factors. CNS Drugs 2009;23:121-37.

11. Witt JA, Elger CE, Helmstaedter C. Adverse cognitive effects of antiepileptic pharmacotherapy: each additional drug matters. Eur Neuropsychopharmacol 2015;25:1954-9.

12. Carpay JA, Aldenkamp AP, Donselaar van CA. Complaints associated with the use of antiepileptic drugs: results from a community-based study. Seizure 2005;14:198-206.

13. Uijl SG, Uiterwaal CS, Aldenkamp AP, Carpay JA, Doelman JC, Keizer K, et al. A cross-sectional study of subjective complaints in patients with epilepsy who seem to be well-controlled with anti-epileptic drugs. Seizure 2006;15:242-8.

14. Witt JA, Elger CE, Helmstaedter C. Which drug-induced side effects would be tolerated in the prospect of seizure control? Epilepsy Behav 2013;29:141-3.

15. Loring DW, Meador KJ. Cognitive side effects of antiepileptic drugs in children. Neurology 2004;62: 872-7.

16. Brodie MJ, Sills GJ. Combining antiepileptic drugs- rational polytherapy? Seizure 2011:20;369-75. 


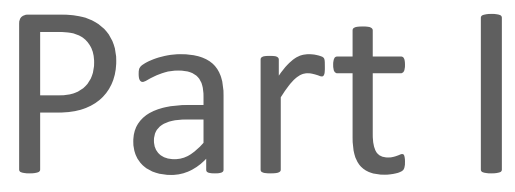

Literature 


\title{
Chapter

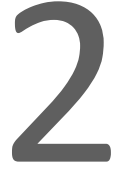

\author{
Cognitive side-effects of \\ antiepileptic drugs
}

Based on:

DM IJff \& AP Aldenkamp Pediatric Epilepsy. New York: McGraw-Hill Professional 2012:424-436 Handbook of clinical neurology. Oxford: Elsevier Science 2013:707-718 


\section{Abstract}

Although the causes of cognitive impairment in patients with epilepsy have not been completely elucidated, three factors are clearly involved: the underlying etiology of epilepsy, the effects of seizures or the epileptiform EEG discharges themselves, and the central nervous system effects of antiepileptic drugs (AEDs). All commonly used AEDs have some effect on cognitive function, and the effect may be substantial when crucial functions are involved, such as learning in children, or driving ability in adults, or when already vulnerable functions are involved, such as memory in elderly patients. For the commonly used AEDs, drug-induced cognitive impairment has been established for phenobarbital, phenytoin and topiramate. Mild effects were found for carbamazepine and valproate. Although the evidence is sketchy, oxcarbazepine and levetiracetam do not seem to have a negative impact on cognition. For lamotrigine, some mild cognitive activating effects were found. In adults, no cognitive effects were found for ethosuximide, rufinamide, tiagabine, and gabapentin, although the evidence requires confirmation. No studies are available for zonisamide. The effects for vigabatrin are inconclusive. For gabapentin, tiagabine, zonisamide, and rufinamide no studies in children are available. 


\section{Introduction}

Cognitive impairment is the most common comorbid disorder in epilepsy. ${ }^{1,2}$ Memory impairments, mental slowing, and attentional deficits are the most frequently reported cognitive disorders. ${ }^{3,4}$ Such consequences may be more debilitating for a patient than the seizures; thus, it is worthwhile to explore the factors that lead to cognitive impairment. The exact cause of cognitive impairment in epilepsy has not been explored fully, but three factors clearly are involved: etiology, the seizures, and the "central" side-effects of drug treatment. ${ }^{5}$ Here we concentrate on the unwanted effects of antiepileptic medication on cognitive function. When evaluating this factor separately, it is imperative to realize that in clinical practice most cognitive problems have a multifactorial origin and that, for the most part, the three aforementioned factors, combined, are responsible for the "makeup" of a cognitive problem in an individual patient. Moreover, the factors are related, which causes therapeutic dilemmas in some patients when seizure control can only be achieved with treatments that are associated with cognitive side-effects.

The interest in the cognitive side-effects of antiepileptic drug (AED) treatment is of recent origin. The possibility that cognitive impairment may develop as a consequence or aftermath of epilepsy was raised as early as 1885 when Gowers described 'epileptic dementia' as an effect of the pathological sequela of seizures. Nonetheless, the topic was not coupled to antiepileptic drug treatment until the 1970 s probably stimulated by the widening range of possibilities for drug treatment during that period (i.e., the introduction of carbamazepine and valproate). ${ }^{6,7}$ Since then, a plethora of studies have been published, the majority on the commonly used AEDs: valproate, carbamazepine, and phenytoin.

In the last decades, several new AEDs have been introduced. Although it is claimed that these drugs have different efficacy profiles and that some drugs are particularly efficacious in specific syndromes, head-to-head comparisons between the newer drugs and the commonly used drugs (such as carbamazepine and valproate) are rare. Nonetheless, meta-analyses such as the influential Cochrane reviews did not show significant differences in efficacy between the newer and classical drugs. ${ }^{8,9}$ Also, studies analyzing long-term retention did not show differences between the drugs. ${ }^{10,11}$

Several studies have shown retention rate to be the best parameter of the long-term clinical usefulness of a particular drug. ${ }^{12}$ Retention rate is considered to be a composite of drug efficacy and drug safety and expresses the willingness of patients to continue drug treatment. It is therefore the best standard for evaluating the clinical relevance of side-effects. The 1-year retention rate is reported to be not higher than $55 \%$ for topiramate ${ }^{13}, 60 \%$ for lamotrigine, $58 \%$ for vigabatrin, and $45 \%$ for gabapentin. ${ }^{14}$ Longterm (mostly 3-year) retention is about 35\% for all newer AEDs. ${ }^{15}$ Side-effects appear to be the major factor affecting long-term retention for most drugs. ${ }^{16,17}$ 
In clinical practice, tolerability is therefore a major issue and the choice of a certain AED is at least partially based on comparison of tolerability profiles of the drugs. Also, the tolerability profiles of the newer drugs have become a more important issue in drug development, stimulated by the interest of regulatory agencies. ${ }^{17}$ Cognitive side-effects have been demonstrated to be one of the most important tolerability problems in chronic AED treatment.

\section{Methodological issues}

In evaluating studies of the cognitive effects of AEDs, we will follow an evidence-based approach. $^{18,19}$ Randomized clinical trials with monotherapy in patients with newly diagnosed epilepsy represent the most accurate procedure for assessing the cognitive impact of AEDs. ${ }^{17}$ These studies are not clouded by the effect of concurrent or previous AED use and permit the accurate collection of non-drug baseline data that is required for determining whether a particular treatment affects cognitive processing (i.e., to isolate drug-induced impairments from those due to other sources such as the seizures). Data from such studies can be supplemented with information from studies using add-on or polytherapy designs. In these studies, the use of two AEDs makes identifying the components of the treatment that are responsible for the observed effects more complex. In many cases, however, patients with epilepsy require dual AED therapy before adequate seizure control is obtained; therefore, information from addon studies does warrant consideration.

Also, data from healthy volunteers should be treated with caution. In general, the power of such studies is limited by small sample sizes, and drug-exposure periods are typically brief. It is possible that chronic treatment results in entirely different types of cognitive impairment that cannot be observed during short-term treatment. For example, such differences in side-effect profile between acute and long-term administration have been found with phenytoin. Moreover, volunteer studies do not provide information for children. Finally, the differing cerebral substrate in patients with epilepsy and healthy volunteers suggests that cognitive responses to AEDs may be different in these populations. Nonetheless, volunteer studies may provide an early insight into the cognitive effects of an AED and therefore provide a foundation for further studies in patients with epilepsy (see Vermeulen and Aldenkamp ${ }^{18}$ for a discussion of methodological aspects of cognitive drug trials in epilepsy).

The results will be discussed, distinguishing 'absolute effects' which are the effects of drug treatment against no-treatment (non-drugs) in the same subjects or in a control condition, which represents the most valuable information. Next, relative effects (comparing the cognitive effects of one drug with those of another drug) will be discussed. Although this is relevant clinical information, this comparison does not 
exclude the possibility that two drugs are not different because they both impair cognitive function to the same extent.

Furthermore, we will discuss the data from pediatric studies. Cognitive side-effects of the antiepileptic drugs are of critical importance when prescribing these drugs in children because children with epilepsy have a higher risk of learning disabilities or more general problems with school progress. Children are potentially more susceptible to the adverse effects of AEDs than adults because of the effect of AEDs on neurodevelopment. Even a modest cognitive effect may therefore have consequences for neurodevelopment. Therefore, cognitive side-effects of the antiepileptic drugs have emerged as an important consideration when an antiepileptic drug is being selected for the treatment of childhood epilepsy. ${ }^{20}$

\section{Phenobarbital (PB)}

The main anticonvulsant mechanism of action is the increase of the duration (not the frequency) of the GABA activated chloride ion channel opening, hence potentiating GABA mediated inhibitory neurotransmission. ${ }^{21} \mathrm{~PB}$ can also activate the $\mathrm{GABA}_{\mathrm{A}}$ receptor in the absence of GABA, which is sometimes considered to be a mechanism leading to its sedative properties. PB is used for the treatment of epilepsy since the discovery of its antiepileptic effect by Hauptman in 1912.

\section{Adults}

The study by MacLeod et al. (1978) is available allowing the evaluation of the cognitive effects of phenobarbital relative to a non-drug condition. This study showed relative serious memory impairment in 19 patients with epilepsy. ${ }^{22}$ Comparisons with other AEDs are available from two studies showing inconsistent results. One revealed greater impairment for PB than phenytoin (PHT) or carbamazepine (CBZ) on visuomotor and memory tests while the other study did not show differences between PB and PHT or CBZ. ${ }^{23-24}$

\section{Children}

When the cognitive and behavior effects of this drug were assessed in toddlers in a randomized, placebo-controlled study of patients who had febrile seizures, no differences were found in IQ scores between placebo and phenobarbital groups after eight to twelve months of therapy, although this is debated in other studies. ${ }^{25-27}$ Schubert and colleagues (2005) reported evidence that phenobarbital may impair attention in children to a degree that an attentional deficit disorder may develop. ${ }^{28}$ There may be a long-term adverse cognitive effect of phenobarbital on the language/verbal developmental skills like reading being acquired during the period of 
treatment. $^{29}$ Comparisons with VPA in children showed impairment of intelligence scores after long-term PB-treatment. ${ }^{30,31}$

\section{Phenytoin (PHT)}

The main anticonvulsant mechanism of action is use-dependent (voltage- and frequency dependent) sodium channel blocking. ${ }^{32}$ PHT binds to the fast inactivated state of the channel, reducing high frequency neuronal firing. PHT has a stronger effect on the sodium-channel than CBZ, delaying recovery stronger than CBZ. PHT may also have mild effects on the excitatory glutamate system and on the inhibitory GABA system. It is unknown which mechanism of action is responsible for the side-effects. PHT has been used as an antiepileptic drug since 1938 by Merritt and Putnam. For 20 years PHT was (together with PB) the universal treatment of epilepsy. PHT has excellent anticonvulsant properties and is used as a broad range AED.

\section{Adults}

For adults, five studies are available comparing phenytoin with a non-drug condition. ${ }^{33-}$ ${ }^{37}$ These studies all reveal PHT-induced cognitive impairment in the areas of attention, memory and especially mental speed. The magnitude of the reported effects is moderate to large but all these studies were carried out in normal volunteers, which opens the possibility that these effects represent short-term outcomes of the drug. The results of head-to-head comparisons showed more cognitive impairment for PHT than for CBZ, although this is debated by others. ${ }^{22-24,36-38}$

\section{Children}

For children one study is available using a withdrawal design, i.e. allowing to compare the effects of PHT with a non-drug condition. In this study antiepileptic drug treatment was withdrawn in 100 children and compared both to a non-drug control group and before-after withdrawal. The study did not show any severe cognitive effects. ${ }^{39}$ This is in contrast with earlier studies that found severe effects in children. ${ }^{40}$ In general, earlier studies used higher dosing, did not control for serum levels and mostly studied children in polytherapy. Moreover, the type of epilepsy is a confounder as more difficult epilepsies seem to be associated with more frequent use of PHT. 


\section{Ethosuximide (ESX)}

ESX modifies the properties of voltage-dependent calcium channels, reducing the Ttype currents and thereby preventing synchronized firing. The reduction is most prominent at negative membrane potentials and less prominent at more positive membrane potentials. Most of the effect is assumed to take place in thalamocortical relay neurons. ESX is introduced in 1960 and mainly used for the treatment of generalized absence seizures.

\section{Adults}

No controlled studies in adults are available.

\section{Children}

A recent study by Mandelbaum et al. (2009) showed mild and temporary attentional problems in children with idiopathic epilepsy (mostly absence seizures) in comparison to a non-treatment baseline. ${ }^{20}$ However, more recently, a double-blind, randomized, controlled clinical trial in children with newly diagnosed childhood absence epilepsy showed that ESX was associated with fewer adverse attentional effects than valproic acid or lamotrigine. ${ }^{41}$

\section{Valproate (VPA)}

VPA, a fatty acid, is believed to possess multiple mechanisms of action. Several studies have demonstrated an effect on sodium channels that is different from PHT and CBZ. An effect on T-type calcium channels has also been demonstrated. Recent studies have, however, demonstrated that a predominant effect concerns the interaction with the GABA-ergic neurotransmitter system. More precisely, VPA elevates brain GABA levels and potentiates GABA responses, possibly by enhancing GABA synthesis and inhibiting degradation. Theoretically, such mechanisms of action may cause cognitive side-effects. Furthermore, VPA may augment GABA release and block the re-uptake of GABA into glia cells. VPA is one of the most effective drugs against generalized absence seizures.

\section{Adults}

Three studies allows the interpretation of absolute effects and showed mild to moderate impairment of psychomotor and mental speed. ${ }^{42-44}$ The comparison with other drugs showed lower performance of memory and visuomotor function compared to $\mathrm{CBZ} .^{23}$ 


\section{Children}

One study reported 'no cognitive impairment' compared to a non-drug condition in a withdrawal design with children in remission. ${ }^{39} \mathrm{~A}$ favourable profile compared to PB on tests for intelligence is found. ${ }^{30,31}$ An indirect effect of valproate is induced by hyperammonemia, resulting in mental slowing. ${ }^{45}$

\section{Carbamazepine (CBZ)}

The main anticonvulsant mechanism of action is similar to that of PHT with a less 'slowing' effect in the recovery state than obtained for PHT. The mechanism of action is also voltage- and frequency dependent. CBZ was first synthesized in the early 1950's and introduced as an antiepileptic drug by Bonduelle in 1964 in Europe. ${ }^{46,47}$ CBZ is used for patients with partial complex seizures, with or without secondary generalization. Approval by the FDA for use in the United States followed much later (1978) because of concerns about serious hematological toxicity (e.g. aplastic anemia).

\section{Adults}

One study in normal volunteers reported 'no cognitive impairment' compared to a nondrug condition. ${ }^{34}$ This is challenged by the group of Meador and coworkers that reported impairments of memory, attention and mental speed, largely the areas that may also be affected by $\mathrm{PHT} .^{36,37}$ When evaluating the comparisons of CBZ with other AEDs there are the conflicting results of the Italian study by Gallassi and coworkers, showing a more favourable profile compared with PHT and PB and the USA-based studies by Meador and coworkers that showed no differences compared with PHT and $\mathrm{PB} .{ }^{23,24,36,37}$

\section{Children}

Two studies in patients with epilepsy reported 'no cognitive impairment' compared to a non-drug condition in a withdrawal design with children in remission. ${ }^{39,48}$ The USA study of Mandelbaum et al. (2009) reported a persistence of attentional problems when newly diagnosed children with localisation-related epilepsy were treated over a period of one year. ${ }^{20}$ This was compared to a non-drug baseline. Some effects on memory for CBZ are suggested, whereas VPA and PHT did not. ${ }^{49,50}$ In comparison with VPA, no differences were found. ${ }^{51}$ 


\section{Oxcarbazepine (OXC)}

OXC is a keto homologue prodrug of CBZ. It is structurally similar to CBZ, but has a different metabolic profile. In humans, the keto group is rapidly and quantitatively reduced to a monohydroxy derivative that is the main active anticonvulsant agent. Metabolism of OXC does not result in the formation of 10,11-epoxy carbamazepine that is considered the main metabolite causing side-effects. The mechanism of action is similar to CBZ, but OXC also reduces presynaptic glutamate release, possibly by reduction of high-threshold calcium currents. OXC was approved in the European Union in 1999 and is indicated for use as a monotherapy or adjunctive therapy for partial seizures with or without secondarily generalized tonic-clonic seizures in patients $\geq 6$ years of age.

\section{Adults}

The effects of OXC on cognitive function have been evaluated in one study in healthy volunteers and in four studies in adults patients with epilepsy. A double-blind, placebocontrolled, crossover study was conducted in 12 healthy volunteers. ${ }^{52}$ The effects of two doses of OXC (150 mg/day and $300 \mathrm{mg} /$ day) and placebo on cognitive function and psychomotor performance were compared. The treatment duration for each condition was 2 weeks. Cognitive function tests were administered before treatment initiation and 4 hours after the morning doses on days 1,8 , and 15. In this study, OXC improved performance on a focused attention task, increased manual writing speed, and had no effect on long-term memory processes.

In patients with epilepsy, four monotherapy comparative studies are available to evaluate the effects of OXC on cognitive functions in adult patients with newly diagnosed epilepsy. The first study was a double-blind, active-control study evaluating the effects of CBZ and OXC on memory and attention in 41 patients with newly diagnosed epilepsy. ${ }^{53}$ The treatment duration was 1 year. Cognitive function and intelligence tests were administered before treatment initiation and after 1 year of treatment. The results indicated no deterioration of memory or attention with either CBZ or OXC.

The second study was an active-control study that evaluated the effects of CBZ, VPA, and OXC on intelligence, learning and memory, attention, psychomotor speed, verbal span, and visuospatial construction in patients with newly diagnosed epilepsy. ${ }^{54}$ The treatment duration was 4 months. Cognitive function and intelligence tests were administered before treatment initiation and after 4 months of treatment. The results indicated no deterioration of cognitive function in any treatment group. Significant improvements in learning and memory tests were found for the CBZ- and OXC-treated patients. Improvements were also found in attention and psychomotor speed tests for the VPA-treated patients and partly for the CBZ-treated patients. 
The third study was a double-blind, randomized, active-control study that evaluated the effects of PHT and OXC on memory, attention, and psychomotor speed in 29 patients with newly diagnosed epilepsy. ${ }^{55}$ The treatment duration was 1 year. Cognitive function tests were administered before treatment initiation and after 6 and 12 months of treatment. The results indicated no significant differential cognitive effects between PHT and OXC during the first year of treatment in patients with newly diagnosed epilepsy who achieved adequate seizure control.

In the fourth study, three groups of 12 patients taking either CBZ, VPA, or PHT took a single $600-\mathrm{mg}$ dose of OXC followed 7 days later by 3 weeks of treatment with OXC 300 $\mathrm{mg}$ thrice daily and matched placebo in random order. ${ }^{56}$ Seven untreated patients, acting as controls, were prescribed the single OXC dose and 3 weeks of active treatment only. There were no important changes in cognitive function test results during administration of OXC compared with placebo.

\section{Children}

The effects in children have been studied in only one study, comparing OXC with CBZ and VPA. ${ }^{57,58}$ The study was an open-label, randomised, active-control, three-arm, parallel-group, 6-month study comparing 55 newly diagnosed patients on OXC monotherapy versus 57 patients taking CBZ or VPA. A broad set of cognitive areas were assessed, including intelligence. After a 6-month treatment period, no evidence for any detrimental change in comparison to baseline or the comparator (CBZ or VPA) was found. As in adults, some mild improvements were reported on the attentional tests.

\section{Topiramate (TPM)}

TPM is a sulfamate-substituted monosaccharide that has clearly multiple mechanisms of action. ${ }^{59}$ TPM blocks neuronal sodium channels in a voltage- and frequencydependent manner, it inhibits CA, it promotes the action of GABA at the $G_{A B A}$ receptor complex, elevates GABA brain concentrations by about $60 \%$ at 3 and 6 hours after a single dose- an increase that is maintained with 4 weeks of TPM administration. ${ }^{60}$ TPM is a carbonic anhydrase inhibiting agent that is effective in refractory chronic partial epilepsy. ${ }^{61,62}$

\section{Adults}

During the initial add-on clinical trials, central nervous system (CNS)-related "cognitive" subjective complaints were frequently reported, including mental slowing, attentional deficits, speech problems, and memory difficulties. ${ }^{61}$ It should be mentioned, however, that higher target doses and faster titration schedules were used than are now common in clinical practice (see Faught et al. ${ }^{62}$ for a discussion of dose and titration 
speed). Recent studies with TPM-treated patients have confirmed high levels of adverse cognitive effects based on subjective complaints. ${ }^{63,64} \mathrm{~A}$ follow-up study showed longterm retention of $30 \%$ for a 4 -year follow-up. ${ }^{65}$ For about half of the $70 \%$ of patients who discontinued treatment, side-effects were the major reason, with cognitive sideeffects being most frequently mentioned.

A study of six normal volunteers used an acute dose of $2.8 \mathrm{mg} / \mathrm{kg}$ ( $200 \mathrm{mg} /$ day) followed by a titration to $5.7 \mathrm{mg} / \mathrm{kg}(\sim 400 \mathrm{mg} /$ day) in 4 weeks, resulting in weekly dose escalations of about $100 \mathrm{mg} .^{66}$ The rate at which TPM was escalated in this study was very similar to the dose escalation used in the initial TPM adjunctive-therapy trials, $^{61}$ in which escalating the TPM dose to 200 or $400 \mathrm{mg} /$ day over 2-3 weeks was associated with somnolence, psychomotor slowing, speech disorders, and concentration and memory difficulties. ${ }^{65}$ The neuropsychometric changes were commensurate with the CNS effects. The cognitive effects of an acute starting dose of $200 \mathrm{mg} /$ day were impairments of verbal function (word finding and verbal fluency) of approximately 2 standard deviations (a very serious impairment) and sustained attention. Titration to $400 \mathrm{mg} /$ day in 4 weeks resulted in impairments of verbal memory and mental speed of $>2$ standard deviations.

Six studies involving patients with epilepsy are available. In a study by Meador (1997) with 155 patients with epilepsy, the effects of the gradual introduction of TPM as addon (a 50-mg starting dose, followed by increments of $50 \mathrm{mg}$ per week over 8 weeks) were compared with those of more rapid dose escalation (initial dose of $100 \mathrm{mg}$, followed by two consecutive weekly increments of 100 and $200 \mathrm{mg}$ ). ${ }^{67}$ In a test battery of 23 variables representing selective attention, word fluency, and visuomotor speed, the subjects who were on a slow-titration schedule and treated with one background AED displayed TPM-associated score changes of more than one third but less than one standard deviation.

A study by Aldenkamp and colleagues (2000) was specifically designed to compare cognitive effects of TPM and VPA added to therapeutic dosages of CBZ in 59 patients with epilepsy. ${ }^{68}$ In this study, a slow titration speed was used with a starting dose of $25 \mathrm{mg} /$ day TPM and weekly increments of $25 \mathrm{mg}$. Moreover, the average achieved dose (approximately $250 \mathrm{mg}$ ) was relatively low. Neuropsychometric testing was conducted 8 weeks after the last dosage increase ( 20 weeks after the start of TPM therapy). The study therefore used optimal conditions (i.e., slow titration, relatively low dose, and a longer treatment period), allowing for patient habituation to the effects of TPM therapy. Nonetheless, cognitive impairment was found for verbal memory function both during titration and at end point.

In a study by Burton and Harden (1997), attention was assessed weekly in ten subjects receiving TPM over a 3-month period. ${ }^{69}$ Four of nine subjects showed significant correlations between TPM dosage and forward digit span measured weekly, such that higher dosage was associated with poorer attention. 
In a retrospective study by Thompson and colleagues (2000), the neuropsychological test scores of 18 patients obtained before and after the introduction of treatment with TPM (median dose $300 \mathrm{mg}$ ) were compared with changes in test performance of 18 patients who had undergone repeated neuropsychological assessments at the same time intervals. ${ }^{70}$ In those patients taking TPM, a significant deterioration in many domains was found. The largest changes were found for verbal IQ, verbal fluency, and verbal learning.

In an open, prospective study, forty-one patients with intractable epilepsy initially received either TPM or tiagabine (TGB) as add-on treatment. ${ }^{71}$ Of these twenty-one patients were assessed at baseline; after a three month titration phase and after a three month maintenance phase. The patients were assessed on various aspects of cognitive functioning such as attention, memory, language and self-report mood and quality of life. The TPM group performed worse on measures of verbal fluency and working memory and reported more depression than the TGB group. They also felt that they were suffering from more adverse effects due to the TPM medication. However, TPM patients did report an increase in mental flexibility between titration and maintenance phase.

In another study, 21 patients with focal epilepsy treated with TPM worsened in the cognitive domains of cognitive speed and verbal fluency, as well as verbal and visual short-term memory compared to patients treated with LEV. ${ }^{72}$

\section{Children}

Few studies have psychometrically measured cognitive changes in children on TPM which corroborate the findings in adults. A high percentage of children (>20\%) suffer from a broad range of cognitive side-effects that persist even at assessments $>1$ year. $^{73}$ In a randomized, double-blind, placebo-controlled study comparing TPM in different dosages $(50 \mathrm{mg} /$ day and $100 \mathrm{mg} /$ day) and placebo, the TPM $100 \mathrm{mg} /$ day dose was associated with slowing in psychomotor reaction times. ${ }^{74}$ Learning, memory and executive function were unchanged.

In another study, the digit symbol test and verbal learning memory test were administered at baseline and study endpoint in children treated with TPM started either in monotherapy or add-on therapy. ${ }^{75}$ Cognitive testing revealed no significant changes during TPM therapy. Comparing pre-post differences, TPM monotherapy was associated with better cognitive outcomes than add-on therapy. However, these results of this 12-week open label study have to be interpreted with caution given the short study duration and the heterogeneity of the study population.

When the cognitive effects of TPM were compared with CBZ in children (5-15 years) with benign rolandic epilepsy after 28 weeks of treatment, patients who received CBZ showed an improvement on the subtest maze from the WISC-R and children with TPM had a poorer performance on the subtest arithmetic. ${ }^{76}$ However, when the patients 
who had maintained the minimum target dose were compared, the TPM group showed an improvement on the subtest object assembly compared to the CBZ treatment group.

\section{Lamotrigine (LTG)}

LTG is a phenyltriazine with weak antifolate activity. It was introduced in Europe in 1991 and in the United States in 1994. The main anticonvulsant mechanism of action is to block voltage-dependent sodium channels that result in voltage- and frequencydependent inhibition of the channel. This suggests that the mechanism of action is similar to that of PHT and CBZ. However in LTG treatment, this mechanism prevents presynaptic excitatory neurotransmitter release and the extent to which the mechanisms of action differ from CBZ is debatable. ${ }^{77}$ Clinical evidence indicates that LTG is effective against partial and secondarily generalized tonic-clonic seizures, as well as idiopathic (primary) generalized epilepsy.

\section{Adults}

A large number of cognitive studies are available for LTG (for an overview see Aldenkamp and Baker, 2001) ${ }^{78}$. Six volunteer studies have been conducted with LTG. Doses of $120 \mathrm{mg}$ and $240 \mathrm{mg}$ did not produce a significant change in cognitive function compared with baseline when administered to 12 normal volunteers in an acute study of 1 day. ${ }^{79}$ Similarly, five volunteers received LTG (acute dose $3.5 \mathrm{mg} / \mathrm{kg}$ and then titrated to a maximum of $7.1 \mathrm{mg} / \mathrm{kg}$ ) in a single-blind manner and were assessed for change in cognitive function after 2 and 4 weeks. ${ }^{66}$ There was no significant change in any of the neurocognitive measures relative to baseline performance.

LTG and CBZ have been compared in 12 healthy male volunteers and associations were made between the observed cognitive effects and plasma concentrations of these drugs. ${ }^{80}$ The effects of these drugs were examined by means of adaptive tracking, which assesses eye-hand coordination and effects of attention, and eye movement tests. LTG treatment was not significantly different from placebo, but increased CBZ saliva concentrations were significantly associated with impaired adaptive tracking and smooth and saccadic eye movements.

The long-term effects of LTG and CBZ were compared in 23 volunteers in a 10-week crossover study. ${ }^{81}$ The neuropsychological battery in this study consisted of 19 instruments yielding 40 variables, including both subjective and objective measures. LTG showed better performance or fewer side-effects in 19 (48\%) of the variables, while no statistically significant differences were seen in the remaining variables.

The cognitive and behavioral effects of LTG and TPM were compared in 47 healthy adults using a double-blind, randomized crossover design with two 12-week treatment periods. ${ }^{82}$ Neuropsychological evaluation included 17 measures yielding 41 variables of 
cognitive function and subjective behavioral effects. Better performance on $33(80 \%)$ variables was seen for LTG, but none for TPM. Even after adjustment for blood levels, performance was better on 19 (46\%) variables for LTG, but none for TPM. Differences concerned both objective cognitive and subjective behavioral measures.

Finally, a study by Aldenkamp and colleagues (2002) in 30 volunteers (12 days of treatment, using a daily dose of $50 \mathrm{mg}$ of LTG) showed evidence for a selective positive effect of LTG on cognitive activation, relative to both placebo and VPA. ${ }^{83}$ Although the results of these volunteer studies provided us preliminary insight into the impact of LTG on cognition, the generalizability of the results from these studies to patients with epilepsy receiving long-term AED treatment is limited.

The effects of LTG on cognitive function have been compared with those of CBZ in patients with newly diagnosed epilepsy. ${ }^{84}$ Patients completed tests of verbal learning and memory, attention, and mental flexibility at baseline and then periodically for up to 48 weeks. Significant differences favoring LTG over CBZ were observed with semantic processing, verbal learning, and attention. The authors concluded that LTG may have a favorable long-term effect on cognitive function when compared with CBZ.

Other studies have reported positive cognitive effects of LTG used as adjunctive therapy. Three independent double-blind, randomized, crossover studies have examined the cognitive effects of LTG used as add-on therapy. ${ }^{85-87}$ Two studies included patients with a history of partial seizures (at least once weekly during the preceding 3 months) who had received no more than two other AEDs or VPA or PHT monotherapy. Both studies also used two treatment periods (12 and 18 weeks), which were separated by a washout period ( 4 and 6 weeks). Despite the similarity in trial design and patients, there is some inconsistency between the findings of these studies. One study showed a marginal reduction in general "cerebral efficiency" (an indirect measure of cognitive function) following LTG treatment. ${ }^{85}$ Conversely, significant improvements were reported in the second study and the third study when compared with TPM. ${ }^{86,87}$

In an uncontrolled add-on study using CBZ as baseline drug, no deterioration on any of the cognitive tests was found after introducing LTG (200 mg). ${ }^{88}$ LTG therapy in seven patients with epilepsy and mental retardation caused both positive and negative psychotropic effects. ${ }^{89}$ These findings were based on the observations of parents and supervising staff. Positive effects included reduced irritability and increased compliance with simple instructions, while negative effects included behavioral deterioration with temper tantrums, restlessness, and hyperactivity. Similarly, a second study in 67 patients with mental retardation showed that following adjunctive treatment with LTG, social functioning was stable or improved in $90 \%$ of patients. ${ }^{90}$

In addition to clinical studies that have assessed the impact of LTG on cognitive function, further evidence can be obtained from examining the effect of LTG on electroencephalographic (EEG) parameters. Overt EEG discharges can occur without any visible clinical correlate in many patients with epilepsy. These epileptiform episodes 
may be associated with transient deterioration in cognitive function. ${ }^{91-93}$ Data from several studies indicate that LTG may reduce spontaneous epileptiform discharges, which may partially explain the favorable cognitive profile of LTG. In five patients displaying spontaneous EEG discharges, a single dose of LTG $(120 \mathrm{mg}$ or $240 \mathrm{mg}$ in addition to existing medication) resulted in a substantial reduction in spontaneous interictal discharges within a 24 -hour period. ${ }^{94}$

The effect of LTG add-on therapy in 11 patients with refractory partial seizures with or without secondary generalization has also been reported. ${ }^{95}$ LTG was added to existing therapy consisting of CBZ with at least one additional AED. EEG recordings were made at rest with eyes closed, during an attentive task (blocking reaction induced by several episodes of eyes open lasting 8 to 9 seconds), during cognitive tasks, and while performing mental arithmetic. In addition, a battery of neuropsychological tests was carried out. Before LTG treatment, EEG data revealed a decrease in fast activity at rest and a reduction in alpha and beta bands during attentive and cognitive tasks. LTG treatment resulted in a selective increase in alpha reactivity and beta power during the attentive tasks with no other detectable changes. During cortical activation, subtle changes were observed that were taken as indicative of a slight improvement in attention. Neuropsychological evaluation revealed that following 3 months of LTG therapy, no deterioration in cognitive function had occurred.

The long-term effects of LTG on paroxysmal abnormalities have also been monitored with a computer-based analysis system. ${ }^{96}$ Twenty-one patients with intractable epilepsy (twenty of whom were receiving multiple AED therapy) were evaluated before and after LTG treatment for EEG ictal events and number of spikes in a 10-minute period. Before LTG treatment, patients typically showed discharges characterized by diffuse spike-wave complexes. However, following a 4-month treatment period with LTG, ictal discharges disappeared and diffuse slow wave activity was seen with no adverse effect on background activity. Nineteen of the 21 patients also showed a reduction in seizure frequency.

LTG also showed a promising cognitive profile in elderly patients suffering from ageassociated memory impairment. ${ }^{97} \mathrm{~A}$ neuropsychological test battery in combination with auditory event-related potentials (ERPs) was used to measure the impact of LTG on cognitive function. LTG treatment caused a reduction in amplitude of the $P_{300}$ component of the ERP and a corresponding improvement in immediate and delayed visual memory and delayed logical memory. LTG may therefore improve simple memory functions in a memory-impaired elderly population.

\section{Children}

In the first placebo-controlled, double-blind, crossover study on the cognitive effects of lamotrigine in children with epilepsy, children with well-controlled or mild epilepsy were randomly assigned to add-on therapy with either lamotrigine followed by placebo or placebo followed by lamotrigine. ${ }^{98}$ For children on VPA, LTG was titrated to 
$2 \mathrm{mg} / \mathrm{kg} /$ day ( $\leq 12$ years old) or $150 \mathrm{mg} /$ day (>12 years old). For children not on VPA, lamotrigine was titrated to $10 \mathrm{mg} / \mathrm{kg} /$ day ( $\leq 12$ years old) or $300 \mathrm{mg} /$ day (>12 years old). Each treatment phase was 9 weeks, the crossover period 5 weeks. A neuropsychological test battery was performed during EEG monitoring at baseline and at the end of placebo and drug phases. There were no cognitive effects for lamotrigine in adjunctive therapy found for children with epilepsy. A favorable cognitive profile was also reported after long-term treatment based on physicians' and parents' experience. ${ }^{99}$ More positive changes were reported, most prominent in concentration and vigilance.

\section{Levetiracetam (LEV)}

LEV is structurally and mechanistically dissimilar to other AEDs. It is believed to bind to a specific, as yet undetermined, site on the synaptic plasma membrane. Moreover, LEV reduces the GABA turnover in the striatum by reducing GABA synthesis and increasing GABA metabolism. It is effective in reducing partial seizures in patients with epilepsy, both as adjunctive treatment and as monotherapy. LEV has many therapeutic advantages for patients with epilepsy. It has favorable pharmacokinetic characteristics (good bioavailability, linear pharmacokinetics, insignificant protein binding, lack of hepatic metabolism, and rapid achievement of steady-state concentrations) and a low potential for drug interactions. It is licensed for use as adjunctive treatment for partial seizures, with or without secondary generalization, in people aged over 16 years.

\section{Adults}

There are no controlled studies available. The small pilot study by Neyens et al. (1995) did not provide conclusions. ${ }^{100}$ A prospective, multicenter, open-label study showed that adjunctive therapy or monotherapy with LEV in adult patients with epilepsy improved cognitive and neuropsychological functions such as recall and language. ${ }^{101}$ The recent study by Bootsma et al. (2009) showed favourable effects. ${ }^{102}$ In comparison to CBZ, LEV has a positive stimulating effect on cognition. ${ }^{103}$

\section{Children}

The effects of adjunctive levetiracetam on memory and attention in children have been investigated in a randomized, double-blind, placebo-controlled study. No impairment in cognitive function was observed over the 8 - to 12 -week treatment period. ${ }^{104}$ The behavioral and emotional effects of adjunctive LEV treatment in children and adolescents (4-16 years old) with uncontrolled partial-onset seizures were also evaluated in a randomized, double-blind, placebo-controlled study. ${ }^{105}$ Patients received adjunctive LEV 20-60 mg/kg/day or placebo for 12 weeks. Selective aspects of 
behavioral and emotional functioning, specifically aggressive behavior, were affected by adjunctive LEV treatment. However, no patient discontinued the trial because of aggressive behavior-related events.

\section{Gabapentin (GBP)}

GBP (1-(aminomethyl) cyclohexane-acetic acid) is a novel AED, currently used as add-on therapy in patients with partial and generalized tonic-clonic seizures. GBP is a cyclic GABA analogue, originally designed as a GABA agonist. ${ }^{106}$ Further research has clearly shown a specific effect of GBP on GABA-ergic neurotransmitter systems, especially influencing GABA turnover. Investigations using nuclear magnetic resonance imaging spectroscopy have confirmed that GBP elevates GABA concentrations, specifically in the occipital cortex of patients with epilepsy. ${ }^{107}$

\section{Adults}

Two volunteer studies and two clinical studies are available to interpret the cognitive effects. Martin et al. (1999) used an acute dose and rapid titration in six volunteers and did not find cognitive effects of GBP. ${ }^{66}$ Meador et al. (1999) compared the cognitive effects of GBP and CBZ in 35 healthy subjects by using a double-blind, randomized, crossover design with two 5 -week treatment periods. During each treatment condition, subjects received either GBP $2400 \mathrm{mg} /$ day or CBZ (mean $731 \mathrm{mg} /$ day). ${ }^{108}$ Subjects were tested at the end of each AED treatment period and in four drug-free conditions (two pretreatment baselines and two post-treatment washout periods [1 month after each AED]). The neuropsychological test battery included 17 measures yielding 31 total variables. Significantly better performance on eight variables was found for GBP, but on no variables for CBZ. Comparison of CBZ and GBP with the nondrug average revealed significant statistical differences for 15 (48\%) of 31 variables.

Leach et al. (1997) studied GBP in 21 patients in an add-on polytherapy study after 4 weeks of adjunctive therapy and found no change in psychomotor and memory tests. Drowsiness was more often found in higher dosing (2400 mg). ${ }^{109}$

Mortimore et al. (1998) did also not find a difference between continued polytherapy and an add-on with GBP in measures of cognition or quality of life. ${ }^{110}$

\section{Children}

No studies are available. 


\section{Tiagabine (TGB)}

TGB is a $\gamma$-aminobutyric acid (GABA) uptake inhibitor that is structurally related to the prototypic GABA uptake blocker nipecotic acid, but has an improved ability to cross the blood-brain barrier. TGB temporarily prolongs the presence of GABA in the synaptic cleft by delayed clearance. Clinical trials have shown that TGB is effective as add-on therapy in the management of patients with refractory partial epilepsy. As TGB was recently marketed, certain aspects of its development are unfinished.

\section{Adults}

Three cognitive studies are available. Dodrill and colleagues (1997) included 162 patients who received the following treatments: placebo $(n=57), 16 \mathrm{mg} /$ day TGB $(n=34), 32 \mathrm{mg} /$ day TGB $(\mathrm{n}=45)$, or $56 \mathrm{mg} /$ day TGB $(\mathrm{n}=26)$ at a fixed-dose for 12 weeks after a 4-week dose titration period. ${ }^{111}$ Eight cognitive tests and three measures of mood and adjustment were administered during the baseline period and again during the double-blind period near the end of treatment (or at the time of dropout). The results showed no cognitive effects of monotherapy with TGB at a low or high dose, but there was some evidence for mood effects of add-on treatment with TGB at higher dosing, possibly related to titration speed.

Thirty-seven patients with partial epilepsy were investigated in the add-on polytherapy study by Kälviäinen and colleagues (1996). The study protocol consisted of a randomized, double-blind, placebo-controlled, parallel-group add-on study and an open-label extension study. ${ }^{112}$ During the 3-month double-blind phase at low doses ( $30 \mathrm{mg} /$ day), TGB treatment did not produce any cognitive changes compared with placebo. TGB treatment also did not cause deterioration in cognitive performance during longer follow-up with successful treatment on higher doses after 6 to 12 months (mean $65.7 \mathrm{mg} /$ day, range $30-80 \mathrm{mg} /$ day) and after 18 to 24 months (mean dose $67.6 \mathrm{mg} /$ day, range $24-80 \mathrm{mg} /$ day).

Finally, Sveinbjornsdottir and colleagues (1994) conducted an open trial of 22 adult patients with refractory partial epilepsy followed by a double-blind, placebo-controlled, crossover trial in 12 subjects. Nineteen patients completed the initial open titration and fixed-dose phase of the study and 11 patients completed the double-blind phase. ${ }^{113}$ The median daily TGB dose was $32 \mathrm{mg}$ during the open fixed-dose and $24 \mathrm{mg}$ during the double-blind period. Neuropsychological evaluation did not show any significant effect on cognitive function in the open or double-blind phase.

\section{Children}

No studies available. 


\section{Vigabatrin (VGB)}

VGB is an irreversible inhibitor of gamma- aminobutyric acid transaminase (GABA-T), the enzyme responsible for the catabolism of GABA. The mechanism of action of vigabatrin is attributed to irreversible enzyme inhibition of GABA-T and consequent increased levels of GABA. It is used as add-on medication in adult patients with complex partial seizures or as monotherapy in babies with infantile spasms.

\section{Adults}

A small sample showed no change from baseline when patients with partial epilepsy were treated with $2 \mathrm{~g}$ VGB during six months. ${ }^{114}$ This finding was supported in a healthy volunteer study. ${ }^{115}$

\section{Children}

In a retrospective study with 84 children no serious cognitive impairment was found. In fact, a shorter period from onset of infantile spasms to treatment with VGB was associated with better cognitive outcome. ${ }^{116}$ In contrast, Gaily and colleagues (1999) reported cognitive impairments during treatment with VGB in a minority of their sample. ${ }^{117}$ However, also in this study the effect of epilepsy was not controlled.

\section{Zonisamide (ZNS)}

The anticonvulsant properties of ZNS were discovered through extensive testing of a variety of sulfonamide compounds. Like TPM, it has multiple mechanisms of action: blockade of voltage-gated sodium channels, reducing sustained repetitive firing, blocking T-type calcium channels, and inhibiting ligand binding tot the $\mathrm{GABA}_{\mathrm{A}}$ receptor. ZNS is also a carbonic anydrase inhibiting drug, just as TPM. Although there is longer experience with ZNS in Japan (were it was developed), it is recently introduced in the USA and in Europe for partial onset seizures in refractory epilepsy.

\section{Adults}

Anecdotal clinical experience reveal a cognitive side-effect profile very similar to TPM but no controlled studies are available.

\section{Children}

No studies available. 


\section{Rufinamide (RUF)}

RUF 331; 1-(2,6-difluoro-phenyl)methyl-1H-1,2,3-triazole-4-carboxamide) is a structurally novel compound which limits the frequency of sodium-dependent neuronal action potentials.

\section{Adults}

One study is available to assess the cognitive effects. ${ }^{118}$ The study used a multicentre, multinational double-blind, randomized, placebo-controlled parallel study design with 4 different doses of RUF (based on prior studies): $200 \mathrm{mg} /$ day, $400 \mathrm{mg} / \mathrm{day}, 800 \mathrm{mg} /$ day and $1600 \mathrm{mg} /$ day as add-on to the existing medication. Cognitive assessments were performed at baseline (before the start with RUF treatment) and at endpoint (after 3 months of treatment). The most important finding is that for none of the cognitive tests a statistically significant worsening occurs for any of the doses of RUF when the period after 12 weeks of treatment was compared with the baseline before introducing RUF. Also, none of the comparisons between dose and placebo showed a statistically significant difference.

\section{Children}

No studies available.

\section{Conclusion}

A general conclusion that may be derived from most of the meta-analyses is that polypharmacy shows a relatively severe impact on cognitive function when compared with monotherapy, irrespective of the type of AEDs included. ${ }^{18}$ Two drugs that individually have mild cognitive effects may induce serious cognitive impairment when used together, possibly because of potentiation of tolerability problems. ${ }^{119}$

Possibly the most remarkable finding is that, although the severity of cognitive sideeffects is generally considered to be mild to moderate for most AEDs, all commonly used AEDs have some impact on cognitive function. ${ }^{18}$ Such mild impact may be amplified in specific conditions and may become substantial in some patients when crucial functions are involved, such as learning in children or driving capacities in adults (often requiring millisecond precision), or when functions are impaired that are already vulnerable, such as memory function in the elderly. ${ }^{4,119}$ Moreover, the cognitive sideeffects represent the long-term outcome of AED therapy; therefore, the effects may increase with prolonged therapy, which contributes to the impact on daily life functioning in refractory epilepsies. ${ }^{120}$ 
The current evidence is summarized in Figure 2.1 and Table 2.1. Drug-induced cognitive impairment has been established for phenobarbital (that even may impact higher-order cognitive function, specifically attention and memory), phenytoin (mental slowing which seems only clinical relevant in higher dosing and in polytherapy) and topiramate (attention, mental slowing and verbal impairments/dysphasia). Mild effects, mostly psychomotor slowing, were found for carbamazepine (although there are conflicting reports between the USA-studies that report an impact on attention and the European studies that do not show cognitive impairment, a reason for this discrepancy may be selection bias or dosing) and valproate (does not seem to impair cognition if sufficiently controlled for hyperammonemia). Although the evidence is sketchy, oxcarbazepine and levetiracetam do not seem to have a negative impact on cognition. For lamotrigine, some mild cognitive activating effects were found. In adults, no cognitive effects were found for ethosuximide, rufinamide, tiagabine and gabapentin, although the evidence requires confirmation. No studies are available for zonisamide. The effects for vigabatrin are inconclusive. For gabapentin, tiagabine, zonisamide, and rufinamide no studies in children are available.

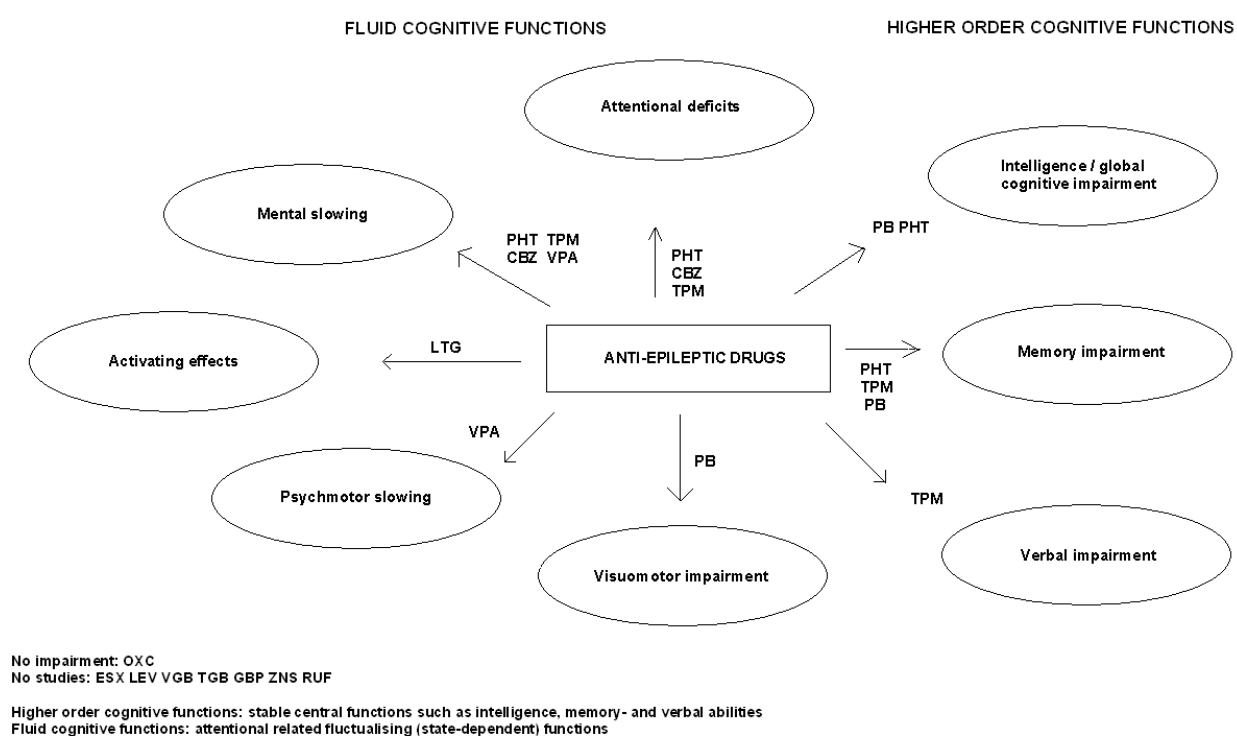

Figure 2.1 Dominant impairment per antiepileptic drug. 
Table 2.1 Cognitive effects of AEDs.

\begin{tabular}{|c|c|c|c|c|}
\hline & Adults & & Children & \\
\hline & $\begin{array}{l}\text { Absolute effects } \\
\text { (comparison with a } \\
\text { non-drug condition) }\end{array}$ & $\begin{array}{l}\text { Relative effects } \\
\text { (impairment when } \\
\text { compared with other } \\
\text { antiepileptic drugs) }\end{array}$ & Cognitive effect & $\begin{array}{l}\text { Area of } \\
\text { cognitive } \\
\text { impairment }\end{array}$ \\
\hline Phenobarbital (PB) & $\begin{array}{l}1 \text { study reporting } \\
\text { impairment } \\
\text { - Memory impairment }\end{array}$ & $\begin{array}{l}5 \text { studies: } 4 \text { reporting } \\
\text { impairment } \\
\text { - Memory and visuomotor } \\
\text { impairment when } \\
\text { compared with PHT and } \\
\text { CBZ } \\
\text { - Impairment of } \\
\text { intelligence after long-term } \\
\text { treatment when compared } \\
\text { to VPA }\end{array}$ & --- & $\begin{array}{l}\text { Memory and } \\
\text { attention }\end{array}$ \\
\hline Phenytoin (PHT) & $\begin{array}{l}5 \text { studies all reporting } \\
\text { impairment } \\
\text { - attentional deficits, } \\
\text { memory impairment } \\
\text { and mental slowing } \\
\text { (mental slowing most } \\
\text { frequently reported) }\end{array}$ & $\begin{array}{l}6 \text { studies, } 1 \text { reporting } \\
\text { impairment } \\
\text { - global cognitive } \\
\text { impairment and mental } \\
\text { slowing }\end{array}$ & - & $\begin{array}{l}\text { At high dosing: } \\
\text { mental speed }\end{array}$ \\
\hline Valproate (VPA) & $\begin{array}{l}3 \text { studies, all reporting } \\
\text { mild impairment } \\
\text { - psychomotor and } \\
\text { mental slowing }\end{array}$ & $\begin{array}{l}4 \text { studies, } 1 \text { reporting } \\
\text { impairment } \\
\text { - memory impairment }\end{array}$ & 0 & $\begin{array}{l}\text { (caveat: hyper- } \\
\text { ammonemia) }\end{array}$ \\
\hline Carbamazepine (CBZ) & $\begin{array}{l}3 \text { studies, } 1 \text { reporting } \\
\text { impairment } \\
\text { - attentional deficits } \\
\text { and mental slowing }\end{array}$ & $\begin{array}{l}4 \text { studies, none reporting } \\
\text { impairment }\end{array}$ & $0 /-$ & $\begin{array}{l}\text { Probably only an } \\
\text { effect with high } \\
\text { dosing }\end{array}$ \\
\hline Oxcarbazepine (OXC) & $\begin{array}{l}1 \text { study, reporting no } \\
\text { impairment }\end{array}$ & $\begin{array}{l}4 \text { studies, none reporting } \\
\text { impairment }\end{array}$ & $0 /+$ & $\begin{array}{l}\text { (improvement of } \\
\text { attention) }\end{array}$ \\
\hline Topiramate (TPM) & $\begin{array}{l}1 \text { study, reporting } \\
\text { impairment } \\
\text { - attentional deficits, } \\
\text { verbal impairments }\end{array}$ & $\begin{array}{l}6 \text { studies, all reporting } \\
\text { impairment } \\
\text { - verbal impairments } \\
\text { (especially word finding } \\
\text { problems/dysphasia), } \\
\text { memory impairment and } \\
\text { mental slowing }\end{array}$ & --- & $\begin{array}{l}\text { Attention, } \\
\text { memory and } \\
\text { language } \\
\text { function. }\end{array}$ \\
\hline Lamotrigine (LTG) & $\begin{array}{l}6 \text { studies, none } \\
\text { reporting impairment } \\
\text { and } 4 \text { reporting } \\
\text { activating effects }\end{array}$ & $\begin{array}{l}7 \text { studies, none reporting } \\
\text { impairment; the majority } \\
\text { reporting psychotropic } \\
\text { effects (activation). }\end{array}$ & + & Attentional tests \\
\hline Levetiracetam (LEV) & No studies & $\begin{array}{l}1 \text { study, reporting no } \\
\text { impairment }\end{array}$ & 0 & \\
\hline Gabapentin (GBP) & $\begin{array}{l}1 \text { study, reporting no } \\
\text { impairment }\end{array}$ & $\begin{array}{l}3 \text { studies, not reporting } \\
\text { impairment }\end{array}$ & No information & \\
\hline Tiagabine (TGB) & $\begin{array}{l}3 \text { studies, none } \\
\text { reporting impairment }\end{array}$ & No studies & No information & \\
\hline Vigabatrin (VGB) & No studies & No studies & No information & \\
\hline Ethosuximide (ESX) & No studies & No studies & 0 & \\
\hline Zonisamide (ZNS) & No studies & No studies & No information & \\
\hline Rufinamide (RUF) & No studies & $\begin{array}{l}1 \text { study, reporting no } \\
\text { impairment }\end{array}$ & No information & \\
\hline
\end{tabular}

Impairment (- mild; -- moderate; --- severe) or improvement (+ mild; ++ moderate; +++ profound), $0=$ no impairment or improvement 


\section{References}

1. Aldenkamp AP, Dodson WE. Epilepsy and education; cognitive factors in learning behavior. Epilepsia 1190;31:S9-20.

2. Dodson WE, Pellock JM. Pediatric epilepsy: diagnosis and treatment. Demos Publications, New York, 1993.

3. Dodson WE, Trimble MR. Epilepsy and quality of life. Raven Press, New York, 1994.

4. Aldenkamp AP, Dreifuss FE, Renier WO, et al. Epilepsy in children and adolescents. CRC Press, Boca Raton, 1995.

5. Aldenkamp AP. Antiepileptic drug treatment and epileptic seizures - effects on cognitive function. In: Trimble M, Schmitz B, eds. The neuropsychiatry of epilepsy.: Cambridge University Press, New York, 2002:256-67.

6. Ideström $\mathrm{CM}$, Schalling $\mathrm{D}$, Carlquist $U$, et al. Acute effects of diphenylhydantoin in relation to plasma levels. Behavioral and psychological studies. Psychol Med 1972;2:111-20.

7. Dodrill CB, Troupin AS. Psychotropic effects of carbamazepine in epilepsy: a double-blind comparison with phenytoin. Neurology 1977;27:1023-8.

8. Marson AG, Kadir ZA, Hutton JL, et al. The new antiepileptic drugs: a systematic review of their efficacy and tolerability. Epilepsia 1997;38:859-80.

9. Jette NJ, Marson AG, Hutton JL. Topiramate add-on for drug-resistant partial epilepsy. Cochrane Database Syst Rev: 2002;CD001417.

10. Wong IC. New antiepileptic drugs. Study suggests that under a quarter of patients will still be taking the new drugs after six years. BMJ 1997;314:603-4.

11. Stefan H, Krämer G, Mamoli B, eds. Challenge epilepsy - new antiepileptic drugs. Blackwell Science, Berlin, 1998.

12. Lhatoo SD, Wong ICK, Sander JW. Prognostic factors affecting long-term retention of topiramate in patients with chronic epilepsy. Epilepsia 2000;41:338-41.

13. Kellet MW, Smith DF, Stockton PA, et al. Topiramate in clinical practice: first year's postlicensing experience in a specialist epilepsy clinic. J Neurol Neurosurg Psychiatry 1999;66:759-63.

14. Marson AG, Kadir ZA, Hutton JL, et al. Gabapentin for drug-resistant partial epilepsy. Cochrane Database Syst Rev: 2000;CD001415.

15. Marson AG, Hutton JL, Leach JP, et al. Levetiracetam, oxcarbazepine, remacemide and zonisamide for drug resistant localization-related epilepsy: a systematic review. Epilepsy Res 2001;46:259-70.

16. Chadwick DW, Marson T, Kadir Z. Clinical administration of new antiepileptic drugs: an overview of safety and efficacy. Epilepsia 1996;37:S17-22.

17. Aldenkamp AP. Cognitive and behavioural assessment in clinical trials: when should they be done? Epilepsy Res 2001;45:155-9.

18. Vermeulen J, Aldenkamp AP. Cognitive side-effects of chronic antiepileptic drug treatment: a review of 25 years of research. Epilepsy Res 1995;22:65-95.

19. Aldenkamp AP, De Krom M, Reijs R. Newer antiepileptic drugs and cognitive issues. Epilepsia 2003;44:S21-29.

20. Mandelbaum DE, Burack GD, Bhise V. Impact of antiepileptic drugs on cognition, behaviour, and motor skills in children with newly onset idiopathic epilepsy. Epilepsy Behav 2009;16:341-4.

21. Twyman RE, Rogers CJ, Macdonald RL. Differential regulation of gamma-aminobutyric acid receptor channels by diazepam and Phenobarbital. Ann Neurol 1989;25:213-20.

22. MacLeod CM, Dekaban AS, Hunt E. Memory impairment in epileptic patients: selective effects of phenobarbital concentration. Science 1978;202:1102-4.

23. Gallassi R, Morreale A, Di Sarro R, et al. Cognitive effects of antiepileptic drug discontinuation. Epilepsia 1992;33:S41-4.

24. Meador KJ, Loring DW, Huh K, et al. Comparative cognitive effects of anticonvulsants. Neurology 1990;40:391-4.

25. Camfield CS, Chaplin S, Doyle AB, et al. Side effects of Phenobarbital in toddlers; behavioural and cognitive aspects. J Pediat. 1979;95:361-5. 
26. Wolf SM, Forsythe A, Studen AA, et al. Long-term effect of phenobarbital on cognitive function in children with febrile convulsions. Pediatrics 1981;68:820-3

27. Farwell JR, Lee $\mathrm{YI}$, Hortz DG, et al. Phenobarbital for febrile seizures-effects on intelligence and on seizure recurrence. N Engl J Med 1990;322:364-9.

28. Schubert R. Attention deficit disorder and epilepsy. Pediatric Neurol 2005;32:1-10.

29. Sulzbacher S, Farwell JR, Temkin N, et al. Late cognitive effects of early treatment with phenobarbital. Clin Pediatr 1999;38:387-94.

30. Vining EP, Mellitis ED, Dorsen MM, et al. Psychologic and behavioral effects of antiepileptic drugs in children: a double-blind comparison between phenobarbital and valproic acid. Pediatrics 1987;80:165-74.

31. Calandre EP, Dominguez-Granados R, Gomez-Rubio M, et al. Cognitive effects of long-term treatment with phenobarbital and valproic acid in school children. Acta Neur Scand 1990;81:504-6.

32. Schwarz JR, Grigat G. Phenytoin and carbamazepine: potential- and frequency-dependent black of NA currents in mammalian myelinated nerve fibers. Epilepsia 1989;30:286-94.

33. Smith WL, Lowrey JB. Effects of diphenylhydantoin on mental abilities in the elderly. J Am Geriatr Soc 1975;23:207-11.

34. Thompson PJ, Huppert F, Trimble MR. Anticonvulsant drugs, cognitive function and memory. Acta Neurol Scand 1980;80:75-80.

35. Thompson PJ, Huppert FA, Trimble MR. Phenytoin and cognitive functions: effects on normal volunteers and implications for epilepsy. British Journ Clin Psychol 1981;20:155-62.

36. Meador KJM, Loring DW, Allen, ME, et al. Comparative cognitive effects of carbamazepine and phenytoin in healthy adults. Neurology 1991;41:1537-40.

37. Meador KJM, Loring DW, Abney OL, et al. Effects of carbamazepine and phenytoin on EEG and memory in healthy adults. Epilepsia 1993;34:153-7.

38. Jha S, Kumar V, Mishra VN. Effect of common anti-epileptic drugs on cognition in schoolchildren with epilepsy. Indian J Physiol Pharmacol 2001;45:507-10.

39. Aldenkamp AP, Alpherts WCJ, Blennow G, et al. Withdrawal of antiepileptic medication - effects on cognitive function in children: The Multicentre Holmfrid Study. Neurology 1993;43:41-50.

40. Trimble MR. Antiepileptic drugs, cognitive function, and behavior in children: evidence from recent studies. Epilepsia 1990;31:S30-4.

41. Glauser TA, Nigro M, Sachdeo R, et al. Ethosuximide, valproic acid and lamotrigine in childhood absence epilepsy. N Engl J Med 2010;362:790-9.

42. Thompson PJ, Trimble MR. Sodium valproate and cognitive functioning in normal volunteers. Br J Clin Pharmacol 1981;12:819-24.

43. Craig I, Tallis R. Impact of valproate and phenytoin on cognitive function in elderly patients: results of a single-blind randomized comparative study. Epilepsia 1994;35:381-90.

44. Prevey ML, Delaney RC, Cramer JA, et al. Effect of valproate on cognitive function comparison with carbamazepine. Arch Neuro 1996;53:1008-16.

45. Nicolai J, Aldenkamp AP, Huizinga JR, et al. Cognitive side-effects of valproate-acid induced hyperammonemia in children with epilepsy. J Clin Psychopharmacol 2007;27:221-4.

46. Parnas J, Flachs H, Gram L. Psychotropic effect of antiepileptic drugs. Acta Neurol Scand 1979;60:32943.

47. Parnas J, Gram L, Flachs H. Psychopharmacological aspects of antiepileptic treatment. Prog Neurobiol 1980;15:119-38.

48. Riva D, Devoti M. Carbamazepine withdrawal in children with previous symptomatic partial epilepsy: effects on neuropsychologic function. J Child Neuro 1999;14:357-62.

49. Seidel WT, Mitchel WG. Cognitive and behavioural effects of carbamazepine in children: data from benign rolandic epilepsy. J Child Neurol 199;14:716-23.

50. Forsythe I, Butler R, Berg I, et al. Cognitive impairment in new cases of epilepsy randomly assigned to carbamazepine, phenytoin and sodium valproate. Dev Med Child Neurol 1991;33:524-34.

51. Stores G, Williams PL, Styles E, et al. Psychological effects of sodium valproate and carbamazepine in epilepsy. Archives of Disease in Childhood 1992;67:1330-37.

52. Curran HV, Java R. Memory and psychomotor effects of oxcarbazepine in healthy human volunteers. Eur J Clin Pharmacol 1993;44:529-33. 
53. Laaksonen R, Kaimola K, Grahn-Teräväinen E, et al. A controlled clinical trial of the effects of carbamazepine and oxcarbazepine on memory and attention. 16th International Epilepsy Congress, Hamburg, 1985 (abstract).

54. Sabers A, Moller A, Dam M, et al. Cognitive function and anticonvulsant therapy: effect of monotherapy in epilepsy. Acta Neurol Scand 1995;92:19-27.

55. Äikiä M, Kälviäinen R, Sivenius J, et al. Cognitive effects of oxcarbazepine and phenytoin monotherapy in newly diagnosed epilepsy: one year follow-up. Epilepsy Res 1992;11:199-203.

56. McKee PJ, Blacklaw J, Forrest G, et al. A double-blind, placebo-controlled interaction study between oxcarbazepine and carbamazepine, sodium valproate and phenytoin in epileptic patients. $\mathrm{Br} \mathrm{J} C$ lin Pharmacol 1994;37:27-32.

57. Donati F, Gobbi G, Campistol J, et al. Effects of oxcarbazepine on cognitive function in children and adolescents with partial seizures. Neurology 2006;67:679-82.

58. Donati F, Gobbi G, Campistol J, et al. The cognitive effects of oxcarbazepine versus carbamazepine or valproate in newly diagnosed children with partial seizures. Seizure 2007;16:670-9.

59. White HS. Clinical significance of animal seizure models and mechanism of action studies of potential antiepileptic drugs. Epilepsia 1997;38:S9-17.

60. Petroff OAC, Hyder F, Rothman DL, et al. Topiramate rapidly raises brain GABA in epilepsy patients. Epilepsia 2001;42:543-8.

61. Privitera $\mathrm{M}$, Fincham R, Penry J, et al. Topiramate placebo-controlled dose-ranging trial in refractory partial epilepsy using 600-, 800-, and 1000-mg daily dosages. Neurology 1996;46:1678-83.

62. Faught E, Wilder BJ, Ramsay RE, et al. Topiramate placebo-controlled dose-ranging trial in refractory partial epilepsy using 200-, 400-, and 600-mg daily dosages. Neurology 1996;46:1684-90.

63. Ketter TA, Post RM, Theodore WH. Positive and negative psychiatric effects of antiepileptic drugs in patients with seizure disorders. Neurology 1999;53:53-67.

64. Tatum WO, French JA, Faught E, et al. Postmarketing experience with topiramate and cognition. Epilepsia 2001;42:1134-40.

65. Bootsma HP, Coolen F, Aldenkamp AP, et al. Topiramate in clinical practice: long-term experience in patients with refractory epilepsy referred to a tertiary epilepsy center. Epilepsy Behav 2004;5:380-7.

66. Martin R, Kuzniecky R, Ho S, et al. Cognitive effects of topiramate, gabapentin, and lamotrigine in healthy young adults. Neurology 1999;52:321-7.

67. Meador KJ. Assessing cognitive effects of a new AED without the bias of practice effects [Abstract]. Epilepsia 1997;38:60.

68. Aldenkamp AP, Baker G, Mulder OG, et al. A multicentre randomized clinical study to evaluate the effect on cognitive function of topiramate compared with valproate as add-on therapy to carbamazepine in patients with partial-onset seizures. Epilepsia 2000;41:1167-78.

69. Burton LA, Harden C. Effect of topiramate on attention. Epilepsy Res 1997;27:29-32.

70. Thompson PJ, Baxendale SA, Duncan JS, et al. Effects of topiramate on cognitive function. J Neurol Neurosurg Psychiatry 2000;69:636-41.

71. Fritz N, Glogau S, Hoffmann J, et al. Efficacy and cognitive side effects of tiagabine and topiramate in patients with epilepsy. Epilepsy Behav 2005;6:373-81.

72. Gomer B, Wagner K, Frings L, et al. The influence of antiepileptic drugs on cognition: a comparison of levetiracetam and topiramate. Epilepsy Behav 2007;10:486-94.

73. Coppola G, Verrotti A, Resicato G, et al. Topiramate in children and adolescents with epilepsy and mental retardation: a prospective study on behavior and cognitive effects. Epilepsy Behav 2008;12:253-6.

74. Pandina GJ, Ness S, Polverejan E, et al. Cognitive effects of topiramate in migraine patients aged 12 through 17 years. Pediatr Neurol 2010;42:187-95.

75. Brandl U, Kurlemann G, Neubauer B, et al. Seizure and cognitive outcomes in children and adolescents with epilepsy treated with topiramate. Neuropediatrics 2010;41:113-20.

76. Kang $\mathrm{HC}$, Eun $\mathrm{BL}$, Lee $\mathrm{CW}$, et al. The effects on cognitive function and behavioural problems of topiramate compared to carbamazepine as monotherapy for children with benign rolandic epilepsy. Epilepsia 2007;48:1716-23.

77. Leach MJ, Lees G, Riddall DR. Lamotrigine: mechanisms of action. In: Levy RH, Mattson RH, Meldrum BS (eds). Antiepileptic drugs, $4^{\text {th }}$ edition. New York: Raven Press, 1995:861-9. 
78. Aldenkamp AP, Baker G. A systematic review of the effects of lamotrigine on cognitive function and quality of life. Epilepsy Behav 2001;2:85-91.

79. Cohen AF, Ashby L, Crowley D, et al. Lamotrigine (BW430C), a potential anticonvulsant. Effects on the central nervous system in comparison with phenytoin and diazepam. Br J Clin Pharmacol 1985;20:61929.

80. Hamilton MJ, Cohen AF, Yuen AW, et al. Carbamazepine and lamotrigine in healthy volunteers: relevance to early tolerance and clinical trial dosage. Epilepsia 1993;34:166-73.

81. Meador KJ, Loring DW, Ray PG, et al. Differential effects of carbamazepine and lamotrigine. Neurology 2001;56:1177-82.

82. Meador KJ, Loring DW, Vahle VJ, et al. Cognitive and behavioural effects of lamotrigine and topiramate in healthy volunteers. Neurology 2005;64:2108-14.

83. Aldenkamp AP, Arends J, Bootsma HP, et al. Randomized, double-blind parallel-group study comparing cognitive effects of a low-dose lamotrigine with valproate and placebo in healthy volunteers. Epilepsia 2002;43:19-26.

84. Gillham R, Kane K, Bryant-Comstock L, et al. A double-blind comparison of lamotrigine and carbamazepine in newly diagnosed epilepsy with health-related quality of life as an outcome measure. Seizure 2000;9:375-9.

85. Banks GK, Beran RG. Neuropsychological assessment in lamotrigine treated epileptic patients. Clin Exp Neurol 1991;28:230-7.

86. Smith D, Baker G, Davies G, et al. Outcomes of add-on treatment with lamotrigine in partial epilepsy. Epilepsia 1993;34:312-22.

87. Blum D, Meador K, Biton V, et al. Cognitive effects of lamotrigine compared with topiramate in patients with epilepsy. Neurology 2006;67:400-6.

88. Aldenkamp AP, Mulder OG, Overweg J. Cognitive effects of lamotrigine as first line add-on in patients with localized related (partial) epilepsy. J Epilepsy 1997;10:117-21.

89. Ettinger $A B$, Weisbrot $D M$, Saracco J, et al. Positive and negative psychotropic effects of lamotrigine in patients with epilepsy and mental retardation. Epilepsia 1998;39:874-7.

90. McKee JR, Sunder TR, FineSmith R, et al. Lamotrigine as adjunctive therapy in patients with refractory epilepsy and mental retardation. Epilepsy Behav 2003;4:386-94.

91. Aarts $J H$, Binnie CD, Smit AM, et al. Selective cognitive impairment during focal and generalized epileptiform EEG activity. Brain 1984;107:293-308.

92. Aldenkamp AP, Arends J, Overweg-Plandsoen TC, et al. Acute cognitive effects of nonconvulsive difficult-to-detect epileptic seizures and epileptiform electroencephalographic discharges. J Child Neurol 2001;16:119-23.

93. Aldenkamp AP, Arends J. The relative influence of epileptic EEG discharges, short nonconvulsive seizures and type of epilepsy on cognitive function. Epilepsia 2004;45:54-63

94. Binnie CD, van Emde BW, Kasteleijn-Nolste-Trenite DG, et al. Acute effects of lamotrigine (BW430C) in persons with epilepsy. Epilepsia 1986;27:248-54.

95. Marciani MG, Spanedda F, Bassetti MA, et al. Effect of lamotrigine on EEG paroxysmal abnormalities and background activity: a computerized analysis. Br J Clin Pharmacol 1996;42:621-7.

96. Marciani MG, Stanzione P, Mattia D, et al. Lamotrigine add-on therapy in focal epilepsy: electroencephalographic and neuropsychological evaluation. Clin Neuropharmacol 1998;21:41-7.

97. Mervaala E, Koivista K, Hanninen T, et al. Electrophysiological and neuropsychological profiles of lamotrigine in young and age-associated memory impairment (AAMI) subjects [Abstract]. Neurology 1995;45:259.

98. Pressler RM, Binnie CD, Coleshill SG, et al. Effect of lamotrigine on cognition in children with epilepsy. Neurology 2006;66:1495-9.

99. Brodbeck V, Jansen V, Fietzek U, et al. Long-term profile of lamotrigine in 119 children with epilepsy. Eur J Paediatr Neurol 2006;10:135-41.

100. Neyens LGJ, Alpherts WCJ, Aldenkamp AP. Cognitive effects of a new pyrrolidine derivative (levetiracetam) in patients with epilepsy. Prog Neuropsychopharmacol Biol Psychiatry 1995;19:411-9.

101. Wu T, Chen CC, Chen TC, et al. Clinical efficacy and cognitive and neuropsychological effects of levetiracetam in epilepsy: an open-label multicenter study. Epilepsy Behav 2009;16:468-74. 
102. Bootsma HP, Ricker L, Hekster YA, et al. The impact of side effects on long-term retention in three new antiepileptic drugs. Seizure 2009;18:327-31.

103. Helmstaedter C, Witt JA. Cognitive outcome of antiepileptic treatment with levetiracetam versus carbamazepine monotherapy: a non-interventional surveillance trial. Epilepsy Behav 2010;18:74-80.

104. Levisohn PM, Mintz M, Hunter SJ, et al. Neurocognitive effects of adjunctive levetiracetam in children with partial-onset seizures: a randomized, double-blind, placebo-controlled, noninferiority trial. Epilepsia 2009;50:2377-89.

105. Loge C, Hunter SJ, Schiemann J, et al. Assessment of behavioral and emotional functioning using standardized instruments in children and adolescents with partial-onset seizures treated with adjunctive levetiracetam in a randomized, placebo-controlled trial. Epilepsy Behav 2010;18:291-8.

106. Macdonald RL, Kelly, KM. Antiepileptic drug mechanisms of action. Epilepsia 1995;36:2-12.

107. Petroff OAC, Rothman DL, Behar KL, et al. The effect of gabapentin on brain gamma-aminobutyric acid in patients with epilepsy. Ann Neurol 1996;39:95-9.

108. Meador KJ, Loring DW, Ray PG, et al. Differential cognitive effects of carbamazepine and gabapentin. Epilepsia 1999;40:1279-85.

109. Leach JP, Girvan J, Paul A, et al. Gabapentin and cognition: a double blind, dose ranging, placebo controlled study in refractory epilepsy. J Neurol Neurosurg Psychiatry 1997;62:372-6.

110. Mortimore C, Trimble M, Emmers E. Effects of gabapentin on cognition and quality of life in patients with epilepsy. Seizure 1998;7:359-6.

111. Dodrill CB, Arnett JL, Sommerville KW, et al. Cognitive and quality of life effects of differing dosages of tiagabine in epilepsy. Neurology 1997;48:1025-31.

112. Kälviäinen $R$, Äikiä $M$, Mervaala $E$, et al. Long-term cognitive and EEG effects of tiagabine in drugresistant partial epilepsy. Epilepsy Res 1996;25:291-7.

113. Sveinbjornsdottir S, Sander JW, Patsalos PN, et al. Neuropsychological effects of tiagabine, a potential new antiepileptic drug. Seizure 1994;3:29-35.

114. Monaco F, Torta R, Cicolin A, et al. Lack of association between vigabatrin and impaired cognition. J Int Med Res 1997;25:296-301.

115. Thomas $L$, Trimble M. The effects of vigabatrin on attention, concentration and mood: an investigation in healthy volunteers. Seizure 1996;5:205-8.

116. Camposano SE, Majoir P, Halpern E, et al. Vigabatrin in the treatment of childhood epilepsy: a retrospective chart review of efficacy and safety profile. Epilepsia 2008;49:1186-91.

117. Gaily E, Appelqvist K, Kantola-Sorsa E, et al. Cognitive deficits after cryptogenic infantile spasms with benign seizure evolution. Dev Med Child Neurol 1999;41:660-4.

118. Aldenkamp AP, Alpherts WCJ. The effect of the new antiepileptic drug rufinamide on cognitive functions. Epilepsia 2006;47:1153-9.

119. Trimble MR. Anticonvulsant drugs and cognitive function: a review of the literature. Epilepsia 1987; $28: 37-45$.

120. American Academy of Pediatrics. Behavioral and cognitive effects of anticonvulsant therapy. Committee on Drugs. Pediatrics 1985;76:644-7. 


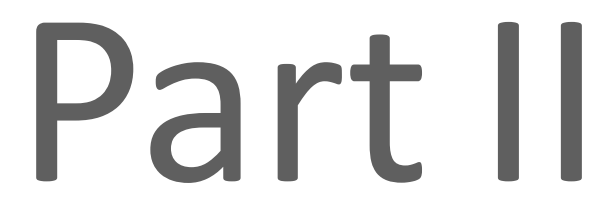

Bridging the gap of our knowledge 


\section{Chapter}

Cognitive effects of lacosamide as

adjunctive therapy in refractory epilepsy

DM IJff, TM van Veenendaal, HJM Majoie, AJA de Louw, JFA Jansen \& AP Aldenkamp Acta Neurol Scand. 2015;131:347-354 


\section{Abstract}

\section{Purpose}

Lacosamide (LCM) is a novel antiepileptic drug (AED) with potential benefit as adjunctive treatment in patients with partial-onset seizures. As yet, limited information on cognitive effects of LCM is available, especially in real-life settings. In this open clinical prospective study, the cognitive effects of LCM were evaluated when used as adjunctive antiepileptic therapy in patients with refractory epilepsy.

\section{Methods}

We included 33 patients aged between 16 and 74 years (mean: 37 years). All patients had a localisation-related epilepsy. Patients were assessed at baseline before starting LCM treatment and during follow-up when the optimal clinical dose was achieved. Subjective complaints were evaluated using the SIDAED; effects on cognition were evaluated using the computerized visual searching task (CVST).

\section{Results}

The CVST showed significant faster information processing reaction times at the second evaluation $(p=.013)$, which was not correlated with seizure control, type of epilepsy, age, gender, drug load, number of concomitant drugs, dose or duration of LCM treatment. On the SIDAED, patients complained more about their cognitive function at the second evaluation $(p=.005)$. For the SIDAED, a positive correlation at follow-up was found between the total severity score and higher age $(r=.375, p=.031)$, but not with epilepsy factors or treatment characteristics.

\section{Conclusion}

Screening of the cognitive effects of LCM showed that LCM does not have negative effects on information processing speed. As this is the most sensitive function for cognitive side effects of AEDs, LCM does not seem to induce the common negative cognitive effects. Remarkably, patients complained more, especially about their cognitive function, which is possible the 'doing better, feeling worse phenomenon'. 


\section{Introduction}

Lacosamide (LCM) is a relatively recent introduced antiepileptic drug (AED). It was approved in Europe and USA in 2008 as adjunctive therapy for the treatment of partialonset seizures in patients with epilepsy aged 16 and older in Europe and in patients 17 and older in the United States. ${ }^{1}$ LCM is unique among existing antiepileptic drugs in that it has been shown to exert its anticonvulsant effects predominantly by enhancement of the slow inactivation of voltage-gated sodium channels without effecting fast inactivation. ${ }^{2,3}$ The post hoc analysis of pooled clinical data by Sake et al. (2010) suggests that there may be an improved tolerability for LCM in patients not on other sodium channel blockers (SCB's). ${ }^{4}$

The efficacy and safety of adjunctive LCM for partial-onset seizures was established in three multicenter, randomized, double-blind, placebo-controlled trials. ${ }^{5-7}$ Drug-induced adverse events with an incidence of at least $10 \%$ during the treatment period were general CNS and gastrointestinal effects (dizziness, nausea, diplopia, vision blurred, headache, vomiting, ataxia, fatigue, somnolence, vertigo, nasopharyngitis, abnormal coordination, nystagmus and tremor). All of these with the exception of headache appeared to be dose related and four of these adverse effects were greater for LCM than for placebo; dizziness [ $31 \%$ vs $8 \%$ ], headache [ $13 \%$ vs $9 \%$ ], nausea [ $11 \%$ vs $4 \%$ ] and diplopia [11\% vs $2 \%$ ]. ${ }^{7-8}$ A recent published meta-analysis of all available randomized controlled trials with LCM which included these three trials and seven trials with other disorders (neuropathic pain, migraine, fibromyalgia, knee osteoarthritis) found that these adverse events were more frequent reported in patients with drug-resistant epilepsy compared to other disorders. ${ }^{9}$ LCM was not associated with any adverse event unambiguously related to cognition in this analysis. However, Doty et al. (2013) criticised that no formal cognitive testing was performed in these randomized controlled trials. $^{10}$

In none of the trials, cognitive side-effects were recorded as a dominant complaint, which is remarkable given the high incidence of reported cognitive side-effects in antiepileptic treatment. ${ }^{11,12}$ The only item indicative of cognitive dysfunction reported was memory impairment, but its association with LCM was limited and not significant. However, no formal cognitive testing was performed in any of these trials, and cognitive effects notoriously evade subjective detection, especially in cases where patient use the drug as a 'last resort'. 9,10 In a long-term study rates of adverse events commonly attributed to other AEDS such as changes in cognition were low. ${ }^{13}$ Recently, the cognitive effects of LCM were compared with lamotrigine and topiramate suggesting a cognitive profile similar to lamotrigine and superior to that of topiramate. $^{14}$

For our specific patient group (i.e., patients with refractory epilepsies in a tertiary epilepsy referral and care centre), data about the cognitive effects of LCM are important for clinical decision making. Cognitive complaints of the epilepsy, the seizures and the drugs may be confusingly entangled, limiting evaluation of the 
effectiveness of a drug in an individual patient. Preferably, cognitive effects of LCM would be studied in a randomized clinical trial (RCT). However, rarely cognition is an outcome (primary or secondary) of the industry driven RCT's. The alternative reports of clinical experience (often case reports) has led, however, to a substantial delay in detecting and understanding some behavioral effects of antiepileptic drugs. ${ }^{15}$ Our study must therefore be seen as a systematic clinical audit, collecting information on the cognitive effects in the naturalistic clinical setting.

\section{Methods}

\section{Subject selection}

Patients who were scheduled to start with LCM between March 2009 and September 2011 were included. They were investigated before this drug was added to their current treatment and when they were using LCM. The study was approved by the local medical ethical committee.

\section{Assessment procedures}

Cognitive effects of LCM were assessed at two different times: at baseline before starting with this drug and at follow-up. The intervals between baseline and follow-up are variable because data were collected as part of normal clinical practice. The patient characteristics (age and sex), type of epilepsy, comedication, drug load, average dose of LCM, length of treatment with LCM at follow-up, efficacy and reasons for discontinuation of LCM were included in the database. Efficacy was evaluated by change in seizure frequency from baseline to follow-up using a 3-point scale; reduction in seizure frequency, seizure remission, or increase in seizure frequency.

\section{Instruments}

Patients were tested with two measurements: a standardized inventory to evaluate subjectively perceived cognitive side-effects and a neuropsychological test to assess possible effects independent of subjective complaints. Complaints were assessed using a list of 46 items with possible AED-related complaints, the SIDAED. ${ }^{16,17}$ A complete overview of the SIDAED is provided in the Appendix A. The included items form 10 categories: general CNS, behavior (increased irritability), depressive symptoms, cognitive function, motor problems and co-ordination, visual complaints, headache, cosmetic and dermatological complaints, gastrointestinal complaints, and sexuality and menses. For each item, the patient rates the severity of the complaint on a four-point Likert scale (no problem, mild, moderate, or serious problem). A total subjective complaints score was calculated for each patient from the SIDAED complaints 
questionnaire, consisting of the number of mentioned complaints, weighing a mild score as 1 , moderate as 2 and severe as 3 points. Thus, the range of the total severity complaints score could vary from 0 to 138 . This questionnaire can be analysed in different ways: regarding the total reported complaints, the different categories and the different items. The SIDAED is chosen because the psychometric properties have been established ${ }^{16-18}$ and cognitive complaints can be measured relative to other domains.

The computerised visual searching task (CVST), an adaptation of Goldstein's visual searching task gives an indication of the visual (complex) information processing speed. ${ }^{19} \mathrm{~A}$ target grid pattern in the centre of the computer screen has to be compared with 24 surrounding patterns. Only one of them is identical to the target pattern. An example of this test is provided in the Appendix $B$. The patient is asked to react as fast as possible; reaction times are recorded. After each correct response, the central target pattern changes. The test consists of 24 different patterns and after 12 presentations the surrounding grids change. This task was included as slowing of central information processing is observed to be the dominant cognitive effect of most AED's and also the first sign of cognitive adverse effects. ${ }^{11,12}$

\section{Dosing and titration}

The initial dose of $50 \mathrm{mg}$ was increased at weekly intervals by $50 \mathrm{mg}$ up to the recommended maintenance dose of 200 to $400 \mathrm{mg} /$ day. However, the titration schedule was individualized in response to patient complaints and seizure frequency.

\section{Statistical analysis}

Data was analysed with SPSS version 21.0, Chicago, IL, USA. For analysing the neuropsychological data, paired sample t-tests were used. Pearson correlations were used to exclude for influential effects on the neuropsychological results. Patients characteristics (gender and age), epilepsy factors (seizure control and type of epilepsy) and treatment characteristics (number of concomitant drugs, drug load, dose and duration of LCM treatment) were taken into account. Because the SIDAED consisted of 10 different categories, a $\mathrm{p}$-value $\leq .005$ was considered significant for the subscales of the SIDAED. This more stringent criterion of significance was based on the Bonferroni adjustment for multiple tests. For the items of the SIDAED, a Bonferroni corrected p-value $\leq .001$ was considered significant. 


\section{Results}

\section{Patient characteristics}

A total of thirty-three patients were included in this study. Most patients $(73 \%, n=24)$ were female. Mean age at baseline was 37 years (SD: 14.5$)$. Most patients $(58 \%, n=19)$ had a symptomatic localisation related epilepsy, $42 \% \quad(n=14)$ had a cryptogenic localisation related epilepsy.

Five patients (15\%) discontinued their LCM treatment before the second evaluation and where excluded for further analysis. Reasons for discontinuation were unsatisfactory therapeutic effect in two patients and side effects in three patients. These side-effects were tiredness, dizziness, coordination and balance problems.

The 28 remaining patients were using LCM treatment with a mean daily dose at followup of $298.2 \mathrm{mg} /$ day (SD: 120.6). LCM was added to the anticonvulsant regimen. Twenty-one of 28 patients (75\%) were taking LCM in addition to a SCB. Concurrent AEDs ranged from 1-4 (mean: 1.9, SD: 0.8 ). The majority of the patients were taking carbamazepine (43\%), clobazam (32\%), lamotrigine (25\%) and levetiracetam (21\%).

Mean follow-up time was 7 months (SD: 6, range 1-24). In nine patients (28\%), comedication was changed at follow-up; in five patients only the dose of co-medication was optimized, and in four patients, there was a medication switch in which LCM was added in exchange for one other anticonvulsant.

Seizure frequency was reduced in $50 \%(n=14)$ of the patients. In 12 patients $(43 \%)$, LCM did not have an effect on seizure frequency. Two patients (7\%) had more seizures than before treatment with LCM was started.

Patients characteristics and their clinical date are provided in Table 3.1.

\section{Neuropsychological findings}

The CVST showed significant faster information processing speed at the second evaluation ( $t=2.644, p=.013$ ). At follow-up, patients showed an average increase of speed of more than three seconds (18\%) on this task at follow-up (mean at baseline: 18.67 seconds; SD: 8.9; mean at follow-up: 15.40 seconds; SD: 7.5$)$.

On the SIDAED, none of the patients mentioned zero complaints at baseline or followup. At baseline, before the start of treatment with LCM, the distribution of subjective complaints as measured by the SIDAED ranged from 3 to 36 (maximal range on the scale is 0-46), with a mean number complaints of 15.8 (SD:7.0). At second evaluation, the average rate of subjective complaints did not differ from baseline $(p=.431)$ with a mean number of complaints of 16.8 (SD:8.5; range:1-35). 


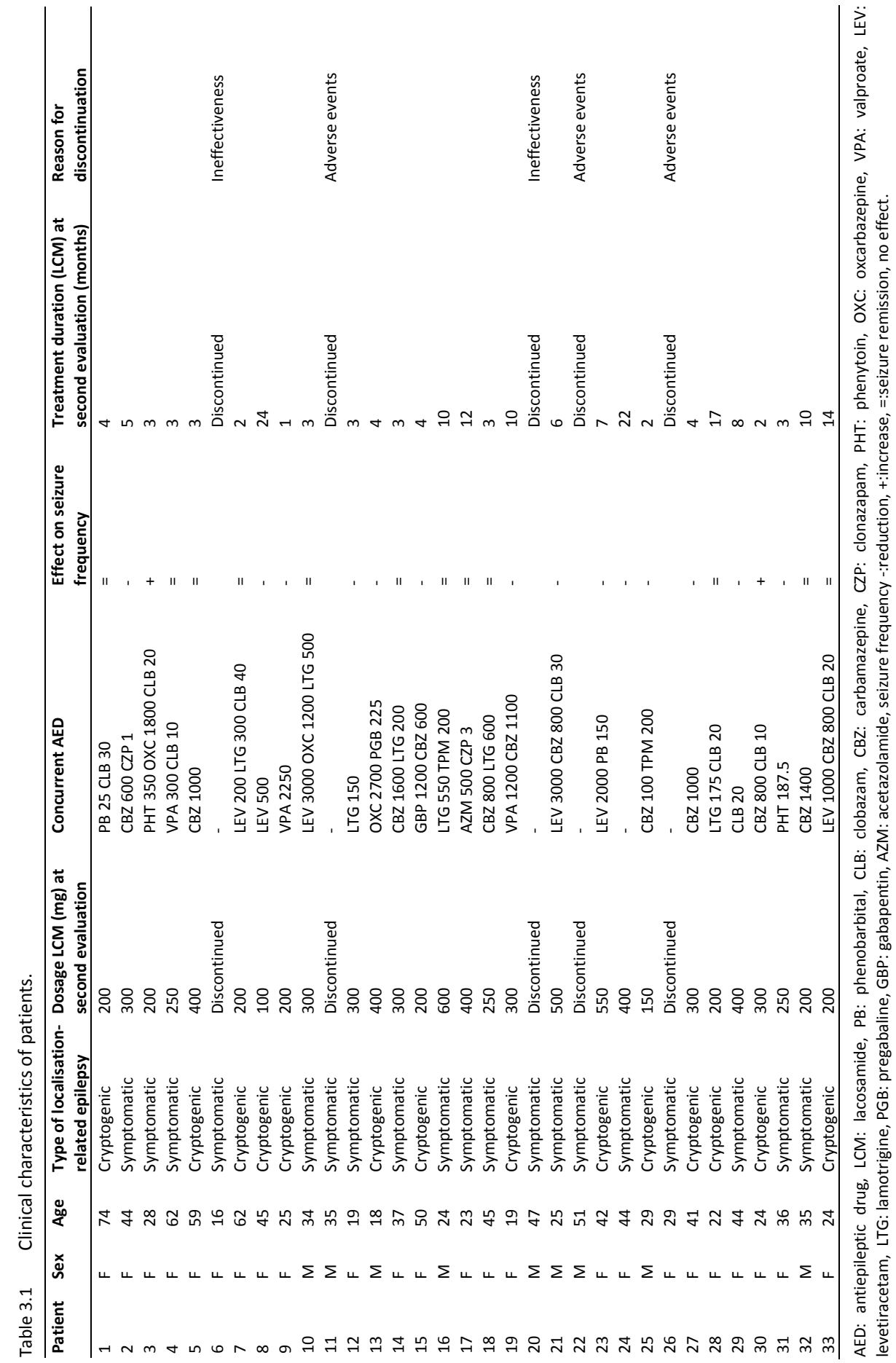


A statistically significant effect was only found for the subscale cognitive complaints. For the other subscales, results did not yield statistical significance (see Figure 3.1). Both the severity of the cognitive complaints ( $t=-3.367, p=.002)$ as the number of the cognitive complaints $(t=-2.992, p=.005)$ increased in the treatment phase. The mean severity score on the subscale cognitive function per item increased from 0.78 to 1.11 (see Table 3.2). At baseline, patients reported to experience on average 4.2 (SD:1.9) of the nine possible cognitive complaints. In the treatment phase, this was increased to an average of 5.3 (SD:2.4).

When analysing the 46 items, a significant higher severity score was found at the second evaluation for the following items from the cognitive function category; 'I have difficulty remembering names' ( $\mathrm{t}=-4.917, \mathrm{p}<.000$ ), 'I notice I sometimes have difficulty expressing myself' ( $t=-3.783, p<.000)$, and ' $\mathrm{l}$ have difficulty finding the right words' $(t=-3.475, p=.001)$

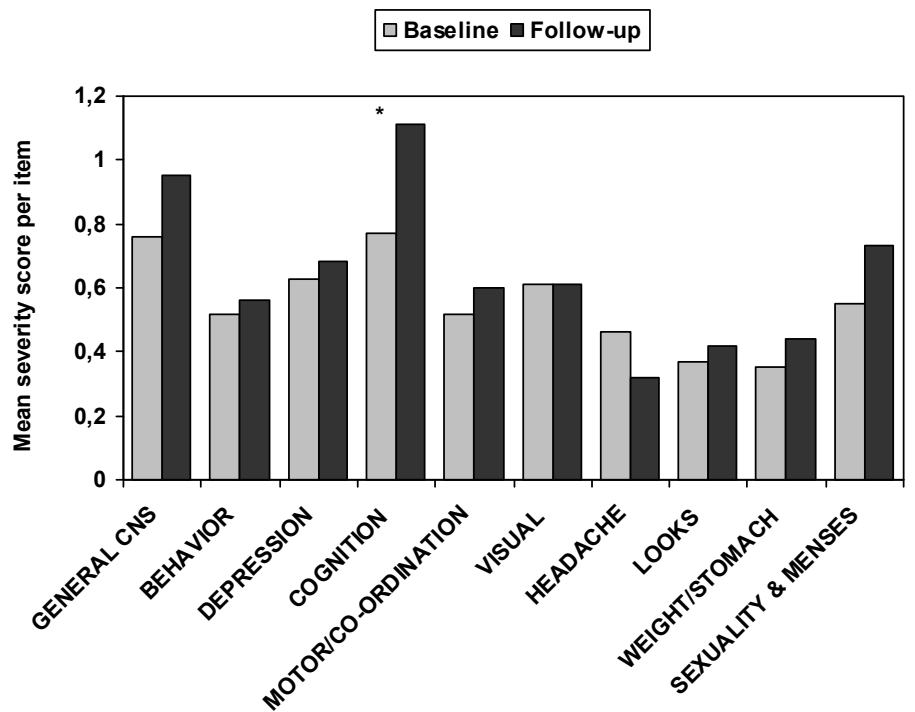

Figure 3.1 Differences in the subscales of the SIDAED between baseline and follow-up.

\section{Correlational analysis}

A significant positive correlation was found at follow-up between processing speed and the SIDAED cognitive items 'I notice my reaction to others is slow' $(r=.465, p=.013)$ and 'I notice my speech is slow' $(r=.467, p=.012)$. Improvement of processing speed was associated with a decrease of complaints. No other cognitive complaints were correlated with the information processing task. 
The improved information processing speed could not be explained by patient characteristics such as gender $(p=.712)$ or age $(p=.771)$, or by epilepsy factors such as seizure control $(p=.332)$ or type of epilepsy $(p=.494)$, or by treatment characteristics such as number of concomitant drugs $(p=.359)$, drug load $(p=.927)$ or dose $(p=.830)$ and duration of LCM treatment $(p=.659)$.

For the SIDAED, a positive correlation at follow-up was found between the total severity score and age $(r=.375, p=.031)$. The older the patients, the more complaints were reported. Gender, epilepsy factors or other treatment characteristics did not affect the results.

Table 3.2 The mean reported severity score per item per subscale.

\begin{tabular}{lcc}
\hline Subscale & Baseline & Follow-up \\
\hline General CNS & 0.80 & 0.94 \\
Behavior (increased irritability) & 0.55 & 0.56 \\
Depressive symptoms & 0.65 & 0.70 \\
Cognitive function & 0.78 & $1.11^{*}$ \\
Motor problems and co-ordination & 0.54 & 0.60 \\
Visual complaints & 0.69 & 0.61 \\
Headache & 0.52 & 0.30 \\
Cosmetic and dermatological complaints & 0.40 & 0.41 \\
Gatsrointestinal complaints & 0.35 & 0.38 \\
Sexuality and menses & 0.59 & 0.70 \\
\hline
\end{tabular}

* $\mathrm{p} \leq 0.05$

\section{Discussion}

Lacosamide is a relatively recent introduced AED with potential benefit as adjunctive treatment in patients with partial-onset seizures. ${ }^{20}$ In this open clinical prospective study, the cognitive effects of LCM when used as adjunctive antiepileptic therapy in adolescent and adult patients with refractory epilepsy were evaluated in the real life setting.

During LCM treatment, we found a statistically significant improvement of information processing speed (increase of $18 \%$ ). This function is generally impaired in individuals taking other AEDs. ${ }^{9,11,12}$ Speed of information processing is the most sensitive function affected by antiepileptic drug treatment; therefore this result is remarkable. However, activating effects have also been reported for lamotrigine. ${ }^{11,12,21,22}$ Ketter et al. (1999) divided AEDs in activating and sedating drugs, and our results suggest that LCM may be classified as a cognitive activating drug. ${ }^{23}$ The results were not biased by interfering factors. The significant improvement of central information processing speed was not correlated with change in seizure frequency, type of epilepsy, age, gender, drug load, number of concomitant drugs or dose and duration of LCM treatment. Therefore, our 
study suggest that LCM does not have a negative impact on this sensitive measurement.

There is a difference between the results of the objective cognitive assessment and the subjective patient report. Patients reported no increase in overall complaints from baseline to treatment phase. However, there is an increase in number and severity of cognitive complaints. More specifically, patients had more complaints about memory ('remembering names'), and language ('expressing themselves' and 'finding the right words'). On the other hand, correlational analysis showed a significant positive correlation at follow-up between processing speed and the SIDAED items 'I notice my reaction to others is slow' and 'I notice my speech is slow'. Improvement of processing speed was associated with a decrease of complaints. This concurs with the findings on the information processing task and these results in combination suggest that improvement of the processing speeds increases awareness in patients of other difficulties such as memory and language, which are generally not related to drug treatment but to the epilepsy. This improvement of adverse drug effect followed by an increased awareness of other cognitive difficulties can be described as the 'doing better, feeling worse phenomenon'.

None of the patients in our study discontinued LCM treatment because of the complaints about cognitive difficulties, which collaborates the result of the cognitive assessment. The reason for withdrawal was adverse events in three patients and unsatisfactory seizure control in two patients. The most common drug related adverse events were tiredness, dizziness, coordination and balance problems. This is in line with the study of García-Morales et al. (2011) who reported that about half of the patients who reported dizziness were taking other sodium channel blockers. ${ }^{24}$ In our study, all patients who discontinued their LCM treatment were using a sodium channel modulator in combination. It has been suggested that neurotoxicity with LCM may be more likely with concomitant use of the more traditional voltage-gated sodium channel blockers such as carbamazepine, phenytoin, lamotrigine and oxcarbazepine due to a pharmacodynamic interaction. ${ }^{4,25-27}$ However, Wehner et al. (2009) and Stephen et al. (2011) concluded that LCM is as well tolerated in patients on traditional SCBs than on non-SCB's. ${ }^{28,29}$

There are some methodological issues that limit the interpretation of our study. With respect to the neuropsychological outcome, this study has assessed the most commonly reported effect on cognition, but no tests using other cognitive functions has been used. Furthermore, preferably the rules of a randomised controlled trial would have been applied. However, generally, cognitive outcomes are not investigated in the industry driven RCT's when a new drug is in development. The alternative is then to study the effects in a naturalistic setting with limited protection against bias. Nonetheless, lacosamide is used in clinical practice and cognition is important for medical decision making. Our recommendation is that in new drug development of AEDs cognition is always used as outcome measure in the RCT's. 
In conclusion, screening of the cognitive effects of LCM showed that LCM does not have negative effects on information processing speed. Further research is needed to investigate the other cognitive domains. However, as this is the most sensitive function for cognitive side effects of anti-epileptic drugs, LCM does not seem to induce the common negative cognitive effects. Possibly, it has a potential cognitive enhancing effect similar to that reported for lamotrigine. 


\section{References}

1. Perucca E, Yasothan U, Clinke G, Kirkpatrick P. Lacosamide. Nat Rev Drug Discov 2008;7:973-4.

2. Beyreuther BK, Freitag J, Heers C, Krebsfänger N, Scharfenecker U, Stöhr T. Lacosamide: a review of clinical properties. CNS Drugs Reviews 2007;1:21-42.

3. Becerra JL, Ojeda J, Corredera E, Giménez JR. Review of therapeutic options for adjuvant treatment of focal seizures in epilepsy. Focus on Lacosamide. CNS Drugs 2011;25S1:3-16.

4. Sake JK, Herbert D, Isojärvi J, Doty P, De Backer M, Davies K, et al. A pooled analysis of lacosamide clinical trial data grouped by mechanism of action of concomitant antiepileptic drugs. CNS Drugs 2010;24:1055-1068.

5. Ben-Menachem E, Biton V, Jatuzis D, Abou-Khalil B, Doty P, Rudd GD. Efficacy and safety of oral Lacosamide as adjunctive therapy in adults with partial-onset seizures. Epilepsia 2007;48:1308-17.

6. Halász $P$, Kälviäinen $R$, Mazurkiewicz-Beldzińska $M$, et al. Adjunctive lacosamide for partial-onset seizures: efficacy and safety results from a randomized controlled trial. Epilepsia 2009;50:443-53.

7. Chung S, Sperling MR, Biton V, et al. Lacosamide as adjunctive therapy for partial-onset seizures: A randomized controlled trial. Epilepsia 2010;51:958-67.

8. Chung S, Ben-Menachem E, Sperling MR, et al. Examining the clinical utility of lacosamide: pooled analyses of three phase II/III clinical trials. CNS Drugs 2010;24:1041-54.

9. Zaccara G, Oerucca O, Loiacono G, Giovannelli, Verrotti A. The adverse event profile of lacosamide: a systematic review and meta-analysis of randomized controlled trials. Epilepsia 2013;54:66-71.

10. Doty P, Herbert D, Mathy FX, Byrnes W, Zackheim J, Simontacchi K. Development of lacosamide for the treatment of partial-onset seizures. Ann N Y Acad Sci 2013;1291:56-68.

11. IJff DM, Aldenkamp AP. Comorbidities of treatment with antiepileptic drugs. In Cross, Duchowny, Glauser, Hirsch, Arzimanoglou, eds. Pediatric Epilepsy, New York: McGraw-Hill Professional, 2012: 424-36.

12. IJff DM, Aldenkamp AP. Cognitive side effects of antiepileptic drugs in children. In: Dulac, Lassonde, Sarnat, eds. Handbook of Clinical Neurology: Pediatric Neurology. New York: Elsevier, 2013:738-49.

13. Husain A, Chung S, Faught E, Isojarvi J, McShea C, Doty P. Long-term safety and efficacy in patients with uncontrolled partial-onset seizures treated with adjunctive lacosamide: results from a phase III openlabel extension trial. Epilepsia 2012;53:521-28.

14. Helmstaedter C, Wit JA. The longer-term cognitive effects of adjunctive anti-epileptic treatment with lacosamide in comparison with lamotrigine and topiramate in a naturalistic outpatient setting. Epilepsy Behav 2013;26;182-7.

15. Gaitatzis A, Sander JW. The long-term safety of antiepileptic drugs. CNS Drugs 2013;27:435-55.

16. Uijl SG, Uiterwaal CSMP, Aldenkamp AP, Carpay JA, Doelman JC, Keizer K, et al. A cross-sectional study of subjective complaints in patients with epilepsy who seem to be well-controlled with anti-epileptic drugs. Seizure 2006;15:242-48.

17. Uijl SG, Uiterwaal CSMP, Aldenkamp AP, Carpay JA, Doelman JC, Keizer K, et al. Adjustment of treatment increases quality of life in patients with epilepsy: a randomized controlled pragmatic trial. European Journal of Neurology 2009;16:1173-77.

18. Carpay JA, Aldenkamp AP, van Donselaar CA. Complaints associated with the use of antiepileptic drugs: results from a community-based study. Seizure 2005;14:198-206.

19. Alpherts WCJ, Aldenkamp AP. FePSY: 'The iron psyche'. Heemstede, the Netherlands: Instituut voor epilepsiebestrijding; 1995.

20. Sachdeo R. Lacosamide. In: Shorvon, Perucca and Engel, eds. The treatment of epilepsy, Blackwell Publishing, 2009:527-33.

21. Aldenkamp AP, Arends J, Bootsma HP, et al. Randomized double-blind parallel-group study comparing cognitive effects of a low-dose lamotrigine with valproate and placebo in healthy volunteers. Epilepsia 2002;43:19-26.

22. Aldenkamp AP, Baker G. A systematic review of the effects of lamotrigine on cognitive function and quality of life. Epilepsy Behav 2001;2:85-91.

23. Ketter TA, Post RM, Theodore WH. Positive and negative psychiatric effects of antiepileptic drugs in patients with seizure disorders. Neurology 1999;53:S53-67. 
24. García-Morales I, Delgado, RT, Falip M, Campos D, García ME, Gil-Nagel A. Early clinical experience with lacosamide as adjunctive therapy in patients with refractory focal epilepsy and nocturnal seizures. Seizure 2011;20:801-4.

25. Novy J, Patsalos PN, Sander JW, Sisodiya SM. Lacosamide neurotoxicity associated with conmitant use of sodium channel-blocking antiepileptic drugs: a pharmacodynamics interaction? Epilepsy Behav 2011;20:20-23.

26. Kamel JT, DeGruyter MA, D'Souza WJ, Cook MJ. Clinical experience with using lacosamide for the treatment of epilepsy in a tertiary centre. Acta Neurol Scand 2013;127:149-153.

27. Villanueva V, López-Gomáriz E, López-Trigo J, Palau J, García M, Villarroya T, et al. Rational polytherapy with lacosamide in clinical practice: results of a Spanish cohort analysis RELACOVA. Epilepsy Behav 2012;23:298-304.

28. Wehner T, Bauer S, Hamer HM, Hattemer K, Immisch I, Knake S. Six months of postmarketing experience with adjunctive lacosamide in patients with pharmacoresistent focal epilepsy at a tertiary epilepsy center in Germany. Epilepsy Behav 2009;16:423-5.

29. Stephen, L, Kelly K, Parker P, Brodie MJ. Adjunctive lacosamide in clinical practice: Sodium blockade with a difference? Epilepsy Behav 2011;22:499-504. 


\section{Appendix A}

\section{SIDAED list of subjective complaints}

1 I have problems with my gums

2 I have lost weight

3 I have difficulty remembering names

4 I often feel drowsy and sleepy

5 I sometimes have to hold on to something to stop myself from falling

6 I forget all sorts of things, such as appointments

7 I find it hard to concentrate

81 tire easily and have little energy

9 I am easily aggressive

10 I can only concentrate on something for short periods

11 I constantly walk into tables, doorposts etc.

12 I feel agitated and restless

13 I notice my reaction to others is slow

14 I cannot concentrate on the same thing for long periods of time

15 I notice my speech is slow

16 I constantly feel pressurized and excitable

17 I often suffer from dizzy spells

18 I have little appetite

19 My periods are irregular

20 I notice I sometimes have difficulty expressing myself

21 I often feel nauseous

22 I worry all day

23 I often suffer from diarrhea

24 My hands shake all the time

25 I have surplus saliva

26 I often suffer from double vision

27 I suffer from skin rash or other skin problems

28 I have gained weight

29 I think more slowly than I used to

$30 \mathrm{I}$ am easily irritated

31 I feel depressed and miserable

32 My bowel movement is often difficult

33 I have difficulty finding the right words

$34 \mathrm{I}$ am becoming less and less active

35 I cannot get to sleep and often lie awake

$36 \mathrm{I}$ am less often in the mood for sex

37 Sometimes I cannot do anything because of headaches

38 I suffer from hair loss

39 My vision is blurred

40 My hair growth has increased

41 When I want to pick up something, my hands start shaking

42 I do not feel capable of performing normal my daily activities

43 I often suffer from headaches

44 Making love has become less pleasant

45 I often suffer from stomach trouble

46 I often feel light-headed

Severity was stated as no problem/mild/moderate/serious problem. 


\section{Appendix B}

Example of an item of the CVST from FePsy

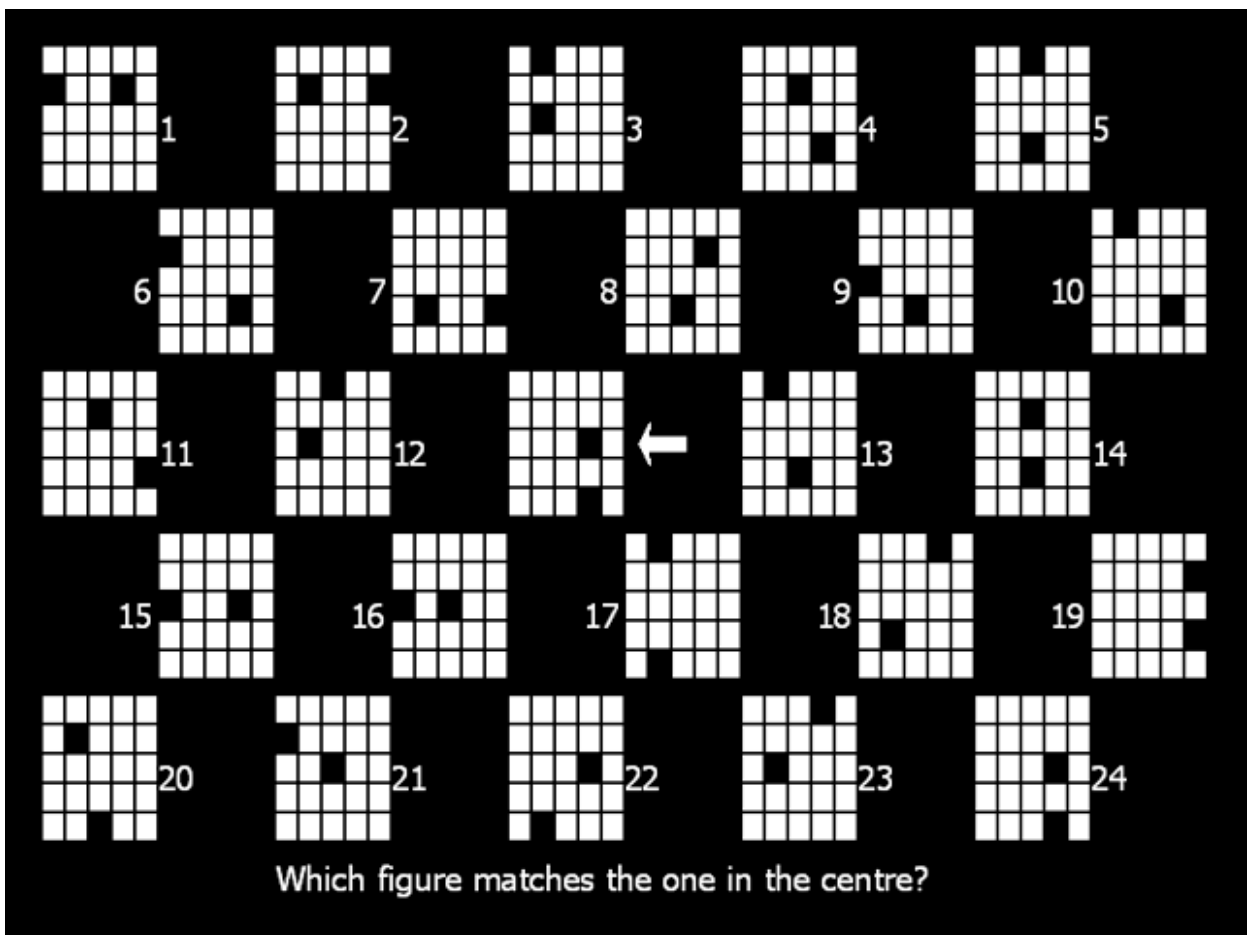




\section{Chapter 4}

\section{The cognitive profile of ethosuximide}

in children

DM IJff, TM van Veenendaal, MH Debeij-van Hall, JFA Jansen, AJA de Louw, HJM Majoie \& AP Aldenkamp

Pediatr Drugs 2016;18:379-385 


\section{Abstract}

\section{Purpose}

Although ethosuximide is one of the oldest anti-epileptic drugs (AEDs), little information is available about the cognitive side-effects of ethosuximide. Therefore, the aim of this study was to investigate the cognitive profile of ethosuximide.

\section{Methods}

In this cross-sectional study, we used an extensive neuropsychological test battery in patients with epilepsy aged 6-16 years who were treated with monotherapy ethosuximide. We evaluated the efficacy of the drug by seizure frequency (seizure free or not).

\section{Results}

We included 61 patients with a mean age of 9.4 years (SD:2.7) who used on average $686 \mathrm{mg} /$ day (SD:245) ethosuximide as monotherapy. Ethosuximide was effective in the majority of the patients ( $70 \%$ were seizure free for at least 6 months at moment of inclusion). The total study population showed impairments of intelligence, visuomotor, and attentional function including activation/alertness. Comparisons between the wellcontrolled patients and patients who were not in remission showed significantly lower intelligence values and lower performance on the visual-perceptual an attentional tasks for the group with ongoing seizures. Our results suggested that the higher order cognitive dysfunctions (such as intelligence and visual-perceptual functions) may be regarded as seizure or aetiology effects and that the impaired fluid cognitive functions, such as activation/alertness, sustained auditory attention and attentional control or switching, were due to ethosuximide.

\section{Conclusion}

This study suggests the attentional dysfunction resulting in psychomotor slowing and alertness deficits may be regarded as effects of ethosuximide. Although no untreated baseline assessment was available, these effects are comparable to those of other AEDs, and ethosuximide may therefore be considered an AED with only mild effects on cognition. As ethosuximide is a first-line therapy for absence seizures in childhood, and drug-induced cognitive impairment may interfere with development, learning and academic achievement, these findings are of interest to clinicians who prescribe this drug, especially when informing parents. 


\section{Introduction}

Approximately $10 \%$ of seizures in childhood epilepsy are absence seizures characterized by brief periods of unconsciousness that may be accompanied by automatic movements. ${ }^{1}$ Generalized tonic-clonic seizures (GTCS) may occur in children with absences, especially late after seizure onset during adolescence. ${ }^{2}$ Ethosuximide is effective as initial monotherapy in children with absence seizures. ${ }^{3}$ Furthermore, initially treated ethosuximide responders may have a lower risk of developing GTCS. ${ }^{4}$

Ethosuximide is one of the oldest anti-epileptic drugs (AEDs), developed in 1960 after the introduction of bromide, phenobarbital, phenytoin and primidone. Ethosuximide modifies the properties of voltage-dependent calcium channels, reducing the T-type currents and thereby preventing synchronized firing. ${ }^{5}$

The first publication concerning the effectiveness of this drug was published in $1958 .{ }^{6}$ Since then, the effect of ethosuximide has been studied in six randomized controlled trials (RCTs). ${ }^{7-12}$ These RCTs were specifically performed to assess efficacy, although the three most recent RCTs also included one attentional test (the Conner's continuous performance test) to assess effects on cognition. ${ }^{10-12}$ These studies showed that attentional dysfunction was more common in patients treated with valproic acid than in those treated with ethosuximide or with lamotrigine at 16-20 weeks of treatment ${ }^{10}$ and after 1 year of treatment. ${ }^{11}$ However, these effects appeared to be caused by the epilepsy and not by ethosuximide. ${ }^{12} \mathrm{~A}$ clinical study also reported attentional problems in children with absence seizures treated with ethosuximide, ${ }^{15}$ but this was a small and heterogeneous study in which not all patients had absence seizures.

No further information is available on the cognitive effects of ethosuximide. Therefore, the aim of this study was to investigate the entire cognitive profile of ethosuximide in children with absence seizures.

\section{Methods}

\section{Subject selection}

Patients with epilepsy aged 6-16 years who were referred to a tertiary referral centre for epilepsy and were treated with monotherapy ethosuximide were included in this cross-sectional study. All patients (parents) signed informed consent to use their data for research. Data on demographical and clinical characteristics such as treatment and seizure type and frequency were collected through medical records. These data are by nature retrospective. Patients were divided in two subgroups based on the efficacy of ethosuximide: a group that had been seizure free for at least 6 months and a group experiencing ongoing seizures. This division was based on clinical evaluation and a recent electroencephalogram (EEG). 


\section{Assessment procedure}

The neuropsychological test battery consisted of two types of tests: (1) tests used to measure higher-order cognitive functions, such as intelligence, memory, and visual perceptual functions and (2) tests assessing fluid functions (functions that can easily fluctuate from moment to moment), such as attentional functions, speed of central information processing, motor speed, and alertness. ${ }^{14,15}$

- Intelligence: The Wechsler Intelligence Scale for Children (WISC-III Dutch version) was used to measure the intellectual ability. ${ }^{16}$ The test consists of 11 subtests that generate a full-scale IQ (FSIQ), as well as a verbal IQ (VIQ) and a performance IQ (PIQ) and three indices: verbal reasoning (VR), perceptual organization (PO), and performance speed (PS).

- Visual-perceptual functions: The Beery Buktenica developmental test of visualmotor integration consists of a sequence of geometric forms of increasing difficulty that the patient copied on paper with a pencil. ${ }^{17}$ In the visual perception test, patients matched geometric forms to the in a given stimulus. In the motor coordination test, the patient traced shapes while remaining inside a double lined path, within a time limit.

- Memory: In the 15-word test (the Dutch version of the Rey Auditory Verbal Learning Test, AVLT), a list of 15 words was orally presented verbally five times. After every presentation, immediate recall (IR) was requested. A delayed recall (DR) was requested after a 20 -min-interval. ${ }^{18}$

- Alertness/activation: In the reaction time measurements, patients had to react as quickly as possible to auditory stimuli presented at random intervals by a computer. $^{14,21}$

- Central information processing speed: In the computerized visual searching task (CVST), the subject had to compare a centred grid pattern against 24 surrounding patterns, one of which was identical to the target pattern. ${ }^{14,19}$

- Attention: The Bourdon-Vos test is a cancellation test that assesses sustained attention. Patients were instructed to cross out the target items. ${ }^{20}$ The Test of Everyday Attention for Children (TEA-Ch) is a standardized battery of tests for assessment across different attentional capacities. ${ }^{21}$ Four different subtests of the TEA-Ch were included: sky search which assessed selective/focused attention (patients had to find as many 'targets' as possible with similar distractors); score!, which assessed sustained attention (patients had to keep a count of the number of 'scoring' sounds they heard); creature counting, which assessed attentional control or switching (patients had to repeatedly switch between two activities in which time taken and accuracy were scored); sky search double task (DT), which assessed sustained and divided attention (patients were asked to combine two tasks; find targets in sky search and keep count of scoring sounds as in score!). 


\section{Statistical analysis}

Data were analysed using the Statistical Package for Social Sciences (SPSS, version 21.0 for Windows). The significance level was set at the $5 \%$ level. First, all neuropsychological test scores of the total study population were converted into z-scores (mean:0, SD:1; which indicates that z-scores between -1 and +1 are within the normal range). Age-matched norms for the general population were used as reference values. To investigate which cognitive domains were impaired in the total study population, comparisons with reference values were made with one-sample t-tests. Second, to eliminate possible interfering effects of the seizures on cognitive functions, differences in test results between seizure-free patients and patients with ongoing seizures were analysed with independent-sample t-tests. Third, to define the cognitive profile of ethosuximide, impaired cognitive functions of the total study population (that were significantly different from reference values and below a z-score of -1 ) that were not affected by seizure effects (not significantly different between seizure-free patients and patients with ongoing seizures) were regarded as effects of ethosuximide.

\section{Results}

In total, 61 patients were included in this study. In most of our patients (70\%), ethosuximide was effective, resulting in seizure freedom, but some patients had ongoing seizures (30\%). All patients had absence seizures, but a minority of the patients had also one or more GTCS in the past. Demographic and clinical characteristics of the study population are provided in Table 4.1.

\section{Neuropsychological tests}

Neuropsychological test results of the total study population were converted into $z$-scores and compared with reference values (Table 4.2). Significantly lower intelligence values were found for VIQ $(t=-2.265, p=.029), P I Q(t=-3.866, p<.001)$, FSIQ $(t=-3.364, p=.002)$, and PO ( $t=-3.680, p=.001)$. Furthermore, the score on the Beery visual motor integration was significantly lower $(t=-7.719, p<.001)$, as well as the Beery motor coordination $(t=-3.658, p=.001)$. Memory was not impaired. On the fluid cognitive functions, a significantly slower reaction time was found on all reaction time tasks (auditory dominant hand $[\mathrm{DH}] \mathrm{t}=4.637, \mathrm{p}<.001$; auditory non-dominant hand [NDH] $t=4.754, p<.001$; visual $\mathrm{DH} t=5.916, p<.001$; visual $\mathrm{NDH} t=5.370, p<.001)$. Attentional functions showed a lower performance for searching time ( $t=-2.321$, $\mathrm{p}=.027$ ), selective attention ( $\mathrm{t}=-2.507, \mathrm{p}=.018$ ), sustained auditory attention ( $\mathrm{t}=-5.518$, $\mathrm{p}<.001)$, attentional control and switching for accuracy $(t=-2.984, p=.006)$ and reaction time $(t=-4.960, p<.001)$. 


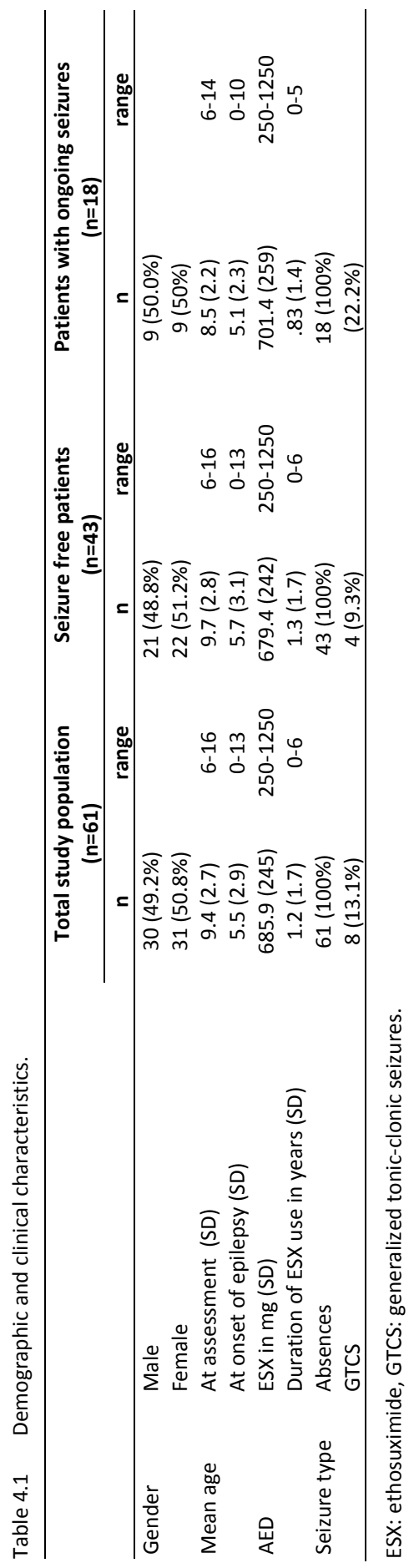


Table 4.2 Differences in neuropsychological test results compared with reference values.

\begin{tabular}{lrrrrc}
\hline & \multicolumn{5}{c}{ Total study population (n=61) } \\
\cline { 2 - 6 } Test & Mean & SD & Mean & SD & p \\
\hline WISC-III VIQ & & & z-score & z-score & $.029^{*}$ \\
WISC-III PIQ & 95.6 & 12.8 & -.34 & .85 & $<.001^{*}$ \\
WISC-III FSIQ & 91.1 & 15.0 & -.61 & 1.01 & $.002^{*}$ \\
WISC-III VR & 92.7 & 14.3 & -.53 & .96 & n.s. \\
WISC-III PO & 97.5 & 12.7 & -.21 & .83 & $.001^{*}$ \\
WISC-III PS & 91.6 & 15.0 & -.58 & 1.01 & n.s. \\
Beery VMI & 96.3 & 17.1 & -.26 & 1.13 & $<.001^{*}$ \\
Beery VP & 87.3 & 11.0 & -.85 & .73 & n.s. \\
Beery MC & 96.4 & 16.8 & -.22 & 1.12 & $.001^{*}$ \\
AVLT IR (number correct) & 87.6 & 16.2 & -.83 & 1.08 & n.s. \\
AVLT DR (number correct) & 42.1 & 10.2 & .31 & 1.07 & n.s. \\
Auditory RT DH (ms) & 8.5 & 2.9 & -.15 & 1.02 & $<.001^{*}$ \\
Auditory RT NDH (ms) & 362.3 & 90.3 & -1.15 & 1.51 & $<.001^{*}$ \\
Visual RT DH (ms) & 345.8 & 76.3 & -1.19 & 1.50 & $<.001^{*}$ \\
Visual RT NDH (ms) & 398.1 & 94.7 & -2.14 & 2.14 & $<.001^{*}$ \\
CVST (sec) & 453.5 & 127.5 & -2.44 & 2.61 & n.s. \\
Bourdon-Vos (reaction time) & 24.4 & 12.3 & -.35 & 1.08 & n.s. \\
Teach Sky Search (number correct) & 16.3 & 5.4 & -.28 & 1.53 & n.s. \\
Teach Sky Search (time) & 9.1 & 2.8 & -.31 & .93 & $.027^{*}$ \\
Teach Sky Search (attention score) & 8.8 & 2.9 & -.41 & .98 & $.018^{*}$ \\
Teach Score! (number correct) & 8.6 & 3.1 & -.47 & 1.04 & $<.001^{*}$ \\
Teach Creature Counting (number correct) & 6.9 & 3.1 & -1.03 & 1.03 & $.006^{*}$ \\
Teach Creature Counting (time) & 8.5 & 2.7 & -.50 & .89 & $<.001^{*}$ \\
Teach Sky Search DT & 6.6 & 3.5 & -1.12 & 1.18 & n.s. \\
\hline
\end{tabular}

TEA-Ch scores are shown in standard scores (mean:10, sd:3). AVLT: auditory verbal learning test, CVST: computerized visual searching task, DH: dominant hand, DR: delayed recall, DT: double task, FSIQ: full scale IQ, IR: immediate recall, MC: Motor Coordination, ms: milliseconds, NDH: non-dominant hand, NS: not significant, PIQ: performance IQ, PO: perceptual organization, PS: performance speed, RT: reaction time, sec: seconds, Teach: test of everyday attention for children, VIQ: verbal IQ, VMI: visual motor integration, VP: visual perception, VR: verbal reasoning, WISC: Wechsler intelligence scale for children. ${ }^{*} \mathrm{p}<.05$

\section{Seizure-free patients versus patients with ongoing seizures}

Comparisons of the neuropsychological test results between the well-controlled patients and patients who were not in remission (Table 4.3), showed significantly lower intelligence values for the group with ongoing seizures (VIQ: $t=2.902, p=.006$; PIQ: $t=2.404, p=.021 ; F S I Q: t=2.752, p=.009$, VR: $t=2.854, p=.007 ; P O: t=2.026, p=.050 ; P S:$ $t=2.302, p=.026)$. Furthermore, the scores on the visual-perceptual tasks were significantly lower for this group (Beery visual motor integration: $t=-2.337, p=.024$; Beery visual perception: $t=2.465, p=.022$ ). For the attentional functions, a significantly lower performance for selective attention $(t=2.711, p=.011)$ was found for the group with ongoing seizures, as well as for the accuracy $(t=2.121, p=.043)$ as the reaction time $(t=3.066, p=.005)$ of this task. 
Table 4.3 Differences between seizure free patients and patients with ongoing seizures.

\begin{tabular}{|c|c|c|c|c|c|}
\hline \multirow[b]{2}{*}{ Test } & \multicolumn{2}{|c|}{$\begin{array}{l}\text { Seizure-free patients } \\
\qquad(n=43)\end{array}$} & \multicolumn{2}{|c|}{$\begin{array}{l}\text { Patients with ongoing } \\
\text { seizures }(n=18)\end{array}$} & \multirow{2}{*}{$\begin{array}{c}\text { Seizure free } \\
\text { vs.ongoing } \\
\text { seizures } \\
p \\
\end{array}$} \\
\hline & Mean & SD & Mean & SD & \\
\hline WISC-III VIQ & 98.5 & 11.5 & 86.1 & 12.8 & $.006^{*}$ \\
\hline WISC-III PIQ & 94.7 & 13.2 & 82.9 & 14.8 & $.021 *$ \\
\hline WISC-III FSIQ & 95.7 & 12.9 & 82.5 & 14.6 & $.008^{*}$ \\
\hline WISC-III VR & 100.3 & 11.5 & 88.2 & 12.6 & $.007^{*}$ \\
\hline WISC-III PO & 94.7 & 13.5 & 84.6 & 14.6 & $.050^{*}$ \\
\hline WISC-III PS & 99.2 & 17.0 & 86.3 & 14.0 & $.026^{*}$ \\
\hline Beery VMI & 89.6 & 10.3 & 81.3 & 11.0 & $.024 *$ \\
\hline Beery VP & 101.4 & 14.9 & 83.7 & 15.8 & $.022 *$ \\
\hline Beery MC & 89.3 & 15.6 & 82.8 & 18.7 & n.s. \\
\hline AVLT IR (number correct) & 42.4 & 9.5 & 38.1 & 10.3 & n.s. \\
\hline AVLT DR (number correct) & 8.7 & 2.9 & 7.8 & 2.9 & n.s. \\
\hline Auditory RT DH (ms) & 342.0 & 70.6 & 404.6 & 113.8 & n.s. \\
\hline Auditory RT NDH (ms) & 337.4 & 75.7 & 364.8 & 77.9 & n.s. \\
\hline Visual RT DH (ms) & 377.7 & 80.0 & 421.1 & 101.2 & n.s. \\
\hline Visual RT NDH (ms) & 423.32 & 123.4 & 476.3 & 103.0 & n.s. \\
\hline CVST (sec) & 24.4 & 12.8 & 24.2 & 11.4 & n.s. \\
\hline Bourdon-Vos (reaction time) & 16.2 & 5.4 & 17.1 & 6.7 & n.s. \\
\hline Teach Sky Search (number correct) & 9.8 & 2.5 & 7.6 & 2.9 & $.043^{*}$ \\
\hline Teach Sky Search (time) & 9.8 & 2.6 & 6.7 & 2.7 & $.005^{*}$ \\
\hline Teach Sky Search (attention score) & 9.6 & 2.8 & 6.6 & 2.8 & $.011^{*}$ \\
\hline Teach Score! (number correct) & 6.8 & 2.8 & 7.1 & 4.1 & n.s. \\
\hline Teach Creature Counting (number correct) & 8.7 & 2.7 & 7.6 & 2.5 & n.s. \\
\hline Teach Creature Counting (time) & 6.8 & 3.5 & 5.5 & 4.2 & n.s. \\
\hline Teach Sky Search DT & 9.2 & 3.0 & 9.6 & 2.7 & n.s. \\
\hline
\end{tabular}

TEA-Ch scores are shown in standard scores (mean:10, sd:3). AVLT: auditory verbal learning test, CVST: computerized visual searching task, DH: dominant hand, DR: delayed recall, DT: double task, FSIQ: full scale IQ, IR: immediate recall, MC: Motor Coordination, ms: milliseconds, NDH: non-dominant hand, NS: not significant, PIQ: performance IQ, PO: perceptual organization, PS: performance speed, RT: reaction time, sec: seconds, Teach: test of everyday attention for children, VIQ: verbal IQ, VMI: visual motor integration, VP: visual perception, VR: verbal reasoning, WISC: Wechsler intelligence scale for children. ${ }^{*} p<.05$.

\section{Cognitive profile of ethosuximide}

The significant lower scores on higher-order cognitive functions (such as intelligence and visual perceptual reasoning) in the total study population could be explained as seizure effects (or effects of a different underlying aetiology) because these functions scored significantly lower in patients with ongoing seizures than in patients in remission. The impaired fluid cognitive functions, such as activation, alertness, sustained auditory attention, and speed of attentional switching, could not be explained by the seizures/aetiology (did not differ beween for seizure-free patients or patients with ongoing seizures) and may therefore be considered as the cognitive effects of ethosuximide. This is also shown in Figure 4.1, in which almost all cognitive domains of the seizure-free patients were within the normal range (z-score between -1 
and +1 ) and were therefore not impaired, except for these fluid functions (which were below a z-score of -1 ).

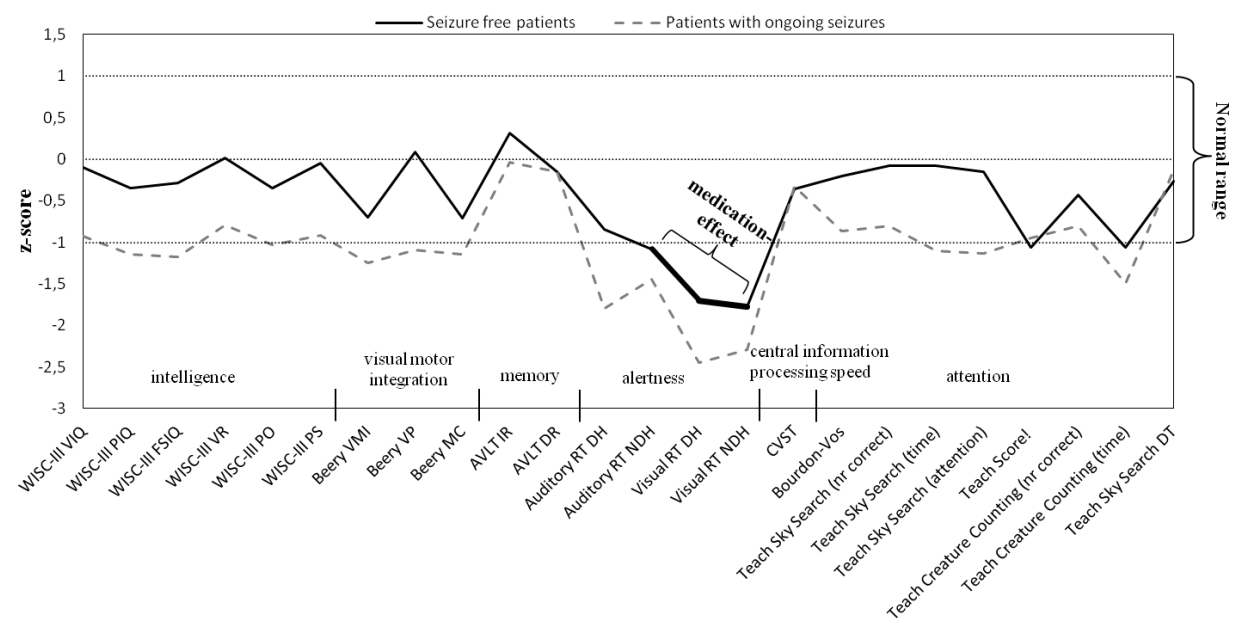

Figure 4.1 Cognitive profile of ESM (in z-scores, between -1 and 1 is within the normal range) shows impaired alertness for ESM (scores below -1 which were not affected by the seizures). VIQ: Verbal IQ, PIQ: Performance IQ, FSIQ: Full Scale IQ, VR: Verbal Reasoning, PO: Perceptual Organization, PS: Performance Speed, VMI: Visual Motor Integration, VP: Visual perception, MC: Motor Coordination, AVLT: Auditory Verbal Learning Test, IR: immediate recall, DR: delayed recall, RT: reaction time, DH: dominant hand, $\mathrm{NDH}$ : non-dominant hand, CVST: computerized visual searching task, nr: number, DT: double task.

\section{Discussion}

Although ethosuximide is one of the oldest AEDs, its effect on cognition has not yet been established in great detail. A recent RCT assessing the efficacy of ethosuximide against other drugs used in absence seizures such as valproic acid and lamotrigine, suggested ethosuximide was superior. ${ }^{3}$ This was because of the higher adverse event rates and negative effects on attention found for valproic acid. However, only one attentional task was used in this comparative RCT. Hence, comprehensive information about the cognitive effects of ethosuximide is lacking. ${ }^{22}$

Therefore, our study investigated the cognitive profile of ethosuximide monotherapy in children. By comparing the results for patients in remission with those for patients with ongoing seizures, the effects of the seizures could be separated from the effects of ethosuximide. Ethosuximide affected fluid 'attentional' functions, especially psychomotor speed and alertness. This type of side-effect is relatively mild with respect to interference with development and learning and does not differ from similar effects in other AEDs such as carbamazepine or oxcarbazepine. ${ }^{15,22,23}$ Apparently, mild 
impairments in alertness and attentional function leading to cognitive slowing is a general reaction to AEDs. ${ }^{14}$

A previous study also showed (mild and temporary) attentional problems in a small group of children with idiopathic generalized epilepsy (mostly absence seizures) compared with the non-treatment baseline. ${ }^{13}$ However, whether this resulted from AED use or the epilepsy itself was unclear as patients included in this study were not seizure free and ethosuximide was used in most, but not all, patients. In two recent RCTs, the higher rate of attentional dysfunction found on one attentional task for valproic acid compared with ethosuximide or lamotrigine after $16-20$ weeks of treatment ${ }^{10}$ persisted after 12 months of treatment. ${ }^{11}$ This confirms our conclusions that cognitive effects for ethosuximide are mild.

Presumably, the main shortcoming of this study is that we did not assess the neuropsychological profile at baseline before ethosuximide treatment was started, which means we cannot compare performance on cognitive tests. This study was performed at a tertiary referral clinic wherein treatment was already started in most patients at referral as most received medication as soon as EEG findings confirmed the diagnosis. Furthermore, treatment effects on cognition can only be investigated in patients with absence seizures who are in remission. Results of an untreated baseline or an early baseline would always be a mixed bag of seizures effects and medication effects. Further confounding factors and methodological issues limit the interpretation of our study. Why some patients were more resistant to treatment than others is unknown. Although all patients had an idiopathic epilepsy, the underlying aetiology may nevertheless have an effect in patients with ongoing seizures. The gold standard design in this type of research would, of course, be an RCT with longitudinal follow-up. However, this is difficult to realize with a relative 'old drug'. Even with new medications, the initial regulatory trials almost never include cognition as an outcome measurement. Therefore, the 'next best' is then to study the effects in a naturalistic setting with limited protection against bias. As cognitive effects are important factors in medical decision making, we recommend that, in the development of new AEDs, cognition always be used as outcome measure in the industry driven RCTs.

Our study is the first that suggest a cognitive profile of ethosuximide and reveal an impact on attentional functions, especially on psychomotor speed and alertness. Such effects do interfere with development, learning and academic achievement, but only mildly compared with the effects of drugs on higher-order functions such as the effect of topiramate on language. As ethosuximide is considered a first-line therapy for absence seizures in childhood, and drug-induced cognitive impairment may interfere with development, learning and academic achievement, these findings are of interest to clinicians who prescribe this drug, especially when informing parents. 


\section{References}

1. Posner EB. Absence seizures in children. BMJ Clin Evid 2013;0317.

2. Caraballo RH, Dalla Bernadina B. Idiopathic generalized epilepsies. In: Dulac O, Lassonde M, Sarnat HB (Eds) Handbook of clinical neurology. Oxford: Elsevier Science; 2013:579-89.

3. Glauser TA, Ben-Menachem E, Bourgeois B, et al. Updated ILAE evidence review of antiepileptic drug efficacy and effectiveness as initial monotherapy for epileptic seizures and syndromes. Epilepsia 2013;54:551-63.

4. Shinnar S, Cnaan A, Hu F, et al. Long-term outcomes of generalized tonic-clonic seizures in a childhood absence epilepsy trial. Neurology 2015;85:1108-14.

5. Patsalos PN. Properties of antiepileptic drugs in the treatment of idiopathic generalized epilepsies. Epilepsia 2005;46:140-8.

6. Zimmerman FT, Burgemeister BB. A new drug for petit mal epilepsy. Neurology. 1958;8:769-75.

7. Callaghan N, Ohara J, Odriscoll D, et al. Comparative study of ethosuximide and sodium valproate in the treatment of typical absence seizures (petitmal). Dev Med Child Neurol 1982;24:830-6.

8. Sato S, White BG, Penry JK, et al. Valproic acid versus ethosuximide in the treatment of absence seizures. Neurology 1982;32:157-63.

9. Martinovic Z. Comparison of ethosuximide with sodium valproate. In Parsonage M, Grant R, Craig AWJr. (Eds) Advances in epileptology, XIVth epilepsy international symposium. Raven Press, New York, 1983:301-5.

10. Glauser TA, Cnaan A, Shinnar S, et al. Ethosuximide, valproic acid, and lamotrigine in childhood absence epilepsy. N Engl J Med 2010;362:790-9.

11. Glauser TA, Cnaan A, Shinnar S, et al. Ethosuximide, valproic acid, and lamotrigine in childhood absence epilepsy: initial monotherapy outcomes at 12 months. Epilepsia 2013;54:141-55.

12. Masur D, Shinnar S, Cnaan A, et al. Pretreatment cognitive deficits and treatment effects on attention in childhood absence epilepsy. Neurology 2013;81:1572-80.

13. Mandelbaum DE, Burack GD, Bhise VV. Impact of antiepileptic drugs on cognition, behavior, and motor skills in children with new-onset, idiopathic epilepsy. Epilepsy Behav 2009;16:341-4.

14. Grevers E, Breuer LEM, IJff DM, et al. Mental slowing in relation to epilepsy and antiepileptic medication. Acta Neurol Scand 2016;134:116-22.

15. IJff DM, Aldenkamp AP. Comorbidities of treatment with antiepileptic drugs. In Duchowny M, Cross JH, and Arzimanoglou A (Eds) Pediatric Epilepsy. New York: McGraw-Hill Professional;2012:424-36.

16. Wechsler D. Wechsler Intelligence Scale for Chrildren derde editie NL, Handleiding en verantwoording, Harcourt Test Publishers, Amsterdam; 2005.

17. Beery KE, Beery NA. The Beery-Buktenica developmental test of visual-motor integration, administration, scoring and teaching manual. 5th ed. Minneapolis: NCS Pearson; 2006.

18. Kalverboer AF, Deelman BG. De 15-woorden tests A en B : (een voorlopige handleiding) (15WT/VWT). Groningen : Academisch Ziekenhuis Groningen, afd. Neuropsychologie; 1986.

19. Alpherts WCJ, Aldenkamp AP. FePsy: 'The Iron Psyche'. Instituut voor epilepsiebestrijding, The Netherlands, Heemstede; 1995.

20. Vos PG. Bourdon-Vos test handleiding. Swetss test services; 1988.

21. Manly T, Robertson I, Anderson V, et al. Test of Everyday Attention in Children. Amsterdam: Pearson; 2004.

22. IJff DM, Aldenkamp AP. Cognitive side-effects of antiepileptic drugs in children. In: Dulac O, Lassonde M, Sarnat HB (Eds) Handbook of clinical neurology. Oxford: Elsevier Science;2013:707-18.

23. Donati F, Gobbi G, Campistol J, et al. Effects of oxcarbazepine on cognitive function in children and adolescents with partial seizures. Neurology 2006;67:679-82. 


\section{Chapter}

Cognitive and behavioural impact of the ketogenic diet in children and adolescents with refractory epilepsy: a randomized controlled trial

DM IJff, D Postulart, DAJE Lambrechts, HJM Majoie, RJA de Kinderen, JGM Hendriksen, SMAA Evers \& AP Aldenkamp 


\section{Abstract}

\section{Purpose}

The ketogenic diet (KD) is increasingly used for the treatment of refractory epilepsy in childhood because of the beneficial effect on seizure reduction. The aim of the current study was to objectively assess cognition and aspects of behavior during the first 4 months of a randomized controlled study in children and adolescents.

\section{Methods}

Participants from a tertiary epilepsy center were randomized to a KD group (intervention) or a care as usual (CAU)group (control). Follow-up assessments on cognition and behavior were performed approximately 4 months after initiation of the KD with a combination of parent report questionnaires and individually administered psychological tests for the children.

\section{Results}

A total of 50 patients were included for this study, 28 patients from the KD group and 22 patients from the CAU group. The KD group showed lower levels of anxious and mood-disturbed behavior and was rated as more productive. Cognitive test results showed an improvement of activation in the KD group.

\section{Conclusion}

This study showed a positive impact of the KD on behavioral and cognitive functioning in children and adolescents with refractory epilepsy. More specifically, an activated mood and cognitive activation were observed in patients treated with the KD. 


\section{Introduction}

Epilepsy is a neurological disorder that is treated with antiepileptic drugs (AEDs) in the majority of the patients. However, AEDs are sometimes not efficacious. About one third of patients suffer from intractable epilepsy. ${ }^{1}$ Furthermore, patients often experience side-effects that lead to discontinuation of the drug. ${ }^{2}$ For these patients alternative nonpharmacological treatment options are available, including the ketogenic diet (KD). The KD was developed in the 1920s as a treatment for refractory epilepsy when few AEDs were available. The KD is a high-fat, low-carbohydrate diet that imitates the metabolic state of fasting while maintaining a normal number of calories. Body energy requirements while on a KD are met by lipolysis and ß-oxidation of fatty acids rather than by the breakdown of carbohydrates. The exact anticonvulsant mechanism of action of the KD has not yet been elucidated. ${ }^{3}$ Side-effects of the KD are in the gastrointestinal domain such as constipation and vomiting. ${ }^{4}$

The effect of the KD has been studied in multiple observational studies ${ }^{5-10}$, reviews ${ }^{11-15}$, and three randomized controlled trials (RCTs). ${ }^{4,16,17}$ The RCT of our study group showed that the KD was effective during the first four months in children and adolescents with refractory epilepsy compared with the care-as-usual (CAU) group. The most often reported side-effects were gastrointestinal symptoms. The focus of these studies is mainly on analyzing efficacy. Less attention has been paid to possible negative or positive effects of KD on behavioral function.

In the observational studies, the majority of parents reported improvements during treatment with the KD in their child's behavior ${ }^{18}$ and cognitive function, ${ }^{19,20}$ particularly with respect to attention/alertness, ${ }^{18,20}$ activity level, and socialization. ${ }^{20,21}$ Furthermore, the KD improves sleep quality in children with therapy-resistant epilepsy. The improvement in sleep quality seems to contribute to the improvement in attentional behavior. ${ }^{22}$ However, all these studies were focused on only one aspect of behavior and used only by-proxy reports with parent-rated questionnaires.

One study that used a combination of individually administered cognitive-oriented psychological tests and parent report questionnaires showed small trends toward improvement in the cognitive functioning and toward worsening in psychosocial adjustment. ${ }^{23}$ However, the study group was small and there was no comparison with CAU. Therefore, the aim of the current study was to assess cognition and behavior in a prospective randomized controlled study in both children and adolescents. 


\section{Methods}

\section{Study population}

Patients were children and adolescents with intractable epilepsy. Patients were eligible to participate if they met the following criteria: aged between 1 and 18 years and having uncontrolled seizures after trying two or more AEDs. Details of the exclusion criteria can be found elsewhere. ${ }^{24}$ Eligible candidates and their parents were referred by their attending physician to the multidisciplinary KD team at epilepsy center Kempenhaeghe in the Netherlands, where they received detailed information about the study before giving their informed consent. This study has been approved by the ethics committee of the Academic Medical Center Utrecht, the Netherlands.

\section{Procedure}

Between July 2010 and August 2014, subjects were randomized to either the KD or to CAU after a 1-month baseline period. The KD group started after the baseline period with the ketogenic diet. The controls were treated and monitored according to good clinical practice. Both patient groups continued to take their AEDs without changes during baseline (except when medically indicated), during the 4 months waiting of the CAU group, and during the first 4 months of treatment with the KD. Assessments were performed at baseline, before randomization, and after a 4-month study period.

\section{Mood and behavior}

- The Profile of Mood States (POMS) was developed to identify and assess transient, fluctuating affective mood states: tension/anxiety, depression/dejection, anger/hostility, vigor/activity, fatigue/inertia and confusion/bewilderment. The POMS contains 65 self-report items using the 5-point Likert Scale. The test is used by proxy and requires parents to indicate for each word or statement how their child have been feeling in the past week. A higher score represents more mood impairment. $^{25}$

- The Personal Adjustment and Role Skills Scale - Third Edition (PARS-III) was specifically developed to measure psychosocial adjustment in children with chronic physical illness. ${ }^{26}$ This instrument is a brief parent-completed index of youth psychosocial adjustment. The 28 items include six subscales: peer relations, dependency, hostility, productivity, anxiety-depression, and withdrawal. Higher scores indicate better psychosocial adjustment. The PARS-III is a reliable and valid index of youth psychosocial adjustment and can be used for both clinical screening and research purposes. ${ }^{27}$

- The Strengths and Difficulties Questionnaire (SDQ) is a brief parent-reported behavioral screening questionnaire that provides balanced coverage of children and 
young people's behaviors, emotions, and relationships. ${ }^{28}$ The SDQ asks about 25 attributes that are divided into five relevant dimensions: namely emotional symptoms, conduct problems, hyperactivity, peer relations, and prosocial behavior. For all scales, except the prosocial scale, a higher score indicates more problems.

- The Hague Restrictions in Childhood Epilepsy Scale (HARCES) is a parent completed 10-item scale to assess impairments in daily functioning that are related to epilepsy. ${ }^{29,30}$ The scale measures the number of restrictions imposed because of seizures. Items reflect the frequency with which the child takes part in activities such as swimming, riding a bicycle, staying elsewhere overnight, and participating in physical education. The scale focuses on the extent to which epilepsy affects a child's ability to take part in everyday childhood activities. Respondents rate each item according to the degree to which the child's activity is limited by epilepsy; a higher score means more disabilities. Furthermore, parents are asked to rate the severity of the seizures, from not severe (low score) to very severe (highest score).

- The Social Emotional Questionnaire (SEV) is a DSM-IV oriented questionnaire to assess four domains of behavioral and social emotional dysfunction: attention deficit and hyperactivity disorders, oppositional defiant behavior and conduct disorders, anxiety and depression, and autism spectrum disorders. ${ }^{31}$ The questionnaire consists of 72 items and yields total scores for each of the four domains. A higher score indicates more problems.

\section{Neuropsychological assessment}

- The Dutch version of the Peabody Picture Test (PPVT-III) assesses receptive vocabulary. ${ }^{32}$ The child has to point to one of four pictures corresponding to the examiner's stimulus word. Raw scores can be converted to age-equivalent standard scores (mean:100, standard deviation: 15). This measurement is often used as a reliable predictor of general cognitive functioning in children and adults. ${ }^{33}$

- The Beery Developmental Test of VMI is a widely used paper-and-pencil test that assesses the extent to which individuals can integrate their visual and motor abilities. $^{34}$ Subjects are asked to copy a developmental sequence of 24 geometric forms. Raw scores are converted into standardized scores (mean: 100, standard deviation: 15$)$.

- Additionally, different subtests from the FePsy neuropsychological computerized test battery were conducted. ${ }^{35}$ Simple reaction time measurements on either visual (a white square) or auditory stimuli assess alertness functions and speed of activation of the information processing system. In the binary choice reaction test, the subject has to react in a different way to two dissimilar stimuli (a red square presented on the left side of the screen and a green square presented on the right side) which assesses the speed of central information processing. In both tasks, reaction times in milliseconds are provided (with a higher score indicating a slower reaction time). In the tapping task, speed of finger tapping is measured for the index finger of the right 
and left hands, separately. Number of taps is recorded and a higher score indicates more motor activation and fluency.

\section{Statistical analysis}

Data analyses were performed using SPSS version 21 for Windows. The level of significance was set at $p<.05$ ( $p$-values were 2 -sided). Independent t-tests were performed to check for differences between the KD group and the CAU group at baseline and at end-point ( 4 months). Correlations between seizure reduction and the behavioral and cognitive data were investigated using Pearson's correlations.

\section{Results}

Between August 2010 and August 2014, a total of 58 patients were included in the study. One patient dropped out of the study before randomization, and seven patients dropped out after randomization: six from the CAU group (because of dissatisfaction regarding the randomization result) and one patient from the KD group (because of spontaneous seizure reduction), leaving 50 patients who were investigated at baseline (28 patients from the KD group (56\%) and 22 patients from the CAU group). The demographic and clinical characteristics of the study population are shown in Table 5.1. Furthermore, of these 50 included patients, eight patients dropped out before the study endpoint of 4 months (five patients from the KD group and three patients from the CAU group). The effectiveness of the KD in our study population is described elsewhere. ${ }^{17}$

\section{Mood and behavior}

The results of the mood and behavior questionnaires are provided in Table 5.2.

On the POMS, differences between groups at baseline were found. Patients randomized to the KD group had higher tension/anxiety levels, higher anger/hostility levels, and higher confusion/bewilderment levels. These differences were not statistically significant at the 4-month follow-up because of the reduction in anxiety/tension/hostility levels in the KD patients. At the 4-month follow-up, the patients from the KD group had a higher score on the subscale 'vigor' ('energy') than the patients from the CAU group $(p=.005)$. There was a positive correlation with seizure reduction in the KD group $(r=.622, p=.004)$. The greater the seizure reduction, the higher the vigor score.

On the PARS, no significant differences were found at baseline. At the 4-month followup, parents reported for the KD group a higher score on the subscale 'productivity' than for the CAU group ( $p=.039)$. There was no significant correlation with seizure reduction. 
Table 5.1 Demographic and clinical characteristics at baseline.

\begin{tabular}{|c|c|c|c|c|}
\hline & KD N=28 & $\%$ & CAU $\mathbf{N}=22$ & $\%$ \\
\hline \multicolumn{5}{|l|}{ Gender } \\
\hline Male & 20 & 71.4 & 9 & 40.9 \\
\hline Female & 8 & 28.6 & 13 & 59.1 \\
\hline \multicolumn{5}{|l|}{ Age } \\
\hline at trial initiation (range) & $7.6(2.1-16.5)$ & & $8.1(1.1-15.7)$ & \\
\hline at seizure onset & $2.3(0-8)$ & & $1.9(0-10)$ & \\
\hline \multicolumn{5}{|l|}{ Type of epilepsy } \\
\hline Syndrome & 10 & 35.7 & 4 & 18.2 \\
\hline Generalized & 5 & 17.9 & 6 & 27.3 \\
\hline Localization related & 13 & 46.4 & 12 & 54.5 \\
\hline \multicolumn{5}{|l|}{ Etiology of epilepsy } \\
\hline Genetic & 7 & 25 & 1 & 4.5 \\
\hline Structural-metabolic & 2 & 7.1 & 10 & 45.5 \\
\hline Unknown & 19 & 67.9 & 11 & 50 \\
\hline \multicolumn{5}{|c|}{ Seizure frequency during baseline } \\
\hline$<1$ month & 1 & 3.6 & 0 & - \\
\hline$\geq 1$ month & 3 & 10.7 & 3 & 13.6 \\
\hline$\geq 1$ week & 14 & 50 & 16 & 72.7 \\
\hline Daily & 10 & 35.7 & 3 & 13.6 \\
\hline \multicolumn{5}{|c|}{ Number of AEDs tried before start AED } \\
\hline Three & 3 & 10.7 & 4 & 18.2 \\
\hline Four & 4 & 14.3 & 5 & 22.7 \\
\hline Five & 9 & 32.1 & 3 & 13.6 \\
\hline Six & 5 & 17.9 & 3 & 13.6 \\
\hline Seven & 2 & 7.1 & 1 & 4.5 \\
\hline Eight & 4 & 14.3 & 2 & 9.1 \\
\hline Nine & 1 & 3.6 & 4 & 18.2 \\
\hline \multicolumn{5}{|l|}{ Number of AEDs at start KD } \\
\hline None & 0 & - & 1 & 4.5 \\
\hline One & 3 & 10.7 & 4 & 18.2 \\
\hline Two & 13 & 46.4 & 8 & 36.4 \\
\hline Three & 9 & 32.1 & 5 & 22.7 \\
\hline Four & 3 & 10.0 & 2 & 9.1 \\
\hline Five & 0 & - & 2 & 9.1 \\
\hline \multicolumn{5}{|l|}{ Type of KD } \\
\hline Classical & 2 & 7.1 & & \\
\hline MCT & 20 & 71.4 & & \\
\hline Only Ketocal & 5 & 17.9 & & \\
\hline Mixture & 1 & 3.6 & & \\
\hline \multicolumn{5}{|l|}{ VNS tried before KD } \\
\hline Yes & 1 & 3.6 & 1 & 4.5 \\
\hline No & 27 & 96.4 & 21 & 95.5 \\
\hline \multicolumn{5}{|l|}{ Epilepsy surgery in the past } \\
\hline Yes & $1^{*}$ & 3.6 & 0 & - \\
\hline No & 29 & 96.4 & 22 & 100 \\
\hline
\end{tabular}

KD: Ketogenic diet, CAU: Care as usual, AEDs: Antiepileptic drugs, MCT: Medium-chain triglycerides, VNS: Vagus nerve stimulator, ADHD: Attention deficit hyperactivity disorder, ADD: Attention deficit disorder.

* One patient from the KD-group had a corpus callosotomy in the past. 
There were no significant differences between the groups on the SDQ, either for the baseline and the 4-month follow-up assessments.

On the HARCES, no differences were found at baseline. At the 4-month follow-up, the severity of the seizures of the KD group was reported as less severe compared to the CAU group $(p=.038)$. There was a negative correlation with seizure reduction in the KD group $(r=-.718, p \leq .000)$. The more severe the seizures were perceived, the less the seizure reduction.

On the SEV, no differences were found at baseline. At the 4-month follow-up, parents reported less anxious and mood disturbed behavior for the KD group than for the controls $(p=.049)$. There was no significant correlation with seizure reduction.

Table 5.2 Differences in mood and behavior between KD vs. CAU.

\begin{tabular}{|c|c|c|c|c|c|c|}
\hline \multirow[b]{2}{*}{ Assessment } & \multicolumn{3}{|c|}{ Baseline } & \multicolumn{3}{|c|}{ Endpoint } \\
\hline & KD & CAU & $\mathbf{p}$ & KD & CAU & $\mathbf{p}$ \\
\hline POMS tension / anxiety & 11.39 & 7.15 & $.005^{*}$ & 9.20 & 9.63 & n.s. \\
\hline POMS depression / dejection & 9.35 & 7.15 & n.s. & 6.47 & 5.71 & n.s. \\
\hline POMS anxiety / hostility & 10.39 & 6.62 & $.042 *$ & 8.80 & 8.13 & n.s. \\
\hline POMS vigor / activity & 19.39 & 19.29 & n.s. & 20.86 & 16.50 & $.005^{*}$ \\
\hline POMS fatique / inertia & 9.67 & 7.93 & n.s. & 8.20 & 8.63 & n.s. \\
\hline POMS confusion / bewilderment & 11.00 & 6.08 & $.005^{*}$ & 8.27 & 9.38 & n.s. \\
\hline PARS-III peer relations & 8.68 & 7.87 & n.s. & 8.36 & 8.00 & n.s. \\
\hline PARS-III dependency & 10.37 & 9.27 & n.s. & 9.92 & 8.33 & n.s. \\
\hline PARS-III hostility & 18.37 & 18.00 & n.s. & 18.62 & 17.83 & n.s. \\
\hline PARS-III productivity & 8.58 & 7.07 & n.s. & 9.31 & 7.42 & $.039 *$ \\
\hline PARS-III anxiety-depression & 19.26 & 18.40 & n.s. & 20.77 & 18.17 & n.s. \\
\hline PARS-III withdrawal & 11.53 & 11.80 & n.s. & 13.31 & 12.92 & n.s. \\
\hline SDQ emotional symptoms & 3.43 & 2.54 & n.s. & 2.00 & 2.50 & n.s. \\
\hline SDQ conduct problems & 1.86 & 1.15 & n.s. & 1.31 & 1.83 & n.s. \\
\hline SDQ peer relations & 3.33 & 2.31 & n.s. & 2.75 & 2.83 & n.s. \\
\hline SDQ hyperactivity & 6.10 & 6.54 & n.s. & 4.81 & 4.92 & n.s. \\
\hline SDQ prosocial behavior & 6.47 & 6.54 & n.s. & 7.31 & 7.00 & n.s. \\
\hline HARCES restrictions & 25.80 & 25.21 & n.s. & 24.06 & 23.00 & n.s. \\
\hline HARCES rating severity of seizures & 8.24 & 8.32 & n.s. & 6.06 & 7.29 & $.038^{*}$ \\
\hline SIDAED general CNS & 5.44 & 3.77 & n.s. & 3.90 & 3.11 & n.s. \\
\hline SIDAED behavior / increased irritability & 3.25 & 2.45 & n.s. & 1.59 & 1.44 & n.s. \\
\hline SIDAED depressive symptoms & 2.07 & 2.00 & n.s. & 0.90 & 1.94 & n.s. \\
\hline SIDAED cognitive functions & 9.85 & 7.71 & n.s. & 6.25 & 7.29 & n.s. \\
\hline SIDAED motor coordination & 1.89 & 1.59 & n.s. & 0.90 & 1.22 & n.s. \\
\hline SIDAED visual complaints & 0.00 & 0.27 & n.s. & 0.00 & 0.11 & n.s. \\
\hline SIDAED headache & 1.07 & 0.43 & n.s. & 0.25 & 0.39 & n.s. \\
\hline SIDAED cosmetic and skin & 2.07 & 2.86 & n.s. & 1.27 & 2.44 & n.s. \\
\hline SIDAED gastrointestinal complaints & 2.29 & 1.68 & n.s. & 3.29 & 1.44 & $.000^{*}$ \\
\hline SEV attention deficit and hyperactivity & 29.85 & 28.69 & n.s. & 26.60 & 25.22 & n.s. \\
\hline SEV social problem behavior & 16.65 & 13.00 & n.s. & 15.67 & 10.78 & n.s. \\
\hline SEV anxious and mood-disturbed behavior & 13.45 & 12.92 & n.s. & 8.73 & 15.22 & $.049 *$ \\
\hline SEV autistic behavior & 8.10 & 7.69 & n.s. & 5.93 & 7.78 & n.s. \\
\hline
\end{tabular}

$*$ p $<.05$, n.s.: not significant. 


\section{Neuropsychological investigation}

Table 5.3 shows the neuropsychological differences between both groups at baseline and endpoint. At baseline and endpoint, a statistically significant difference was found between the KD group and the control group for word comprehension on the Peabody Picture Test (baseline: $p=.036$, endpoint: $p=.006$ ). Patients from the KD group had $a$ higher score than patients from the control group. There was no significant correlation with seizure reduction. At baseline, significantly higher scores were found on two of the four simple reaction time activation tests for the KD group. These differences disappeared at the 4-month follow-up because of improvement of scores in the KD group.

Table 5.3 Differences in neuropsychological investigation between KD vs. CAU.

\begin{tabular}{lrrrrrc}
\hline & \multicolumn{3}{c}{ Baseline } & \multicolumn{3}{c}{ Endpoint } \\
\cline { 2 - 7 } Assessment & \multicolumn{1}{c}{ KD } & CAU & p & \multicolumn{1}{c}{ KD } & CAU & p \\
\hline PPVT-III & 92.67 & 81.27 & $.036^{*}$ & 96.30 & 82.56 & $.006^{*}$ \\
Beery VMI & 85.93 & 81.40 & n.s. & 87.73 & 81.56 & n.s. \\
FePsy auditory reaction time DH & 672.85 & 445.44 & $.031^{*}$ & 474.40 & 455.22 & n.s. \\
FePsy auditory reaction time NDH & 649.23 & 484.11 & n.s. & 564.90 & 487.67 & n.s. \\
FePsy visual reaction time DH & 757.58 & 572.78 & n.s. & 624.10 & 517.29 & n.s. \\
FePsy visual reaction time NDH & 785.33 & 567.89 & $.023^{*}$ & 745.60 & 566.86 & n.s. \\
FePsy binary choice reaction time & 671.38 & 518.78 & n.s. & 564.40 & 579.00 & n.s. \\
FePsy tapping DH & 32.86 & 34.78 & n.s. & 34.42 & 34.34 & n.s. \\
FePsy tapping NDH & 30.79 & 30.22 & n.s. & 34.12 & 29.89 & n.s. \\
\hline
\end{tabular}

* p<.05, n.s.: not significant, DH: dominant hand, $\mathrm{NDH}$ : non-dominant hand.

\section{Discussion}

This RCT shows a positive cognitive and behavioral effect of the KD in children and adolescents. With respect to mood, patients on the KD showed higher levels of mood problems at baseline. These problems, however, disappeared at the 4-month follow up because of reduction in anxiety/tension/hostility levels in the KD patients. With respect to social emotional functioning, patients from the KD group showed lower levels of anxious and mood-disturbed behavior at 4 months, which were independent of the improved seizure control. Furthermore, they had a higher productivity at 4 months (e.g. continued working until it was finished and even though it was difficult without encouragement) which was also independent of the seizure reduction. Cognitive test results showed a higher receptive vocabulary for patients randomized to the KD at 4 months, which already existed at baseline and was independent of the improved seizure control. This seems to be a baseline characteristic of the patients without a relation to the KD. Furthermore, patients on the KD showed slower reaction times at baseline. This mental slowing, however, disappeared at the 4-month follow-up because 
of improvement of activation of the KD patients and appears not to be an effect of improved seizure control. Both patient groups continued to take their AEDs without changes. Therefore, these findings could not be an effect of the medication. Figure 5.1 summarizes the obtained KD-related effects on mood and cognition.

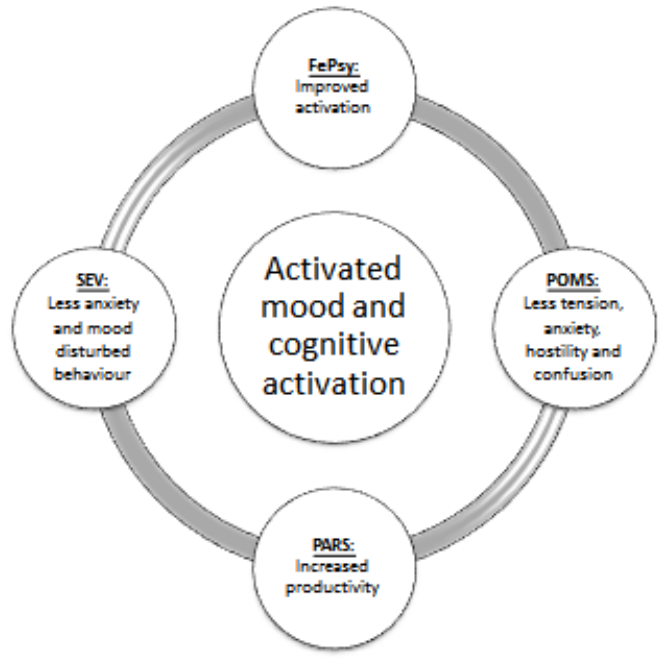

Figure 5.1 Summary of the KD effects on mood and cognition.

To our knowledge, this is the first RCT that evaluated the cognitive and behavioral effect of the KD versus a control group. Furthermore, little research is done in this area in children and adolescents, which makes it difficult to compare our results with previous findings. The activated cognition found in our study is consistent with previous reports of children on the KD showing increased mental alertness ${ }^{18,21,36,37}$, improved attention $^{20,21}$, and improved cognition..$^{19,20,23}$ The activated mood and behavior during the KD is consistent with previous findings reporting improvement in activity level and socialization ${ }^{21}$ but in contrast with an earlier observational study. ${ }^{23}$ Based on these improvements, extensive objective neuropsychological investigation and systematic questionnaires during the KD seem to be unnecessary. However, this was a group approach. Of course, there is some interindividual variability, so vigilance with monitoring of cognitive functions and emotional well-being is always advised. Furthermore, it is not clear how these effects evolve over the long-term. Therefore, further research focusing on the chronic effects of the KD on cognition and behavior of children is needed.

This study has some limitations. Both the classical and MCT KD protocols was used. However, these are comparable in efficacy and tolerability. ${ }^{38}$ The dropout rate in our 
study population is $16 \%$ and therefore relatively high. However, previous research showed that $96 \%$ of the KD users who discontinued the diet would recommend this nonpharmacological treatment option to others, ${ }^{39}$ and more than half of them recommend starting the KD before trying AEDs. This indicates that, although compliance to the KD is difficult because of practical issues, the KD is recommended. We used by-proxy measures for assessing the impact of the KD on behavior which could be influenced by the efficacy of the diet. Therefore, the results were correlated with seizure reduction. Although the KD group had a significantly higher level of cognitive functioning than the CAU group, we used neuropsychological tests which could be used in the majority of the patients because they matched their cognitive age and chronological age levels which made comparison of the results across the study population possible.

In conclusion, this RCT showed a positive impact of the KD on behavioral and cognitive functioning in children and adolescents with refractory epilepsy. Moreover, some improvements during treatment with the KD were observed in this study population. This activated mood and cognitive activation was not related to reduction in seizure frequency and corresponds with the well-known effects of the KD. It also contributes to the growing motivation for consideration of the KD as a treatment option in childhood refractory epilepsy. 


\section{References}

1. Sillanpaa M, Schmidt D. Natural history of treated childhood-onset epilepsy: prospective, long-term population-based study. Brain 2006;129:617-24.

2. IJff D, Kinderen R, Vader C, et al. Subjectively perceived side-effects of anti-epileptic drugs in chronic refractory epilepsy. Adv Pharmacoepidemiol Drug Saf 2015;4(4):186.doi: 10.4172/2167-1052.1000186

3. Freeman J, Veggiotti P, Lanzi G, et al. The ketogenic diet: from molecular mechanisms to clinical effects. Epilepsy Res 2006;68:145-80.

4. Neal EG, Chaffe H, Schwartz RH, et al. The ketogenic diet for the treatment of childhood epilepsy: a randomized controlled trial. Lancet Neurol 2008;7:500-6.

5. Coppola G, Veggiotti P, Cusmai R, et al. The ketogenic diet in children, adolescents and young adults with refractory epilepsy: an Italian multicentric experience. Epilepsy Res 2002;48:221-7.

6. Freeman JM, Vining EP, Pillas DJ, et al. The efficacy of the ketogenic diet-1998: a prospective evaluation of intervention in 150 children. Pediatrics 1998;102(6):1358-63.

7. Kang HC, Kim YJ, Kim DW, et al. Efficacy and safety of the ketogenic diet for intractable childhood epilepsy: Korean multicentric experience. Epilepsia 2005;46:272-9.

8. Kankirawatana $P$, Jirapinyo $P$, Kankirawatana $S$, et al. Ketogenic diet: an alternative treatment for refractory epilepsy in children. J Med Assoc Thai 2001;84:1027-32.

9. Maydell BV, Wyllie E, Akhtar N, et al. Efficacy of the ketogenic diet in focal versus generalized seizures. Pediatr Neurol 2001;25:208-12.

10. Vining EP. Clinical efficacy of the ketogenic diet. Epilepsy Res 1999;37:181-90.

11. Keene DL. A systematic review of the use of the ketogenic diet in childhood epilepsy. Pediatr Neurol 2006;35:1-5.

12. Lefevre $\mathrm{F}$, Aronson N. Ketogenic diet for the treatment of refractory epilepsy in children: A systematic review of efficacy. Pediatrics 2000;105:E46.

13. Levy R, Cooper P. Ketogenic diet for epilepsy. Cochrane Database Syst Rev 2003;(3):CD001903.

14. Sinha SR, Kossoff EH. The ketogenic diet. Neurologist 2005;11:161-70.

15. Levy RG, Cooper PN, Giri P. Ketogenic diet and other dietary treatments for epilepsy. The Cochrane Database of Syst Rev 2012;3:CD001903.

16. Sharma S, Sankhyan N, Gulati S, et al. Use of the modified Atkins diet for treatment of refractory childhood epilepsy: a randomized controlled trial. Epilepsia 2013;54:481-6.

17. Lambrechts DAJE, de Kinderen RJA, Vles JSH, et al. A randomized controlled trial of the ketogenic diet in refractory childhood epilepsy. Acta Neurol Scand 2016; doi: 10.1111/ane.12592.

18. Kinsman SL, Vining EP, Quaskey SA, et al. Efficacy of the ketogenic diet for intractable seizure disorders: review of 58 cases. Epilepsia 1992;33:1132-6.

19. Mak SC, Chi CS, Wan CJ. Clinical experience of ketogenic diet on children with refractory epilepsy. Acta Paediatr Taiwan 1999;40:97-100.

20. Pulsifer MB, Gordon JM, Brandt J, et al. Effects of ketogenic diet on development and behavior: preliminary report of a prospective study. Dev Med Child Neurol 2001;43:301-6.

21. Nordli Dr Jr, Kuroda MM, Carroll J, et al. Experience with the ketogenic diet in infants. Pediatrics 2001;108:129-33.

22. Hallbook T, Lundgren J, Rosen I. Ketogenic diet improves sleep quality in children with therapy-resistant epilepsy. Epilepsia 2007;48:59-65.

23. Lambrechts DA, Bovens MJ, de la Parra NM, et al. Ketogenic diet effects on cognition, mood and psychosocial adjustment in children. Acta Neurol Scand 2013;127:103-8.

24. de Kinderen RJA, Lambrechts DAJE, Postulart D, et al. Reserach into the (cost-) effectiveness of the ketogenic diet among children and adolescents with intractable epilepsy: design of a randomized controlled trial. BMC Neurology, 2011;11:10.

25. Ark LA van der, Marburger D, Mellenbergh GJ, et al. De Aangepaste Profile of Mood States (Aangepaste POMS); Handleiding en verantwoording. Nijmegen: Berkhout-Nijmegen BV; 2005.

26. Walker DK, Stein RE, Perrin EC, et al. Assessing psychosocial adjustment of children with chronic illnesses: a review of the technical properties of PARS III. J Dev Behav Pediatr. 1990;11:116-21. 
27. Hendriksen JG, Poysky JT, Schrans DG, et al. Psychosocial adjustment in males with Duchenne muscular dystrophy: psychometric properties and clinical utility of a parent-report questionnaire. J Pediatr Psychol 2009,34:69-78.

28. Berkel A van, Crone, M, Neppelenbroek S, et al. Handleiding voor het gebruik van de SDQ binnen de jeugdgezondheidszorg. Zutphen: Markant Congressen; 2006.

29. Carpay HA, Vermeulen J, Stroink H, et al. Disability due to restrictions in childhood epilepsy. Dev Med Child Neurol. 1997;39:521-6.

30. Sherman E, Slick DJ, Connolly MB, et al. Validity of three measures of health related quality of life in children with intractable epilepsy. Epilepsia 2002;43:1230-8.

31. Scholte \& Van der Ploeg, Handleiding Sociaal-Emotionele Vragenlijst (SEV). Houten: Bohn Stafleu van Loghum; 2007.

32. Schlichting L. Peabody PictureVocabulary Test-III-NL. Amsterdam: Harcourt Test Publisher; 2005.

33. Castellino SM, Tooze JA, Flowers $L$, et al. The Peabody picture vocabulary test as a pre-screnning tool for global cognitive functioning in childhood brain tumor survivors. J Neurooncol. 2011;104:559-63.

34. Beery KE, Beery NA. The Beery-Buktenica developmental test of visual-motor integration. In: Administration, scoring and teaching manual. 5th ed. Minneapolis: NCS Pearson; 2006.

35. Alpherts WC, Aldenkamp AP. Computerized neuropsychological assessment of cognitive functioning in children with epilepsy. Epilepsia 1990;31:S35-40.

36. Kossoff EH, Pyzik PL, McGrogan JR, Rubenstein JE. The impact of early versus late anticonvulsant reduction after ketogenic diet initiation. Epilepsy Behav 2004;5:499-502.

37. Nigro NA, Ventimiglia J, Selcen D, Beierwaltes P. Seizure frequency, behavioral, and performance effects of the ketogenic diet. Annals of Neurology 1995;38:549-50.

38. Neal EG, Chaff $\mathrm{H}$, Schwartz $\mathrm{RH}$, et al. A randomized trial of classical and medium-chain triglyceride ketogenic diets in the treatment of childhood epilepsy. Epilepsia 2009; 50:1109-17.

39. Patel A, Pyzik PL, Turner Z, Rubenstein JE, Kossoff EH. Long-term outcomes of children treated with the ketogenic diet in the past. Epilepsia 2010;61:1277-82. 


\section{Chapter}

\section{Long-term impact of antiepileptic drug treatment on cognitive development}

DM IJff, TM van Veenendaal, JFA Jansen, HJM Majoie \& AP Aldenkamp Submitted 


\section{Abstract}

\section{Purpose}

Children with epilepsy are at increased risk for cognitive impairment and difficulties in learning that may affect school performance, in which long-term anti-epileptic drug (AED) therapy likely plays a role. This study focused on the impact of long-term AED treatment, specifically with carbamazepine (CBZ) and valproate (VPA), on cognitive development.

\section{Methods}

Epilepsy patients aged 6-16 years, who were treated $\geq 6$ months with monotherapy CBZ or VPA from the epilepsy onset and without any switch to other medication in the past were included in this cross-sectional study. Outcome measures included the Wechsler Intelligence Scale for Children-III (WISC-III) and other cognitive tests assessing alertness, information processing speed and memory.

\section{Results}

In total, 50 patients aged 6-16 were included (CBZ $n=21$ and VPA $n=29)$. The two groups did not differ in demographical and epilepsy related characteristics such as gender, type of epilepsy, seizure frequency, age, drug load, and duration of drug treatment. Patients on CBZ had significantly lower intelligence values than patients on VPA. There were no other differences found in the cognitive profile.

\section{Conclusion}

Our study suggested that chronic use of AEDs has a detrimental impact on cognitive development during childhood, possibly through accumulating effect of drug-induced impairments on cognitive developmental processes. 


\section{Introduction}

Cognitive impairment is a common problem in patients with epilepsy. ${ }^{1}$ Children with epilepsy have a higher risk of learning disabilities and poor academic performance, because of the neurological disorder and related issues. ${ }^{2}$ The etiology of cognitive impairment in people with epilepsy is multi-factorial. Many factors such as premorbid brain dysfunction, age at onset, etiology, type, frequency, severity, and duration of seizures and treatment can adversely affect cognition. ${ }^{1,3}$ Cognitive side-effects of the antiepileptic drugs (AEDs) have emerged as an important consideration when an AED is being selected for the treatment of childhood epilepsy. ${ }^{4}$ The first formal studies on the cognitive side effects of AEDs were published in the early $1970^{\prime} s^{5}$ and many followed since then. However, most regulatory trials are carried out in adults, ${ }^{6}$ even recently, which limits the generalization of findings to children. ${ }^{7}$

The cognitive effects of AEDs are, therefore, still in debate. Carbamazepine (CBZ) and valproate (VPA), commonly used first line AEDs in newly diagnosed epilepsy, are considered to have comparable and mild effects on cognitive functioning. ${ }^{8-10}$ However, there have been reports that in children the outcome is less favourable for CBZ over a longer period of time. ${ }^{4,11,12}$

Most studies, however, have a limited duration with trial durations mostly not exceeding the 12 weeks period and base the detrimental effects of CBZ on noncontrolled extensions of trials. Meanwhile, there still remains a large contrast between the average trial duration that has provided us with the current knowledge and clinical practice with treatment durations of years instead of weeks. In the past, concern has been expressed about long-term effects of AED use on cognitive development in children. $^{13,14}$

Theoretically, children are potentially more susceptible to the adverse effects of AEDs than adults because of the potential effect of AEDs on brain maturation and hence on neurodevelopment. Subtle effects on the fluid cognitive functions leading to attentional or arousal deficits could, therefore, accumulate over time and result in deficits in higher-order cognitive functions such as memory or learning. ${ }^{2,3,15}$ Early identification of possible long-term AED-induced impacts on cognitive development is crucial to avoid future negative educational, occupational and social outcomes. ${ }^{16}$ During the development of oxcarbazepine, a compound related to $C B Z$, similar concerns were expressed by the regulatory agents and therefore a trial was designed with much longer duration and cognitive development (among others intelligence) as outcome. ${ }^{17,18}$ However, also that trial was limited to six months, which is still in contrast with normal treatment duration in clinical practice.

Our study, therefore, focused on the impact of long-term AED treatment, specifically with CBZ and VPA, on cognitive development in children with epilepsy. Long-term is defined in our study as $\geq 6$ months of treatment. 


\section{Methods}

\section{Subject selection}

Epilepsy patients aged 6-16 years who were referred to a tertiary referral centre for epilepsy and were treated $\geq 6$ months with monotherapy CBZ or VPA were included in this cross-sectional study. Only patients were included who had been on monotherapy CBZ or VPA from the epilepsy onset and without any switch to other medication in the past. Data about demographical and clinical characteristics were collected through medical records.

Type of epilepsy was divided in localization related epilepsy (cryptogenic, symptomatic or idiopathic), generalized epilepsy (idiopathic) or not yet classified (non-classified). Seizure frequency was divided in three groups; seizure free for at least 6 months, a seizure reduction of $\geq 50 \%$ or seizure reduction of $<50 \%$. Drug load for each individual patient was estimated as the sum of the prescribed daily dose (PDD)/defined daily dose (DDD), where DDD corresponds to the assumed average maintenance daily dose of a drug prescribed for its main indication (World Health Organization). ${ }^{19}$

\section{Assessment procedures}

The assessment procedure consisted of two types of tests, see Table 6.1. Tests that have been demonstrated to be sensitive to cognitive side-effects of AEDs. These tests assess fluid functions (functions that are state-dependent and can easily fluctuate), such as attentional function, speed of central information processing, psychomotor speed and alertness. ${ }^{20}$ To assess possible long-term effects of AEDs on development, tests were used measuring higher-order stable cognitive function: memory and intelligence.

Furthermore, the Wechsler Deterioration Index (WDI) was used to estimate the premorbid intellectual ability of our study population. ${ }^{21,22}$ The WDI for each individual patient was estimated, which subtracts the sum of the scaled scores on the 'hold' subtests from those achieved on 'don't hold' subtests/ 'hold' subtests. 'Hold' subtests (Vocabulary, Information, Object Assembly, and Picture Completion) were thought to be insensitive to deterioration in cognitive or brain functions, while 'don't hold' subtests (Digit Span, Similarities, Coding, and Block Design) were felt to decrease significantly in the face of insults to brain functions. ${ }^{23}$ 
Table 6.1 Assessment protocol.

\begin{tabular}{|c|c|c|}
\hline \multirow[t]{4}{*}{$\begin{array}{l}\text { Fluid state- } \\
\text { dependent } \\
\text { functions }\end{array}$} & $\begin{array}{l}\text { Psychomotor } \\
\text { speed / } \\
\text { alertness / } \\
\text { attention }\end{array}$ & $\begin{array}{l}\text { Simple reaction time measurements: the patients had to react as } \\
\text { quickly as possible on auditory stimuli that were presented at } \\
\text { random intervals by the computer, activation and alertness are } \\
\text { measured by these tests and a strong motor component is } \\
\text { involved. }\end{array}$ \\
\hline & $\begin{array}{l}\text { Central } \\
\text { information } \\
\text { processing } \\
\text { speed }\end{array}$ & $\begin{array}{l}\text { Binary choice reaction-time measurement: a reaction time test } \\
\text { with a decision component. The patient has to react differentially } \\
\text { to a red square on the left side of the screen and to a green square } \\
\text { at the right side of the screen. The reaction time does not only } \\
\text { reflect motor speed, but also the decision making process. }{ }^{24}\end{array}$ \\
\hline & & $\begin{array}{l}\text { Computerized visual searching task: an adaptation of Goldstein's } \\
\text { Visual Searching Task. A centred grid pattern has to be compared } \\
\text { with } 24 \text { surrounding patterns. Only one of them is identical to the } \\
\text { target pattern. The test consists of } 24 \text { trials and gives an indication } \\
\text { of the information processing speed and perceptual mental } \\
\text { strategies. }\end{array}$ \\
\hline & & Processing Speed from the WISC-III. ${ }^{25}$ \\
\hline \multirow[t]{2}{*}{$\begin{array}{l}\text { Higher-order } \\
\text { cognitive } \\
\text { functions }\end{array}$} & Intelligence & $\begin{array}{l}\text { Wechsler Intelligence Scale for Children-III measures intellectual } \\
\text { ability which is expressed in Full Scale IQ (FSIQ), Verbal IQ (VIQ), } \\
\text { Performance IQ (PIQ) with a mean IQ:100, SD:15. }\end{array}$ \\
\hline & Memory & $\begin{array}{l}\text { The } 15 \text { word test, a Dutch version of the Rey Auditory Verbal } \\
\text { Learning Test (AVLT): a list of } 15 \text { words is orally presented five } \\
\text { times. After every presentation, immediate recall (IR) is requested. } \\
\text { A delayed recall (DR) is requested after a } 20 \text { minutes interval. }{ }^{26}\end{array}$ \\
\hline
\end{tabular}

\section{Statistical analysis}

Data were analyzed using the Statistical Package for Social Sciences (SPSS, version 21.0 for Windows). To check if there are any differences between both groups in demographical and epilepsy related characteristics Pearson's chi-square tests were performed for the categorical variables (gender, type of epilepsy, seizure frequency) and independent samples t-tests were used for the continuous variables (age, drug load, and duration of drug treatment). Differences in test results between the two groups were analyzed with two-sided independent samples t-tests. Significance level was set at the $5 \%$ level.

\section{Results}

\section{Demographics}

We enrolled a total of 50 children in this study: the total cohort consists of 21 patients using CBZ and 29 patients using VPA. In both treatment groups, the mean age at start treatment was 7 years (range 4-15). The mean duration of AED treatment was approximately two years (with a range from 6 months up to 8 years). The clinical and 
demographic characteristics of these groups are summarized in Table 6.2. The two groups did not differ in demographical and epilepsy related characteristics such as gender, type of epilepsy, seizure frequency, age, drug load, and duration of drug treatment. Furthermore, the WDI showed no significant difference between the CBZ group and the VPA group ( $t=.209, p=.835)$, which indicated that there was no difference in premorbid intellectual ability between both groups.

Table 6.2 Demographical and clinical characteristics.

\begin{tabular}{|c|c|c|c|c|c|c|c|c|}
\hline & & \multicolumn{3}{|c|}{ CBZ-group (n=21) } & \multicolumn{3}{|c|}{ VPA-group ( $n=29)$} & \multirow[t]{2}{*}{$\mathbf{p}$} \\
\hline & & $\mathbf{N}$ & $\%$ & & $\mathbf{N}$ & $\%$ & & \\
\hline \multirow[t]{3}{*}{ Gender } & & & & & & & & n.s. \\
\hline & Male & 8 & 38.1 & & 11 & 37.9 & & \\
\hline & Female & 13 & 61.9 & & 18 & 62.1 & & \\
\hline \multirow[t]{6}{*}{ Type of epilepsy } & & & & & & & & n.s. \\
\hline & Cryptogenic localization related & 8 & 38.1 & & 9 & 31 & & \\
\hline & Symptomatic localization related & 1 & 4.8 & & 4 & 13.8 & & \\
\hline & Idiopathic localization related & 6 & 28.6 & & 4 & 13.8 & & \\
\hline & Idiopathic generalized & 1 & 4.8 & & 7 & 24.1 & & \\
\hline & Non-classified & 5 & 23.8 & & 5 & 17.2 & & \\
\hline \multirow{5}{*}{ Seizure frequency } & & & & & & & & n.s. \\
\hline & Seizure free $>6$ months & 12 & 57.1 & & 17 & 58.6 & & \\
\hline & Seizure reduction $\geq 50 \%$ & 8 & 38.1 & & 12 & 41.4 & & \\
\hline & Seizure reduction $<50 \%$ & 1 & 4.8 & & 0 & & & \\
\hline & & M & SD & Range & $M$ & SD & Range & \\
\hline \multirow[t]{3}{*}{ Age (in years) } & At assessment & 10.1 & 2.6 & $6-15$ & 10.3 & 2.8 & $6-16$ & n.s. \\
\hline & At onset epilepsy & 6.3 & 3.1 & $1-12$ & 6.2 & 3.8 & $1-15$ & n.s. \\
\hline & At start treatment & 7.8 & 2.4 & $4-12$ & 7.7 & 3.1 & $4-15$ & n.s. \\
\hline \multirow[t]{3}{*}{ AED } & Daily dosage (mg) & 553.3 & 240.6 & $120-960$ & 760.3 & 358.1 & $160-1800$ & \\
\hline & Drug load & .55 & .24 & $.12-.96$ & .51 & .24 & $.11-1.20$ & n.s. \\
\hline & Duration of AED use (years) & 1.86 & 1.6 & $0-6$ & 2.1 & 2 & $0-8$ & n.s. \\
\hline
\end{tabular}

n.s.: not significant

\section{Neuropsychological test results}

When the two treatment groups were compared, no significant differences were found on the fluid, state-dependent functions such as alertness and information processing speed, see Table 6.3. On the stable, higher-order cognitive function, no significant differences in memory performance were found between the CBZ group and the VPA group. For intelligence values, the $C B Z$ group scored significantly lower than the VPA group (FSIQ $t=-2.264, p=.028$, VIQ: $-2.328, p=.024$ ), see Figure 6.1 . 
Table 6.3 Neuropsychological test results.

\begin{tabular}{llccccc}
\hline & & \multicolumn{2}{c}{ CBZ } & \multicolumn{2}{c}{ VPA } \\
\cline { 3 - 7 } & Assessment & Mean & SD & Mean & SD & p \\
\hline Fluid & Auditory reaction time DH (ms) & 331.6 & 101.1 & 325.8 & 86.1 & n.s. \\
state- & Auditory reaction time NDH (ms) & 363.8 & 108.9 & 357 & 115.4 & n.s. \\
dependent & Binary choice reaction time (ms) & 430.5 & 83.5 & 448.7 & 147 & n.s. \\
functions & CVST (sec) & 18.9 & 8.4 & 23.5 & 14.7 & n.s. \\
& Processing Speed (WISC-III) & 88.9 & 17.5 & 94.6 & 19.4 & n.s. \\
Higher- & AVLT IR & 40.9 & 14.1 & 42.4 & 13.5 & n.s. \\
order & AVLT DR & 8.0 & 3.7 & 8.4 & 3.6 & n.s. \\
cognitive & FSIQ & 84.8 & 14.2 & 93.1 & 11.8 & $.028^{*}$ \\
functions & VIQ & 85.8 & 12 & 94 & 12.4 & $.024^{*}$ \\
& PIQ & 87 & 16.5 & 93.9 & 12.3 & n.s. \\
\hline
\end{tabular}

$\mathrm{DH}$ : dominant hand, NDH: non dominant hand, ms: milliseconds, CVST: computerized visual searching task, AVLT: auditory verbal learning task, IR: immediate recall, DR: delayed recall, FSIQ: full scale IQ, VIQ: verbal IQ, PIQ: performance IQ, n.s.: not significant. ${ }^{*} p<.05$

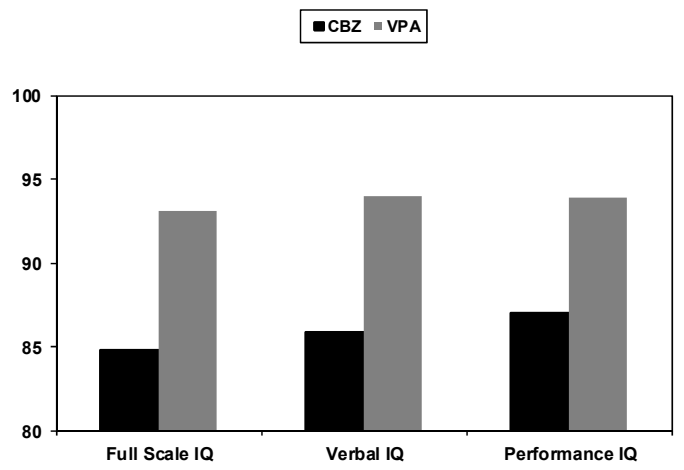

Figure 6.1 Outcome of IQ of patients with monotherapy CBZ or VPA.

\section{Discussion}

This clinical comparative cohort study investigated the long-term impact of AED treatment on cognitive development in children. Two types of results were found: on tests assessing fluid, state-dependent functions we did not find statistically significant differences between children treated with CBZ versus children treated with VPA. This confirms earlier reports of no differences between these AEDs on such functions. ${ }^{7,10}$ Our study showed that this remains stable over time. Although there were no differences found, this only expresses equivalence but still may imply that both drugs impair such fluid function to the same extent. Moreover, it has been suggested that such effects could accumulate over longer periods. ${ }^{17}$ Consequently, these accumulating 
effects can potentially affect stable, higher-order cognitive functions. On tests assessing higher-order and more stable cognitive functions, our study demonstrated an effect on intelligence, specifically for CBZ. Children on CBZ scored statistically significantly lower on intelligence measures than children on VPA. More specifically, the difference between the two AEDs for Verbal IQ and Full Scale IQ were statistically significant but not for Performance IQ which includes more fluid cognitive functions and emphasizes more on speed factors.

Our results are consistent with Piccillini et al. (2010) who found that children treated with CBZ, but not with VPA, had a mild deterioration of IQ after one year of therapy. ${ }^{12}$ Forsythe and co-workers (2001) found that carbamazepine in moderate dosage adversely affected memory in children, whereas VPA did not. ${ }^{11}$ The USA study of Mandelbaum et al. (2009) reported a persistence of impairment of reaction times when children with newly diagnosed localisation-related epilepsy were treated with CBZ over a period of one year. ${ }^{4}$ This was compared to a non-drug baseline. Our results are inconsistent with previous findings of Chen et al. (2001) who found no significant differences in the WISC-R between VPA and CBZ treated for one year, and after complete withdrawal of the treatment. ${ }^{9}$ However, that study only included seizure free children while our study included children with an active epilepsy.

Our findings confirmed the hypothesis by Drane and Meador (1996) who suggested that dysfunction in areas such as arousal, attention, and psychomotor functioning can contribute to deficits in higher cognitive processes such as memory and learning over time. ${ }^{15}$ Loring and Meador (2004) concluded from their studies that long-term AED therapy is at least one of the components that contribute to the increased risk for cognitive impairment, and difficulties in learning that may affect school performance in children with epilepsy. ${ }^{2}$

Knowledge of the mechanisms of action of AEDs is essential to explain the occurrence of side-effects. ${ }^{27}$ Cross (2010) concluded that AEDs may have different effects in the immature brain because of its impact on neuroreceptor function which may interfere with normal maturation. ${ }^{13}$ One explanation for the cognitive effects on the long-term may be found in the different mechanisms of action of these drugs. VPA is predominantly a GABA-ergic drug with a more temporarily effect whereas CBZ stabilize the inactive form of the voltage ion channel, ${ }^{28}$ inducing a more permanent change. Currently, we use Magnetic Resonance Spectroscopy (MRS) that enables in vivo measurements of neurotransmitter and other brain metabolite concentrations and may provide us more insight in the metabolisme of AEDs. Another explanation may be found in brain activity, as assessed by functional Magnetic Resonance Imaging (fMRI). In adult epilepsy patients, chronic epilepsy causes cognitive deficits in intellectual functioning, by loss of network efficiency. ${ }^{29}$ The role of AED use remained unclear in such studies but must certainly not be underestimated.

The main shortcoming of this study is that we did not assessed the neuropsychological profile at baseline, before AED treatment was started. Because this study was 
performed at a tertiary referral clinic, treatment was already started in most patients at referral. We used the WDI to estimate the premorbid intellectual ability of our study population. There was no significant difference in the WDI between the treatment groups at baseline, before treatment was started. Additionally, in a limited number of children ( 5 on CBZ and 7 on VPA) we did have data on their intelligence prior to treatment. These data also suggested no differences in IQ's between the CBZ and the VPA group before treatment was started. It may be assumed that these groups were comparable in their intellectual performance before antiepileptic drug treatment was started.

To conclude, our study emphasized the need to study effects of chronic AED use, especially in children. Furthermore, our study suggests that chronic use of AEDs has a detrimental impact on cognitive development during childhood and may impact higherorder cognitive functions and even intelligence, possibly through accumulating effect of drug-induced impairments of fluid function on cognitive developmental processes. 


\section{References}

1. Aldenkamp AP, Krom MD, Reijs R. Newer antiepileptic drugs and cognitive issues. Epilepsia 2003;44: 21-9.

2. Loring DW, Meador KJ. Cognitive side effects of antiepileptic drugs in children. Neurology 2004;62: 872-7.

3. Meador KJ. Cognitive outcomes and predictive factors in epilepsy. Neurology 2002;58:S21-6.

4. Mandelbaum DE, Burack GD, Bhise VV. Impact of antiepileptic drugs on cognition, behaviour, and motor skills in children with new-onset, idiopathic epilepsy. Epilepsy Behav 2009;16:341-4.

5. Trimble M. The effect of anti-convulsant drugs on cognitive abilities. Pharmacol Ther B 1979;4:677-85.

6. Vermeulen J, Aldenkamp AP. Cognitive side-effects of chronic antiepileptic drug treatment: a review of 25 years of research. Epilepsy Res 1995;22:65-95.

7. IJff DM, Aldenkamp AP. Cognitive side-effects of antiepileptic drugs in children. In: Dulac O, Lassonde M, Sarnat HB, eds. Handbook of clinical neurology. Oxford: Elsevier Science; 2013:707-18.

8. Aldenkamp AP, Alpherts WCJ, Blennow G, Elmqvist D, Heijbel J, Nilsson HL, et al. Withdrawal of antiepileptic medication- effects on cognitive function in children: The Multicentre Holmfrid Study. Neurology 1993;43:41-50.

9. Chen YJ, Chi Chow JC, Lee IC. Comparison the cognitive effect of anti-epileptic drugs in seizure-free children with epilepsy before and after drug withdrawal. Epilepsy Res 2001;44:65-70.

10. Stores G, Williams PL, Styles E, Zaiwalla Z. Psychological effects of sodium valproate and carbamazepine in epilepsy. Arch Dis Child 1992;67:1330-7.

11. Forsythe I, Butler R, Berg I, McGuire R. Cognitive impairment in new cases of epilepsy randomly assigned to carbamazepine, phenytoin and sodium valproate. Dev Med Child Neurol 2001;33:524-34.

12. Piccinelli P, Beghi E, Borgatti R, Ferri M, Giordano L, Romeo A, et al. Neuropsychological and behavioural aspects in children and adolescents with idiopathic epilepsy at diagnosis and after 12 months of treatment. Seizure 2010;19:540-6.

13. Cross JH. Neurodevelopmental effects of anti-epileptic drugs. Epilepsy res 2010;88:1-10.

14. Mula M, Trimble MR. Antiepileptic drug-induced cognitive adverse effects. CNS drugs 2009;23:121-37.

15. Drane D, Meador K. Epilepsy, anticonvulsant drugs and cognition. Baillieres Clin Neurol 1996;5:877-85.

16. Sillanpää $\mathrm{M}$, Jalava $\mathrm{M}$, Kaleva $\mathrm{O}$, Shinnar S. Long-term prognosis of seizures with onset in childhood. $\mathrm{N}$ Engl J Med 1998;338:1715-22.

17. Donati F, Gobbi G, Campistol J, Rapatz G, Daehler M, Sturm Y, et al. Effects of oxcarbazepine on cognitive function in children and adolescents with partial seizures. Neurology 2006;67:679-82.

18. Donati F, Gobbi G, Campistol J, Rapatz G, Daehler M, Sturm Y, et al. The cognitive effects of oxcarbazepine versus carbamazepine or valproate in newly diagnosed children with partial seizures. Seizure 2007;16:670-679.

19. WHO. ATC/DDD Index derived at December 2015. http://www.whocc.no/ atc_ddd_index/?code=N03A. World Health Organization Collaborating Centre for Drug Statistics Methodology; 2015.

20. IJff DM, Aldenkamp AP. Comorbidities of treatment with antiepileptic drugs. In: Duchowny M, Cross JH, and Arzimanoglou A, eds. Pediatric Epilepsy. New York: McGraw-Hill Professional; 2012:424-36.

21. Kamphaus RW. Clinical assessment of child and adolescent intelligence. $2^{\text {nd }}$ ed. New York: Springer; 2005:550-1.

22. Prifitera A, Saklofske D. WISC-III Clinical use and interpretation. San Diego CA: Academic Press; 1998:103.

23. Bowers TG, Risser MG, Suchanec JF, Tinker DE, Ramer JC, Domoto M. A developmental index using the Wechsler Intelligence Scale for Children: implications for the diagnosis and nature of ADHD. J Learn Disabil 1992;25:179-85.

24. Alpherts WCJ, Aldenkamp AP. FePsy: 'The Iron Psyche'. Instituut voor epilepsiebestrijding, The Netherlands, Heemstede; 1995.

25. Wechsler D. Wechsler Intelligence Scale for Children. 3th ed. NL. Handleiding en verantwoording. Amsterdam: Harcourt Test Publishers; 1995.

26. Kalverboer AF, Deelman BG. De 15-woorden tests A en B : (een voorlopige handleiding) (15WT/VWT). Groningen: Academisch Ziekenhuis Groningen, afd. Neuropsychologie; 1986. 
27. Veenendaal TM van, IJff DM, Aldenkamp AP, Hofman PA, Vlooswijk MC, Rouhl RP, et al. Metabolic and functional MR biomarkers of antiepileptic drug effectivenees: a review. Neurosci Biobehav Rev 2015;59:92-9.

28. Kwan P, Sills GJ, Brodie MJ. The mechanisms of action of commonly used antiepileptic drugs. Pharmacol Ther 2001;90:21-34.

29. Vlooswijk M, Vaessen M, Jansen J, de Krom MC, Majoie HJ, Hofman PA, et al. Loss of network efficiency associated with cognitive decline in chronic epilepsy. Neurology 2011;77:938-44. 


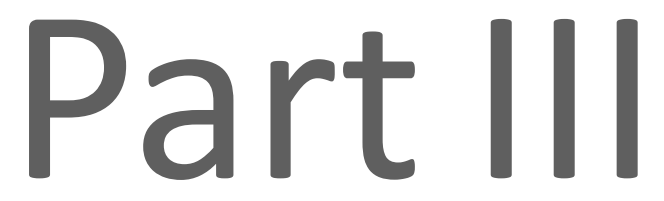

Clinical relevance of subjective reports 


\section{Chapter}

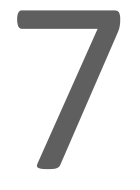

Subjectively perceived side-effects of antiepileptic drugs in chronic refractory epilepsy

DM IJff, RJ de kinderen, CI Vader, HJM Majoie \& AP Aldenkamp Adv Pharmacoepidemiol Drug Saf 2015;4:18 


\section{Abstract}

\section{Purpose}

Antiepileptic drugs (AEDs) can cause side-effects. Patient-reported side-effects due to this type of medication are very common, but thus far only investigated in community based populations. We investigated the subjectively perceived side-effects of antiepileptic drug treatment in patients with refractory epilepsy.

\section{Methods}

A non-selected group, of patients visiting the outpatient department between September 2011 and November 2011 was invited to complete a questionnaire only if they had experienced side-effects of their AED treatment during last year. The questionnaire, the SIDAED, assessed four different categories; cognition, mood, cosmetics and general health. Subgroup analyses were based on their medication use: mono- or polytherapy, older and newer AEDs and AEDs with a high or a low risk for cognitive and behavioral/mood side-effects.

\section{Results}

In total, 203 patients or their relatives completed the questionnaire. Mean age of the patients was 37 years (2-81). Most reported complaints (85\%) were about their general health followed by cognition, mood and cosmetics. Subgroup analyses showed no differences between patients using monotherapy or polytherapy. Also, no differences were found between patients using older AEDs or newer drugs. Patients using AEDs with a high risk for side-effects, did complain more about their mood but not about their cognition. Regression analysis showed that using a high risk AED for behavioral side-effects contributed significantly to the total experienced side-effects.

\section{Conclusion}

In conclusion, our study illustrates that patients are a reliable respondent to indicate side-effects despite of their refractory epilepsy. Particularly, mood complaints due to antiepileptic drugs (such as levetiracetam) are correctly noticed. 


\section{Introduction}

The best possible outcome of antiepileptic drug (AED) treatment is to achieve complete seizure freedom without adverse events. However, AEDs are frequently accompanied by a variety of side-effects. The prevalence of AED-related subjective complaints in routine clinical practice in a community-based population was almost $60 \%{ }^{1}$ The two domains which yielded the highest prevalence of complaints are general CNS-related complaints (68\%) and cognitive complaints (62\%). The most frequently reported complaints within the general CNS-related domain are fatigue and tiredness. Memory problems and concentration difficulties are most frequently reported within the cognitive domain. Mood and behavioural complaints such as agitation or irritability and depression are reported less frequently (22\%). Another study reported a prevalence of $67 \%$ of moderate to severe subjective complaints of patients who were considered to be well-controlled (defined as unchanged medication for the last six months). ${ }^{2}$ Cognitive complaints were reported most frequently. Furthermore, patients on polytherapy reported more side-effects than patients on monotherapy. ${ }^{1-3}$

The new antiepileptic drugs such as lamotrigine (LTG), levetiracetam (LEV), oxcarbazepine (OXC), gabapentin (GBP), pregabalin (PGB) and lacosamide (LCS) seem to be similar to the older compounds in efficacy, but superior in tolerability. ${ }^{4}$ Cognitive complaints, related to confirmed cognitive dysfunction has been reported with almost all the older drugs and especially for phenobarbital (PB), phenytoin (PHT) and vigabatrin (VGB). ${ }^{4,5}$ Some newer AEDs such as topiramate (TPM) and zonisamide (ZNS) are also known to cause significant cognitive side-effects: both have diffuse cognitive effects, as well as specific effects on language and memory. ${ }^{5-9}$ This concurs with the patientreported cognitive side-effects that are more common with TPM, followed by ZNS and phenytoin (PHT) and are least likely to be reported with GBP, valproate (VPA), LTG and carbamazepine (CBZ). ${ }^{10-11}$ Furthermore, the newer anti-epileptic drug LEV is known for its high-risk to cause mood effects. ${ }^{12-13}$ Mood side-effects are therefore most common in patients-reports with (LEV). ${ }^{14,15}$ The subjective reports about these drugs seem to be by and large equivalent to measured cognitive effects of these AEDs. ${ }^{16,17}$

Negative consequences of the antiepileptic drugs necessitate interventions ranging from minor interventions such as drug switches to very expensive hospitalization. It is estimated that side-effects due to antiepileptic drugs have a major impact on health care costs which can be as high as $€ 20.751$ (US \$26.675) per patient per year. ${ }^{18}$ It is desirable to reduce these costs to a level as low as possible. Earlier studies already showed that side-effects are more important for patients than efficacy in long-term treatment and that long-term retention time is mainly based on subjectively perceived side-effects. ${ }^{19}$ Previous research showed also that subjectively perceived side-effects about cognitive functions are used as a sensitive screening instrument for clinical practice which can help to identify who is at risk and needs further referral for neuropsychological assessment while keeping the burden on financial and time 
resources to a minimum. ${ }^{20}$ This allows screening at an early stage and minimizes the use of expensive assessment facilities.

In addition to the community-based studies from our group, ${ }^{1,2,21}$ we attempted to investigate the impact of subjective complaints in a hospital-based study, in patients with chronic refractory epilepsy. In the community based studies most patients were in remission or they had only infrequent seizures and most were on low dose monotherapy. In the patient population of a tertiary referral center most patients have frequent seizures, are afraid of status epilepticus, and often use high dosing polytherapy. Within this study we also focused on subgroup comparisons. Firstly, a combination of AEDs can produce negative interactions which can lead to side-effects. Separate subgroup analyses were, therefore, performed to check for differences between patients on monotherapy or polytherapy. Secondly, as side-effects of AEDs are claimed to have less effects in the newer generation of AEDs, differences between the newer and older generation of AEDs were compared. Thirdly, some drugs are known to have a higher risk for side-effects than others. Therefore a high-risk group was compared with a low-risk group.

\section{Methods}

\section{Procedure}

All epilepsy patients using antiepileptic drugs, who visited our tertiary epilepsy center Kempenhaeghe, Heeze, The Netherlands, between September 2011 and November 2011, received a patient information letter by mail including an invitation to complete a questionnaire. ${ }^{18}$ Patients were invited to complete the questionnaire only when they had experienced side-effects of the AEDs during the previous 12 months. The questionnaire could either be completed digitally via the internet or on paper. For young children and patients with severe mental retardation, proxy measures were used. All participants (patients, parents or caregivers) gave their informed consent.

\section{Questionnaire}

The questionnaire was specifically developed for this study and was subdivided into five different categories of commonly reported side-effects. The SIDe effects of AED treatment questionnaire (SIDAED) ${ }^{2}$, developed by our group, was used as the basis for the questionnaire. The original 10 side-effect categories of the SIDAED were compressed into four categories in order to focus on the most commonly reported side-effects. The categories used in this study were: cognition, cosmetic, mood and general health (i.e. general CNS, vision, headache, gastrointestinal, sexuality/menses complaints). 


\section{Subgroup and statistical analysis}

The subgroup analyses were performed using independent t-tests with SPSS version 21.0, Chicago, IL, USA. A p-value of $\leq .05$ was considered significant. Linear regression analysis was used to evaluate the impact of the treatment factors (mono vs. polytherapy, old vs. new AEDs and cognitive/behavioral high vs. low risk AEDs) on the total number of complaints.

\section{Results}

\section{Demographic and clinical characteristics}

In total, 1386 epilepsy patients received the request to complete a questionnaire. In total, 210 patients completed the questionnaire. Although we asked patients only to fill out the questionnaire when they had experienced any side-effect during the previous 12 months, seven patients returned the forms reporting no side-effects. These patients were excluded from the analysis, yielding a total of 203 patients reporting side-effects (14.6\%).

Main characteristics of the 203 patients are shown in Table 7.1. Mean age was 37 years, with a range from 2 to 81 years. Most patients were treated with polytherapy (range 2-6 AEDs). Most patients used LTG as AED during the last 12 months, followed by LEV, CBZ, VPA and CLB. OXC, TPM, PHT, PGB, GBP, LCS, PB and ethosuximide (ESX) were used less frequently. AEDs that were only used by one patient were primidone, ZNS, VGB and acetazolamide. These drugs were grouped as 'other drugs'(3.0\%). Most of the patients were treated with a combination of an older (such as CBZ, VPA, PB, PHT, ETX or benzodiazepines) and a newer (such as LTG, LEV, OXC, GBP, PGB, LCS, TPM) antiepileptic drug during the last 12 months. Table 7.2 shows that in monotherapy LTG, VPA, CBZ and LEV are mostly used and OXC and TPM are used less frequently.

Based on the literature, ${ }^{16,17,22}$ we grouped PB, PHT, TPM, ZNS, and VGB as drugs with a high risk for side-effects. The other AEDs are grouped as AEDs with a low risk for sideeffects except LEV which is known for its behavioral effect but has no cognitive sideeffects. ${ }^{23}$ Therefore, this drug is only added in the behavioral high risk group and not in the cognitive high risk group. During the last 12 months $16 \%$ of the patients used at least one of the cognitive high risk drugs and $46.8 \%$ of the patients used at least one of the behavioral high risk AEDs. 
Table 7.1 Demographic and clinical characteristics ( $N=203)$.

\begin{tabular}{|c|c|c|}
\hline & $\mathbf{N}$ & $\%$ \\
\hline Age mean (range) & $37(2-81)$ & \\
\hline \multicolumn{3}{|l|}{ Gender } \\
\hline Male & 101 & 49.8 \\
\hline Female & 102 & 50.2 \\
\hline \multicolumn{3}{|l|}{ Mono vs polytherapy } \\
\hline Monotherapy & 67 & 33.0 \\
\hline Polytherapy & 136 & 67.0 \\
\hline \multicolumn{3}{|l|}{ Number of different AEDs per patient } \\
\hline Two & 71 & 35.0 \\
\hline Three & 40 & 19.7 \\
\hline Four or more & 25 & 12.3 \\
\hline \multicolumn{3}{|l|}{ AED use during the last 12 months } \\
\hline LTG & 77 & 37.9 \\
\hline LEV & 68 & 33.5 \\
\hline CBZ & 68 & 33.5 \\
\hline VPA & 65 & 32.0 \\
\hline CLB & 50 & 24.6 \\
\hline Other BZP & 15 & 7.4 \\
\hline OXC & 27 & 13.3 \\
\hline TPM & 15 & 7.4 \\
\hline PHT & 10 & 4.9 \\
\hline PGB & 11 & 5.4 \\
\hline GBP & 8 & 3.9 \\
\hline LCS & 7 & 3.4 \\
\hline PB & 7 & 3.4 \\
\hline ESX & 6 & 3.0 \\
\hline Other AEDs & 5 & 2.5 \\
\hline \multicolumn{3}{|l|}{ Old versus new AEDs } \\
\hline Old AEDs & 48 & 23.6 \\
\hline New AEDs & 54 & 26.6 \\
\hline Combination of old and new AEDs & 101 & 49.8 \\
\hline \multicolumn{3}{|l|}{ Low risk versus high risk $A E D s$} \\
\hline Cognitive low risk AEDs & 170 & 83.7 \\
\hline Cognitive high risk AEDs & 33 & 16.3 \\
\hline Behavioral low risk AEDs & 108 & 53.2 \\
\hline Behavioral high risk AEDs & 95 & 46.8 \\
\hline
\end{tabular}

LTG: lamotrigine, LEV: levetiracetam, CBZ: carbamazepine, VPA: valproate, CLB: clobazam, BZP: benzodiazepines, OXC: oxcarbazepine, TPM: topiramate, PHT: phenytoin, PGB: pregabalin, GBP: gabapentin, LCS: lacosamide, PB: phenobarbital, ESX: ethosuximide. Old AEDs: CBZ, VPA, BZP, PB, PHT, ESX. New AEDs: LTG, LEV, OXC, GBP, PGB, LCS, TPM. High-risk AEDs: PB, PHT, TPM, ZNS, VGB. LEV is only added for the behavioral high-risk AEDs. 
Table 7.2 AED use in monotherapy patients.

\begin{tabular}{lcc}
\hline & $\mathbf{N}$ & $\mathbf{\%}$ \\
\hline LTG & 14 & 20.9 \\
VPA & 13 & 19.4 \\
CBZ & 13 & 19.4 \\
LEV & 12 & 17.9 \\
OXC & 6 & 9.0 \\
TPM & 4 & 6.0 \\
CLB & 3 & 4.5 \\
PHT & 1 & 1.5 \\
Other BZP & 1.5 \\
\hline
\end{tabular}

LTG: lamotrigine, VPA: valproate, CBZ: carbamazepine, LEV: levetiracetam, OXC: oxcarbazepine, TPM: topiramate, CLB: clobazam, PHT: phenytoin, BZP: benzodiazepines.

\section{Type of side-effects}

The largest group of patients $(38 \%, n=78)$ reported problems in three of the five categories, $24 \%(n=49)$ reported to have side-effects in two of the categories, $23 \%$ $(n=47)$ reported side-effects in four of the categories, $12 \%(n=24)$ reported problems in one of the five categories and five patients (3\%) reported to have problems in all categories (see Figure 7.1). Most of the patients (85\%) had experienced some kind of general health side-effect due to AEDs during the last 12 months, such as sleep problems and fatigue, motor and balance problems, headache and dizziness (see Table 7.3). Cognitive side-effects were the second most commonly reported problem among the patients (77\%). Most described cognitive complaint was memory problems and to a lesser extent concentration problems, language difficulties, mental slowing and problems with information processing. Behavioral side-effects were reported in $69 \%$ of the patients. Most commonly described mood complaint was a depressive mood, irritable and angry or agitated behavior. Cosmetic side-effects such as skin rash, weight problems and gum problems occurred in $42 \%$ of the patients and $7 \%$ reported other side-effects that could not be classified. Only in the cosmetic category of the questionnaire there was a significant difference between males and females. More females reported cosmetic problems during the last 12 months ( $t=-2.229, p=.027)$. Only in the mood category, there was a significant negative correlation found for age $(r=-.141, p=.044)$; the younger the patients, the more mood complaints were reported. 

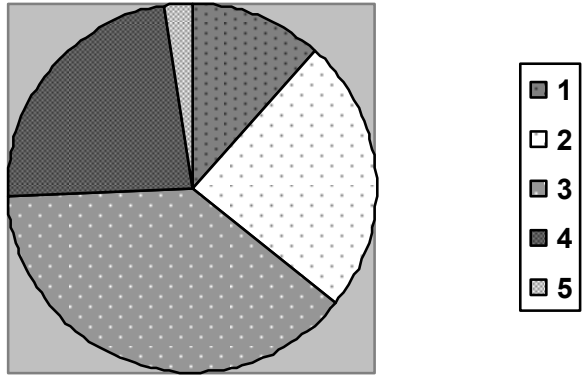

Figure 7.1 Number of side-effects.

Table 7.3 Type of side-effect and complaints.

\begin{tabular}{|c|c|c|c|c|}
\hline & $\mathbf{N}$ & $\%$ & Type of complaints & $\% *$ \\
\hline \multirow[t]{6}{*}{ General health complaints } & 172 & 84.7 & Fatigue and sleep problems & 62 \\
\hline & & & Motor and balance problems & 29 \\
\hline & & & Headache & 24 \\
\hline & & & Dizziness & 23 \\
\hline & & & Gastrointestinal problems & 14 \\
\hline & & & Nausea & 13 \\
\hline \multirow[t]{4}{*}{ Cognitive complaints } & 157 & 77.3 & Memory problems & 73 \\
\hline & & & Concentration problems & 29 \\
\hline & & & Language difficulties & 25 \\
\hline & & & Mental slowing & 13 \\
\hline \multirow[t]{6}{*}{ Mood complaints } & 139 & 68.5 & Depressive mood & 37 \\
\hline & & & Irritable and angry behavior & 36 \\
\hline & & & Agitated behavior & 20 \\
\hline & & & Mood sings & 16 \\
\hline & & & Aggressive behavior & 13 \\
\hline & & & Anxious behavior & 5 \\
\hline \multirow[t]{6}{*}{ Cosmetic complaints } & 86 & 42.4 & Skin rash & 45 \\
\hline & & & Weigh problems & 44 \\
\hline & & & Problems with gums & 26 \\
\hline & & & Hair loss & 15 \\
\hline & & & Itch & 4 \\
\hline & & & Shaking hands & 4 \\
\hline
\end{tabular}

* patients can have problems in more than one area.

\section{Subgroup analyses}

No differences were found between the mono- and the polytherapy group; patients on polytherapy did not report more side-effects than patients on monotherapy (see Table 7.4). For the comparison between the older and the newer AEDs, patients who used a combination of these medication regimens were not taken into account. There were also no differences between the old and new AEDs; patients who used older AEDs did not experience more side-effects than patients who were treated with newer AEDs. 
Furthermore, there were also no differences between the cognitive risk groups; the cognitive high risk group did not report more side-effects than the cognitive low risk group. However, there was a significant difference between the behavioral risk groups for the mood complaints ( $t=-2.776, p=.006)$ and total number of complaints ( $t=-2.221$, $\mathrm{p}=.027$ ); patients from the behavioral high risk group did have significantly more problems than patients from the behavioral low risk group, especially concerning their mood.

Table $7.4 \mathrm{p}$-values for the different subgroup analyses.

\begin{tabular}{lcccc}
\hline Type of side-effect & mono vs. poly & old vs. new & $\begin{array}{c}\text { Cognitive low risk } \\
\text { vs. high risk }\end{array}$ & $\begin{array}{c}\text { Behavioral low risk } \\
\text { vs. high risk }\end{array}$ \\
\hline Cognition & .772 & .699 & .492 & .235 \\
Mood & .549 & 1.000 & .305 & $.006^{*}$ \\
General health & .466 & .955 & .614 & .843 \\
Cosmetic & .309 & .962 & .696 & .620 \\
Total & .248 & .991 & .925 & $.027^{*}$ \\
\hline
\end{tabular}

$* \mathrm{p} \leq .05$

\section{Linear regression analysis}

Thus far, each comparison was made independently from the other treatment regimen. However, subgroup divisions are correlated. Therefore, regression analysis was performed with total number of complaints as dependent variable and 1) mono vs. polytherapy, 2) old vs. new AED, 3) cognitive high vs. low risk AED and 4) behavioral high vs. low risk AED as predictors. A backward procedure was used. Although both the cognitive and behavioral high vs. low risk AEDs contributed significantly (F-value:3.044, $\mathrm{p}=.05$ ), the procedure identified a one-factor solution as the strongest predictor of the total complaints: a behavioral high risk AED (F-value:4.932, $\mathrm{p}=.027$ ). The total percentage of explained variance was $2.4 \%$.

\section{Discussion}

This study compared subjective reported side-effects among different AED treatments in a population referred to a tertiary epilepsy center. No more than $15 \%$ of the patients who visited the outpatient clinic reported to have side-effects. It is unlikely that this is due to the absence of side-effects. Rather this percentage reflects the weight the patients with chronic refractory epilepsy attribute to side-effects. Side-effects are commonly reported in community based studies in which the majority of the patients are in remission. In our population, much more importance is probably attributed to the seizures and, hence, the importance of the efficacy of the drugs. 
Of the patients who did report side-effects, most had experienced some complaints in their general health, cognition or mood due to their AEDs during the last 12 months. Cosmetic side-effects occurred in a minority of the patients; more in females than males which is consistent with previous literature. ${ }^{24}$ In our specific population, polytherapy did not induce more complaints than monotherapy. This is inconsistent with previous literature who did report more side-effects ${ }^{1-3}$ and a lower quality of life ${ }^{25}$ for polytherapy. This probably again illustrates a different efficacy/tolerability attribution in our patient group compared to studies in the community. Furthermore, the generation of the AEDs (older versus newer) was not relevant. The newer AEDs have been thought to have decreased the incidence of certain side-effects such as cosmetic side-effects when compared with older antiepileptic medication. ${ }^{24,26}$ However, previous research showed that there was no difference between patients using newer versus classic AEDs in their quality of life. ${ }^{25}$ Moreover, patients with a highrisk AED for cognitive side-effects did not complain more about their cognitive functions than patients with a cognitive low-risk AED. However, when LEV was added to this high risk AED group, patients with a high risk AED for behavioral side-effects did complain more about their mood than patients with a behavioral low-risk AED. As shown in our regression analysis, using a high risk AED for behavioral side-effects contributed significantly to the total experienced side-effects. Note, however, that the percentage explained variance is low, indicating that the complaints are also related to other factors, in this group probably the epilepsy. The mood complaints of patients using LEV treatment were an essential factor in our study and is in line with a number of studies and meta-analyses. ${ }^{27-30}$ LEV had an adverse event profile within the range of the other older drugs like PHT but with a different profile; self-reported anger and hostility were particularly frequent. ${ }^{13,15}$

The primary limitation of our study stem from self-reporting. The side-effects were subjectively reported. Our study therefore critically relied on the validity and reliability of subjective self-report as no formal neuropsychological testing was used. Nevertheless, this is a naturalistic situation and the assessment of possible side-effects of AEDs in routine daily care of patients with epilepsy is based on these same selfreports which can be used as a sensitive screening instrument. ${ }^{20}$

In conclusion, our study illustrates that patients are a reliable respondent to indicate side-effects despite of their refractory epilepsy. Particularly, mood complaints due to antiepileptic drugs (such as LEV) are correctly noticed. 


\section{References}

1. Carpay JA, Aldenkamp AP, Donselaar van CA. Complaints associated with the use of antiepileptic drugs: results from a community-based study. Seizure 2005;14:198-206.

2. Uijl SG, Uiterwaal CS, Aldenkamp AP, Carpay JA, Doelman JC, Keizer K, et al. A cross-sectional study of subjective complaints in patients with epilepsy who seem to be well-controlled with anti-epileptic drugs. Seizure 2006;15:242-8.

3. Andrew A, Milinis K, Baker G, Wieshmann U. Self-reported adverse effects of mono and polytherapy for epilepsy. Seizure 2012;21:610-13.

4. Beghi E. Efficacy and tolerability of the new antiepileptic drugs: comparison of two recent guidelines. Lancet Neurol 2004;3:618-21.

5. Aldenkamp AP. Effects of anti-epileptic drugs on cognition. Epilepsia 2001;42:46-49.

6. Bootsma HPR, Coolen F, Aldenkamp AP, Arends J, Diepman L, Hulsman J, et al. Topiramate in clinical practice: long-term experience in patients with refractory epilepsy referred to a tertiary epilepsy center. Epilepsy Behav 2004;5:380-7.

7. Bootsma HPR, Aldenkamp AP, Diepman L, Hulsman J, Lambrechts D, Leenen L, et al. The effect of antiepileptic drugs on cognition: patient perceived cognitive problems of topiramate versus levetiracetam in clinical practice. Epilepsia 2006;47:24-7.

8. Bootsma HPR, Ricker L, Diepman L, Gehring J, Hulsman J, Lambrechts D, et al. Long-term effects of levetiractetam and topiramate in clinical practice: a head to head comparison. Seizure 2008;17:19-26.

9. Park SP, Hwang YH, Lee HW, Suh CK, Kwon SH, Lee BI. Long-term cognitive and mood effects of zonisamide monotherapy in epilepsy patients. Epilepsy Behav 2008;12:102-8.

10. Arif H, Buchsbaum R, Weintraub D, Pierro J, Resor Jr SR, Hirsch LJ. Patient-reported cognitive side effects of antiepileptic drugs: Predictors and comparison of all commonly used antiepileptic drugs. Epilepsy Behav 2009;14:202-9.

11. Tatum WO, French JA, Faught E, Morris GL, Liporace J, Kanner A, et al. Postmarketing experience with topiramate and cognition. Epilepsia 2001;42:1134-40.

12. Bootsma HPR, Ricker L, Diepman L, Gehring J, Hulsman J, Lambrechts D, et al. Levetiracetam in clinical practice: longterm experience in patients with refractory epilepsy referred to a tertiary epilepsy center. Epilepsy Behav 2007;10:296-303.

13. Wieshmann UC, Baker GA. Self-reported feelings of anger and aggression towards others in patients on levetiracetam: data from the UK antiepileptic drug register. BMJ Open 2013;3:1-4.

14. Weintraub D, Buchsbau R, Resor Jr SR, Hirsch L. Psychiatric and behavioral side effects of the newer antiepileptic drugs in adults with epilepsy. Epilepsy Behav 2007;10:105-10.

15. Wieshmann UC, Tan GM, Baker G. Self-reported symptoms in patients on antiepileptic drugs in monotherapy. Acta Neurol Scand 2011;124:355-8.

16. IJff DM, Aldenkamp AP. Comorbidities of treatment with antiepileptic drugs. In: M. Duchowny, J.H. Cross, A. Arzimanoglou, eds. Pediatric epilepsy. New York: McGraw-Hill Professional, 2012;424-36.

17. IJff, DM \& Aldenkamp, AP. Cognitive side effects of antiepileptic drugs in children. In: Dulac, Lassonde, Sarnat, eds. Handbook of Clinical Neurology: Pediatric Neurology. New York: Elsevier, 2013:738-49.

18. Kinderen de RJA, Evers SMAA, Rinkins R, Postulart D, Vader CI, Majoie HJM. Side-effects of antiepileptic drugs: the economic burden. Seizure 2014;23:184-90.

19. Bootsma HP, Ricker L, Hekster YA, Hulsman J, Lambrechts D, Majoie M, et al. The impact of side effects on long-term retention in three new antiepileptic drugs. Seizure 2009;18:327-31.

20. Aldenkamp AP, van Meel HF, Baker GA, Brooks J, Hendriks MPH. The A-B neuropsychological assessment schedule (ABNAS): the relationship between patient-perceived drug related cognitive impairment and results of neuropsychological tests. Seizure 2002;11:231-7.

21. Uijl SG, Uiterwaal CS, Aldenkamp AP, Carpay JA, Doelman JC, Keizer K, et al. Adjustment of treatment increases quality of life in patients with epilepsy: a randomized controlled pragmatic trial. Eur J Neurol 2009;16:1173-7.

22. Loring DW, Marino S, Meador KJ. Neuropsychological and behavioral effects of antiepilepsy drugs. Neuropsychol Rev. 2007;28:413-25. 
23. Mbizvo GK, Dixon P, Hutton JL, Marson AG. Levetiracetam add-on for drug-resistant focal epilepsy: an updated Cochrane Review. Cochrane Database Syst Rev 2012;12;9:CD001901.

24. Chen B, Choi H, Hirsch LJ, Moeller J, Jayed A, Kato K, et al. Cosmetic side effects of antiepileptic drugs in adults with epilepsy. Epilepsy Behav 2015;42:129-37.

25. Haag A, Strzelczyk A, Bauer S, Kühne S, Hamer HM, Rosenow F. Quality of life and employment status are correlated with antiepileptic monotherapy versus polytherapy and not with use of "newer" versus "classic" drugs: results of the "Compliant 2006" survey in 907 patients. Epilepsy Behav 2010;19:618-22.

26. Talati R, Scholle JM, Phung OJ, Baker WL, Baker EL, Ashaye A, et al. Effectiveness and safety of antiepileptic medications in patients with epilepsy; 2011 [Rockville (MD)].

27. Cramer JA, De Rue K, Devinsky O, Edrick P, Trimble MR. A systematic review of the behavioral effects of levetiracetam in adults with epilepsy, cognitive disorders, or anxiety disorder during clinical trials. Epilepsy Behav 2003;4:124-32.

28. Dinkelacker V, Dietl T, Widman G, Lengler U, Elger CE. Aggressive behavior of epilepsy patients in the course of levetiracetam add-on therapy: report of 33 mild to severe cases. Epilepsy Behav 2003;4:53747.

29. Mula M, Trimble, MR, Yuen A, Liu RS, Sander JW. Psychiatric adverse events during levetiracetam therapy. Neurology 2003:61:704-6.

30. Weintraub D, Buchsbaum R, Resor SR Jr, Hirsch LJ. Psychiatric and behavioral side effects of the newer antiepileptic drugs in adults with epilepsy. Epilepsy Behav. 2007;10:105-10. 


\section{Chapter}

\section{Cognitive adverse effects of antiepileptic drug treatment; how to recognize who is at risk}




\section{Abstract}

\section{Introduction}

Patients with epilepsy can have major benefits from AEDs. Cognitive adverse effects and subjective complaints are very common. Being able to predict which patient is at risk for developing cognitive adverse effects would be of great value in avoiding unnecessary cognitive tests. The aim of this study was to determine the profile of patients at risk for developing cognitive adverse effects of AED treatment in chronic epilepsy.

\section{Method}

In this cross-sectional study, patients with localisation related epilepsy taking lamotrigine or levetiracetam (low risk group) and phenytoin or topiramate (high risk group) were included. A neuropsychological assessment was used to evaluate the cognitive impairments and questionnaires were used to assess mood and subjective perceived adverse effects.

\section{Results}

This study included 53 patients (low risk group $n=32$ and high risk group $n=21$ ). The high risk group had a significantly slower information processing speed than the low risk group. No other significant differences in cognition, mood or subjective complaints were found. A backward linear regression analysis identified duration of epilepsy and subjectively complaints of the AED treatment as the strongest indicators of mental slowing for the whole study population.

\section{Conclusion}

This study confirms that patients taking high risk AEDs have drug-induced cognitive impairment, expressed as slowing of central information processing. This mental slowing can be predicted by a longer duration of epilepsy and the presence of subjectively perceived adverse effects of the AED treatment. Although there were some methodological issues, this study revealed that patients with chronic epilepsy complaining about their AED treatment may be regarded as being at risk for developing cognitive adverse effects. In clinical practice, further neuropsychological assessment is indicated for these patients. 


\section{Introduction}

Epilepsy is treated in the majority of patients with AEDs. One of the complications of AED-treatment is the occurrence of adverse effects. Cognitive adverse effects are among the most frequent complaints by patients ${ }^{1}$ as well as the most frequently demonstrated drug-induced impairments. ${ }^{2}$ In general, these adverse effects involve 'fluid' attentional-type of functions, especially slowing of central information processing. ${ }^{3}$ The risk of impaired cognition due to AED treatment differs between AEDs. ${ }^{2,4}$ AEDs considered to have a high risk for cognitive adverse effects are for example phenytoin (PHT) and topiramate (TPM), especially relative to low risk AEDs such as lamotrigine (LTG) and levetiracetam (LEV). ${ }^{5-10}$ These latter drugs may even have activating effects on cognition. Drugs such as carbamazepine (CBZ), oxcarbazepine (OXC), or valproate (VPA) can be regarded as intermediate drugs. ${ }^{11-14}$

Although some of the epilepsy guidelines advise to monitor for cognitive adverse effects when administering high risk drugs, ${ }^{15}$ many patients may not experience such effects while patients taking low risk drugs may have serious cognitive adverse effects. ${ }^{16,17}$ Apparently, risk category alone is not a sufficient predictor for cognitive problems which are also influenced by other factors. Ortinski and Meador (2004) reported that an earlier onset of seizures leads to more severe cognitive adverse effects of AEDs, possibly due to a longer accumulation of effects. ${ }^{18}$ In addition, not only the type of medication, but also drug load may negatively affect cognitive function. ${ }^{19}$ Furthermore, the mood status of patients may impact the perception of the cognitive adverse effects and lead to more complaints. ${ }^{20,21}$

Being able to predict which patient is at risk for developing cognitive adverse effects could be of great value in avoiding unnecessary cognitive tests, when a review of antiepileptic medication might be more appropriate. The important question is whether cognitive adverse effects of AED treatment can be predicted by risk category alone or in combination with other factors. Other possible factors include the severity of the epilepsy, additional treatment characteristics such as drug load, or subjective complaints of the AED treatment. The present study was therefore set up to determine the risk profile of patients for developing cognitive adverse effects of AED treatment in chronic epilepsy in a cross-sectional study design.

\section{Methods}

\section{Patients}

All patients were consecutively included from the outpatient clinic of our tertiary epilepsy centre (Kempenhaeghe). All subjects gave written informed consent and approval by the local Medical Ethical Committee was obtained. The inclusion criterion 
for this study was localization-related epilepsy which was treated with AEDs. The following patient data were collected: gender, age, educational level (converted into the American education system), epilepsy characteristics (duration and type of epilepsy, type of seizure and seizure frequency), and AED use. These drugs were subdivided into two risk categories based on the cognitive risk: ${ }^{2,22}$ LEV and LTG were included in the 'low risk' category, and PHT and TPM in the 'high risk' category. Patients were allowed to use one add-on drug of the mild category (CBZ, OXC or VPA). Drug load was calculated for each individual patient as the sum of the prescribed daily dose (PDD)/defined daily dose (DDD), where DDD corresponds to the assumed average maintenance daily dose of a drug, prescribed for its main indication. ${ }^{23}$

\section{Neuropsychological assessment}

A neuropsychological test battery was used which included tasks that have been demonstrated to be sensitive for cognitive adverse effects, because they assess fluid functions such as alertness, attention, and central information processing speed. Furthermore, we included tests that assess psychomotor speed, memory, language and cognitive ability, because high risk drugs may also impact the higher-order cognitive functions. ${ }^{2}$ We used questionnaires to measure mood and subjective complaints about AED treatment.

\section{Alertness / attention / information processing speed}

- Simple Reaction-Time Measurement: The reaction time for simple auditory tones or visual stimuli is measured. ${ }^{24}$

- Binary Choice Reaction Test (BCRT): The subject has to react differentially to a red square, presented on the left hand side of the computer screen, then to a green square, presented on the right side. ${ }^{3}$

- Computerised Visual Searching Task (CVST): The task consists of finding a grid pattern out of 24 , which matches the one in the centre of the screen. ${ }^{3}$

\section{Psychomotor speed}

- Finger Tapping Test: Speed of finger tapping is measured for the index finger of the dominant hand; five times for a period of 10 seconds each. ${ }^{3}$

\section{Memory}

- Recognition of words and figures: Six words and four figures are presented. After a delay, the target item has to be recognised amongst a series of distracters. ${ }^{24}$

- The Rey's Auditory Verbal Learning Test (AVLT), testing memory and learning. ${ }^{25} \mathrm{~A}$ list of 15 words is orally presented five times. After every presentation, immediate recall is requested. A delayed recall is requested after a 20 minutes interval. 


\section{Language}

- The Lindeboom Naming task; naming of images, measuring word retrieval. ${ }^{26}$

\section{Cognitive abilities}

The Raven's Standard Progressive Matrices, measuring global cognitive functioning. ${ }^{27}$ It provides a measure of the capacity to observe, solve problems, and learn. This test includes multiple choice tests of abstract reasoning in which patients are asked to identify the missing element required to complete a pattern.

\section{Mood}

- Profile of mood states (POMS), Dutch language version measures state-dependent mood changes for the previous week according to adjectives. ${ }^{28}$ Ratings are scored for six mood states: tension-anxiety, depression-dejection, anger-hostility, fatigueinertia, confusion-bewilderment and vigour-activity. A Total Mood Disturbance (TMD) can be calculated by adding the scores for Tension, Depression, Anger, Fatigue and Confusion and then subtracting the score for Vigour.

\section{Subjective complaints}

- SIDAED (SIDeffects of AEDs). Three categories from the original version were included; behaviour (increased irritability), depressive symptoms and cognitive function. ${ }^{29}$ For each item the patient rates the severity of the complaint on a fourpoint Likert scale ( $0=$ no problem, $1=$ mild, $2=$ =moderate, or $3=$ serious problem).

- The A-B neuropsychological assessment schedule (ABNAS) measures seven critical domains of cognition (tiredness/fatigue, hyper-excitability, slowing (mental and motor), memory impairment, attention disorders, and impairment of motor coordination and language disorders). ${ }^{30}$ For each item, the patient rates the severity of the complaint, again on a four-point Likert scale.

\section{Subgroup and statistical analysis}

Statistical analyses were performed with SPSS version 21 for Windows (SPSS Inc., Chicago, IL, USA). To check if there are any differences between the treatment groups in demographical and epilepsy related characteristics, independent samples t-tests were used for the continuous variables (age, drug load, and duration of epilepsy), and Pearson's chi-square tests were performed for the categorical variables (gender, educational level, type of epilepsy and seizure, seizure frequency). Furthermore, independent samples t-tests were performed to check for differences between the groups on the neuropsychological test results and the questionnaires. Backward linear regression analyses were applied to determine which measurements predicted 
cognitive adverse effects and which patients were at risk for developing drug-induced cognitive adverse effects.

\section{Results}

\section{Demographics and clinical characteristics}

In total, 53 patients were included in this study. The demographic and clinical characteristics are summarized in Table 8.1. The groups differed significantly in age; patients from the high risk group were older than the low risk group ( $p=.018)$. There were no significant differences in gender, educational level, duration of epilepsy, type of epilepsy or seizures, seizure frequency or drug load.

Table 8.1 Demographics and clinical characteristics.

\begin{tabular}{|c|c|c|c|c|}
\hline & & $\begin{array}{c}\text { Low risk } \\
(n=32)\end{array}$ & $\begin{array}{c}\text { High risk } \\
(n=21)\end{array}$ & p \\
\hline \multirow[t]{2}{*}{ Gender (\%) } & Male & $12(37.5)$ & $8(38.1)$ & n.s. \\
\hline & Female & $20(62.5)$ & $13(61.9)$ & \\
\hline \multirow[t]{6}{*}{ Age } & At assessment (SD) & $42.8(13.4)$ & 51.9 (12.9) & $.018^{*}$ \\
\hline & Range & $22-69$ & $20-69$ & \\
\hline & At onset epilepsy (SD) & $16.8(14.2)$ & $20.6(13)$ & n.s. \\
\hline & Range & $2-68$ & $6-52$ & \\
\hline & Duration of epilepsy (SD) & $26.1(13.1)$ & $31.5(15.7)$ & n.s. \\
\hline & Range & $1-52$ & $1-59$ & \\
\hline \multirow[t]{4}{*}{ Educational level (\%) } & Elementary school & $2(6.3)$ & $1(4.8)$ & n.s. \\
\hline & High school diploma & $4(12.5)$ & $4(19.0)$ & \\
\hline & Associate's degree & $14(43.8)$ & $10(47.6)$ & \\
\hline & Bachelor's degree & $12(37.5)$ & $6(28.6)$ & \\
\hline \multirow[t]{2}{*}{ Type of epilepsy (\%) } & Symptomatic & $11(34.4)$ & $6(28.6)$ & n.s. \\
\hline & Non symptomatic & $21(65.6)$ & $15(71.4)$ & \\
\hline \multirow[t]{2}{*}{ Type of seizures (\%) } & Tonic-clonic & $22(68.8)$ & $13(61.9)$ & \\
\hline & Other & $10(31.3)$ & $8(38.1)$ & \\
\hline \multirow[t]{4}{*}{ Seizure frequency (\%) } & Weekly & $1(3.1)$ & - & n.s. \\
\hline & Monthly & $6(18.8)$ & $1(4.8)$ & \\
\hline & Annually & $6(18.8)$ & $4(19.0)$ & \\
\hline & Seizure free & $19(59.4)$ & $16(76.2)$ & \\
\hline \multirow[t]{6}{*}{ AED (\%) } & Monotherapy & $16(50.0)$ & $8(38.1)$ & n.s. \\
\hline & Polytherapy & $16(50.0)$ & $13(61.9)$ & \\
\hline & LTG & 19 (55.9) & - & \\
\hline & LEV & $13(38.2)$ & - & \\
\hline & TPM & & $5(23.8)$ & \\
\hline & PHT & & $16(76.2)$ & \\
\hline \multirow[t]{4}{*}{ Add-on } & $\mathrm{CBZ}$ & $11(34.4)$ & $6(28.6)$ & \\
\hline & OXC & $3(9.4)$ & - & \\
\hline & VPA & $2(6.3)$ & $6(28.6)$ & \\
\hline & Drugload (SD) & $1.6(.7)$ & $1.5(.7)$ & n.s. \\
\hline
\end{tabular}

${ }^{*} p<.05$, n.s.: not significant. 


\section{Neuropsychological assessment}

Most neuropsychological functions were in the normal range, except the reaction times on visual stimuli and the CVST reaction time, which were slower than normal for the high risk group. Furthermore, the outcomes of most tasks were not significantly different between the groups (Table 8.2). Only the CVST, a test assessing speed of central information processing, showed a significant difference between the low and the high risk group; patients from the high risk group performed this task significantly slower $(t=-2.053, p=.045)$. Furthermore, a trend was found on the auditory reaction time test $(t=-1.924, p=.065)$, which assesses activation.

Table 8.2 Neuropsychological assessment.

\begin{tabular}{lccc}
\hline Assessment & Low risk & High risk & \\
& Mean (SD) & Mean (SD) & p \\
\hline Auditory reaction time DH (ms) & $240.6(51.4)$ & $283.3(93.0)$ & n.s. \\
Auditory reaction time NDH (ms) & $236.2(53.3)$ & $257.1(95.3)$ & n.s. \\
Visual reaction time DH (ms) & $310.4(50.8)$ & $321.1(70.3)$ & n.s. \\
Visual reaction time NDH (ms) & $319(65.3)$ & $344.9(117.4)$ & n.s. \\
Binary choice reaction time (ms) & $468.9(124.6)$ & $487.5(174.6)$ & n.s. \\
CVST reaction time (sec) & $13.3(5.4)$ & $16.6(5.9)$ & $.045^{*}$ \\
Tapping DH & $54.5(8.1)$ & $55.9(9.0)$ & n.s. \\
Tapping NDH & $50.3(8.0)$ & $50.9(9.3)$ & n.s. \\
Recognition words & $19.0(3.3)$ & $18.3(3.5)$ & n.s. \\
Recognition figures & $7.1(2.1)$ & $7.0(2.0)$ & n.s. \\
Rey AVLT immediate recall & $40.9(8.1)$ & $40.7(8.8)$ & n.s. \\
Rey AVLT delayed recall & $8.1(2.6)$ & $8.1(3.2)$ & n.s. \\
Raven total number correct & $43.3(5.9)$ & $43.5(5.5)$ & n.s. \\
Lindeboom Naming Task & $14.8(.5)$ & $14.6(.9)$ & n.s. \\
\hline
\end{tabular}

${ }^{*} \mathrm{p}<.05 \mathrm{DH}$ : dominant hand, NDH: non-dominant hand, ms: milliseconds, sec: seconds, n.s.: not significant.

\section{Mood and subjective complaints}

There were no significant differences in mood or subjective complaints between the two treatment groups (see Table 8.3). Patients did not differ in their reported adverse effects of AED-treatment concerning their cognition (mental slowing, memory, attention, language), behaviour and mood (fatigue or hyper-excitability).

\section{Linear regression analyses}

To confirm the results presented in Table 8.2, but to remove the effect of shared correlation between the tests, a linear regression analysis was performed. Only tests considered sensitive to drug effects, ${ }^{3}$ i.e. tests assessing fluid functions (auditory reaction time, visual reaction time, BCRT, CVST), were included. The cognitive risk category was used as dependent variable. A backward procedure was used. The procedure identified a two-factor solution as the strongest indicator of the cognitive 
risk category: the CVST and the auditory reaction-time task (F-value: 3.061, $p=.037$ ). This is in line with the results of t-testing as presented in Table 8.2. However, the auditory reaction task has the strongest effect $(r=.289, p=.018)$, followed by the CVST $(r=.276, p=.023)$.

We subsequently created a new variable which was called the 'mental slowing score', defined as the sum of the auditory reaction time performed with the dominant hand and the reaction time for the CVST. A higher score indicates more mental slowing. In a second step, a linear regression analysis was performed with the mental slowing score as dependent variable and age as demographic variable (because of the age-difference between the groups), duration and type of epilepsy as indicators of the epilepsy severity, drug load as medication factor, total mood disturbance as indicator of mood and subjective complaints (sum of total ABNAS-score and total SIDAED-score) as independent variables. A backward procedure was used. The procedure identified a two-factor solution as the strongest predictor of mental slowing: duration of epilepsy and subjective complaints (F-value: 4.262, $\mathrm{p}=.020$ ). The total of subjective complaints $(r=.302, p=.015)$ had the strongest effect, followed by duration of epilepsy $(r=.223$, $p=.056)$.

Table 8.3 Mood and subjective complaints.

\begin{tabular}{lccc}
\hline Questionnaires & Low risk & High risk & \\
& Mean (SD) & Mean (SD) & $\mathbf{p}$ \\
\hline POMS tension/anxiety & $12.2(4.9)$ & $10.1(5.7)$ & n.s. \\
POMS depression/dejection & $9.5(7.9)$ & $10.9(12.9)$ & n.s. \\
POMS anxiety/ hostility & $9.1(6.6)$ & $8.1(8.5)$ & n.s. \\
POMS vigor & $18.4(6.0)$ & $18.1(6.6)$ & n.s. \\
POMS fatique & $8.4(5.4)$ & $6.9(6.0)$ & n.s. \\
POMS confusion & $10.7(4.9)$ & $9.2(5.1)$ & n.s. \\
POMS total mood disturbance & $31.6(26.1)$ & $27.1(32.8)$ & n.s. \\
ABNAS number of complaints & $10.6(6.9)$ & $8.7(7.6)$ & n.s. \\
ABNAS total & $15.8(14.3)$ & $14.0(15.1)$ & n.s. \\
SIDAED number of complaints & $6.1(4.6)$ & $6.6(5.6)$ & n.s. \\
SIDAED behaviour & $2.1(2.3)$ & $1.6(2.9)$ & n.s. \\
SIDAED depressive symptoms & $1.8(2.5)$ & $2.4(2.8)$ & n.s. \\
SIDAED cognitive functions & $5.7(5.4)$ & $6.8(6.9)$ & n.s. \\
SIDAED total & $19.1(15.7)$ & $18.9(20.7)$ & n.s. \\
\hline
\end{tabular}

n.s.: not significant

\section{Discussion}

Patients taking AEDs with a high risk for cognitive adverse effects had a slower information processing speed than patients taking low risk AEDs. Linear regression analysis revealed that mental slowing was determined by two tasks, namely the CVST 
and the auditory reaction task. This drug-induced mental slowing appeared to be predicted by subjective complaints and the duration of epilepsy.

Our results are in line with previous neuropsychological studies that consistently identify 'speed factors' as the most sensitive area in relation to drug treatment. ${ }^{31-33}$ Only the CVST and simple reaction time measurements showed a significant effect and are therefore useful parameters to screen for cognitive adverse effects of AEDs, which is consistent with previous findings. ${ }^{3}$ Moreover, this study confirms that the presence of subjective complaints due to AED-treatment is a reliable indicator of cognitive adverse effects. ${ }^{1,30}$ Subjective complaints in patients with chronic epilepsy should therefore be taken seriously and should lead to referral for neuropsychological assessment. This study confirms furthermore that a longer duration of epilepsy is associated with more drug-induced cognitive impairments. ${ }^{18,34}$

Previous research of our group using fMRI showed that chronic epilepsy is associated with global brain network changes and impaired white matter connectivity. ${ }^{35,36}$ Although the effects of AEDs were not separately investigated in this study, one can speculate that the resulting vulnerable brain may be more susceptible to adverse effects of AEDs. So far, there is a scarcity of $\mathrm{fMRI}$ studies investigating drug-related changes of brain activity and function. ${ }^{37}$ The mechanisms underlying the cognitive effects caused by AEDs are therefore poorly understood. Further research needs to investigate the neuronal mechanisms underlying this cognitive impairment due to AEDtreatment, which may explain why cognitive functioning of some patients with epilepsy is impaired by AEDs while it is not affected in other patients. ${ }^{38}$

There are some confounding factors and methodological issues that limit the interpretation of our study. Although duration of epilepsy was included in this study, treatment had already been started in most patients at referral because this study was performed at a tertiary referral clinic. It is therefore unknown when treatment was started in our study population. Although the sample size was relatively small, especially in the high risk group, it allowed us to detect moderate effects. ${ }^{39}$ Undoubtedly, more effects would have been detected with larger sample sizes, however, not necessarily increasing the clinical relevance of our findings. Furthermore, our findings were in line with our expectations based on literature; slowing of central information processing is an important cognitive 'marker' of AED-induced side-effects and longer duration seems to represent chronicity of treatment. Although we tried to include comparable patients groups, age was not equally distributed across treatment groups, suggesting that our study population was biased, which is another limitation of our study. However, patients did not differ in their educational level and global cognitive functioning (as assessed with the Raven test), which suggests that these groups are comparable in their performance on general neuropsychological tests. Moreover, regression analysis in which age was included, showed that age did not significantly contribute to cognitive impairment in AED-treated patients. 
In conclusion, this study confirms that patients taking high risk AEDs have more druginduced cognitive impairments, expressed as slowing of central information processing. This mental slowing can be predicted by a longer duration of epilepsy and the presence of subjectively perceived adverse effects of AED-treatment. In clinical practice, patients with chronic epilepsy complaining about their AED-treatment may be regarded as being at risk for developing cognitive adverse effects in which further neuropsychological assessment is indicated. 


\section{References}

1. IJff D, Kinderen R, Vader C, et al. Subjectively Perceived side-effects of anti-epileptic drugs in chronic refractory epilepsy. Adv Pharmacoepidemiol Drug Saf 2015;4:186.

2. IJff, DM, Aldenkamp, AP. Comorbidities of treatment with antiepileptic drugs. In Duchowny, Cross, and Arzimanoglou (Eds.), Pediatric Epilepsy, New York: McGraw-Hill Professional, 2012;424-36.

3. Grevers E, Breuer LEM, IJff DM, et al. Mental slowing in relation to epilepsy and antiepileptic medication. Acta Neurol Scand: 2016;134:166-22.

4. Schmidt D, Schachter SC. Drug treatment of epilepsy in adults. BMJ 2014;28:348.

5. Aldenkamp AP, Baker G. A systematic review of the effects of lamotrigine on cognitive function and quality of life. Epilepsy Behav 2001;2:85-91.

6. Aldenkamp AP, Alpherts WC, Diepman L, et al. Cognitive side-effects of phenytoin compared with carbamazepine in patients with localization-related epilepsy. Epilepsy Res 1994;19:37-43.

7. Gomer G, Wagner K, Frings L, et al. The influence of antiepileptic drugs on cognition: a comparison of levetiracetam with topiramate. Epilepsy Behav 2007;10:486-94.

8. Blum D, Meador K, Biton V, et al. Cognitive effects of lamotrigine compared with topiramate in patients with epilepsy. Neurology 2006;67:400-6.

9. Bootsma HP, Ricker L, Diepman L, et al. Long-term effects of levetiracetam and topiramate in clinical practice: A head-to-head comparison. Seizure 2008;17:19-26.

10. Mula M. Topiramate and cognitive impairment: evidence and clinical implications. Ther Adv Drug Saf 2012;3:279-89.

11. Donati F, Gobbi G, Campistol J, et al. Effects of oxcarbazepine on cognitive function in children and adolescents with partial seizures. Neurology 2006; 67:679-82.

12. Donati F, Gobbi G, Campistol J, et al. The cognitive effects of oxcarbazepine versus carbamazepine or valproate in newly diagnosed children with partial seizures. Seizure 2007;16:670-9.

13. Arif $H$, Buchsbaum R, Weintraub $D$, et al. Patient-reported cognitive side effects of antiepileptic drugs: predictors and comparison of all commonly used antiepileptic drugs. Epilepsy Behav 2009;14:202-9.

14. Vermeulen J, Aldenkamp AP. Cognitive side-effects of chronic antiepileptic drug treatment: a review of 25 years of research. Epilepsy Res 1995;22:65-95.

15. Witt JA, Helmstaedter C. Monitoring the cognitive effects of antiepileptic pharmacotherapyapproaching the individual patient. Epilepsy Behav 2013;26:450-6.

16. Das KB, Harris C, Smyth DP, et al. Unusual side effects of lamotrigine therapy. J Child Neurol 2003;18:479-80.

17. Werz MA, Schoenberg MR, Meader KJ, et al. Subjective preference for lamotrigine or topiramate in healthy volunteers: relationship to cognitive and behavioral functioning. Epilepsy Behav 2006;8:181-91.

18. Ortinski P, Meador KJ. Cognitive side effects of antiepileptic drugs. Epilepsy Behav 2004;5:S60-5.

19. Witt JA, Elger CE, Helmstaedter C. Adverse cognitive effects of antiepileptic pharmacotherapy: each additional drug matters. Eur Neuropsychopharmacol 2015;25:1954-9.

20. Marino SE, Meador KJ, Loring DW, et al. Subjective perception of cognition is related to mood and not performance. Epilepsy Behav 2009;14:459-64.

21. Samarasekera SR, Helmstaedter C, Reuber M. Cognitive impairment in adults with epilepsy: the relationship between subjective and objective assessments of cognition. Epilepsy Behav 2015;52:9-13.

22. IJff DM, Aldenkamp AP. Cognitive side effects of antiepileptic drugs in children. Handb Clin Neurol. 2013;111:707-18.

23. Deckers $\mathrm{CL}$, Hekster YA, Keyser A, et al. Reappraisal of polytherapy in epilepsy: a critical review of drug load and adverse effects. Epilepsia 1997;38:570-5.

24. Alpherts WCJ, Aldenkamp AP. FePSY: 'The Iron Psyche'. Instituut voor epilepsiebestrijding, Heemstede, The Netherlands, 1995. 
25. Kalverboer AF, Deelman BG. De 15-woorden tests A en B: (een voorlopige handleiding) (15WT/VWT). Groningen: Academisch Ziekenhuis Groningen, afd. Neuropsychologie, 1986.

26. Bouma A, Mulder J, Lindeboom J, et al. Handboek neuropsychologische diagnostiek. Amsterdam: Pearson, 2012.

27. Raven J, Raven JC, Court JH. Manual for the Raven's Progressive Matrices and Vocabulary scales 2000 edition. Section 3 Standard Progressive Matrices. Oxford Psychologists Press Ltd., 2000.

28. Ark LA, van der Marburger D, Mellenbergh GJ, et al. De Aangepaste Profile of Mood States; Handleiding en verantwoording. Nijmegen: Berkhout-Nijmegen B.V., 1995.

29. Uijl SG, Uiterwaal CS, Aldenkamp AP, et al. A cross-sectional study of subjective complaints in patients with epilepsy who seem to be well controlled with anti-epileptic drugs. Seizure 2006;15:242-8.

30. Aldenkamp AP, van Meel HF, Baker GA, et al. The A-B neuropsychologial assessment schedule (ABNAS): the relationship between patient-perceived drug related cognitive impairment and results of neuropsychological tests. Seizure 2002;11:231-7.

31. Drane DL, Meador KJ. Cognitive and behavioural effects of antiepileptic drugs. Epilepsy Behav 2002;3:49-53.

32. Kwan P, Brodie MJ. Neuropsychological effects of epilepsy and antiepileptic drugs. Lancet 2001;357:216-22.

33. Park SP, Kwon SH. Cognitive effects of antiepileptic drugs. J Clin Neurol 2008;4:99-106.

34. Hermann B, Meador KJ, Gaillard WD, et al. Cognition across the lifespan: antiepileptic drugs, epilepsy, or both? Epilepsy Behav 2010;17:1-5.

35. Vlooswijk MCG, Vaessen MJ, Jansen JFA, et al. Loss of network efficiency associated with cognitive decline in chronic epilepsy. Neurology 2011;77:938-44.

36. Vaessen MJ, Jansen JF, Vlooswijk MC, et al. White matter network abnormalities are associated with cognitive decline in chronic epilepsy. Cereb Cortex 2012;22:2139-47.

37. Beltramini GC, Cendes F, Yasuda CL. The effects of antiepileptic drugs on cognitive functional magnetic resonance imaging. Quant Imaging Med Surg 2015;5:238-46.

38. Veenendaal TM van, IJff DM, Aldenkamp AP, et al. Metabolic and functional MR biomarkers of antiepileptic drug effectivenees: a review. Neurosci Biobehav Rev 2015;59:92-9.

39. Cohen, J. Statistical Power Analysis for the Behavioral Sciences, Revised Edition; Academic Press, 1977. 


\section{Chapter}

Effect of chronic high risk antiepileptic drug use on functional status; a ten year follow-up study using the Barthel Index 


\section{Abstract}

\section{Background}

The prevalence of epilepsy among people with ID is much higher than in the general population. Chronic treatment with high risk medication is more common in this population. The aim of this longitudinal, clinical study is to investigate the impact of 'high risk' AEDs on functional status in patients with ID.

\section{Methods}

The Barthel Index was used yearly to assess the functional status of every adult patient with epilepsy who lived in the long-stay care facility of Kempenhaeghe. Number and type of seizures were also recorded. Phenobarbital, levetiracetam, phenytoin, topiramate were selected as 'high risk' AEDs. Other AEDs were classified as 'low risk' medication.

\section{Results}

There was a consistent trend on the long-term for lower functional status for the "high risk' AED-group. The decreasing Barthel scores over the ten year period was not affected by AED regimen or type of seizures, but due to an increasing age and related to level of ID.

\section{Conclusion}

In comparison to the demographic effects of the patients, AED-treatment has no impact on the functional status in patients with epilepsy and ID. Furthermore, chronic use of high risk AEDs does not lead to a decline in activities of daily living in this patient population. 


\section{Introduction}

The prevalence of epilepsy among people with intellectual disabilities (ID) is much higher than in the general population. ${ }^{1}$ In people with intellectual disabilities, one in five will have epilepsy (22\%), whereby prevalence increased with increasing level of intellectual disability. ${ }^{2}$ Previous research showed that patients with intellectual disabilities and epilepsy have more physical impairments than those without epilepsy. ${ }^{2}$ Seizures in this population are often complex and difficult to treat. A complicating factor is that treatment in this population is often chronic (or even lifelong) treatment. Although the adverse events in this population are similar to the adverse events in patients with epilepsy and without intellectual disabilities, ${ }^{3}$ the chronicity or treatment as such may impact daily function especially with high risk medication.

From studies in the general epilepsy population it is known that all commonly used antiepileptic drugs (AEDs) have some effect on cognitive functions and on mood, although some agents have a more profound effect. ${ }^{4}$ From the older agents, phenobarbital (PB) induces the most severe cognitive impairment. ${ }^{4,5}$ Phenytoin (PHT) may also have a substantial impact on cognitive function with declines in concentration, memory, visuomotor functions, intelligence and mental speed. ${ }^{4,5}$ Among the new AEDs, topiramate (TPM) seems to have a large negative impact on cognition. ${ }^{6,7}$ Levetiracetam (LEV) is associated with an increased risk of developing behavioural, mood and even psychiatric side-effects such as irritability and aggression, ${ }^{8}$ which is more frequently seen in people with ID. ${ }^{9}$ Long-term exposure to such medications may lead to severe impact over time, even detectable as change in functional status.

The Barthel Index (BI) was first published in 1965 and is widely used as measure of functional status because of its validity, reliability, and sensitivity. ${ }^{10}$ Its use for research and clinical practice is recommended in people with ID. ${ }^{11}$ The $\mathrm{BI}$ was originally developed to assess the change in functional status in patients with neurologic or musculoskeletal disorders ${ }^{12}$ but is also used in the setting of brain tumors and brain metastases, ${ }^{13-16}$ and in patients with multiple sclerosis and stroke. ${ }^{17-18}$

In epilepsy, patients receiving drug treatment did not significantly differ in their need for aid in their activities of daily living ( $A D L$ ) than patients receiving surgical treatment. ${ }^{19}$ Level of dependence in ADL is mostly assessed in patients aged 60 years and over. Some reports suggests that there is a greater risk of impairment of ADL among noninstitutionalized people using psychoactive drugs such as anticonvulsants. ${ }^{20}$ Also in patients living in nursing homes, level of functional dependence was more severe in AED users, both in those with and without a history of epileptic seizures, than in non AED users, even in spite of their significantly younger age. ${ }^{21,22}$ However, all AED users were also taking other drugs than AEDs including drugs that may interact with AEDs such as antipsychotics. In patients with dementia due to Alzheimer's disease, AEDs were associated with lower instrumental functionality. ${ }^{23}$ 
Some reports focused on specific AEDs in particular. In a small number of adult patients with brain tumor-related epilepsy treated with monotherapy LEV, a significant worsening after 6 months follow-up was found on the BI. ${ }^{24}$ However, in patients with post stroke partial seizures or generalized tonic-clonic seizures, the impairment of the ADL was greater for carbamazepine than for LEV-treatment. ${ }^{25}$ In stroke patients, a 'detrimental' drug group which included PB and PHT was compared with a 'neutral' drug group and showed a lower degree of independence in $A D L{ }^{26}$

However, there is no information available of the effects of AED use on functional status in adult epilepsy patients with ID. It may hypothesised that 'high risk' AEDs also have a more deleterious impact on ADL than 'low risk' AEDs and therefore lead to a faster decline of functional status. The aim of this study is therefore to investigate the impact of 'high risk' AEDs on functional status over time in patients with ID.

\section{Methods}

\section{Study population}

This study was performed at the long-stay care facility of Kempenhaeghe. Adult patients (18 years and older) with chronic, refractory epilepsy were included in this longitudinal, clinical study. Patients had either a mild (IQ: 50-70), moderate (IQ: 35-50), severe (IQ:20-35) or profound intellectual disability (IQ<20). During the study period, between January 2005 and January 2014, number of seizures and type of seizures were recorded. Patients were only included if they still had seizures, which were classified in minor seizures such as partial seizures, myoclonic seizures and absences, or major seizures such as tonic seizures, tonic-clonic seizures and atonic seizures. AED use was controlled every year. Patients who switched from the 'low risk' group to the 'high risk' group or vice versa during the study period were excluded. Due to their negative effects on cognitive or behavioural functioning, PB, LEV, PHT and TPM were selected as 'high risk' AEDs. Other AEDs were classified as 'low risk' AEDs. Patients were categorised according to their AEDs associated with the greatest risk.

\section{Assessment of functional status}

The Barthel Index of Activities of Daily Living was used for assessment of functional status. Ten primary activities of daily living such as feeding, bathing, grooming, dressing, bowels, bladder, toilet use, transfers, mobility and stairs are scored, each with two to four response categories (see Appendix). The number of points is based on the amount of help a patient needs. The highest score means that this activity can be performed independently. Minimum total score is 0 (completely dependent), maximum total score is 20 (completely independent). The functional state was routinely assessed every year, at all time points, for every patient by their professional caregiver. 


\section{Data analysis}

Data were analyzed with the Statistical Packages for the Social Sciences SPSS version 21.0 for Windows. First, to compare the 'high risk' group with the 'low risk' group, independent samples t-tests were performed for every time point. Furthermore, as level of ID and seizure type may affect these results, subgroup comparisons were made using ANOVA or independent samples t-tests. Second, to control for possible interfering effects of the demographics (age and level of ID) and epilepsy characteristics (seizure type) on functional status, a general linear model was chosen for the repeated measurement analysis testing the effects of AED ('low risk' versus 'high risk') on the BI after controlling for age, level of ID and seizure type as covariates. In case of a significant $(p<.05)$ Mauchly's W test for sphericity, the corrected Greenhause Geissers F was used.

\section{Results}

\section{Demographic characteristics}

In total, 153 patients were included in this study. The study group consisted of 89 men $(58 \%)$ and 64 women (42\%). Mean age at screening was 42 years. More than half of the patients (56\%) used at least one 'high risk' AED. In both groups, most patients had a moderate intellectual disability, and had both minor and major seizures. The demographic and clinical characteristics are presented in Table 9.1.

Table 9.1 Demographic and clinical characteristics.

\begin{tabular}{|c|c|c|c|c|}
\hline & \multicolumn{2}{|c|}{$\begin{array}{l}\text { Low risk AED } \\
\quad(n=68)\end{array}$} & \multicolumn{2}{|c|}{$\begin{array}{l}\text { High risk AED } \\
\quad(n=85)\end{array}$} \\
\hline & $\mathbf{N}$ & $\%$ & $\mathbf{N}$ & $\%$ \\
\hline \multicolumn{5}{|l|}{ Gender } \\
\hline Male & 36 & 52.9 & 53 & 62.4 \\
\hline Female & 32 & 47.1 & 32 & 37.6 \\
\hline Mean age at baseline & 42.3 & (SD:13.4) & 42.8 & (SD:11.6) \\
\hline (range) & $(18-72)$ & & $(21-63)$ & \\
\hline \multicolumn{5}{|l|}{ Intellectual disability } \\
\hline Mild & 17 & 25.0 & 17 & 20.0 \\
\hline Moderate & 24 & 35.3 & 34 & 40.0 \\
\hline Severe & 16 & 23.5 & 20 & 23.5 \\
\hline Profound & 11 & 16.2 & 14 & 16.5 \\
\hline \multicolumn{5}{|l|}{ Seizure type } \\
\hline Minor & 11 & 16.2 & 8 & 9.4 \\
\hline Major & 57 & 83.8 & 77 & 90.6 \\
\hline
\end{tabular}




\section{Functional status}

Figure 9.1 shows a consistent trend for lower scores for the 'high risk' AED-group on functional status than for the 'low risk' AED-group, which remain constant over the study period. These differences did not reach the statistical significance level (Table 9.2).

Level of ID affected the functional status of patients, which was significant $(p<.000)$ during the whole study period (Table 9.2). Although there was a consistent trend for lower scores for patients with both minor and major seizures on functional status than for patients with only minor seizures (Table 9.2), which remain constant over the study period (Figure 9.2), this only reached the statistical significance level in 2006 ( $t=1.982$, $p=.049)$.

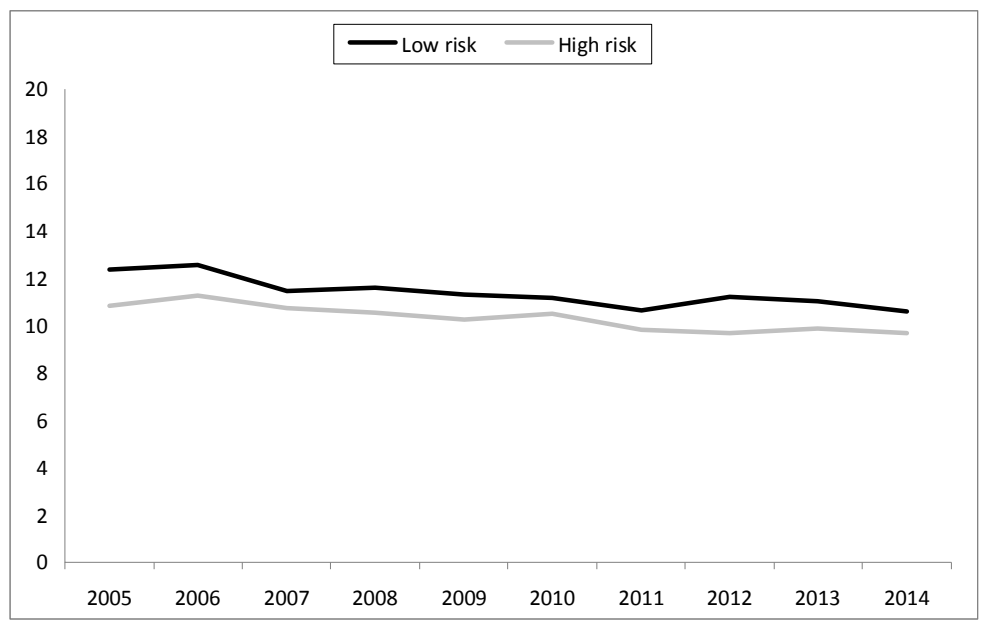

Figure 9.1 Effect of AED on functional status.

Table 9.2 Mean Barthel scores.

\begin{tabular}{|c|c|c|c|c|c|c|c|c|c|c|c|}
\hline \multirow[b]{2}{*}{ Year } & \multicolumn{3}{|c|}{ AED-group } & \multicolumn{5}{|c|}{ Intellectual Disability } & \multicolumn{3}{|c|}{ Seizure type } \\
\hline & Low risk & High risk & p & Mild & Moderate & Severe & Profound & p & Minor & Major & p \\
\hline 2005 & 12.4 & 10.9 & n.s. & 16.3 & 13.7 & 9.7 & 2.6 & $\leq .000^{*}$ & 14.2 & 11.2 & n.s. \\
\hline 2006 & 12.6 & 11.3 & n.s. & 16.6 & 14.0 & 10.3 & 2.7 & $\leq .000^{*}$ & 14.7 & 11.5 & $.049 *$ \\
\hline 2007 & 11.5 & 10.8 & n.s. & 15.2 & 13.1 & 10.1 & 2.2 & $\leq .000^{*}$ & 13.7 & 10.7 & n.s. \\
\hline 2008 & 11.6 & 10.6 & n.s. & 15.5 & 13.0 & 10.1 & 1.7 & $\leq .000^{*}$ & 13.6 & 10.6 & n.s. \\
\hline 2009 & 11.3 & 10.3 & n.s. & 15.1 & 12.3 & 10.1 & 1.8 & $\leq .000^{*}$ & 13.0 & 10.4 & n.s. \\
\hline 2010 & 11.2 & 10.5 & n.s. & 15.7 & 12.5 & 9.8 & 1.8 & $\leq .000^{*}$ & 13.0 & 10.5 & n.s. \\
\hline 2011 & 10.7 & 9.9 & n.s. & 14.4 & 11.9 & 9.4 & 1.7 & $\leq .000^{*}$ & 12.5 & 9.9 & n.s. \\
\hline 2012 & 11.2 & 9.7 & n.s. & 14.7 & 12.2 & 9.0 & 2.1 & $\leq .000^{*}$ & 12.2 & 10.1 & n.s. \\
\hline 2013 & 11.0 & 9.9 & n.s. & 14.5 & 12.33 & 9.3 & 1.8 & $\leq .000 *$ & 11.8 & 10.2 & n.s. \\
\hline 2014 & 10.6 & 9.7 & n.s. & 14.3 & 12.0 & 8.8 & 2.0 & $\leq .000^{*}$ & 12.1 & 9.8 & n.s. \\
\hline
\end{tabular}

${ }^{*} p<.05$, n.s.: not significant. 


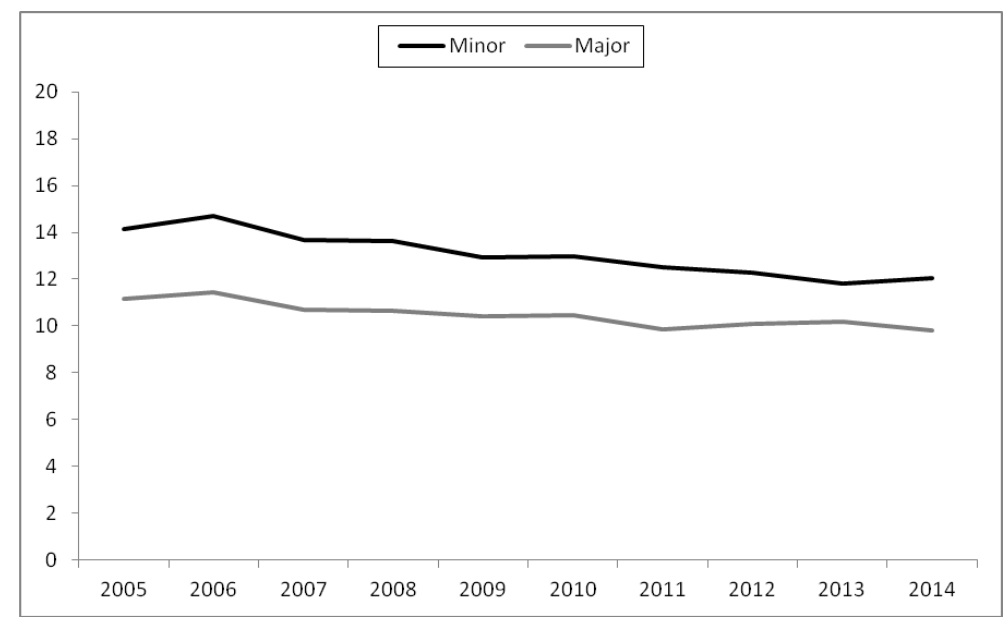

Figure 9.2 Effect of type of seizures on functional status.

Repeated measures were performed to test whether there was an effect for AEDtreatment over time, so throughout the 10 years, when controlling for age, level of ID and seizure type. There was no significant effect of time $(F=.487, p=.882)$ which shows that there is no change in $\mathrm{BI}$ scores across the ten year period. After adjusting for age, level of ID and seizure type, there was no significant difference on the BI between the AED-treatment groups $(F=.708, p=.401)$. The covariates age $(F=5.121, p=.025)$ and level of ID ( $F=109.219, p<.001)$ were significantly related with the change in Barthel scores during the study period while seizure type was not $(F=2.133, p=.146)$.

\section{Discussion}

Our study demonstrated that type of AED does not influence functioning in daily activities, even on the long-term. Although there was a consistent trend for AEDs with a high risk for cognitive or behavioural effects to have a lower functional status compared to 'low risk' AEDs, this did not reach the statistical significant level. Furthermore, the change in Barthel scores over the ten year period was not affected by AED regimen or type of seizures. Naturally, level of functional dependency decreases over time due to an increasing age and was, as expected, affected by level of ID. So, in comparison to the demographic effects of the patients and the effect of the epilepsy, AED treatment has no impact on the functional status in patients with epilepsy and ID.

Previous research showed a more severe level of functional dependence in AED users compared to non AED users ${ }^{20-23}$ but no distinction was made between different AEDs. Moreover, these studies included only patients aged 60 years and over and the AEDs 
were not only and solely used for epileptic seizures. Our study is the first that investigated the impact of different AEDs on functional status in patients with ID. We found no effect of AED treatment which is inconsistent with previous research in which a greater impairment of ADL is reported in AEDs such as PB, PHT and LEV. ${ }^{24,26}$ However, there is some inconsistency about specific AEDs effects on functional status in literature. $^{25,27}$ The demographic effects on dependence in ADL found in our study are in line with previous findings which showed that the degree of independence in ADL is primarily determined by level of $\mathrm{ID}^{11}$ and is influenced by age. ${ }^{26}$

In this study, we selected four 'high risk' AEDs based on previous research which were used throughout the longitudinal study period. These 'high risk' AEDs are used in polytherapy in this study population, which is a limitation of this study. However, reduced functional abilities were more observed in monotherapy than in polytherapy. ${ }^{22}$ Further research is needed in this area to provide a more thorough understanding of the long-term effects of AED treatment in people with epilepsy and ID. Presumably, the focus should then be on more subtle effects than the functional status that we studied. In conclusion, although there was a systematic trend for high risk medication to have a greater negative impact on functional status, chronic use of 'high risk' AEDs does not lead to a decline in functional status of patients with ID. Furthermore, type of epileptic seizures has no effect. The largest effects were found for demographic characteristics. Over time, a trend was found of lowering functional status, explained by increasing age and related with level of ID. Our main conclusion is that chronic AED use has no impact on the functional status in patients with ID and do not lead to a decline in ADL in this patient population. 


\section{Appendix}

\begin{tabular}{|c|c|}
\hline Barthel Index & \\
\hline Activity & Score \\
\hline Bowels & $0=$ incontinent \\
\hline & 1 = occasional accident \\
\hline & 2 = continent \\
\hline Bladder & $0=$ incontinent of catheter \\
\hline & 1 = occasional accident \\
\hline & 2 = continent \\
\hline Grooming & $0=$ needs to help with personal care \\
\hline & 1 = independent \\
\hline Toilet use & $0=$ independent \\
\hline & $1=$ needs some help \\
\hline & 2 = independent \\
\hline Bathing & $0=$ dependent \\
\hline & 1 = independent \\
\hline Feeding & $0=$ unable \\
\hline & $1=$ needs help (cutting or spreading) \\
\hline & 2 = independent \\
\hline Transfers (bed to chair and back) & $0=$ unable \\
\hline & $1=$ major help \\
\hline & $2=$ minor help \\
\hline & $3=$ independent \\
\hline Mobility & $0=$ immobile \\
\hline & $1=$ wheelchair dependent \\
\hline & $2=$ walks with help of one person \\
\hline & $3=$ independent \\
\hline Dressing & $0=$ dependent \\
\hline & $1=$ needs help but can do about half unaided \\
\hline & 2 = independent \\
\hline Stairs & $0=$ unable \\
\hline & $1=$ needs help \\
\hline & 2 = independent \\
\hline Maximum score & 20 \\
\hline
\end{tabular}




\section{References}

1. Bowley C, M Kerr. Epilepsy and intellectual disability. J Intellect Disabil Res 2000;44:529-43.

2. Robertson, J, Hatton C, Emerson E, Baines S. Prevalence of epilepsy among people with intellectual disabilities: a systematic review. Seizure 2015;29:46-62.

3. Jackson CF, Makin SM, Marson AG, Kerr M. Pharmacological interventions for epilepsy in people with intellectual disabilities. Cochrane Database Syst Rev 2015;3:CD005399.

4. Kwan P, Brodie MJ. Neuropsychological effects of epilepsy and antiepileptic drugs. Lancet 2001;357:216-22.

5. Alvarez N, Besag F, Livanainen M. Use of antiepileptic drugs in the treatment of epilepsy in people with intellectual disability. J Intellect Disabil Res 1998;42:1-15.

6. Brandt C, Lahr D, May TW. Cognitive adverse events of topiramate in patients with epilepsy and intellectual disability. Epilepsy Behav 2015;45:261-4.

7. Brunbech $L$, Sabers A. Effect of antiepileptic drugs on cognitive function in individuals with epilepsy: a comparative review of newer versus older agents. Drugs 2002;62:593-604.

8. Dinkelacker V, Dietl T, Widman G, Lengler U, Elger CE. Aggressive behavior of epilepsy patients in the course of levetiracetam add-on therapy: report of 33 mild to severe cases. Epilepsy Behav 2003;4: 537-47.

9. Helmstaedter C, Fritz NE, Kockelmann E, Kosanetzky N, Elger CE. Positive and negative psychotropic effects of levetiracetam. Epilepsy Behav 2008;13:535-41.

10. Cohen ME, Marino RJ. The tools of disability outcomes research functional status measures. Arch Phys Med Rehabil 2000;81:S21-9.

11. Hilgenkamp TI, van Wijck R, Evenhuis HM. (Instrumental) activities of daily living in older adults with intellectual disabilities. Res Dev Disabil 2011;32:1977-87.

12. Mahoney FI, Barthel DW. Functional evaluation: the Barthel Index. Md State Med J 1965;14:61-5.

13. Brazil L, Thomas R, Laing R, Hines F, Guerro D, Ashley S, et al. Verbally administered Barthel Index as functional assessment in brain tumour patients. J Neurooncol 1997;34:187-92.

14. Grant R, Slattery J, Gregor A, Whittle IR. Recording neurological impairment in clinical trials of glioma. J Neurooncol 1994;19:37-49.

15. Herman MA, Tremont-Lukats I, Meyers CA, Trask DD, Froseth C, Renschler MF, et al. Neurocognitive and functional assessment of patients with brain metastases: a pilot study. Am J Clin Oncol 2003;26:273-9.

16. Jalali R, Dutta D, Kamble R, Gupta T, Munshi A, Sarin R, et al. Prospective assessment of activities of daily living using modified Barthel's Index in children and young adults with low-grade gliomas treated with stereotactic conformal radiotherapy. J Neurooncol 2008;90:321-8.

17. Hsueh IP, Lin JH, Jeng JS, Hsieh CL. Comparison of the psychometric characteristics of the functional independence measure, 5 item Barthel index, and 10 item Barthel index in patients with stroke. J Neurol Neurosurg Psychiatry 2002;73:188-90.

18. van der Putten JJ, Hobart JC, Freeman JA, Thompson AJ. Measuring change in disability after inpatient rehabilitation: comparison of the responsiveness of the Barthel index and the Functional Independence Measure. J Neurol Neurosurg Psychiatry 1999;66:480-4.

19. Guldvog B, Løyning Y, Hauglie-Hanssen E, Flood S, Bjørnaes H. Surgical versus medical treatment for epilepsy II. Outcome related to social areas. Epilepsia 1991;32:477-86.

20. Cabrera MA, Dellaroza MS, Trelha CS, Paccola LB, da Cruz Domiciano Perdigão S, de Barros Pinto ME, et al. Psychoactive drugs as risk factors for functional decline among noninstitutionalized dependent elderly people. J Am Med Dir Assoc. 2010;11:519-22.

21. Galimberti CA, Magri F, Magnani B, Arbasino C, Cravello L, Marchioni E, et al. Antiepileptic drug use and epileptic seizures in elderly nursing home residents: a survey in the province of Pavia, Northern Italy. Epilepsy Res 2006;68:1-8.

22. Galimberti CA, Tartara E, Dispenza S, Marchese D, Bonizzoni, E, Perucca E. Antiepileptic drug use and epileptic seizures in nursing home residents in the Province of Pavia, Italy: A reappraisal 12 years after a first survey. Epilepsy Res 2016;119:41-8. 
23. de Oliveira FF, Bertolucci PH, Chen ES, Smith Mde A. Pharmacological modulation of cognitive and behavioral symptoms in patients with dementia due to Alzheimer's disease. J Neurol Sci 2014;336: 103-8.

24. Dinapoli L, Maschio M, Jandolo B, Fabi A, Pace A, Sperati F, et al. Quality of life and seizure control in patients with brain tumor-related epilepsy treated with levetiracetam monotherapy; preliminary data of an open-label study. Neurol Sci 2009;30:353-9.

25. Consoli D, Bosco D, Postorino P, Galati F, Plastino M, Perticoni G.F, et al. Levetiracetam versus carbamazepine in patients with late poststroke seizures: a multicenter prospective randomized openlabel study. Cerebrovasc Dis 2012;34:282-9.

26. Goldstein LB. Common drugs may influence motor recovery after stroke. Neurology 1995;45:865-71.

27. Towanabut S, Rungreangyingyod L, Suthisisang C. Efficacy and safety of gabapentin as add-on therapy in refractory partial epileptic patients. J Med Assoc Thai. 2001;84:554-61. 


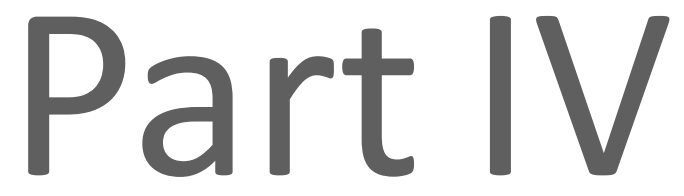

AEDs and the brain 


\section{Chapter}

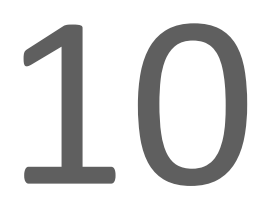

\section{Glutamate concentrations vary with antiepileptic drug use and mental slowing}

TM van Veenendaal, DM IJff, AP Aldenkamp, RH Lazeron, NAJ Puts, RAE Edden, PA Hofman, AJA de Louw, WA Backes \& JFA Jansen Epilepsy Behav. 2016;64:200-205 


\section{Abstract}

\section{Objective}

Although antiepileptic drugs (AEDs) are effective in suppressing epileptic seizures, they also induce (cognitive) side effects, with mental slowing as general effect. This study aimed to assess whether concentrations of MR detectable neurotransmitters, glutamate and GABA, are associated with mental slowing in patients with epilepsy taking AEDs.

\section{Methods}

Cross-sectional data were collected from patients with localization-related epilepsy using a variety of AEDs from three risk categories, i.e. AEDs with low, intermediate, and high risks for developing cognitive problems. Patients underwent 3T MR spectroscopy, including a PRESS $(n=55)$ and MEGA-PRESS $(n=43)$ sequence, to estimate occipital glutamate and GABA concentrations, respectively. The association was calculated between neurotransmitter concentrations and central information processing speed, which was measured using the Computerized Visual Searching Task (CVST), and compared between the different risk categories.

\section{Results}

Combining all groups, patients with lower processing speeds had lower glutamate concentrations. Patients in the high risk category had a lower glutamate concentration and lower processing speed compared with patients taking low risk AEDs. Patients taking intermediate risk AEDs also had a lower glutamate concentration compared with patients taking low risk AEDs, but processing speed did not differ significantly between those groups. No associations were found between the GABA concentration and risk category or processing speed.

\section{Conclusion}

For the first time a relation is shown between glutamate concentration and both mental slowing and AED use. It is suggested that the reduced excitatory action, reflected by lowered glutamate concentrations, may have contributed to the slowing of information processing in patients using AEDs with higher risks for cognitive side effects. 


\section{Introduction}

Although antiepileptic drugs (AEDs) are effective in suppressing epileptic seizures, they may also induce side effects. These side effects can strongly affect the quality of life of patients, with slowing of central information processing speed as dominant cognitive effect of most AEDs and also the first sign of cognitive adverse effects. ${ }^{1,2}$ Cognitive side effects are commonly seen among the different AED regimes, but the occurrence and severity varies between different AEDs. The newer AEDs lamotrigine and levetiracetam are suggested to have no adverse, and maybe even beneficial, cognitive effects, while topiramate is known for its deleterious cognitive effects. Other AEDs, such as valproate or carbamazepine, are associated with milder cognitive effects. ${ }^{1,3,4}$

AEDs aim to control for epileptic seizures via a number of distinct mechanisms of action, which can be subdivided in suppression of the excitatory mechanisms or enhancement of inhibitory mechanisms. ${ }^{5}$ Although cognitive side effects are likely to result from the anticonvulsant activity of the AEDs, these effects cannot be linked to any particular mechanism of action, and other mechanisms might be involved as well. ${ }^{6}$ It has been hypothesized that especially AEDs with mechanisms acting on the $\gamma$ aminobutyric acid (GABA) system cause cognitive side effects, but similar side effects are also induced by AEDs with other mechanisms of action. ${ }^{7}$ Furthermore, it is currently not possible to predict which patients will suffer from these side effects and who will not. However, compliance to AED therapy relies on efficacy as well as tolerance to side effects.

In vivo measurements of the main inhibitory and excitatory neurotransmitters GABA and glutamate can be provided by proton magnetic resonance spectroscopy ( $\left.{ }^{1} \mathrm{H}-\mathrm{MRS}\right)$. In healthy individuals, higher GABA concentrations and lower glutamate concentrations have been associated with better cognitive performance. ${ }^{8-10}$ Previous studies also showed that AED treatment can be associated with altered neurotransmitter concentrations. ${ }^{11}$ Although several studies have been performed to associate GABA and glutamate concentrations with seizure control, ${ }^{12-14}$ to our knowledge the association with cognitive side effects has not been investigated yet. The aim of this cross-sectional study was to assess whether GABA and glutamate concentrations can be linked to cognitive functioning, in terms of decreased processing speed, in epilepsy patients on long-term AED treatment.

\section{Methods}

\section{Patients}

Patients with localization-related epilepsy, recruited from our tertiary epilepsy referral center, were included in this study. Inclusion criteria were an age between 18 and 
70 years and no contra-indications for MRI (metal implants, claustrophobia, or pregnancy). This study was approved by the local Medical Ethical Committee and written informed consent was obtained from all patients before the examination.

To obtain a variation in information processing speed, three groups of patients using different AEDs were included. The groups were defined according to Samarasekera and collegaues, ${ }^{15}$ based on the known risk for developing cognitive side effects: a low risk category (levetiracetam and lamotrigine), an intermediate risk category (valproate, carbamazepine, oxcarbazepine and phenytoin), and a high risk category (topiramate). Both patients on mono- as polytherapy were included, but patients took maximal two different AEDs. Patients on polytherapy were classified according to the AED in the highest risk category.

\section{Neuropsychological investigation}

Information processing speed was used as a measure for cognitive side effects, as slowing of central information processing speed is the most common side-effect of AEDs. ${ }^{2}$ For this, the Computerized Visual Searching Task (CVST) was used. ${ }^{16}$ In this task, a centered grid pattern has to be compared to 24 surrounding grid patterns. Participants have to find the grid pattern identical to the centered pattern. The score is the average time needed to complete this task. Additionally, as global cognitive abilities are assumed to be unaffected by AEDs, ${ }^{2}$ the Raven Standard Progressive Matrices was performed to correct for possible variation in cognitive abilities between the patients. ${ }^{17}$ This is a non-verbal reasoning test, in which participants have to identify the figure that is required to fulfill a series of eight other figures.

\section{Data acquisition}

MR data were acquired on a 3.0T MR scanner equipped with an 8-channel head coil (Philips Achieva, Philips Medical Systems, Best, the Netherlands). Glutamate concentrations were measured using a PRESS sequence $\left(T_{E} / T_{R}: 35 / 2000 \mathrm{~ms}\right.$, 128 averages, VAPOR water suppression). GABA edited MR spectra were acquired using a MEGA-PRESS sequence $\left(T_{E} / T_{R} 68 / 2000 \mathrm{~ms}, 320\right.$ averages, with editing pulses at 1.9 (ON) and $7.46 \mathrm{ppm}$ (OFF) interleaved in 40 blocks, MOIST water suppression). Both spectra were acquired from the same $3 \times 3 \times 3 \mathrm{~cm}^{3}$ voxel located around the parietooccipital sulcus (Figure 10.1). This location has an optimal signal-to-noise and is commonly selected in MRS studies. ${ }^{18}$ To estimate the water signal, separate scans without water suppression were made directly after the PRESS and MEGA-PRESS scans (with $T_{E} / T_{R} 35 / 2000 \mathrm{~ms}$ and 128 averages, or $T_{E} / T_{R} 68 / 2000 \mathrm{~ms}$ and 8 averages, respectively). Additionally, a T1-weighed scan was made to determine the voxel composition (voxel size $1 \times 1 \times 1 \mathrm{~mm}$, flip angle $8^{\circ}, 3 \mathrm{D}$ fast spoiled gradient echo sequence, $T_{E} / T_{1} / T_{R} 4.8 / 1022 / 8.3 \mathrm{~ms}, 180$ slices). 
A

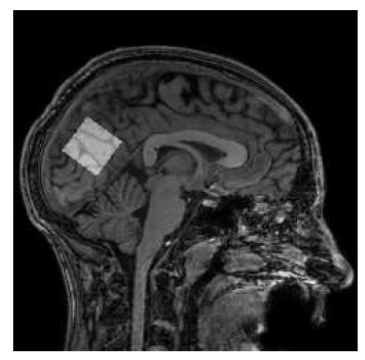

B

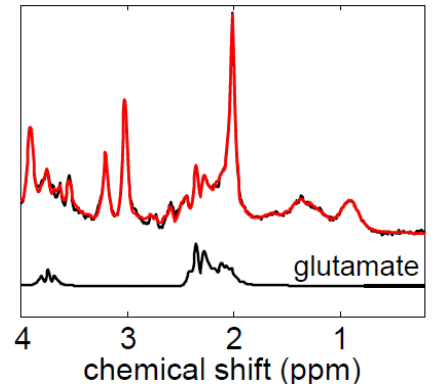

C

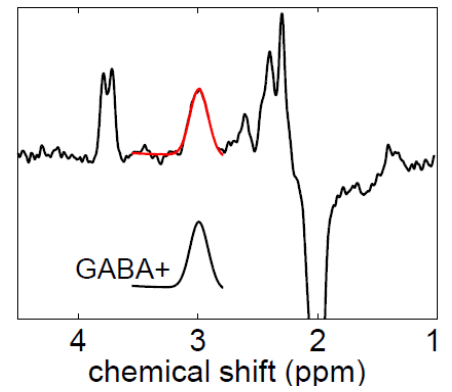

Figure 10.1 Example of the voxel placement (A), a PRESS spectrum with the LCModel fit (in red), which fits a linear combination of metabolite spectra (B), and a MEGA-PRESS spectrum with the GANNET fit (in red), which only fits the GABA+ peak (GABA + co-edited macromolecules) (C). Individual glutamate or GABA fits are displayed in the figures as well.

\section{Data analysis}

PRESS spectra were analyzed using LCModel (version 6.3-1L). LCModel fits the spectrum with a linear combination of individual metabolite spectra. ${ }^{19} \mathrm{~A}$ standard basis set with sixteen different simulated metabolite spectra was used in this analysis and spectra were analyzed within the resonance frequency range from 0.2 to $4.0 \mathrm{ppm}$. In addition to glutamate, tNAA ( $\mathrm{N}$-acetyl aspartate $+\mathrm{N}$-acetylaspartylglutamate), tCho (phoshporylcholine + glycerophosphorylcholine), and tCr (creatine + phosphocreatine) concentration estimates were collected for further analyses.

Gannet (version 2.0) was used for the preprocessing and quantification of the GABA+ concentration (i.e. GABA and co-edited macromolecules). ${ }^{20}$ The GABA peak is fitted to a Gaussian model curve. Gannet is designed for GABA+ quantification, but also enables Glx quantification from MEGA-PRESS spectra. ${ }^{21}$ Gannet has the advantage that it also includes frequency and phase corrections. ${ }^{22,23}$ MEGA-PRESS scans are more vulnerable for field drifts and movement artefacts than typical PRESS scans due to addition of an editing pulse and subtraction of ON and OFF scans to obtain difference spectra, potentially leading to subtraction artifacts. Frequency correction can reduce quantification errors. ${ }^{22}$ All spectra were visually inspected on subtraction artifacts and adequate noise levels.

Repeatability of these methods was tested in five healthy volunteers (age $29 \pm 4$ year, four male), who underwent two PRESS and MEGA-PRESS scans immediately after each other. The results showed a coefficient of variation of $2.1 \%, 5.6 \%$ and $3.9 \%$ for glutamate (using PRESS/LCModel), Glx (using MEGA-PRESS/Gannet) and GABAt, respectively. Because of the better coefficient of variation of glutamate estimations with PRESS than Glx estimations with MEGA-PRESS, and because of a moderate concordance between these measurements in the included patients (Pearson 
correlation coefficient $=0.31, p=0.046$ ), only glutamate measurements with PRESS were considered in this study.

All concentrations are reported relative to the unsuppressed water signal from the same volume. FMRIB's Automated Segmentation Tool (FAST), part of FSL (version 5.0.1), was applied to determine the voxel composition in terms of grey matter, white matter, and cerebral spinal fluid (CSF) content. ${ }^{24,25}$ Assuming that the neurometabolites are only present in the grey and white matter, the concentrations relative to the water signal were corrected for the CSF content of the voxel. Therefore, the neurometabolite concentrations were divided by the sum of the grey and white matter fractions.

\section{Statistical analysis}

Associations between the neurometabolite concentrations (i.e. glutamate, GABAt, tNAA, tCho, and $\mathrm{tCr}$ ) and CVST were tested with linear regression analysis, with CVST as dependent variable and the concentrations as independent variables. Separate analyses were performed for each neurometabolite. Besides the neurometabolite concentration, age and the percentage correct answers in the Raven test (as measure for intelligence) were added to these analyses as independent variables, as the information processing speed usually correlates with age and cognitive abilities.

To test whether the neurometabolite concentrations varied with risk degree an ANCOVA (analysis of covariance) test was applied, with the neurometabolite concentrations as outcome variable and the risk categories as fixed factors. Covariates in the analyses were age, gender, and the grey matter fraction in the voxel (grey matter fraction divided by the sum of the white and grey matter fractions). In case of significant group effects, post-hoc tests (Students t-tests) were applied to test for individual group differences.

To check for possible confounding effects, the analyses were repeated with drug load (defined as the ratio of the prescribed daily dose to the defined daily dose ${ }^{26}$ ), having symptomatic epilepsy, or epilepsy severity added as additional covariate. Epilepsy severity was defined by a composed score ranging from 0-7 based on seizure type (tonic-clonic:1, other:0), previous occurrence of status epilepticus (yes:1, no:0), seizurerelated injury (yes:1, no:0), and seizure frequency (seizure free:0, yearly:1, monthly:2, weekly:3, daily:4). In all analyses, $p$-values $<0.05$ were considered significant.

\section{Results}

\section{Patient characteristics}

Fifty-eight patients were included in this study. Three of these patients did not finish the MRI examination due to claustrophobia, resulting in suitable data of 55 patients for further analysis. Seventeen of the 55 patients had symptomatic epilepsy. MRI lesions 
included cerebral athrophy (6), cortical dysplasia's (5), infarctions (3), malformations (1), tumors (1), and cysts (1). The remaining 38 patients had non-symptomatic epilepsy.

The low and intermediate risk group differed significantly age and drug load (Table 10.1). Furthermore, the number of patients taking polytherapy was significantly higher in the intermediate and high risk category than in the low risk category. Patients in the different risk categories did not differ significantly in educational level, seizure frequency, epilepsy severity score, or years since epilepsy onset.

The CVST reaction time ranged from 7.3 to $30.8 \mathrm{~s}$ (mean $\pm \mathrm{sd}$ in a normal adult population: $10.3 \pm 4.1 \mathrm{~s}$ [26]). Both the patients taking intermediate-risk as high risk AEDs had a significantly lower processing speed compared with patients taking low-risk AEDs ( $p=0.003$ and $p=0.042$, respectively, Table 10.1). When age, gender, and the percentage correct answers in the Raven test were added as covariates to this analysis (ANCOVA), there was a significant effect of risk category $(p=0.009)$. Post-hoc tests revealed a significant longer CVST reaction time in the intermediate $(p=0.035$, adjusted mean difference $3.5 \mathrm{~s}$ ), and in the high risk category ( $p=0.004$, adjusted mean difference $7.8 \mathrm{~s}$ ), compared with patients taking low risk AEDs. The CVST reaction time did not differ significantly between the intermediate and high risk group. All participants had a Raven score above the $5^{\text {th }}$ percentile of a normal, age-matched adult population, and the Raven score was not significantly different between the groups.

\section{Spectroscopy results}

The quality of the PRESS spectra was adequate in all patients. Visual inspection did not reveal spectra of insufficient quality, all spectra had a signal-to-noise ratio above 20, and the Cramér-Rao lower bounds (CRLB) of glutamate were below $10 \%$. Forty-three MEGA-PRESS spectra were included in the statistical analysis (15 from the low risk group, 26 from the intermediate risk group, and 2 from the high risk group). In four patients, no MEGA-PRESS data were available because of acquisition problems, and another eight MEGA-PRESS scans were excluded due to insufficient quality of the spectrum. The error of the GABA fit was below $15 \%$ in the remaining spectra, while the mean absolute drift of the water peak between two subsequent blocks was $0.009 \pm 0.004$ ppm.

Across all participants, the glutamate and GABA concentrations were $9.3 \pm 0.8$ i.u. (institutional units) and $1.7 \pm 0.4$ i.u., respectively (mean $\pm \mathrm{sd}$ ). tNAA, tCr, and tCho concentrations were $9.0 \pm 0.5$ i.u., $6.8 \pm 0.6$ i.u., and $1.2 \pm 0.2$ i.u., respectively.

The CVST reaction time was significantly associated with glutamate concentration ( $\beta=-3.1, p=0.001$, with correction for age and global intelligence), indicating that patients with a lower processing speed had a lower glutamate concentration (Figure 10.2). The CVST reaction time was not significantly associated with the GABA $(p=0.45)$, tNAA ( $p=0.99), \operatorname{tCr}(p=0.82)$, or tCho $(p=0.13)$ concentrations. 
Table 10.1 Patient characteristics for the three risk categories ${ }^{\mathrm{a}}$. Results are displayed for the participants included in the PRESS analysis.

\begin{tabular}{|c|c|c|c|}
\hline & $\begin{array}{c}\text { Low risk } \\
(n=16)\end{array}$ & $\begin{array}{c}\text { Intermediate risk } \\
(n=34)\end{array}$ & $\begin{array}{c}\text { High risk } \\
(n=5)\end{array}$ \\
\hline \multicolumn{4}{|l|}{ General } \\
\hline Male/female & $5 / 11(31 / 69 \%)$ & $16 / 18(47 / 53 \%)$ & $0 / 5(0 / 100 \%)$ \\
\hline Age (years) ${ }^{\text {b }}$ & $39.5 \pm 13.4$ & $50.7 \pm 12.5^{*}$ & $42.4 \pm 15.8$ \\
\hline Educational level $^{c}$ & 5 (range $2-6$ ) & 5 (range $2-7$ ) & 5 (range 4-6) \\
\hline \multicolumn{4}{|l|}{ Epilepsy-related } \\
\hline Symptomatic/non-symptomatic & $2 / 14(13 / 88 \%)$ & $15 / 19(44 / 56 \%)$ & $0 / 5$ \\
\hline \multicolumn{4}{|l|}{ Seizure frequency } \\
\hline Weekly & 0 & $1(3 \%)$ & 0 \\
\hline Monthly & $4(25 \%)$ & $3(9 \%)$ & 0 \\
\hline Yearly & $2(13 \%)$ & $6(18 \%)$ & $2(40 \%)$ \\
\hline Seizure free & $10(63 \%)$ & $24(71 \%)$ & $3(60 \%)$ \\
\hline Years since epilepsy onset ${ }^{b}$ & $22.7 \pm 11.7$ & $30.4 \pm 13.4$ & $26.8 \pm 23.3$ \\
\hline Epilepsy severity score ${ }^{\mathrm{b}}$ & $1.4 \pm 0.8$ & $1.2 \pm 1.0$ & $1.0 \pm 0.7$ \\
\hline \multicolumn{4}{|l|}{ AED-related } \\
\hline Mono-/polytherapy & $16 / 0$ & $8 / 26(24 / 77 \%)^{*}$ & $3 / 2(60 / 40 \%)^{\dagger}$ \\
\hline \multicolumn{4}{|l|}{ Medication type } \\
\hline $\mathrm{CBZ}$ & 0 & $17(50 \%)$ & $1(20 \%)$ \\
\hline LEV & $7(44 \%)$ & $6(18 \%)$ & 0 \\
\hline LTG & $9(56 \%)$ & $10(29 \%)$ & $1(20 \%)$ \\
\hline OXC & 0 & $4(12 \%)$ & 0 \\
\hline PHT & 0 & $16(47 \%)$ & 0 \\
\hline TPM & 0 & 0 & $5(100 \%)$ \\
\hline VPA & 0 & $7(21 \%)$ & $1(20 \%)$ \\
\hline Drug load $d^{b, d}$ & $1.3 \pm 0.6$ & $1.8 \pm 0.7^{*}$ & $1.2 \pm 1.0$ \\
\hline \multicolumn{4}{|l|}{ Neuropsychological results } \\
\hline CVST reaction time $^{\mathrm{b}}$ & $11.5 \pm 2.9$ & $15.7 \pm 6.4^{*}$ & $20.2 \pm 6.7^{\dagger}$ \\
\hline Raven $\left(\%\right.$ correct answers) ${ }^{b}$ & $71.7 \pm 10.3 \%$ & $73.2 \pm 10.1 \%$ & $71.7 \pm 3.1 \%$ \\
\hline
\end{tabular}

Differences between the risk groups were tested using a Fisher's exact test (gender, symptomatic epilepsy, mono/polytherapy), a Mann-Whitney test (educational level, seizure frequency, epilepsy severity score), or a student's t-test (all remaining variables). "indicates significant differences between the low and intermediate risk category $(p<0.05)$; ${ }^{\dagger}$ indicates differences between the low and high risk category $(p<0.05) .{ }^{a}$ Low risk: lamotrigine (LTG), levetiracetam (LEV); Intermediate risk: valproate (VPA), carbamazepine (CBZ), oxcarbazepine (OXC) and phenytoin (PHT); High risk: topiramate (TPM); ${ }^{b}$ mean \pm standard deviation; ${ }^{c}$ Median (range). Scores are according to Verhage (1964), range 1 (did not finish primary school) to 7 (Master's degree); ${ }^{\mathrm{d}}$ The drug load is defined as the ratio of the prescribed daily dose to the defined daily dose (26)

The glutamate and GABA concentrations are illustrated for the different groups in Figure 10.3. A significant effect of cognitive risk category on the glutamate concentration was observed ( $p=0.028$, ANCOVA, with age, gender, and grey matter fraction as covariates). Post-hoc tests showed a significantly lower glutamate concentration in the intermediate risk category than in the low risk category $(p=0.021$, adjusted mean difference 0.49 ) and in the high compared with the low risk category $(p=0.032$, adjusted mean difference 0.72 ). The intermediate and high risk categories did not differ significantly in the glutamate concentrations $(p=0.47)$. Risk category did not 
have a significant effect on the GABA $(p=0.83)$, tNAA $(p=0.47)$, tCho $(p=0.085)$, or tCr $(p=0.17)$ concentration.

The additional analyses, with epilepsy severity score, drug load, or having symptomatic epilepsy added as covariates, showed comparable results as the analyses without these additional covariates ( $<10 \%$ change in effect size). Furthermore, epilepsy severity, drug load, or having symptomatic epilepsy were not significant covariates in any of the analyses.

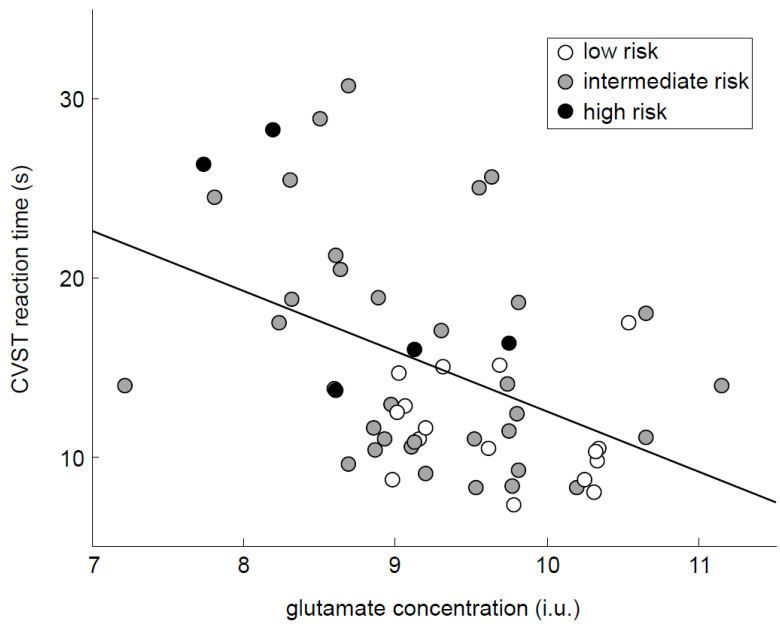

Figure 10.2 Association of the glutamate concentration and CVST reaction time.

Patients with lower glutamate concentrations, had a longer CVST reaction time, i.e. a lower processing speed, than patients with higher glutamate concentrations. The depicted line represents the uncorrected linear regression estimate to guide the eye. This association remained significant after correction for age and global intelligence $(\beta=-3.1, p=0.001)$. From the graph it can be noticed that patients taking low risk AEDs (open circles), had high glutamate concentrations and low CVST reaction times, while lower glutamate concentrations and higher CVST reaction times were only measured in patients taking intermediate (grey circles) or high risk (black circles) AEDs. CVST: computerized visual searching task. 
A

glutamate

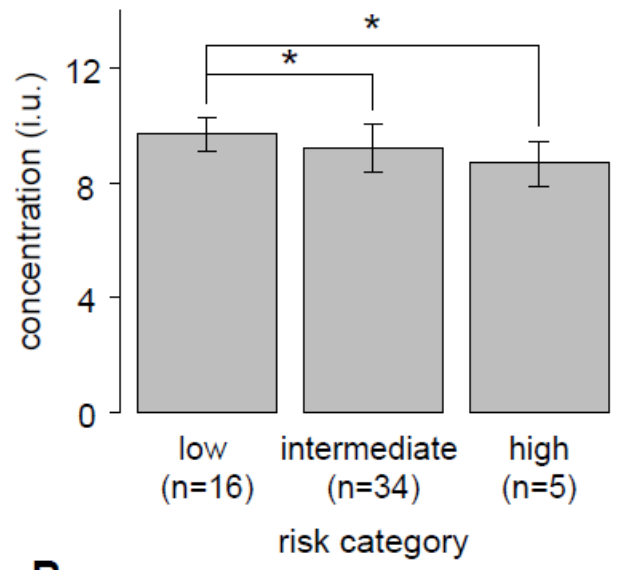

B

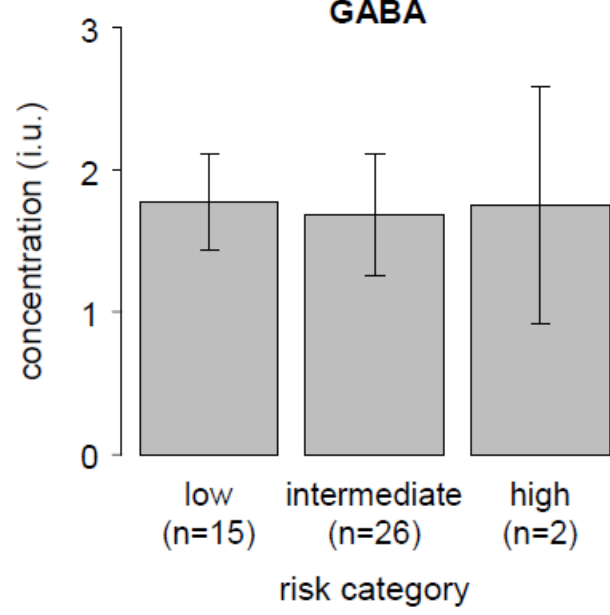

Figure 10.3 Glutamate (A) and GABA (B) concentrations for the three risk groups.

Concentrations are relative to the water concentration, corrected for the cerebral spinal fluid content of the voxel, and displayed in institutional units. Low risk category: lamotrigine or levetiracetam; Intermediate risk category: carbamazepine, oxcarbazepine, phenytoin or valproate; High risk category: topiramate. Standard deviations are displayed with error bars. * indicate significant differences $(p<0.05)$, when adjusted for age, gender, and grey matter fraction. 


\section{Discussion}

This study assessed associations between neurotransmitter concentrations, AED treatment, and cognitive functioning in patients with epilepsy. Lower glutamate concentrations were associated with a lower processing speed, the most common type of drug-induced cognitive impairment. Furthermore, patients taking AEDs from higher risk category had lower glutamate concentrations than patients taking AEDs from lower risk categories. No significant associations were found between the GABA+ concentration and risk category or processing speed.

\section{Glutamate concentrations and cognitive slowing}

To our knowledge, this is the first study showing associations between neurotransmitter concentrations and drug-induced cognitive side effects (i.e. mental slowing) in patients with epilepsy. Studies in other diseases did also show associations between the glutamate concentration and cognitive functioning, but the variety of the applied cognitive tests is large, and both positive and negative associations have been found. ${ }^{27}$ Different explanations are proposed for these associations. For instance, it is hypothesized that neurotoxic effects of high glutamate concentrations affect cognitive functioning, ${ }^{28}$ that a higher GABA/glutamate concentration improves decision-making, ${ }^{8}$ or that glutamate concentration acts as a marker for neuronal integrity. ${ }^{29}$ Precise associations between glutamate and cognitive function and the underlying mechanisms may depend on the specific disease and cognitive functions being studied.

The glutamate concentration measured by MRS is a combination of glutamate functioning as neurotransmitter and glutamate stored in synaptic vesicles and metabolic pools. Although the precise mechanisms are unknown, the glutamate concentration appears to be roughly linearly related to excitatory activity, possibly due to its involvement in the glucose metabolism in the brain. ${ }^{30,31}$ As AEDs generally tend to suppress (abnormal) brain activity, ${ }^{5}$ it seems likely that the lower glutamate concentrations in this study reflect more suppressed brain activity, which may be associated with a slowing of information processing at the downside of this effect.

\section{AED use and glutamate concentrations}

Although differences in glutamate concentrations were observed between the different risk category, none of the known mechanisms of action of AEDs are likely to affect the glutamate concentration directly. ${ }^{5}$ However, it is possible that modulation of the sodium channels, seen in PHT, CBZ, OXC, TPM, and VPA, which blocks high frequency repetitive action potentials, indirectly decrease the glutamate release. Three previous longitudinal studies showed no changes in the Glx concentration (glutamate and its precursor glutamine combined) after VPA use, or glutamate concentrations after TPM or LEV use, ${ }^{32-34}$ AEDs which were also used in the current study. Taken together, the 
current study does not provide evidence that AEDs from different risk categories alter glutamate concentrations directly, but the results do suggest a link between glutamate concentration and mental slowing due to AED use.

\section{GABA}

In this study, no associations were found between the GABA concentration and information processing speed or cognitive risk category, in contrast to the hypothesized involvement of GABAergic mechanisms in cognitive side effects of AEDs. ${ }^{7,35}$ Existing associations might have been undetected in this study due to the small group size. Due to exclusion of MEGA-PRESS spectra, this group size was smaller compared with the other results ( $n=43$ versus $n=55$ ). Also confounding effects of the different AEDs might have had different effects on the GABA concentration. For instance, both TPM and LTG are suggested to increase the GABA concentration, but a higher increase was reported with TPM use than with LTG use. ${ }^{36}$ Using the current clinical study design, it is not feasible to assess distinct effects of the different AEDs, due to the many different combinations of AEDs which were being used by the included patients. However, it cannot be excluded that for individual AEDs, also GABA concentrations are associated with cognitive functioning.

\section{Other neurometabolites}

tNaa, tCho, and tCr concentrations were not significantly associated with CVST reaction time nor risk group in this study, while previous studies did show associations with for example NAA and information processing speed ${ }^{37}$ or executive functioning ${ }^{38}$ in healthy elderly populations. Age-specific mechanisms may underlie these associations, that cannot be generalized to other study populations. For instance, NAA is considered a marker for neuronal integrity and is often associated with cognitive functioning. However, cognitive side effects of AED use are reversible, and therefore not likely to be accompanied by neuronal cell damage as might be the case in aging. Previous studies have not reported associations with $\mathrm{tNAA}$, tCho, or tCr and AED use. ${ }^{11}$

\section{Study considerations}

This study was performed in patients with epilepsy on long-term AED treatment, which is most relevant for clinical practice. However, adherent to these studies is the heterogeneity of the study population and the different combinations of AEDs that were taken. An important possible confounder in this study is whether patients were on mono- or polytherapy, which largely coincides with taking AEDs from the low- or intermediate risk category. Importantly, polytherapy itself is already associated with higher risk on cognitive side effects. ${ }^{39}$ It can furthermore not be excluded that both glutamate concentrations and processing speed were affected by epilepsy 
characteristics or underlying causes rather than AED use. Future studies are needed to distinguish these factors, and to clarify the precise, causal relationship between neurotransmitter concentrations, AED use, and cognitive side effects.

Because of its negative cognitive side effects, topiramate is not commonly prescribed in our epilepsy center. This resulted in a limited number of patients taking high risk AEDs in this study, but the results of this group are in line with the results from the intermediate risk category. The lack of significant differences between the intermediate and high risk category might therefore be due to the small group size of the high risk category.

The MRS measurements used in this study showed good repeatability. However, the low concordance between glutamate estimations from PRESS and Glx from MEGAPRESS is striking. A possible explanation is the presence of macromolecules in one of these spectra, but future studies are prompted to investigate this topic. A final consideration regarding MRS measurements is the voxel location. As in many previous studies, the occipital lobe was chosen because it gives the best signal-to-noise ratio. ${ }^{18,22}$ However, regions important for cognitive processes include the prefrontal cortex and subcortical structures, and not the occipital lobe. ${ }^{40}$ Currently, it remains to be determined whether relevant spatial variations exist in the neurotransmitter concentrations in relation to adverse cognitive effects.

\section{Future perspectives}

Currently, it is not possible to predict which patients will or will not suffer from these side effects, while this would aid clinical decision making. The results of this study show potential of glutamate measurements as a candidate biomarker. In order to predict these side effects, it is necessary to first longitudinally assess changes in neurotransmitter concentration, to see whether the differences in glutamate levels possibly precede the cognitive problems or coincide with the cognitive problems.

\section{Conclusions}

For the first time a relation is shown between the lowered glutamate concentration and both AED use and mental slowing in patients with epilepsy. This observation hints at a possible contribution to a neurobiological mechanism of mental slowing due to AED use. More knowledge about this relation might help to explain why some patients with epilepsy experience cognitive side effects while the cognitive function of other patients is not affected by AEDs. Future studies with MRS and AEDs are warranted to further elucidate more details of underlying mechanisms. 


\section{References}

1. IJff DM, Aldenkamp AP. Cognitive side-effects of antiepileptic drugs. Handb Clin Neurol. 2013;111: 707-8.

2. Grevers E, Breuer LE, DM IJ, Aldenkamp AP. Mental slowing in relation to epilepsy and antiepileptic medication. Acta Neurol Scand 2015.

3. Luoni C, Bisulli F, Canevini MP, De Sarro G, Fattore C, Galimberti CA, et al. Determinants of healthrelated quality of life in pharmacoresistant epilepsy: results from a large multicenter study of consecutively enrolled patients using validated quantitative assessments. Epilepsia 2011;52: 2181-91.

4. Fisher RS, Vickrey BG, Gibson P, Hermann B, Penovich P, Scherer A, et al. The impact of epilepsy from the patient's perspective II: views about therapy and health care. Epilepsy Research 2000;41: 53-62.

5. Rogawski MA, Loscher W. The neurobiology of antiepileptic drugs. Nat Rev Neurosci 2004;5: 553-64.

6. Hamed SA. The aspects and mechanisms of cognitive alterations in epilepsy: the role of antiepileptic medications. CNS Neurosci Ther 2009;15: 134-56.

7. Sankar R, Holmes GL. Mechanisms of Action for the Commonly Used Antiepileptic Drugs: Relevance to Antiepileptic Drug--Associated Neurobehavioral Adverse Effects. Journal of Child Neurology 2004;19: S6-S14.

8. Jocham G, Hunt LT, Near J, Behrens TE. A mechanism for value-guided choice based on the excitationinhibition balance in prefrontal cortex. Nat Neurosci 2012;15: 960-1.

9. Sandberg K, Blicher JU, Dong MY, Rees G, Near J, Kanai R. Occipital GABA correlates with cognitive failures in daily life. Neuroimage 2014;87: 55-60.

10. Sumner P, Edden RA, Bompas A, Evans CJ, Singh KD. More GABA, less distraction: a neurochemical predictor of motor decision speed. Nat Neurosci 2010;13: 825-7.

11. Veenendaal TM, IJff DM, Aldenkamp AP, Hofman PA, Vlooswijk MC, Rouhl RP, et al. Metabolic and functional MR biomarkers of antiepileptic drug effectiveness: A review. Neurosci Biobehav Rev 2015;59: 92-9.

12. Mueller S, Weber O, Duc C, Weber B, Meier D, Russ W, et al. Effects of Vigabatrin on Brain GABA+/CR Signals in Patients with Epilepsy Monitored by $1 \mathrm{H}-\mathrm{NMR}-\mathrm{Spectroscopy}$ : Responder Characteristics. Epilepsia 2001;42: 29-40.

13. Mueller S, Weber O, Duc C, Meier D, Russ W, Boesiger $P$, et al. Effects of vigabatrin on brain $G A B A+/ C r$ signals in focus-distant and focus-near brain regions monitored by $1 \mathrm{H}-\mathrm{NMR}$ spectroscopy. European Journal of Neurology 2003;10: 45-52.

14. Petroff OAC, Behar KL, Mattson RH, Rothman DL. Human Brain Y-Aminobutyric Acid Levels and Seizure Control Following Initiation of Vigabatrin Therapy. Journal of neurochemistry 1996;67: 2399-2404.

15. Samarasekera SR, Helmstaedter C, Reuber M. Cognitive impairment in adults with epilepsy: The relationship between subjective and objective assessments of cognition. Epilepsy Behav 2015;52: 9-13.

16. Aldenkamp A, Arends J, de la Parra N, Migchelbrink E. The cognitive impact of epileptiform EEG discharges and short epileptic seizures: relationship to characteristics of the cognitive tasks. Epilepsy \& Behavior 2010;17: 205-9.

17. Raven J, Raven JC, Court JH. Manual for Raven's Progressive Matrices and Vocabulary Scales. Section 3: The Standard Progressive Matrices. San Antonio, TX: Harcourt Assessment 2000.

18. Puts NA, Edden RA. In vivo magnetic resonance spectroscopy of GABA: a methodological review. Prog Nucl Magn Reson Spectrosc 2012;60: 29-41.

19. Provencher SW. Estimation of metabolite concentrations from localized in vivo proton NMR spectra. Magnetic Resonance in Medicine 1993;30: 672-9.

20. Edden RA, Puts NA, Harris AD, Barker PB, Evans CJ. Gannet: A batch-processing tool for the quantitative analysis of gamma-aminobutyric acid-edited MR spectroscopy spectra. J Magn Reson Imaging 2014;40: 1445-52.

21. O'Gorman RL, Michels L, Edden RA, Murdoch JB, Martin E. In vivo detection of GABA and glutamate with MEGA-PRESS: reproducibility and gender effects. J Magn Reson Imaging 2011;33: 1262-7.

22. Evans CJ, Puts NA, Robson SE, Boy F, McGonigle DJ, Sumner P, et al. Subtraction artifacts and frequency (mis-)alignment in J-difference GABA editing. J Magn Reson Imaging 2013;38: 970-5. 
23. Near J, Edden R, Evans CJ, Paquin R, Harris A, Jezzard P. Frequency and phase drift correction of magnetic resonance spectroscopy data by spectral registration in the time domain. Magn Reson Med 2015;73: 44-50.

24. Zhang Y, Brady M, Smith S. Segmentation of brain MR images through a hidden Markov random field model and the expectation-maximization algorithm. Medical Imaging, IEEE Transactions on 2001;20: 45-57.

25. Smith SM, Jenkinson M, Woolrich MW, Beckmann CF, Behrens TE, Johansen-Berg $H$, et al. Advances in functional and structural MR image analysis and implementation as FSL. Neuroimage 2004;23 Suppl 1: S208-19.

26. Alpherts W, Aldenkamp A. FePsy: the iron psyche. Heemstede: Instituut voor Epilepsiebestrijding 1994.

27. Ende G. Proton Magnetic Resonance Spectroscopy: Relevance of Glutamate and GABA to Neuropsychology. Neuropsychol Rev 2015;25: 315-25.

28. Lyoo IK, Yoon SJ, Musen G, Simonson DC, Weinger K, Bolo N, et al. Altered Prefrontal GlutamateGlutamine- $\gamma$-Aminobutyric Acid Levels and Relation to Low Cognitive Performance and Depressive Symptoms in Type 1 Diabetes Mellitus. Archives of general psychiatry 2009;66: 878-87.

29. Unschuld PG, Edden RA, Carass A, Liu X, Shanahan M, Wang X, et al. Brain metabolite alterations and cognitive dysfunction in early Huntington's disease. Mov Disord 2012;27: 895-902.

30. Rae CD. A guide to the metabolic pathways and function of metabolites observed in human brain $1 \mathrm{H}$ magnetic resonance spectra. Neurochem Res 2014;39: 1-36.

31. Novotny EJ, Jr., Fulbright RK, Pearl PL, Gibson KM, Rothman DL. Magnetic resonance spectroscopy of neurotransmitters in human brain. Ann Neurol 2003;54 Suppl 6: S25-31.

32. Simister RJ, McLean MA, Barker GJ, Duncan JS. The effect of sodium valproate on proton MRS visible neurochemical concentrations. Epilepsy Res 2007;74: 215-9.

33. Moore CM, Wardrop M, Frederick BdB, Renshaw PF. Topiramate raises anterior cingulate cortex glutamine levels in healthy men; a $4.0 \mathrm{~T}$ magnetic resonance spectroscopy study. Psychopharmacology (Berl) 2006;188: 236-43.

34. Pollack MH, Jensen JE, Simon NM, Kaufman RE, Renshaw PF. High-field MRS study of GABA, glutamate and glutamine in social anxiety disorder: response to treatment with levetiracetam. Prog Neuropsychopharmacol Biol Psychiatry 2008;32: 739-43.

35. Mula M, Trimble MR. Antiepileptic drug-induced cognitive adverse effects. CNS drugs 2009;23: 121-37.

36. Kuzniecky R, Ho S, Pan J, Martin R, Gilliam F, Faught E, et al. Modulation of cerebral GABA by topiramate, lamotrigine, and gabapentin in healthy adults. Neurology 2002;58: 368-72.

37. Kochunov P, Coyle T, Lancaster J, Robin DA, Hardies J, Kochunov V, et al. Processing speed is correlated with cerebral health markers in the frontal lobes as quantified by neuroimaging. Neuroimage 2010;49: 1190-9.

38. Charlton RA, Mclntyre DJ, Howe FA, Morris RG, Markus HS. The relationship between white matter brain metabolites and cognition in normal aging: the GENIE study. Brain Res 2007;1164: 108-16.

39. Kwan P, Brodie MJ. Neuropsychological effects of epilepsy and antiepileptic drugs. The Lancet 2001;357: 216-22

40. Cabeza R, Nyberg L. Imaging cognition II: An empirical review of 275 PET and fMRI studies. Journal of cognitive neuroscience 2000;12: 1-47. 


\section{Chapter 11}

\section{Chronic AED use and functional network efficiency}

TM van Veenendaal, DM IJff, AP Aldenkamp, RH Lazeron, PA Hofman, AJA de Louw, WA Backes \& JFA Jansen Submitted 


\section{Abstract}

\section{Purpose}

Cognitive side effects, such as slowing of central information processing, is a common complication of antiepileptic drug (AED) treatment. To increase our insight in the neuronal mechanisms underlying such cognitive side-effects, the relation between functional MR-acquired brain network measures, AED use, and cognitive function was investigated.

\section{Methods}

Three groups of patients with epilepsy with a different risk profile for developing cognitive side effects were included: a 'low risk' category (lamotrigine or levetiracetam), an 'intermediate risk' category (carbamazepine, oxcarbazepine, phenytoin, or valproate) and a 'high risk' category (topiramate). Brain connectivity was assessed using resting state functional MRI and graph theoretical network analysis. The Computerized Visual Searching Task (CVST) were used to measure central information processing speed and global cognitive performance, respectively.

\section{Results}

Central information processing speed was lower in patients taking AEDs from the intermediate and high risk categories, compared with patients from the low risk category. Patients from the high risk category had a higher global efficiency compared with the other patients, while the global efficiency did not differ between the low and intermediate risk category.

\section{Conclusion}

The results of this study indicated that only topiramate could be associated with altered improved graph measures reflecting more globally efficient networks, which might be a mechanism to compensate for the cognitive slowing. Alterations in functional brain network organization may be only subtle and measureable in patients with more severe cognitive side effects. 


\section{Introduction}

Epilepsy is generally treated with antiepileptic drugs (AEDs). A persistent problem in AED treatment is the occurrence of adverse events among which cognitive side effects are commonly seen. ${ }^{1,2}$ The cognitive side effects account for a high percentage of the disease burden ${ }^{3}$ and lead to early drug discontinuation. ${ }^{4}$ The prevalence and severity of the cognitive side effects varies among different AEDs. Several AEDs, such as topiramate, are associated with cognitive problems such as language deficit (anomia), while other AEDs such as lamotrigine seem to induce less cognitive side effects or even have activating effects. ${ }^{5}$ Despite specific differences, a decreased central information processing speed is commonly observed among the different AEDs to some extent. ${ }^{2}$

AEDs control epileptic seizures via several distinct mechanisms, such as enhancement of GABAergic inhibition, reduction of glutamatergic neurotransmission, or modulation of the voltage-gated ion channels. ${ }^{6}$ Changes in brain metabolic processes also affect healthy brain activity, and are likely to be responsible for cognitive side effects. ${ }^{1}$ Functional magnetic resonance imaging ( $\mathrm{fMRI}$ ) enables assessment of this brain activity, and can be employed to measure combined effects of different mechanism of action of AEDs. ${ }^{7}$ Several $\mathrm{fMRI}$ studies have shown altered brain activity patterns in healthy participants $^{8}$ or patients with epilepsy ${ }^{9,10}$ treated with AEDs. For instance, altered brain activity patterns appeared to be associated with language impairments when taking topiramate. $^{11-13}$

Cognitive functions are mediated by the concerted action of multiple and distributed brain regions. These brain regions show correlations of their fMRI time signals, which is commonly interpreted as functional connectivity. Collectively, these functional connections form a brain network, which can be analyzed and characterized using graph theoretical analysis. Brain networks appear to be efficient networks, characterized by a high functional segregation and integration, i.e. different brain regions form densely interconnected groups, enabling specialized information processing, and also rapid communication between distributed brain regions. Several graph measures are available to quantify these characteristics. ${ }^{14}$

Cognitive performance has been associated with the efficiency of functional brain networks, ${ }^{15,16}$ while impaired functional brain networks have been associated with cognitive decline in epilepsy. ${ }^{17,18}$ Furthermore, associations between drug load, cognition and graph measures were shown in one of these studies, although this was not the main focus of the current study. ${ }^{17}$ Another study associated the use of carbamazepine with altered graph measures when compared with other AEDs, but did not investigate the relation with cognitive effects. ${ }^{19}$ In the current study, we aim to test whether chronic use of AEDs, associated with a high risk for cognitive side-effects, affects functional resting-state network measures differently than long-term use of AEDs associated with milder cognitive side-effects. Furthermore, we will test whether 
functional resting-state network measures are associated with impaired cognitive functioning.

\section{Methods}

\section{Patients}

Three groups of patients with epilepsy were compared in this observational, crosssectional study. These groups were subdivided based on the AEDs that were being used, in accordance to Samarasekera et al. ${ }^{20}$ The first group, the low risk category, consisted of patients using lamotrigine or levetiracetam. Patients taking carbamazepine, oxcarbazepine, phenytoin, or valproate were included in the intermediate risk category, while the high risk category comprised patients taking topiramate. Patients on polytherapy took at most two different AEDs and were categorized according to their AED associated with the greatest cognitive risk. By including patients with AEDs from the three risk groups, a range in slowing of information processing speed is set out for.

All patients were clinically diagnosed with localization-related epilepsy and aged between 18 and 70 years. The patients were recruited from our tertiary epilepsy referral center. Participants not eligible for MRI, because of metal implants, claustrophobia, or pregnancy, were excluded from this study. Furthermore, patients did not experience seizures at least 12 hours prior to MRI. This study was approved by the local Medical Ethical Committee and all participants provided written informed consent.

\section{Neuropsychological investigation}

Cognitive functioning was assessed by two neuropsychological tasks. The Computerized Visual Searching Task (CVST) was used to measure visual (complex) information processing speed. ${ }^{21}$ Slowing of this central information processing speed is a common side effect of AEDs, ${ }^{22}$ and therefore the CVST is considered to be sensitive for treatment effects. ${ }^{23}$ With the CVST, a centered grid is shown surrounded by 24 other grid patterns. Participants have to find the (only) grid identical to the centered one as fast as possible. The Raven Standard Progressive Matrices was administered to assess global cognitive performance. This is a non-verbal reasoning test which gives an indication of fluid intelligence. ${ }^{24}$ Previous studies suggested that intelligence stays relatively unaffected by AEDs. $^{23}$ 


\section{Epilepsy severity}

As several epilepsy related characteristics might affect functional brain networks, ${ }^{25}$ a score was composed to account for these effects. This epilepsy severity score was assessed in all patients and compared between the different risk categories. Epilepsy severity was characterized using a summarized score between zero and seven, composed by the sum of subscores for seizure type (tonic-clonic: 1 , other: 0 ), previous occurrence of status epilepticus (yes: 1, no:0), seizure-related injury (yes:1, no:0) and seizure frequency (seizure free: 0 , yearly: 1 , monthly: 2 , weekly: 3 , daily: 4 ).

\section{MRI data acquisition}

MRI data were acquired on a 3.0T MRI scanner equipped with an 8-channel head coil (Philips Achieva, Philips Medical Systems, Best, the Netherlands). The scanning protocol included resting-state functional MRI and a T1-weighted scan. Functional MRI data were acquired using whole-brain single-shot multi-slice echo planar imaging (EPI) sequence sensitive to the blood-oxygen-level-dependent (BOLD) effect (195 volumes, 32 slices, in-plane resolution $2 \times 2 \mathrm{~mm}, 4 \mathrm{~mm}$ thick slices, repetition time $2000 \mathrm{~ms}$, echo time $35 \mathrm{~ms}$, flip angle: $90^{\circ}$, acquisition time: $7 \mathrm{~min}$ ). A 3D T1-weighted scan was acquired for anatomic reference (voxel size $1 \times 1 \times 1 \mathrm{~mm}$, repetition time $8.3 \mathrm{~ms}$, echo time $4.8 \mathrm{~ms}$, inversion time $1022 \mathrm{~ms}, 180$ slices, flip angle $8^{\circ}$, acquisition time $6 \mathrm{~min}$ ).

\section{Data preprocessing}

Preprocessing of the functional images was performed using SPM8 (Wellcome Department of Cognitive Neurology, London, UK). The functional images were corrected for differences in slice timing and head movement, coregistered to the T1 image and spatially (FWHM $6 \mathrm{~mm}$ ) and temporally filtered (band pass $0.01-0.1 \mathrm{~Hz}$ ). The BOLD signal originating from the white matter and ventricles, which is assumed to reflect physiological noise, ${ }^{26}$ and the six translation and rotation parameters obtained from the motion correction were deregressed from the BOLD signal.

The T1-weighted scan was parcellated into 82 cortical and subcortical brain regions using FreeSurfer v5.1.0 (The General Hospital Corporation, Boston MA, USA). Subsequently, a connectivity matrix was created by calculating the Pearson's correlation coefficient between the average (deregressed) BOLD time signal of each combination of two regions. Negative correlations were set to zero. The correlation values were thresholded, based on the average connectivity matrix, to obtain connectivity matrices with only the strongest connections. The number of included connections was varied, with sparsity levels ranging from 0 to 0.9 ( 0 is fully connected, whereas 1 indicates no connections). 


\section{Data analysis}

The Brain Connectivity Toolbox ${ }^{14}$ was employed to compute graph measures for each individual connectivity matrix. The clustering coefficient and the characteristic path length are commonly used to characterize the functional segregation and integration, respectively. The clustering coefficient quantifies the fraction of a node's neighbor that are also connected to each other. The characteristic path length is defined as the average shortest distance (the inverse correlation coefficient) between all pairs of nodes. As, in sparse networks, a single weak connection can result in a large, or even infinite average path lengths, global efficiency was computed instead of characteristic path length, which avoids this effect by using inverse path lengths. ${ }^{27}$

One hundred null models of the connectivity matrices were computed by randomizing the connections of the original matrices, while preserving the degree and weight distribution. ${ }^{28}$ The graph measures were divided by the mean global efficiency and clustering coefficient of these null models, providing a normalized global efficiency $(E g)$ and clustering coefficient $(\gamma)$.

\section{Statistical analysis}

To test whether the clustering coefficient and global efficiency differed between the risk categories, an analysis of covariance (ANCOVA) was applied with the graph measures as outcome, cognitive risk category as fixed factor and age as covariate. Associations with cognition were assessed with linear regression analysis, with CVST time as outcome, and $E g$ or $\gamma$, age, and the percentage corrects answers in the Raven test as independent variables. To assess whether these results were affected by confounders, these analyses were repeated with gender, epilepsy severity score, or drug load (ratio of prescribed daily dose to defined daily dose $\mathrm{e}^{26}$ ) added to the regression analyses as additional covariates. All statistical analyses were performed in Matlab (version R2012b). P-values lower than 0.05 were considered significant.

\section{Results}

In total, 58 patients were included in this study. Three of these patients did not finish the procedures due to claustrophobia, resulting in 16 patients taking AEDs from the low risk category, 34 taking AEDs from the intermediate risk category, and 5 taking high risk AEDs. The age and drug load were significantly higher in the intermediate risk category than in the low risk category (Table 11.1). Also the number of patients on polytherapy was significantly higher in the intermediate risk category compared with the low risk category, while the high and low risk categories significantly differed in number of patients on polytherapy. The risk categories did not differ in gender distribution, educational level, or epilepsy severity. 
Table 11.1 Patient characteristics for the three risk categories. ${ }^{a}$

\begin{tabular}{|c|c|c|c|}
\hline & $\begin{array}{c}\text { Low risk } \\
(n=16)\end{array}$ & $\begin{array}{c}\text { Intermediate risk } \\
(n=34)\end{array}$ & $\begin{array}{c}\text { High risk } \\
(n=5)\end{array}$ \\
\hline \multicolumn{4}{|l|}{ General } \\
\hline Male/female & $5 / 11(31 / 69 \%)$ & $16 / 18(47 / 53 \%)$ & $0 / 5(0 / 100 \%)$ \\
\hline Age (years) & $39.5 \pm 13.4$ & $50.7 \pm 12.5^{*}$ & $42.4 \pm 15.8$ \\
\hline Educational level $^{\mathrm{c}}$ & 5 (range $2-6$ ) & 5 (range $2-7$ ) & 5 (range 4-6) \\
\hline \multicolumn{4}{|l|}{ Epilepsy-related } \\
\hline Symptomatic/non-symptomatic & $2 / 14(13 / 88 \%)$ & $15 / 19(44 / 56 \%)$ & $0 / 5$ \\
\hline \multicolumn{4}{|l|}{ Seizure frequency } \\
\hline Weekly & 0 & $1(3 \%)$ & 0 \\
\hline Monthly & $4(25 \%)$ & $3(9 \%)$ & 0 \\
\hline Yearly & $2(13 \%)$ & $6(18 \%)$ & $2(40 \%)$ \\
\hline Seizure free & $10(63 \%)$ & $24(71 \%)$ & $3(60 \%)$ \\
\hline Years since epilepsy onset ${ }^{b}$ & $22.7 \pm 11.7$ & $30.4 \pm 13.4$ & $26.8 \pm 23.3$ \\
\hline Epilepsy severity score $^{\mathrm{b}}$ & $1.4 \pm 0.8$ & $1.2 \pm 1.0$ & $1.0 \pm 0.7$ \\
\hline \multicolumn{4}{|l|}{ AED-related } \\
\hline Mono-/polytherapy & $16 / 0$ & $8 / 26(24 / 77 \%)^{*}$ & $3 / 2(60 / 40 \%)^{\dagger}$ \\
\hline \multicolumn{4}{|l|}{ Medication type } \\
\hline $\mathrm{CBZ}$ & 0 & $17(50 \%)$ & $1(20 \%)$ \\
\hline LEV & $7(44 \%)$ & $6(18 \%)$ & 0 \\
\hline LTG & $9(56 \%)$ & $10(29 \%)$ & $1(20 \%)$ \\
\hline OXC & 0 & $4(12 \%)$ & 0 \\
\hline PHT & 0 & $16(47 \%)$ & 0 \\
\hline TPM & 0 & 0 & $5(100 \%)$ \\
\hline VPA & 0 & $7(21 \%)$ & $1(20 \%)$ \\
\hline Drug load ${ }^{b, d}$ & $1.3 \pm 0.6$ & $1.8 \pm 0.7^{*}$ & $1.2 \pm 1.0$ \\
\hline
\end{tabular}

Differences between the risk groups were tested using a Fisher's exact test (gender, symptomatic epilepsy, number of different AEDs), a Mann-Whitney test (educational level, seizure frequency, epilepsy severity score), or a student's t-test (all remaining variables). "indicates significant differences between the low and intermediate risk category $(p<0.05) ;{ }^{\dagger}$ indicates differences between the low and high risk category $(p<0.05)$. a Low risk: lamotrigine (LTG), levetiracetam (LEV); Intermediate risk: valproate (VPA), carbamazepine (CBZ), oxcarbazepine (OXC) and phenytoin (PHT); High risk: topiramate (TPM); ${ }^{b}$ mean \pm standard deviation; ${ }^{\mathrm{C}}$ Median (range). Scores are according to Verhage (1964), range 1 (did not finish primary school) to 7 (Master's degree)

\section{Neuropsychological assessment}

The results of the CVST and the Raven task are summarized in Table 11.2. The CVST reaction time was slower than the normal range (range: 7.3 to $30.8 \mathrm{~s}$, while the mean \pm sd was $10.3 \pm 4.1 \mathrm{~s}$ in normal population ${ }^{29}$ ). A significant effect of risk category on CVST reaction time was observed, which remained significant when controlling for age, gender, and global cognitive level ( $p=0.009$, ANCOVA). Post-hoc tests showed significant differences in CVST between the low and intermediate risk category $(p=0.035$, estimated adjusted mean difference $3.5 \mathrm{~s}$ ), and between the low and high risk category ( $p=0.004$, adjusted mean difference $7.8 \mathrm{~s}$ ). No significant differences were found between the percentage correct answers Raven scores of the different risk categories. 
Table 11.2 Results of the neuropsychological investigation, represented as mean \pm standard deviation for each risk category.

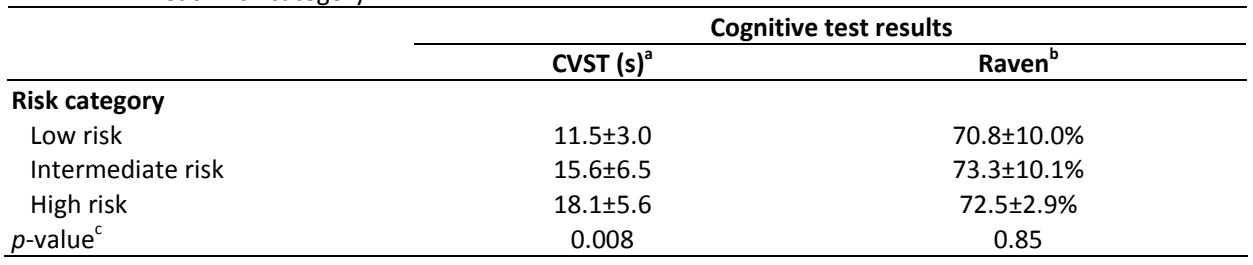

${ }^{a}$ mean reaction time on the Computerized Visual Searching Task (CVST) ${ }^{21} ;{ }^{b}$ Percentage correct answers on the Raven Standard Progressive Matrices ${ }^{24} ;{ }^{c}$ Tested with ANOVA.

\section{Network topology}

Of the 55 included patients, seven were excluded from further analysis: one patient was excluded because of excessive head motion (maximum head movement of $8.0 \mathrm{~mm}$, while the maximum head movement was below $1.5 \mathrm{~mm}$ in all other patients), one because of a deeper large lesion mass, and five patients were excluded because of a failure to automatically parcellate the cortex, due to cortical abnormalities. The analysis was therefore performed on 48 patients: 15 patients taking AEDs from the low-risk category, 29 patients taking AEDs from the intermediate risk category and 4 patients taking the high risk medication. The maximum head displacement did not differ between the three risk categories.

The functional networks were fully connected and showed small-world characteristics within the sparsity range $0.32-0.66$ (which was defined as $\gamma / \lambda$ significantly larger than one, with $\gamma$ the normalized clustering coefficient, and $\lambda$ the normalized characteristic path length). Only the sparsity levels within this range were considered for further analyses. The ANCOVA test revealed significant effects of risk category on $E g$ at most sparsities within this sparsity range (Figure 11.1). Post-hoc tests showed a significantly higher $\mathrm{Eg}$ for patients from the low category compared with the high risk category, and for patients from the intermediate category compared with the high risk category. $E g$ or $\gamma$ did not differ significantly between patients from the low and intermediate risk categories ( $p>0.2$ at all sparsity levels), and no significant associations were observed between $\gamma$ or $E g$ and CVST time ( $p>0.15$ at all sparsity levels). Gender, epilepsy severity score, or drug load were not significantly associated with the $\gamma, E g$, or CVST reaction time, and the results of these adjusted analyses were consistent with the results of the analyses without these additional covariates $(<10 \%$ change in effect size of the variable of interest). 

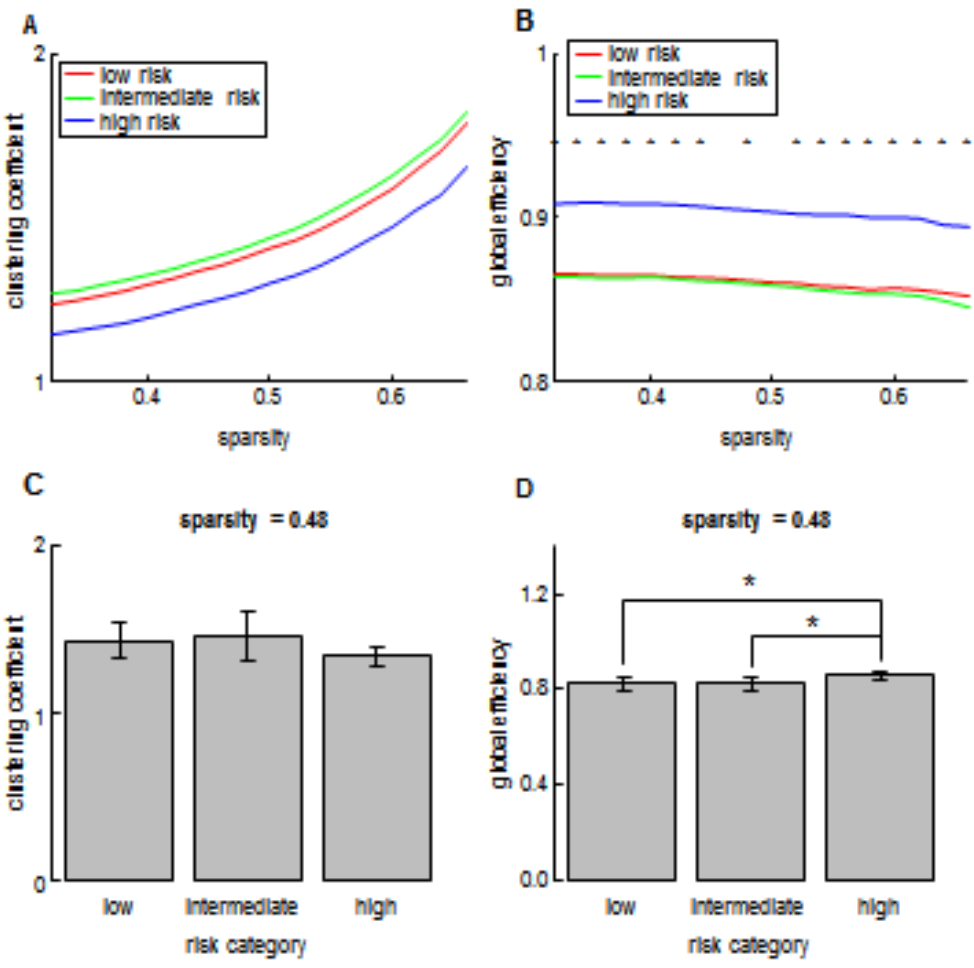

Figure 11.1 Mean clustering coefficient (A, C) and global efficiency (B, D) for each risk category. Both clustering coefficient and global efficiency are normalized, i.e. the measures are divided by the clustering coefficient and global efficiency of random networks. A and B show the graph measures as a function of sparsity, while $B$ and $D$ show the results at a single sparsity level. Error bars show standard deviations, while the asterisks indicate significant differences between the risk categories ( $p<0.05$, with age included as covariate).

\section{Discussion}

The current study investigated whether patients taking AEDs with a different risk for cognitive side-effects have different functional brain topologies. To this end, we included epilepsy patients with chronic AED treatment with different risk profiles, i.e. a low risk category, intermediate-risk, and high risk category. Furthermore, we assessed whether cognitive problems, in terms of a decreased central information processing speed, could be associated with the functional brain organization.

A higher global efficiency was shown in the patients taking TPM (the high risk category), compared with patients taking the low and intermediate risk AEDs. The directionality of this difference is strikingly, as this result seems to contradict the cognitive side effects 
of TPM. The global efficiency is suggested to be particularly important for more

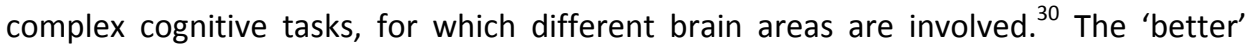
global efficiency in TPM users might however be interpreted as a compensatory mechanism, or could be explained by a 'survivor effect'. As patients with side effects are more likely to switch to other AEDs, it is likely that these patients are less vulnerable for cognitive problems. The higher global efficiency in the high-risk group might therefore reflect a lower susceptibility for cognitive side effects of these patients. ${ }^{31,32}$ However, these patients did have a lower processing speed compared with the other patients, which argues against this explanation and for a compensatory mechanisms.

No differences in graph measures were observed between the patients groups taking AEDs from the low and from the intermediate risk category. It is possible that the effects of TPM on brain organization are more pronounced compared with effects of other AEDs, but TPM can also have distinctive effects on brain organization. TPM is suggested to have a unique cognitive profile, with specific effects on verbal fluency. Moreover, it has multiple mechanisms of action, and both these mechanisms and its chemical structure differ from other AEDs. ${ }^{33}$

Furthermore, no associations were found between processing speed and graph measures, in contrast to a previous study that showed not only associations between intellectual decline and a lowered clustering coefficient in patients with epilepsy, but also with increasing drug load. ${ }^{17}$ The latter suggests that the intellectual decline (which was based on intelligence tests) was a side effect of the AED treatment, but this could also result from differences in epilepsy characteristics. That study included more patients with a high drug load ( $15 \%$ of the patients had a drug load higher than 3 ) than the current study (no drug loads higher than 3 in the included patients), thus it is possible that the effects on graph measures are only measureable in patients with higher drug loads or AEDs with high risks on cognitive complaints.

The measured information processing speed covered the whole range from normal to a clearly affected processing speed, and patients taking AEDs known to induce cognitive side effects, showed lower processing speeds than patients with lower risk AEDs. These results could therefore not explain the lack of associations between graph measures and information processing speed, or the lack of differences in graph measures between the low and intermediate risk category. Also no trends were shown, while the total number of participants (48), and the number of patients in the low (16) and intermediate risk categories (34) were relatively large, making it unlikely that this lack of findings were due to limited power.

All included patients in the current study were diagnosed with localization-related epilepsy. Epilepsy is associated with a decreased global efficiency and increased clustering coefficient, although some studies showed a decreased clustering coefficient in patients with epilepsy. ${ }^{34}$ It is therefore plausible that the functional brain networks of 
all three groups of patients in this study were already altered compared with healthy participants, irrespective of AED treatment.

This study has several limitations. Although we tried to include comparable patient groups, the risk categories differed in age and drug load, suggesting that our study population is biased. Therefore, the analyses were corrected for these characteristics by including age and drug load as covariates. Besides these characteristics, also other factors could have confounded our results, such as the location of the epileptic focus or effects of AEDs on the neurovascular coupling, which should be assessed in separate studies. ${ }^{35}$ Finally, no information is available about changes over time and causality due to the cross-sectional design.

\section{Conclusions}

No differences in functional network graph measures could be detected between patients with epilepsy after chronic use of AEDs with a different risks on cognitive side effects. Only patients taking TPM, which has a high risk for developing cognitive side effects, showed a more efficient brain network topology, which might be a compensatory mechanism. Also no associations were found between the graph measures and the measured cognitive impairments, specifically slowing of central information processing. Alterations in functional brain network organization may be only subtle and measureable in patients with more severe cognitive side-effects. 


\section{References}

1. Perucca P, Gilliam FG. Adverse effects of antiepileptic drugs. The Lancet Neurology 2012;11:792-802.

2. IJff DM, Aldenkamp AP. Cognitive side-effects of antiepileptic drugs. Handb Clin Neurol 2013;111:70718.

3. Helmstaedter C, Aldenkamp AP, Baker GA, Mazarati A, Ryvlin P, Sankar R. Disentangling the relationship between epilepsy and its behavioral comorbidities - the need for prospective studies in new-onset epilepsies. Epilepsy Behav 2014;31:43-7.

4. Bootsma HP, Ricker L, Hekster YA, et al. The impact of side effects on long-term retention in three new antiepileptic drugs. Seizure 2009;18:327-31.

5. Kwan P, Brodie MJ. Neuropsychological effects of epilepsy and antiepileptic drugs. The Lancet 2001;357:216-22.

6. Rogawski MA, Loscher W. The neurobiology of antiepileptic drugs. Nat Rev Neurosci 2004;5:553-64.

7. Van Veenendaal TM, ljff DM, Aldenkamp AP, et al. Metabolic and functional MR biomarkers of antiepileptic drug effectiveness: A review. Neurosci Biobehav Rev 2015;59:92-9.

8. Li X, Ricci $\mathrm{R}$, Large $\mathrm{CH}$, et al. Interleaved transcranial magnetic stimulation and fMRI suggests that lamotrigine and valproic acid have different effects on corticolimbic activity. Psychopharmacology (Berl) 2010;209:233-44.

9. Jokeit H, Okujava M, Woermann FG. Carbamazepine reduces memory induced activation of mesial temporal lobe structures: a pharmacological fMRI-study. BMC Neurol 2001;1:6.

10. Wandschneider B, Stretton J, Sidhu M, et al. Levetiracetam reduces abnormal network activations in temporal lobe epilepsy. Neurology 2014;83:1508-12.

11. Jansen JF, Aldenkamp AP, Marian Majoie HJ, et al. Functional MRI reveals declined prefrontal cortex activation in patients with epilepsy on topiramate therapy. Epilepsy Behav 2006;9:181-5.

12. De Ciantis A, Muti M, Piccolini C, et al. A functional MRI study of language disturbances in subjects with migraine headache during treatment with topiramate. Neurol Sci 2008;29:S141-3.

13. Yasuda CL, Centeno M, Vollmar C, et al. The effect of topiramate on cognitive fMRI. Epilepsy Res 2013;105:250-5.

14. Rubinov $M$, Sporns $\mathrm{O}$. Complex network measures of brain connectivity: uses and interpretations. Neuroimage 2010;52:1059-69.

15. Van Den Heuvel MP, Stam CJ, Kahn RS, Hulshoff Pol HE. Efficiency of functional brain networks and intellectual performance. J Neurosci 2009;29:7619-24.

16. Giessing C, Thiel CM, Alexander-Bloch AF, Patel AX, Bullmore ET. Human brain functional network changes associated with enhanced and impaired attentional task performance. J Neurosci 2013;33:5903-14.

17. Vlooswijk M, Vaessen $M$, Jansen J, et al. Loss of network efficiency associated with cognitive decline in chronic epilepsy. Neurology 2011;77:938-44.

18. Bonilha L, Tabesh A, Dabbs K, et al. Neurodevelopmental alterations of large-scale structural networks in children with new-onset epilepsy. Hum Brain Mapp 2014;35:3661-72.

19. Haneef Z, Levin HS, Chiang S. Brain Graph Topology Changes Associated with Anti-Epileptic Drug Use. Brain Connect 2015;5:284-91.

20. Samarasekera SR, Helmstaedter C, Reuber M. Cognitive impairment in adults with epilepsy: The relationship between subjective and objective assessments of cognition. Epilepsy Behav 2015;52:9-13.

21. Aldenkamp A, Arends J, De La Parra N, Migchelbrink E. The cognitive impact of epileptiform EEG discharges and short epileptic seizures: relationship to characteristics of the cognitive tasks. Epilepsy \& Behavior 2010;17:205-9.

22. Ijff D, Aldenkamp A. Comorbidities of treatment with antiepileptic drugs. Duchowny M, Cross JH Arzimanoglou A, eds Pediatric epilepsy New York: McGraw-Hill Professional 2012:424-36.

23. Grevers E, Breuer LE, Dm IJ, Aldenkamp AP. Mental slowing in relation to epilepsy and antiepileptic medication. Acta Neurol Scand 2015.

24. Raven J, Raven JC, Court JH. Manual for Raven's Progressive Matrices and Vocabulary Scales. Section 3: The Standard Progressive Matrices. San Antonio, TX: Harcourt Assessment 2000. 
25. Van Diessen E, Diederen SJ, Braun KP, Jansen FE, Stam CJ. Functional and structural brain networks in epilepsy: what have we learned? Epilepsia 2013;54:1855-65.

26. Murphy K, Birn RM, Bandettini PA. Resting-state $\mathrm{fMRI}$ confounds and cleanup. Neuroimage 2013;80:349-59.

27. Bullmore ET, Bassett DS. Brain graphs: graphical models of the human brain connectome. Annu Rev Clin Psychol 2011;7:113-40.

28. Rubinov $\mathrm{M}$, Sporns $\mathrm{O}$. Weight-conserving characterization of complex functional brain networks. Neuroimage 2011;56:2068-79.

29. Alpherts W, Aldenkamp A. FePsy: the iron psyche. Heemstede: Instituut voor Epilepsiebestrijding 1994.

30. Giessing $\mathrm{C}$, Thiel CM. Pro-cognitive drug effects modulate functional brain network organization. Front Behav Neurosci 2012;6:53.

31. Hahn A, Kranz GS, Sladky R, et al. Individual diversity of functional brain network economy. Brain Connect 2015;5:156-65.

32. Santarnecchi E, Rossi S, Rossi A. The smarter, the stronger: Intelligence level correlates with brain resilience to systematic insults. Cortex 2015;64:293-309.

33. Mula M. Topiramate and cognitive impairment: evidence and clinical implications. Ther Adv Drug Saf 2012;3:279-89.

34. Van Diessen E, Zweiphenning WJ, Jansen FE, Stam CJ, Braun KP, Otte WM. Brain Network Organization in Focal Epilepsy: A Systematic Review and Meta-Analysis. PLoS One 2014;9:e114606.

35. Kida I, Smith AJ, Blumenfeld H, Behar KL, Hyder F. Lamotrigine suppresses neurophysiological responses to somatosensory stimulation in the rodent. Neuroimage 2006;29:216-24. 


\section{Chapter 12}

General discussion 
Chapter 12 


\section{General discussion}

Epilepsy is a neurological disorder that is estimated to affect almost 70 million people worldwide. ${ }^{1,2}$ The highest incidence is found in children. ${ }^{3}$ The prevalence of epilepsy among people with intellectual disabilities is much higher than in the general population with one in five having epilepsy (22\%). ${ }^{4}$ In the majority of the patients, epilepsy is treated with anti-epileptic drugs (AEDs) to prevent seizures. About one third of patients suffer from drug refractory epilepsy. ${ }^{5}$ For these patients additional nonpharmacological treatment options are available, such as epilepsy surgery, vagus nerve stimulation and the ketogenic diet.

The best possible outcome of AED-treatment is to achieve complete seizure freedom without adverse events. However, one of the complications of AED-treatment is the occurrence of side-effects, especially in the cognitive domain. ${ }^{6,7}$ These cognitive sideeffects may even outbalance the effectiveness of the drug which limits the compliance. Cognitive side-effects are therefore an important aspect of establishing overall treatment effectiveness.

The aim of this thesis was to investigate the cognitive adverse effects of anti-epileptic treatment in patients with refractory epilepsy. This thesis was divided in four parts that has provided information and allows attempting answering five pertinent clinical questions:

\section{What kind of cognitive functions can be affected by antiepileptic drug therapy?}

All commonly used AEDs have some effect on cognitive function. The severity of impaired cognition due to treatment differs per AED. From the older agents, phenobarbital (PB) induces the most severe cognitive impairment, especially on memory and visuomotor functions. ${ }^{8}$ Another AED of the first generation, phenytoin (PHT) may also have a substantial impact on cognitive function with impairments in concentration, memory and mental speed. ${ }^{9}$ Mild to moderate impairments of psychomotor and mental speed are described for valproate (VPA) and carbamazepine (CBZ) ${ }^{10}$ No cognitive impairments are described for oxcarbazepine (OXC) in adults ${ }^{11}$ and children. ${ }^{12,13}$ Among the newer AEDs, topiramate (TPM) potentially has a severe negative impact on cognition, especially on verbal function. ${ }^{14}$ The cognitive side-effect profile of zonisamide (ZNS) is regarded to be comparable with TPM. ${ }^{15}$ This is contrary to lamotrigine (LTG) and levetiracetam (LEV) that may even have activating effects on cognition. ${ }^{16,17}$ However, LEV is associated with an increased risk of developing behavioral, mood and even psychiatric side-effects such as aggressiveness, irritability and hostility. ${ }^{18}$

Higher-order cognitive functions that are more stable, reasoning functions, such as intelligence or memory are only affected by AEDs from the very first generation and the newer drug TPM and ZNS. The most common cognitive area that is affected by drug 
treatment are attentional related state dependent 'fluid functions' in particular psychomotor speed and speed of central information processing. ${ }^{19,20}$ The dominant cognitive impairment per AED is schematically shown in Figure 12.1. In addition to literature, the neuropsychological profile of two AEDs (one drug from the older generation and one from the newest generation) were discussed in this thesis. Lacosamide is positioned in the class of activating drugs on cognition, comparable with lamotrigine. Ethosuximide is positioned in the class of drugs with mild effects on cognition, comparable to e.g. carbamazepine and oxcarbazepine.

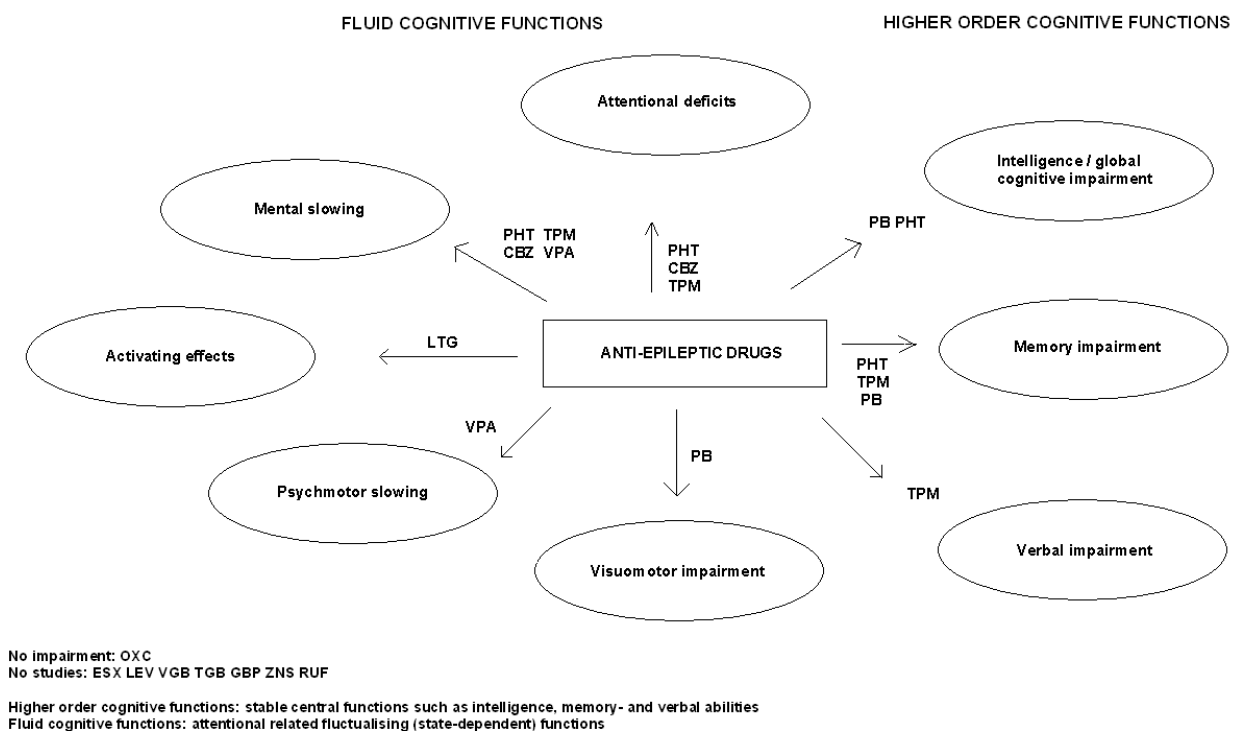

Figure 12.1 Dominant impairment per antiepileptic drug.

Adapted from: IJff, DM and Aldenkamp, AP. Comorbidities of treatment with antiepileptic drugs. In Duchowny, Cross, and Arzimanoglou (Eds.), Pediatric Epilepsy, New York: McGraw-Hill Professional, 2012.

\section{Are the cognitive side-effects of nonpharmacological treatment options comparable to AED-treatment?}

Nonpharmacological treatment options such as epilepsy surgery, vagus nerve stimulation and the ketogenic diet are available for patients with drug-resistant epilepsy, also for children. As opposed to AEDs, there are no negative effects on cognition reported for vagus nerve stimulation. ${ }^{21}$ In children treated with the ketogenic diet an activated mood and cognitive activation was observed. ${ }^{22}$ Similar reports are available for successful epilepsy surgery. ${ }^{23,24}$ This positions the nonpharmacological 
treatment options in the same class as the activating AED such as lacosamide, which has also been reported in literature for lamotrigine ${ }^{25}$ or oxcarbazepine. ${ }^{11-13}$

\section{Has chronic use of AEDs a detrimental impact on cognitive development during childhood?}

Current knowledge is mostly based on research with trial durations of weeks instead of years which is in contrast with clinical practice. Furthermore, data in children are limited. As AEDs may have an effect on brain maturation and hence on neurodevelopment, children are potentially more susceptible to the adverse effects of AEDs than adults. ${ }^{26}$ Concern has therefore been expressed about long-term effects of AED use on cognitive development in children ${ }^{27}$ which was confirmed by one of our studies in this thesis (chapter 6).

\section{How useful are subjective reports for indicating cognitive side-effects?}

Following the community-based studies which were published previously, ${ }^{6,28}$ we assessed the value of subjective complaints, now in a hospital-based population, i.e. in patients with chronic refractory epilepsy visiting the outpatient departments of our tertiary referral center. Most reported complaints were about their general health (85\%), followed by cognition (77\%), mood (69\%) and cosmetics (42\%). Although previous reports showed the highest rate of intolerable cognitive complaints for TPM, ${ }^{29-}$ 31 patient-perceived complaints could not distinguish the AEDs associated with a greater risk of cognitive dysfunction such as TPM, PB, PHT or ZNS in our patient population. ${ }^{32}$ However, regression analysis showed that using a high risk AED for behavioral side-effects (such as LEV) contributed significantly to the total subjectively experienced side-effects and to mood effects. This indicates that subjective cognitive complaints may be less reliable than subjective mood reports.

The usefulness of patient-based reports in detecting the adverse effects of AEDs on cognitive function is still in debate. Although it may identify patients who are at risk for developing drug-induced cognitive impairment ${ }^{33,34}$ which was confirmed in this thesis (chapter 8), complaints may reflect depressed mood instead of cognitive impairments. ${ }^{35-37}$ It is therefore suggested to use a combination of subjective and objective assessments of cognition, including caregivers reports. ${ }^{38}$ Subjective selfreports or cognitive tests are, however, not possible for every patient. Patients with intellectual disabilities are less likely to report cognitive side-effects due to difficulty detecting subtle forms of cognitive impairment in intellectually disabled patients and underreporting. ${ }^{29}$ We therefore used a new approach, assessing the effects of AEDs on functional status using long-term follow up with caregiver reports on the Barthel Index of Activities of Daily Living in this patient population. 


\section{What is the effect of AED-treatment on the brain?}

As some patients may be more susceptible to cognitive impartments due to antiepileptic treatment than others, ${ }^{39}$ a better understanding of neuronal mechanisms of action causing cognitive side-effects is needed to improve the tolerability of antiepileptic treatment. One mechanisms of action is neurotransmitter-related. Some of the AEDs are thought to affect GABAergic mechanisms directly or to alter the glutamate concentrations indirectly by decreasing the sensitivity of the glutamate receptors. ${ }^{40}$ Neurotransmitter concentrations and brain activity can be measured using MR spectroscopy (MRS) and functional MR imaging ( $\mathrm{FMRI}$ ) respectively. Although there is a scarcity of clinical MR-studies investigating the effectiveness of AEDs, these techniques provide biomarkers that may predict treatment outcomes in the individual patient and enable assessment of mechanisms of cognitive side-effects. ${ }^{41,42} \mathrm{fMRI}$ studies suggest that several AEDs such as CBZ, ${ }^{43} \mathrm{LEV}^{44}{ }^{4} \mathrm{VPA},{ }^{45}$ and $\mathrm{TPM}^{46-48}$ have effects on cognitive brain networks in patients with epilepsy. Based on our clinical MRI studies using MR spectroscopy and resting-state functional MR imaging to investigate the effects of AED-treatment on brain function and brain activity, respectively, we concluded that drug-induced slowing of central information processing speed is associated with reduced excitatory neurotransmitter function and subtle changes in brain connectivity. ${ }^{49,50}$ Such alterations in neurotransmitters and brain organization may therefore underlie the development of cognitive side-effects.

\section{How to proceed from here?}

\section{Implications for clinical practice}

A neuropsychological investigation is commonly used to obtain a neurocognitive profile for an individual patient in relation to subjective complaints, type of $A E D$, and drug load. Valid and reliable screening instruments are however, necessary on the one hand for early detection of side-effects, on the other hand to avoid unnecessary referral for costly and time-consuming neuropsychological investigations. Our work has shown that a screening instrument may be based on the subjective complaints of the patients, under the condition of structural assessment. A subjective complaint list, focused on assessing cognitive side-effects such as the $\mathrm{ABNAS}^{34}$ or focused on a broader range of side-effects including the cognitive domain such as the SIDAED, ${ }^{6}$ may be helpful. Other questionnaires exist and are available in the public domain. Such questionnaires can be completed online or in the waiting room prior to a consultation for clinical practice.

To objectify the subjective complaints, a neuropsychological investigation can be used. We have demonstrated that fluid cognitive functions are most sensitive for the cognitive impact of AEDs and in particularly information processing speed. Even mild effects on fluid functions must therefore be controlled with neuropsychological followup when longer treatment durations (i.e. years) are necessary, especially in children to 
avoid interference with normal cognitive development. Computerized cognitive assessment to monitor alertness, information processing speeds and other attentional functions has the advantage of reducing assessment time to a mere 20 minutes and the immediate availability of test results for advising the patients. ${ }^{51}$ In many occasions, assessment of potential cognitive side-effects requires repeated testing and a short focused test battery is then an advantage.

\section{Implications for future research}

The most preferable research design to investigate the impact of AEDs, would be a longitudinal, double-blind, randomized controlled trial in patients (adults and children) with newly diagnosed epilepsy with a non-medicated baseline. These studies are not affected by concurrent or previous AED use, heterogeneous patient populations, or the seizures. However, this optimal research design is not achievable in our patient population because in most patients, treatment is already started before referral to our tertiary referral clinic and the epilepsy syndrome may be unclear or misdiagnosed.

As cognitive outcomes are usually not investigated in the industry driven randomized controlled trials when a new drug is in development, it is only possible to speculate about the potential impact on cognition based on the mechanism of action. ${ }^{52}$ The alternative is to study the effects in a naturalistic setting with limited protection against bias. We therefore recommend that when new AEDs become available for clinical practice, networks of centers are formed to identify the cognitive profile of the new drug as soon as possible. Possibly tertiary epilepsy centers can serve as an organizational 'hub' in such networks. We have to close the gap between introduction of a drug and the identification of its cognitive and mood profile. Levetiracetam was internationally introduced in clinical practice in $1999 / 2000$ but the very first publication describing its possible psychiatric effects was $4-5$ years later. ${ }^{53}$ From 2007/2008 first publications appeared that the increased irritability is not a rare, but rather a common side-effect of this AED.

Furthermore, most studies have a limited duration with trials mostly not exceeding the 12-weeks period, which is in contrast with treatment durations of years instead of weeks in clinical practice. Especially in more vulnerable groups such as children or patients with intellectual disabilities, in which chronic anti-epileptic treatment may impact cognitive developmental processes by accumulating effects, this is an important issue. Therefore, more research is needed to investigate the effects of chronic antiepileptic treatment, in particular in children and patients with intellectual disabilities. These studies should also focus on useful parameters to assess side-effects. Although neuropsychological testing is not always possible in patients with intellectual disabilities, the focus should be on more subtle effects than the functional status that we studied. A possible new technique to investigate drug-induced impairments may be eye tracking which measures eye positioning and eye movements, and can also be used in these more specific patient populations. Future studies should also focus on the 
usefulness of MR-based biomarkers and more advanced MR-technologies such as Magnetic Resonance Spectroscopy imaging of the prefrontal cortex. 


\section{References}

1. Ngugi AK, Bottomly C, Kleinschmidt I, Sander JW, Newton CR, Estimation of the burden of active and life-time epilepsy: a meta-analytic approach. Epilepsia 2010;51:883-90.

2. Ngugi AK, Kariuki SM, Bottomley C, Kleinschmidt I, Sander JW, Newton CR. Incidence of epilepsy: a systematic review and meta-analysis. Neurology 2011;77:1005-12.

3. Kotsopoulos IA, van Merode T, Kessels FG, de Krom MC, Knottnerus JA. Systematic review and metaanalysis of incidence studies of epilepsy and unprovoked seizures. Epilepsia 2002;43:1402-9.

4. Bowley C, M Kerr. Epilepsy and intellectual disability. J Intellect Disabil Res 2000;44:529-43.

5. Sillanpää M, Schmidt D. Natural history of treated childhood-onset epilepsy: prospective, long-term population-based study. Brain 2006;129:617-24.

6. Uijl SG, Uiterwaal CS, Aldenkamp AP, Carpay JA, Doelman JC, Keizer K, et al. A cross-sectional study of subjective complaints in patients with epilepsy who seem to be well-controlled with anti-epileptic drugs. Seizure 2006;15:242-8.

7. Witt JA, Elger CE, Helmstaedter C. Which drug-induced side effects would be tolerated in the prospect of seizure control? Epilepsy Behav 2013;29:141-3.

8. Devinsky O. Cognitive and behavioral effects of antiepileptic drugs. Epilepsia 1995;36:S46-65.

9. Thompson PJ, Huppert FA, Trimble MR. Phenytoin and cognitive functions: effects on normal volunteers and implications for epilepsy. Br J Clin Psychol 1981;20:155-62.

10. Duncun JS, Shorvon SD, Trimble MR. Effects of removal of phenytoin, carbamazepine, and valproate on cognitive function. Epilepsia 1990;31:584-91.

11. Kim SM, Song JY, Lee C, Lee HW, Kim JY, Hong SB, et al. Effect of oxcarbazepine on background EEG activity and cognition in epilepsy. J Epilepsy Res 2013;30:7-15.

12. Donati F, Gobbi G, Campistol J, Rapatz G, Daehler M, Sturm Y, et al. Effects of oxcarbazepine on cognitive function in children and adolescents with partial seizures. Neurology 2006;67:679-82.

13. Donati F, Gobbi G, Campistol J, Rapatz G, Daehler M, Sturm Y, et al. The cognitive effects of oxcarbazepine versus carbamazepine or valproate in newly diagnosed children with partial seizures. Seizure 2007;16:670-9.

14. Mula M. Topiramate and cognitive impairment: evidence and clinical implications. Ther Adv Drug Saf 2012;3:279-89.

15. Park SP, Hwang YH, Lee HW, Suh CK, Kwon SH, Lee BI. Long-term cognitive and mood effects of zonisamide monotherapy in epilepsy patients. Epilepsy Behav 2008;12:102-8.

16. Eddy CM, Rickards HE, Cavanna AE. The cognitive impact of antiepileptic drugs. Ther Adv Neurol Dis 2011;4:385-407.

17. Park SP, Kwon SH. Cognitive effects of antiepileptic drugs. J Clin Neurol 2008;4:99-106.

18. Brodie MJ, Besag F, Ettinger AB, Mula M, Gobbi G, Comai S, et al. Epilepsy, antiepileptic drugs and aggression: an evidence-based review. Pharmacol Rev 2016;68:563-602.

19. Grevers E, Breuer LEM, IJff DM, Aldenkamp AP. Mental slowing in relation to epilepsy and antiepileptic medication. Acta Neurol Scand 2016;134:116-22.

20. IJff DM, Aldenkamp AP. Comorbidities of treatment with antiepileptic drugs. In Duchowny M, Cross JH, and Arzimanoglou A (Eds) Pediatric Epilepsy. New York: McGraw-Hill Professional;2012:424-36.

21. Klinkenberg S, van den Bosch CN, Majoie HJ, Aalbers MW, Leenen L, Hendriksen J, et al. Behavioral and cognitive effects during vagus nerve stimulation in children with intractable epilepsy - a randomized controlled trial. Eur J Paediatr Neurol 2013;17:82-90.

22. IJff DM, Postulart D, Lambrechts DA, Majoie MH, de Kinderen RJ, Hendriksen JG, et al. Cognitive and behavioral impact of the ketogenic diet in children and adolescents with refractory epilepsy: a randomized controlled trial. Epilepsy Behav 2016;17:153-7.

23. Besag F, Caplan R, Aldenkamp A, Dunn DW, Gobbi G, Sillanpää M. Psychiatric and behavioural disorders in children with epilepsy: Behavioural effects of epilepsy surgery. Epileptic Disord 2016;18:S68-76.

24. Hallböök T, Tideman P, Rosén I, Lundgren J, Tideman E. Epilepsy surgery in children with drug-resistant epilepsy, a long-term follow-up. Acta Neurol Scand 2013;128:414-21. 
25. Aldenkamp AP, Arends J, Bootsma HP, Diepman L, Hulsman J, Lambrechts D, et al. Randomized doubleblind parallel-group study comparing cognitive effects of a low-dose lamotrigine with valproate and placebo in healthy volunteers. Epilepsia. 2002;43:19-26.

26. Mula M, Trimble MR. Antiepileptic drug-induced cognitive adverse effects. CNS drugs 2009;23:121-37.

27. Cross JH. Neurodevelopmental effects of anti-epileptic drugs. Epilepsy Res 2010;88:1-10.

28. Carpay JA, Aldenkamp AP, Donselaar van CA. Complaints associated with the use of antiepileptic drugs: results from a community-based study. Seizure 2005;14:198-206.

29. Javed A, Cohen B, Detyniecki K, Hirsch L, Legge A, Chen B, et al. Rates and predictors of patientreported cognitive side-effects of anti-epileptic drugs: an extended follow-up. Seizure 2015;29:34-40.

30. Arif H, Buchsbaum R, Weintraub D, Pierro J, Resor SR Jr, Hirsch L. Patient-reported cognitive side effects of antiepileptic drugs: predictors and comparison of all commonly used antiepileptic drugs. Epilepsy Behav 2009;14:202-9.

31. Bootsma HP, Aldenkamp AP, Diepman L, Hulsman J, Lambrechts D, Leenen L, et al. The effect of antiepileptic drugs on cognition: patient perceived cognitive problems of topiramate versus levetiracetam in clinical practice. Epilepsia 2006;47:24-7.

32. IJff D, Kinderen R, Vader C, Majoie M, Aldenkamp A. Subjectively Perceived side-effects of anti-epileptic drugs in chronic refractory epilepsy. Adv Pharmacoepidemiol Drug Saf 2015;4:186.

33. Aldenkamp AP, Baker G, Pieters MSM, Schoemaker HC, Cohen AF, Schwabe S. The Neurotoxicity Scale: the validity of a patient-based scale, assessing neurotoxicity. Epilepsy Res 1995:20:229-39.

34. Aldenkamp AP, van Meel HF, Baker GA, Brooks J, Hendriks MP. The A-B neuropsychological assessment schedule (ABNAS): the relationship between patient-perceived drug related cognitive impairment and results of neuropsychological tests. Seizure 2002;11:231-7.

35. Witt JA, Helmstaedter C. Monitoring the cognitive effects of antiepileptic pharmacotherapyapproaching the individual patient. Epilepsy Behav 2013;26:450-6.

36. Velissaris SL, Wilson SJ, Newton MR, Berkovic SF, Saling MM. Cognitive complaints after a first seizure in adultshood: influence on psychosocial adjustment. Epilepsia 2009;50:1012-21.

37. Hermann B, Meador KJ, Gaillard WD, Cramer JA. Cognition across the lifespan: antiepileptic drugs, epilepsy, or both? Epilepsy Behav 2010;17:1-5.

38. Samarasekera SR, Helmstaedter C, Reuber M. Cognitive impairments in adults with epilepsy: the relationship between subjective and objective assessments of cognition. Epilepsy Behav 2015;52:9-13.

39. Taylor J, Kolamunnage-Dona R, Marson AG, Smith PE, Aldenkamp AP, Baker GA. Patients with epilepsy: cognitively compromised before the start of antiepileptic drug treatment? Epilepsia 2010;51:48-56.

40. Kwan P, Sills GJ, Brodie MJ. The mechanisms of action of commonly used antiepileptic drugs. Pharmacol. Ther 2001;90:21-34.

41. Beltramini GC, Cendes F, Yasuda CL. The effects of antiepileptic drugs on cognitive functional magnetic resonance imaging. Quant Imaging Med Surg 2015;5:238-46.

42. Veenendaal TM van, IJff DM, Aldenkamp AP, Hofman PAM, Vlooswijk MCG, Rouhl RPW, et al. Metabolic and functional MR biomarkers of antiepileptic drug effectivenees: a review. Neurosci Biobehav Rev 2015;59:92-9.

43. Jokeit H, Okujava M, Woermann FG. Carbamazepine reduces memory induced activation of mesial temporal lobe structures: a pharmacological fMRI-study. BMC Neurol 2001;1:6.

44. Wandschneider B, Stretton J, Sidhu M, Centeno M, Kozák LR, Symms M, et al. Levetiracetam reduces abnormal network activations in temporal lobe epilepsy. Neurology 2014;83:1508-12.

45. Vollmar C, O'Muircheartaigh J, Barker GJ, Symms MR, Thompson P, Kumari V, et al. Motor system hyperconnectivity in juvenile myoclonic epilepsy: a cognitive functional magnetic resonance imaging study. Brain 2011;134:1710-9.

46. Jansen JF, Aldenkamp AP, Majoie MHJ, Reijs RP, de Krom MC, Hofman PA, et al. Functional MRI reveals declined prefrontal cortex activation in patients with epilepsy on topiramate therapy. Epilepsy Behav 2006;9:181-5.

47. Szaflarski JP, Allendorfer JB. Topiramate and its effect on fMRI of language in patients with right or left temporal lobe epilepsy. Epilepsy Behav 2012;24:74-80.

48. Yasuda CL, Centeno M, Vollmar C, Stretton J, Symms M, Cendes F. The effect of topiramate on cognitive fMRI. Epilepsy Res 2013;105:250-5. 
49. Veenendaal TM van, IJff DM, Aldenkamp AP, Lazeron RHC, Hofman PAM, de Louw AJA, et al. Chronic antiepileptic drug use and functional network efficiency. Submitted, 2016.

50. Veenendaal TM van, IJff DM, Aldenkamp AP, Lazeron RHC, Puts NAJ, Edden RAE, et al. Glutamate concentration vary with antiepileptic drug use and mental slowing. Epilepsy Behav. 2016;64:200-205.

51. Alpherts WCJ, Aldenkamp AP. FePsy: The Iron Psyche. Instituut voor epilepsiebestrijding, The Netherlands, Heemstede; 1995.

52. Mula M. Recent and future antiepileptic drugs and their impact on cognition: what can we expect? Expert Rev Neurother 2012;12:667-71.

53. Glauser TA. Behavioral and psychiatric adverse events associated with antiepileptic drugs commonly used in pediatric patients. J Child Neurol 2004;19:S25-38. 
Summary 


\section{Summary}

Chapter 1, the general introduction, provides background information on epilepsy and antiepileptic treatment. Also, the main research questions and the structure of this thesis is provided.

Chapter 2 gives an overview of the current knowledge on the cognitive effects of all commonly used antiepileptic drugs. A relatively large number of studies are available for adults but for children the evidence is sketchy. Phenobarbital has serious cognitive effects that may even impact higher-order cognitive function. Phenytoin may also have an impact on higher-order cognitive function, specifically on memory, mental speed and concentration. Valproate and carbamazepine do not seem to impair cognition to a great extent. No detrimental effect on cognitive function is described for oxcarbazepine. Among the newer antiepileptic drugs, there is clear evidence for druginduced cognitive impairment in language function for topiramate and zonisamide. Levetiracetam and lamotrigine may have a cognitive enhancing effect, especially on attentional function. For other antiepileptic drugs, including the drugs from the newest generation, the data are inconclusive.

Chapter 3 presents the cognitive effects of lacosamide, a relatively new antiepileptic drug therapy with potential benefit as adjunctive treatment in patients with partial onset seizures. None prior studies on the cognitive effects of lacosamide were available. Thirty-three patients with localization related epilepsy between 16-74 years were assessed at baseline before starting lacosamide treatment and during follow-up when the optimal clinical dose was achieved. Although patients had a significantly faster information processing speed (which could not be explained by improved seizure control), they complained more about their cognitive function than before using this drug. This was described as the 'doing better, feeling worse' phenomenon due to an increased awareness of patients of other cognitive difficulties.

Chapter 4 presents the cognitive effects of ethosuximide which is one of the oldest antiepileptic drugs. Nonetheless, information on the cognitive effects of this antiepileptic drug was almost completely absent. Sixty-one patients aged 6-16 years treated with monotherapy ethosuximide for their absence seizures were investigated with a neuropsychological test battery. Treatment was effective in the majority of these patients; $70 \%$ were seizure free for at least 6 months. The higher-order cognitive functions (such as intelligence, memory and visual-perceptual functions) were affected by the seizures but not by the treatment. The fluid cognitive functions, such as activation, alertness, sustained auditory attention and attentional control or switching, showed mild impairments that were attributed to ethosuximide. It was concluded that 
the cognitive impact on psychomotor slowing and alertness of this drug is mild, which is comparable to other antiepileptic drugs such as carbamazepine or oxcarbazepine.

For patients with drug-resistant epilepsy, nonpharmacological treatment options are available. Chapter $\mathbf{5}$ evaluates the cognitive and behavioral impact of the ketogenic diet which is a high-fat, low-carbohydrate diet. In this randomized controlled trial, the performance of 28 patients using the ketogenic diet was compared with 22 patients from the care as usual (control) group. Follow-up assessments at four months showed lower levels of anxious and mood disturbed behavior for the ketogenic diet-group who was also rated as more productive. Cognitive test results showed an improvement of activation in the ketogenic diet-group. Overall, an activated mood and cognitive activation was observed in patients treated with the ketogenic diet which lead to the conclusion that the ketogenic diet has a positive impact on behavioral and cognitive functioning in children and adolescents with refractory epilepsy.

Chapter 6 discusses the impact of long-term treatment with antiepileptic drugs on cognitive development. Fifty patients with epilepsy, aged 6-16 years, who had been treated with monotherapy with either carbamazepine or valproate since epilepsy onset and without any switch to other medication in the past were included in this study. Both treatment groups had a mean treatment duration of approximately two years and were comparable in demographical and epilepsy related characteristics. Cognitive tests assessing 'fluid functions' such as alertness or information processing speed showed no differences between both groups. Apparently, both drugs affected these functions to the same extent. However, patients on carbamazepine had significant lower intelligence values than patients on valproate. These findings suggest that chronic use of carbamazepine may impact higher-order cognitive function and even intelligence over longer periods of time, possibly through accumulating effect of drug-induced impairments on cognitive developmental processes. This emphasizes the need to study effects of chronic use of antiepileptic drugs, especially in children.

Chapter $\mathbf{7}$ describes the subjectively perceived side-effects of antiepileptic drug treatment in patients with chronic refractory epilepsy visiting the outpatient departments of a tertiary referral center. In total, 203 patients completed the questionnaire. Mean age of the patients was 37 years (2-81). Most reported complaints were about their general health (85\%), followed by cognition (77\%), mood $(69 \%)$ and cosmetics (42\%). This study found no differences in the rate and type or severity of complaints between patients using polytherapy versus monotherapy and between patients using older versus newer medication. Patients using antiepileptic drugs with a high risk for side-effects did complain more about their mood but not about their cognition. 
Chapter 8 reports the profile of patients who are at risk for developing cognitive sideeffects of antiepileptic drug treatment. Fifty-three patients aged 20-69 years using antiepileptic medication were divided in a low risk group (levetiracetam or lamotrigine) and a high risk group (phenytoin or topiramate). Patients in the high risk group were slower on a central information processing task than patients in the low risk group. This drug-induced mental slowing appeared to be predicted by subjective complaints about the antiepileptic drug treatment and the duration of epilepsy. In clinical practice, patients with chronic epilepsy complaining about their treatment may be regarded as at risk for developing cognitive side-effects justifying referral for specialized neuropsychological assessment.

Chapter 9 evaluates the impact of chronic use of 'high risk' antiepileptic medication on functional status in patients with intellectual disabilities. The Barthel Index of Activities of Daily Living was used in 153 patients, aged 18-72 years, over a ten year period. This study showed that chronic treatment with 'high risk' medication did not lead to a faster decline of functional status than 'low risk' medication. Furthermore, type of epileptic seizures had no effect. Naturally, level of functional dependency decreases over time due to an increasing age and was affected by level of intellectual disability. Based on this study, it was concluded that, compared to the demographic effects of the patients, antiepileptic drug treatment had no additional negative impact on the functional status in patients with epilepsy and intellectual disabilities.

Chapter 10 and chapter 11 describe the effects of drug-induced impairment on brain function and brain activity. For these MR-studies, 55 patients using a variety of antiepileptic drugs from three categories with different risks for cognitive side-effects, i.e. a low (levetiracetam or lamotrigine), intermediate (carbamazepine, oxcarbazepine, valproate or phenytoin), and a high (topiramate) risk, were investigated with different assessments. Cognition was assessed with the Computerized Visual Searching Task (CVST). Brain connectivity was assessed using resting state functional MRI and graph theoretical network analysis and patients underwent MR spectroscopy. These studies showed that patients with lower processing speeds had lower glutamate concentrations. Furthermore, the functional brain organization for patients in the highest risk category was altered and associated with the drug-induced mental slowing. These studies suggest that mild alterations in neurotransmitter concentration levels and functional brain network organization may have contributed to the development of cognitive side-effects.

In chapter 12, the general discussion, the results of all studies are discussed by answering five pertinent clinical questions. Furthermore, the discussion suggests implications for clinical practice and future research. 
Samenvatting 


\section{Samenvatting}

Hoofdstuk 1, de algemene inleiding, verstrekt achtergrondinformatie over epilepsie en over anti-epileptische medicatie. Ook de belangrijkste onderzoeksvragen en de opzet van dit proefschrift is weergegeven.

Hoofdstuk 2 geeft een overzicht van de huidige kennis over de cognitieve bijwerkingen van alle algemeen gebruikte anti-epileptica. Een relatief groot aantal studies zijn beschikbaar voor de interpretatie van effecten bij volwassenen maar voor kinderen zijn er veel minder studies en gegevens. Fenobarbital heeft ernstige cognitieve bijwerkingen die zelfs de hogere-orde cognitieve functies en dan met name het geheugen kunnen beïnvloeden. Fenytoïne kan eveneens hogere-orde cognitieve functies beïnvloeden, met name de mentale snelheid, concentratie en het geheugen. Valproaat en carbamazepine zijn middelen die in de regel slechts een mild effect hebben op met name de fluïde cognitieve functies (functies die sterk kunnen wisselen, zoals aandachtsfuncties). Hetzelfde geldt ook voor het medicament oxcarbazepine. Van de nieuwere anti-epileptica zien we enerzijds activerende effecten voor levetiracetam en lamotrigine, anderzijds stoornissen van een hogere-orde cognitieve functie, namelijk de taalfunctie voor topiramaat en zonisamide. Voor de andere anti-epileptica, waaronder ook medicamenten van de nieuwste generatie, zijn feitelijk geen gegevens voorhanden.

Hoofdstuk 3 beschrijft de cognitieve effecten van lacosamide, een relatief nieuw antiepilepticum dat gebruikt wordt bij partiële epilepsie. Er waren geen eerdere studies naar de cognitieve effecten van lacosamide beschikbaar en tijdens de voor de registratie noodzakelijke gerandomiseerde klinische studies is niet op cognitie gelet. Drieëndertig patiënten met een gelokaliseerde epilepsie, tussen 16-74 jaar oud, werden onderzocht op baseline (voordat gestart werd met de lacosamide behandeling) en tijdens de followup (wanneer de optimale klinische dosering was bereikt). De patiënten toonden enerzijds een significant snellere centrale informatieverwerkingssnelheid (niet samenhangend met een verbeterde aanvalscontrole). Anderzijds klaagden ze meer over hun cognitief functioneren. Dit is in de literatuur eerder beschreven als het 'doing better, feeling worse' fenomeen, dat het gevolg is van een verhoogd besef van patiënten op andere cognitieve problemen.

Hoofdstuk 4 beschrijft de cognitieve effecten van ethosuximide, een van de antiepileptica van de eerste generatie. Desalniettemin was informatie over de cognitieve bijwerkingen van dit anti-epilepticum nauwelijks aanwezig. Eenenzestig patiënten in de leeftijd 6-16 jaar die behandeld werden met monotherapie ethosuximide voor hun absences werden onderzocht met een neuropsychologische testbatterij. Behandeling was effectief bij het merendeel van onze patiënten: 70\% was minstens 6 maanden 
aanvalsvrij. De hogere-orde cognitieve functies zoals intelligentie, geheugen en visueelperceptuele functies werden beïnvloed door de aanvallen maar niet door de behandeling. De fluïde cognitieve functies zoals activatie, alertheid, volgehouden auditieve aandacht, aandachtscontrole en het switchen van de aandacht, toonden milde verstoringen die toegeschreven werden aan de ethosuximide. Geconcludeerd werd dat de cognitieve bijwerkingen van dit anti-epilepticum mild zijn en het daarmee gerangschikt kan worden in de klasse middelen zoals carbamazepine of oxcarbazepine.

Voor patiënten met een medicatie-resistente epilepsie zijn er non-farmacologische behandelingsopties beschikbaar. Hoofdstuk $\mathbf{5}$ evalueert de cognitieve en gedragsmatige effecten van het ketogeen dieet, dat een vetrijk en koolhydraatarm dieet is. In deze gerandomiseerde gecontroleerde studie werd de prestatie van 28 patiënten die het ketogeen dieet gebruikten vergeleken met 22 patiënten die de gebruikelijke zorg kregen en als controlegroep dienden. Follow-up metingen na vier maanden toonden voor de ketogeen dieet-groep een betere stemming en productiever gedrag. Cognitieve test resultaten toonden een verbeterde activatie bij de ketogeen dieet-groep. Dit leidde tot de conclusie dat het ketogeen dieet een positief effect heeft op het gedragsmatigen cognitief functioneren bij kinderen en adolescenten met refractaire epilepsie.

Hoofdstuk 6 bespreekt het effect van chronische behandeling met anti-epileptica op de cognitieve ontwikkeling bij kinderen. Vijftig patiënten met epilepsie, in de leeftijd 6-16 jaar, die sinds het debuut van de epilepsie uitsluitend behandeld werden met monotherapie carbamazepine of valproaat werden in deze studie geïncludeerd. Beide groepen hadden een gemiddelde behandelduur van bijna twee jaar en waren vergelijkbaar in demografische en epilepsie gerelateerde kenmerken. Cognitieve testen die de fluïde cognitieve functies meten zoals de alertheid en informatieverwerkingssnelheid toonden geen verschillen tussen beide groepen. Klaarblijkelijk beïnvloedden deze anti-epileptica deze functies in dezelfde mate. Patiënten die carbamazepine gebruikten, hadden echter significant lagere intelligentiewaarden dan patiënten die valproaat gebruikten. Deze bevindingen suggereren dat chronisch gebruik van carbamazepine de hogere-orde cognitieve functies kan aantasten na een langere periode. Mogelijk is er sprake van accumulerende effecten waarbij langdurige verstoringen van fluïde cognitieve processen uiteindelijk ook kunnen leiden tot afwijkingen in de cognitieve ontwikkeling. Dit benadrukt de noodzaak om de effecten van chronisch gebruik van anti-epileptica te onderzoeken, vooral bij kinderen.

Hoofdstuk 7 beschrijft de subjectieve klachten over bijwerkingen door patiënten met een chronische, refractaire epilepsie die de polikliniek van een derdelijns instelling bezochten. In totaal werden 203 patiënten geïncludeerd. De meest gerapporteerde klachten gingen over de algemene gezondheid (85\%), gevolgd door klachten over het cognitief functioneren (77\%), de stemming (69\%) en het uiterlijk (42\%). In dit 
onderzoek werden er geen verschillen gevonden in het aantal of de ernst van de klachten tussen patiënten die polytherapie en monotherapie gebruikten. Dit gold ook voor de patiënten die oudere versus nieuwere medicatie gebruikten. Patiënten die een anti-epilepticum gebruikten met een hoog risico op bijwerkingen, klaagden meer over hun stemming maar niet over hun cognitie.

In hoofdstuk 8 wordt onderzocht of het mogelijk is het risico op het ontwikkelen van cognitieve bijwerkingen van anti-epileptica te voorspellen. Drieënvijftig patiënten, in de leeftijd 20-69 jaar die medicatie gebruikten werden in een laag risico groep (levetiracetam of lamotrigine) en een hoog risico groep (fenytoïne of topiramaat) verdeeld. Patiënten in de hoge risico groep waren trager op een centrale informatieverwerkingstaak. Deze door medicatie veroorzaakte mentale traagheid was gecorreleerd met subjectieve klachten over de anti-epileptische behandeling en met de duur van de epilepsie. Patiënten met chronische epilepsie die klagen over hun medicatie, lopen inderdaad risico op het ontwikkelen van cognitieve bijwerkingen. Dergelijke klachten moeten serieus genomen worden en doorverwijzing voor neuropsychologisch onderzoek is dan nuttig.

Hoofdstuk 9 evalueert de invloed van het gebruik van hoog risico anti-epileptische medicijnen op de activiteiten van het dagelijks leven van patiënten met een verstandelijke beperking. De Barthel Index van 153 patiënten, in de leeftijd 18-72 jaar, werd gevolgd gedurende een periode van 10 jaar. Dit onderzoek toonde dat chronische behandeling met hoog-risico medicatie niet leidt tot een meetbare achteruitgang in het uitvoeren van algemeen dagelijkse handelingen dan laag-risico medicatie. Aanvalstype bleek eveneens geen effect te hebben. De functionele status vermindert (wat leidt tot een toename van afhankelijkheid) gedurende deze periode door algemene factoren als veroudering en de mate van verstandelijke beperking. Op basis van dit onderzoek werd geconcludeerd dat anti-epileptische medicatie geen additioneel negatief effect heeft op de algemeen dagelijkse handelingen in de groep patiënten met epilepsie en een verstandelijke beperking.

In hoofdstuk 10 en hoofdstuk 11 worden de onderzoekingen gerapporteerd naar neuronale achtergronden van cognitieve bijwerkingen. Voor deze MRI-studies werden 55 patiënten ingedeeld in drie categorieën op basis van hun medicatie: een groep met een laag risico op cognitieve bijwerkingen (levetiracetam of lamotrigine), een tussengroep (carbamazepine, oxcarbazepine, valproaat of fenytoïne) en een hoge risicogroep (topiramaat). Zij werden op verschillende manieren onderzocht. De snelheid van centrale informatieverwerking (mentale snelheid) als meest gevoelige functie voor de cognitieve effecten van anti-epileptica, werd vastgesteld met de FePsy gecomputeriseerde visuele zoektaak (CVST). Hersenconnectiviteit werd bepaald door het gebruik van functionele MRI tijdens rust en graaf theoretische analyse methodes en 
patiënten kregen MR spectroscopie. Deze onderzoekingen toonden aan dat patiënten met een lagere centrale verwerkingssnelheid, lagere glutamaat concentraties hadden. De functionele hersenorganisatie voor patiënten in de hoogste risicoklasse was veranderd en geassocieerd met de door medicatie geïnduceerde mentale vertraging. Deze studies suggereren dat milde veranderingen in neurotransmitter concentratie niveaus en functionele hersen netwerkorganisatie kunnen hebben bijgedragen aan de ontwikkeling van cognitieve bijwerkingen.

In hoofdstuk 12, de algemene discussie, worden de resultaten van alle studies besproken door het beantwoorden van vijf belangrijke, klinische vragen. Bovendien worden er aanbeveling gegeven voor in de klinische praktijk en voor vervolgonderzoek. 
Valorisation 


\section{Valorisation}

\section{Relevance}

Worldwide, about 70 million people are estimated to have epilepsy. ${ }^{1,2}$ Epilepsy is characterized by recurrent unprovoked seizures. Seizure control is imperative for medical reasons but also because the unpredictable paroxysmal nature of the symptoms (seizures), as well as feeling of loss of control may negatively impact the psychosocial situation affecting the emotional state, coping and consequently, quality of life. Moreover, some objective limitations go with the diagnosis with impact on the social position, such as losing driving license, or restrictions in some sports (such as swimming) as well as occupational limitations.

In most patients with epilepsy, antiepileptic drug (AED) treatment is the first choice of treatment. The best possible outcome of AED treatment is to achieve complete seizure freedom without adverse events. However, AED-induced cognitive side-effects are a major issue in the treatment of epilepsy. Deficiencies in attention, memory, language ability and reaction time are frequently reported side-effects of AEDs. ${ }^{3}$ All AEDs have the potential for adverse effects on cognitive functioning. However, variability between types of drugs and individuals is considerable. Therapeutic dilemmas arise when reduction of seizure frequency can only be accomplished with medication that is associated with cognitive side-effects. As side-effects of AEDs have a major impact on health care costs ${ }^{4}$ and given that most patients with epilepsy consider the adverse cognitive effects of antiepileptic medication to substantially influence their quality of life, ${ }^{5}$ and to be an important reason for AED discontinuation, ${ }^{6,7}$ the possibility of sideeffects should be taken into the medical decision making as a top priority in the choice of AEDs or in the need to switch.

\section{Target groups}

The results of this thesis are relevant for patients with epilepsy and all physicians who treat patients with epilepsy (such as neurologists, child neurologists, general practitioners, pediatricians). Nowadays, as some AEDs are also used for other diseases such as migraine (valproate, topiramate) and neuropathic pain (carbamazepine, gabapentin, pregabalin), this makes this thesis also of interest for psychiatrics who should be aware of the cognitive effects of AED use.

Patients should be informed about the possible negative effects of an AED on their cognition. Furthermore, the outcomes of this thesis help to identify patients with epilepsy at risk for developing cognitive side-effects in an early stage. We paid special attention to subjective reports e.g. self-reported complaints and caregiver reports. Early recognition of patients with epilepsy at risk for cognitive impairments due to treatment through screening procedures can lead to early interventions in their 
treatment strategies. Monitoring cognition and discussing their side-effects should be common in clinical practice when starting or changing AED treatment.

This results of this thesis are also interesting for pharmacologists and the pharmaceutical industry. In the industry-driven regulatory trials only a limited number of subjectively reported side-effects are recorded (using fixed systems such as the WHO-ART system). Objective assessment of side-effects is generally not included. We have highlighted the relevance of taking cognition as an outcome measurement in the randomized controlled trials. Until this is realized, identification of the cognitive profile of new drugs available for clinical practice in the naturalistic setting is a good, but slow, alternative.

\section{Activities}

The research described in this thesis have led to a more understanding of the cognitive adverse effects of AEDs in patients with refractory epilepsy. It has given an overview of the available literature about the cognitive functions that can be affected by antiepileptic treatment in adults and in children and has discussed some of the missing information. Furthermore, the focus has been not only at detecting side-effects, but a start has been made to explain why side-effects occur in specific patients in reaction to specific drugs. We used two (MR-)techniques to identify the neuronal substrates of cognitive side-effects.

The results of this thesis are published (or submitted) in international peer-reviewed journals and are discussed during (poster)presentations at (inter)national symposia. Furthermore, in the Dutch guidelines for epilepsy it is stated that a neuropsychological screening is indicated when cognitive deficits due to medication are reported and for patients using AEDs with a high risk for cognitive effects (such as phenobarbital, phenytoin or topiramate) or for behavioral effects (levetiracetam).

\section{Innovation}

Although the first studies about the cognitive side-effects of AED-treatment are from the late 1970's, ${ }^{8}$ many newer AEDs became available of which the cognitive effects were unknown. Furthermore, evidence was and is clearly lacking for children compared to adult patients with epilepsy. In the last part of this thesis (chapter 12), five pertinent clinical questions could be answered based on the results discussed in this thesis. Some of these questions were also raised by the so-called 'anti-epileptic drug committee' ('Geneesmiddelen commissie') of our epilepsy center. This committee consisting of six neurologists, one pharmacist, three trial nurses, one clinical chemist, and one neuropsychologist is meeting every month to discuss the progress of all drug-related research that is performed in our center. This includes the implementation of the pharmacological studies initiated by the industry but also of investigator driven studies. 


\section{Implementation}

The results of this thesis can be used in clinical practice and for further research implications which are also discussed in the discussion part of this thesis. We have highlighted that screening instruments can be used for early detection of side-effects that can be confirmed with a neuropsychological investigation. It is not known whether and when our recommendations for the pharmaceutical industry and for clinically driven studies will be implemented. At this moment, we are gathering data of patients with epilepsy using AEDs performing computerized cognitive tasks (assessing alertness and information processing speed) simultaneously with eye tracking, which measures eye positioning and eye movements. This might possibly be a new useful technique to investigate drug-induced impairments. 


\section{References}

1. Ngugi AK, Bottomly C, Kleinschmidt I, Sander JW, Newton CR, Estimation of the burden of active and life-time epilepsy: a meta-analytic approach. Epilepsia 2010;51:883-90.

2. Ngugi AK, Kariuki SM, Bottomley C, Kleinschmidt I, Sander JW, Newton CR. Incidence of epilepsy: a systematic review and meta-analysis. Neurology 2011;77:1005-12.

3. Aldenkamp AP, De Krom M, Reijs R. Newer antiepileptic drugs and cognitive issues. Epilepsia 2003;44: 21-9.

4. Kinderen RJA de, Evers SMAA, Rinkens R, Postulart D, Vader Cl, Majoie MHJM, Aldenkamp AP. Sideeffects of antiepileptic drugs: the economic burden. Seizure 2014;23:184-90.

5. Brunbech L, Sabers A. Effect of antiepileptic drugs on cognitive function in individuals with epilepsy: A comparative review of newer versus older agents. Drugs 2002;62:593-604.

6. Bootsma HPR, Coolen F, Aldenkamp AP, Arends J, Diepman L, Hulsman J, et al. Topiramate in clinical practice: long-term experience in patients with refractory epilepsy referred to a tertiary epilepsy center. Epilepsy Behav 2004;5:380-7.

7. White JR, Walczak TS, Leppik IE, Rarick J, Tran T, Beniak TE, et al. Discontinuation of levetiracetam because of behavioral side effects. Neurology 2003;61:1218-21.

8. Trimble M. The effect of anti-convulsant drugs on cognitive abilities. Pharmacol Ther B 1979;4:677-85. 
Dankwoord 


\section{Dankwoord}

En dan... is het af! Dankzij een flinke eindspurt op het laatst, is de eindstreep ineens bereikt. En wat heb ik ervan genoten! Nooit gedacht dat ik met zoveel enthousiasme data zou verzamelen om deze vol nieuwsgierigheid te analyseren. Vervolgens kon ik wel wat aansporing gebruiken om de bevindingen daadwerkelijk op te schrijven. Ik heb dit hele traject als zó leuk en uitdagend ervaren, dat het bijna jammer is dat dit proefschrift klaar is. Gelukkig is het uitvoeren van wetenschappelijk onderzoek nooit 'af' of 'klaar' en hopelijk kan ik in de toekomst deze passie blijven volgen. Dit proefschrift zie ik dan ook graag als een nieuw begin dat zonder de hulp van zovelen nooit mogelijk was geweest. Een woord van dank lijkt me dan ook zeer gepast.

Op de eerste plaats aan alle patiënten die hebben deelgenomen aan de wetenschappelijke onderzoeken. Of het nu ging om een afname van 'slechts' enkele korte taken of een hele uitgebreide MRI-studie, steeds weer werd ik aangenaam verrast door het enthousiasme en de motivatie van de deelnemers. Zelfs als er een flinke afstand voor overbrugd moest worden (en dat soms tot twee keer toe wanneer de scans niet voldoende bruikbaar bleken te zijn). Zonder deze bereidwillige patiënten is het uitvoeren van wetenschappelijk onderzoek niet mogelijk.

Prof. dr. A.P. Aldenkamp, beste Bert, al heel snel was ik onder de indruk van jouw kennis, ervaring en expertise als clinicus en als wetenschapper. Ik wilde dan ook dolgraag onderzoek doen met jou als mijn promotor en samen bedachten we dit onderwerp; uiteraard al bekend terrein voor jou maar helemaal nieuw voor mij. Jij hebt me heel veel geleerd en me steeds jouw hulp geboden. Als ik het even niet meer zag zitten, liep ik bij jou binnen (ik heb inmiddels geleerd om meteen om hulp te vragen) en doordat jij overal een positieve draai aan weet te geven, kon ik daarna weer enthousiast en gemotiveerd aan het werk. Dank ook voor het vertrouwen in mij, de kansen die jij me biedt en je supersnelle, opbouwende en kritische feedback (ook al was ik soms een beetje eigenwijs). Bedankt ook voor het overnemen van mijn klinische werkzaamheden zodat ik me volledig kon richten op het afronden van mijn proefschrift. Als je maar weet dat ik me niet nog eens laat wegjagen van de GWD $:$.

Prof. dr. H.J.M. Majoie, beste Marian, oorspronkelijk was je niet eens betrokken bij mijn promotie, maar wat zijn jouw kennis, inzet en altijd snelle en kritische commentaar van toegevoegde waarde gebleken! Je attendeerde me op elk nieuw project en betrok me overal bij, wat zeer motiverend werkt. Jouw eindeloze enthousiasme werkt aanstekelijk, niet alleen voor mij maar ook voor jouw patiënten die bereidwillig waren deel te nemen aan de verschillende studies. Het grootste compliment dat ik tijdens mijn promotietraject heb gekregen, is dat ik op jou zou lijken. 
Dr. J.F.A. Jansen, beste Jaap, zonder jouw kennis, ideeën en internationale contacten was de uitvoer van de AED MRI studie nooit mogelijk geweest. Als ik tegen moeilijkheden aanliep, was jij daar met de oplossing. Daarnaast blijf je altijd geduldig om mij al die ingewikkelde technische methoden uit te leggen. Ik blijf onder de indruk van jouw gave om steeds weer zulke snelle, scherpe en bruikbare feedback te geven, zelfs op de klinische artikelen.

Dr. R.H. Lazeron, beste Richard, jij bent het brein achter de AED MRI studie. Het eerste idee bleek praktisch onhaalbaar te zijn, maar ook daar werd een oplossing voor gevonden. Jouw klinische blik was hierbij erg belangrijk. Dankzij jou heb ik een groot aantal deelnemers kunnen includeren. Dank voor jouw vertrouwen in mij om deze studie uit te voeren en dank dat je de herbeoordelingen van alle patiënten met me wilden bekijken.

Ook dank aan Prof. dr. P.A.M. Hofman, Prof. dr. ir. W.H. Backes en Dr. A.J.A. de Louw voor het beoordelen van alle MRI-scans en hun adviezen omtrent de AED MRI studie. Remco Berting en Esther Peeters, bedankt voor het maken van alle MRI-scans.

Graag wil ik de leden van de beoordelingscommissie Prof. dr. G.A. Baker, Dr. H.P. Bootsma, Dr. R.P.W. Rouhl, Prof. dr. F.R.J. Verhey onder voorzitterschap van Prof. dr. R.J. van Oostenbrugge hartelijk danken voor het lezen en beoordelen van mijn proefschrift.

Dank ook aan de raad van bestuur van Kempenhaeghe; Dr. M. Chatrou en Drs. N. Geurts, en aan de afdeling Onderzoek \& Ontwikkeling van Kempenhaeghe; Prof. dr. Boon, Dr. Laura Gottmer-Welschen en Sunita Bunyadi, voor het mogelijk maken en stimuleren van wetenschappelijk onderzoek. Prof. dr. Boon, beste Paul, ook al was u niet direct betrokken, $u$ bleef altijd geïnteresseerd en middels de promovendidagen volgde u mijn traject. Ik zal de gezellige promovendi-diners bij Vangaelen missen. Alhoewel ik presenteren in het Engels aanvankelijk vreselijk eng vond, moet ik eerlijk toegeven dat het inderdaad steeds iets makkelijker wordt. Om te worden uitgenodigd als spreker op het jaarlijkse Kempenhaeghe-congres vond ik dan ook een enorme eer!

Ook dank aan mijn collega's van de Gedragswetenschappelijk Dienst; een aantal jaar geleden begon ik met mijn stage en dankzij jullie en de fijne werksfeer voelde ik me hier meteen thuis. Dank voor het afnemen en scoren van de neuropsychologische onderzoeken, het overnemen van mijn werkzaamheden en jullie belangstelling en steun. Een aantal collega's wil ik graag in het bijzonder bedanken: Dr. Jos Hendriksen, dank dat je me de mogelijkheid bood de GZ-opleiding te combineren met mijn promotieonderzoek. Als praktijkopleider waak je ervoor dat mijn opleiding niet onder druk staat en zorg je ervoor dat ik daar het maximale uit kan halen. Het voorstel me een 
half jaar te onttrekken uit de patiëntenzorg om me compleet op de afronding van mijn promotie te kunnen richten, was even schrikken maar bleek het laatste zetje dat ik nodig had. Caroline van der Linden, jij bent altijd zeer betrokken, oprecht geïnteresseerd en hebt het beste met mij en mijn collega's voor. Dat maakt dat ik graag bij je binnen loop om van alles met je te delen, voor advies of om eens heerlijk te kunnen lachen. Een dag zonder jou op de GWD, is dan ook een dag niet gelachen. Lisette van Gemert, tijdens mijn supervisie kwamen ook situaties uit de onderzoekswereld ter sprake waarin je met me meedacht en me advies gaf waar ik mee verder kon. Dr. Nynke Bodde, dank voor je belangstelling en betrokkenheid, met name tijdens de afrondende fase van mijn promotie kon ik al jouw tips goed gebruiken. Je bent de enige aan wie ik dit dankwoord eerder durfde te laten lezen. Els van der Horst, dank voor jouw begrip als ik door mijn onderzoekwerkzaamheden een rapport nog niet in zijn geheel af had of onze werkbegeleiding wilde verschuiven. Door jou leer ik nog kritischer te kijken naar mijn verslagen (zelfs naar de punten en komma's), wat ook heel bruikbaar was tijdens het schrijven van dit proefschrift. José Wirken, we zijn tegelijkertijd als stagiaire begonnen en we zijn er nog steeds! Heel veel succes toegewenst met jouw GZ-opleiding. Annemarie Buermans, dank voor het rekening houden met drukke perioden rondom mijn promotie waarin je me zoveel mogelijk probeerde te ontzien bij de planning. Christie Stals en Astrid van Engelen, dank voor het plannen van alle promotie-overleggen en overige afspraken, het regelen van zoveel verschillende dingen en dat ik altijd een beroep op jullie mag doen. (Moeder) Thérèse van den Boogaard: ik mis jou (maar ook jouw koekjes) nog steeds.

Graag wil ik mijn beide paranimfen bedanken dat ze deze dag aan mijn zijde willen staan. Janneke, het combineren van de GZ-opleiding, patiëntenzorg en promotie bleek soms best een uitdaging en wat was het dan fijn om een 'buddy' te hebben, die in hetzelfde vaarwater zat. Gelukkig werden we tegelijkertijd naar den Boondert 'verbannen' waar we al onze belevenissen (al dan niet promotie-gerelateerd) met elkaar konden delen. Sylvie, tegelijkertijd zijn we begonnen aan onze stage in Kempenhaeghe. We bleken een aantal overeenkomsten te hebben en er was (daardoor) meteen een klik. Geregeld heb ik je om hulp gevraagd en altijd ben je bereid me te helpen waar nodig en denk je met me mee. Heel plezierig dat we elkaar nog geregeld zien! Ook dank aan mijn overige onderzoeksmaatjes waardoor dit werk nóg leuker en vooral gezelliger werd. Geke, jij introduceerde mij in onderzoeksland en nam me overal mee op sleeptouw naartoe. Ik mis mijn reislustige en enthousiaste congresmaatje nog steeds. Reina, dankzij jou kreeg ik een aantal leuke projecten in handen en hebben we samen aan artikelen kunnen werken. Ook het gezamenlijk plannen van onze bruiloften op de Boondert, werkte erg inspirerend. Debby, nadat onze voorgangers al klaar waren, bleven wij nog over... Gelukkig ben ik nog niet weg van Kempenhaeghe en kan ik jouw promotie blijven volgen. Ik wens je veel succes met jouw promotieonderzoek. 
Dank aan alle coauteurs voor hun waardevolle bijdragen aan de artikelen in dit proefschrift. Speciaal woord van dank aan Tamar van Veenendaal, mijn 'twin'. Wat ben ik blij met een vrouwelijke (girlpower) technicus! Samen hebben we de AED MRI studie uitgevoerd en ook bij de andere studies was je steeds betrokken. Geregeld hebben we overleg gehad via mail, telefoon of op de woensdag in Maastricht. Altijd ben je scherp en kritisch maar ook geduldig en behulpzaam bij het telkens uitleggen van al die lastige technische dingen. Ook dank aan een aantal voorgangers die mij hebben geïnspireerd en geënthousiasmeerd voor het uitvoeren van wetenschappelijk onderzoek. Dr. Mariëlle Vlooswijk, jouw verdediging was de eerste die ik meemaakte waardoor ik dacht: 'dat wil ik ook'! Dr. Hilde Braakman, Dr. Nynke Bodde, Dr. Saskia Ebus en Dr. Danielle Lambrechts, bedankt dat ik bij een deel van jullie promotieonderzoek betrokken mocht zijn. Hierdoor groeide mijn motivatie om een eigen proefschrift te realiseren. Ook dank aan diegenen die me hebben geholpen bij het vormgeven van dit proefschrift; Tiny Wouters voor de opmaak en Xander Abbink voor het ontwerpen van de kaft.

Graag wil ik ook de leden van de geneesmiddelengroep Kempenhaeghe noemen, het werkt erg inspirerend om met jullie te kunnen brainstormen en discussiëren. Prof. dr. Johan Arends, bedankt dat ik op een zondagmiddag bij jou (de inmiddels ex-buurman van mijn ouders) mocht binnenlopen, waardoor ik op Kempenhaeghe terecht ben gekomen. Irene Gijselhart, dank voor al jouw hulp bij het opvragen van de literatuur. André Kamping, bedankt voor het organiseren van de MIS-uitdraaien. Afdeling I\&A, dank voor het oplossen van alle computer problemen (het herstarten van mijn computer blijft een handige tip). Linda Linssen-Ghielen, het plannen van alle afspraken met Marian is een uitdaging, dankjewel daarvoor. Ook dank aan Leonie Diepman, Sonja Vervoort, Marlies Dolmans en alle overige belangstellende collega's, voor jullie support. Ook bedank ik graag Pieter Beckers, dankzij een kleine attentie van jou op mijn bureau begint de werkdag nóg plezieriger.

In dit dankwoord mag ook de oppas niet ontbreken, waardoor ik onbezorgd aan het werk kan, wetende dat Oscar in goede handen is. Marie-Louise, wat ben ik blij dat ik jou als gastouder heb gevonden. Het duurde even, maar Oscar lijkt zijn draai gevonden te hebben. Ook dank aan mijn familie die de opvang vol enthousiasme voor een aanzienlijk deel op zich neemt; Imke \& Nicole, een vrije dag opofferen, bijspringen op het laatste moment of logeerpartijtjes, niets is jullie teveel gevraagd. Jon, jij ontfermt je over Oscar alsof het jullie eigen kleinkind is en dat wordt gevoeld, getuige de foto's van een grote 'big smile'. Sterre \& Willem, jullie brengen graag een dag door met Oscar om me uit de brand te helpen, zelfs als de wekker dan erg vroeg gaat. Roanne, de rol van peettante was jou tijdens onze kinderjaren al toebedeeld en die rol maak jij helemaal waar. Mama, ondanks je fulltime baan kan ik steeds weer op je rekenen. Jij neemt zelfs vrij van je werk zodat je kan komen oppassen en wij kunnen gaan werken. Sandra, jij 
bent van onschatbare waarde! Maar liefst twee dagen per week neem jij de zorg voor onze zoon op je en dit wordt geregeld uitgebreid met blijven eten, logeerpartijtjes en extra uurtjes tussendoor. Oscar is dol op jullie!

Graag wil ik alle vrienden, vriendinnen, de UvA-meiden, mijn GZ-intervisieclubje en andere belangstellenden bedanken voor hun support de afgelopen jaren. Voor een familiemens als ik mogen in dit dankwoord eveneens mijn oma, Gon, ooms \& tantes en neven \& nichten niet ontbreken. Door de afstand zien we elkaar (te) weinig maar wat is het gezellig als we allemaal bij elkaar zijn. En aangezien ik nu weer tijd heb... ik zie een uitnodiging voor een paar dagen Spanje of weekendje Parijs graag tegemoet hoor! Ook dank aan familie Barceló, voor jullie lieve mails, appjes en belletjes en aan familie Couteaux, of er nu geklust moet worden in en rondom huis of leuke, gezellige dingen doen (dagjes shoppen in Antwerpen, naar de film, KRAS-vergaderingen, samen op vakantie, heerlijke etentjes en de familieborrels in het weekend), jullie staan altijd klaar voor mij en mijn gezin en dat waardeer ik enorm!

Mijn schoonfamilie; Henri \& San, Bart, Pim, jullie hadden vanaf het begin vertrouwen in mij. Tijdens mijn studie op kamers wonen in Amsterdam werd dankzij jullie samenwonen in een appartement op de Albert Cuyp, dat een paar jaar later vanwege mijn stage verruild werd voor Eindhoven. Bij jullie ben ik 'eigen', een Pennings (ondanks dat mijn aangetrouwde naam niet op de kaft staat) en voel ik jullie trots. Ik ben blij onderdeel uit te mogen maken van jullie gezin en ben jullie voor zoveel ontzettend dankbaar!

En dank aan mijn 'eigen' gezin; Sterre, dyslexie of epilepsie, dat is toch eigenlijk hetzelfde? Dat geldt ook voor ons; ogenschijnlijk anders maar toch lijken we zoveel op elkaar. We delen de passie voor ons eigen vak, de gedrevenheid daarin en de zorgzaamheid voor anderen (jij met dieren en ik met mensen). Dat maakt dat ik zo dol op jou ben, Guppie! Roanne, het hebben van zo'n brave en serieuze studiebol als oudere zus zal niet altijd makkelijk geweest zijn. Inmiddels ben je allang uit mijn schaduw gestapt en zijn de rollen helemaal omgedraaid; wat ben ik trots op jou, Ro! Stenmar, een zusje als advocaat en een zusje als paraveterinair is natuurlijk veel boeiender (en handiger) dan een zusje als neuropsycholoog dat zich bezig houdt met onderzoek. Het is dat jij zoveel meemaakt waardoor we nooit uitgepraat zijn. Die bevlogenheid van jou maakt dat ik in jou geloof, Poederbaas! Ook dank aan jullie partners: Willem, helaas zie ik je weinig maar gelukkig heb ik met Oscar tegenwoordig een troef in handen. Dat broodje Mangiare op de zondagmiddag is wat mij betreft voor herhaling vatbaar! Daan, you made my sister smile again! Je gaat me nog vaak zien in Amsterdam. Inge, bij jou kan ik altijd terecht, je helpt me om alles te relativeren en van een positieve kant te bekijken. Ik bof met jou als mijn $3^{\mathrm{e}}$ zus, Sienna! 
Pap \& mam, jullie hebben me altijd gestimuleerd het beste uit mezelf te halen en mijn uiteindelijke doel voor ogen te houden. Jullie dachten met me mee welke studie bij me zou passen en brachten me op het idee om vakantiewerk bij Kempenhaeghe te gaan doen. Jullie steunen me in de keuzes die ik maak en staan voor me klaar wanneer ik het nodig heb. Dank voor zoveel!

Lieve, allerliefste Oscar, soms kan ik nog steeds niet geloven zo'n mooi en lief mannetje van mij is. Jouw komst bleek een goede drijfveer te zijn om dit boekje daadwerkelijk af te maken. Ook jij hebt hieraan een steentje bijgedragen; tijdens jouw slaapjes kon mama (zonder schuldgevoel) fijn doorwerken. Het is fantastisch om jouw moeder te mogen zijn, jij bent mijn allergrootste trots!

Lieve Rolf, we gaan inmiddels al lang terug... Je was er al bij toen ik mijn diploma op de middelbare school haalde. Terwijl ik de continue drang heb mezelf te bewijzen en mezelf opnieuw uit te dagen, geef jij me steeds de bevestiging die ik zo nodig heb. Jij en jouw onvoorwaardelijke liefde zorgen ervoor dat ik in balans blijf. Jij en Oscar zijn mijn alles, ik hou van jullie. 
Curriculum Vitae 


\section{Curriculum Vitae}

Dominique Mistral IJff werd op 3 mei 1987 geboren in Weert en groeide op in Waalre. Na het behalen van haar VWO-diploma in 2005 aan het Van Maerlantlyceum in Eindhoven, verhuisde ze naar Amsterdam. Van 2005 tot 2010 studeerde zij klinische neuropsychologie aan de Universiteit van Amsterdam. Naast haar studie werkte ze als pedagogisch medewerker bij Unieke Kinderopvang in Amsterdam. Tijdens de zomervakanties werkte ze als begeleider in de dagelijkse zorg en activiteiten van volwassenen en kinderen met epilepsie bij het Epilepsiecentrum Kempenhaeghe in Heeze, waar haar

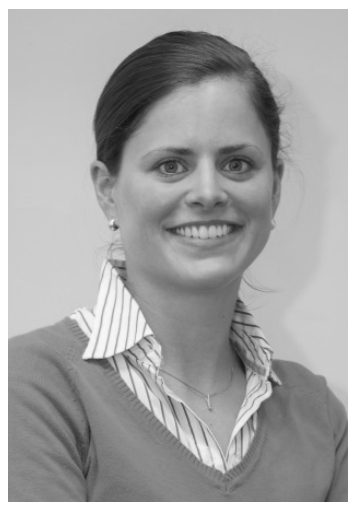
interesse voor epilepsie groeide. In het laatste jaar van haar tweejarige master Gezondheidszorgpsychologie verrichte zij een klinische stage en een wetenschapsstage te Kempenhaeghe. Hieruit volgde de eerste publicatie waar ze aan heeft bijgedragen over het cognitieve en gedragsmatige profiel van kinderen met een frontaalkwabepilepsie. $\mathrm{Na}$ haar afstuderen werkte zij 3 jaar als psycholoog bij de Gedragswetenschappelijke Dienst van Kempenhaeghe. In september 2013 startte zij aldaar met de postdoctorale opleiding tot GZ-psycholoog in combinatie met haar promotieonderzoek. Momenteel rondt ze het klinische gedeelte van haar opleiding af. In de toekomst ambieert ze het combineren van patiëntenzorg met wetenschappelijk onderzoek.

Dominique Mistral IJff was born on May $3^{\text {rd }} 1987$ in Weert. She was raised in Waalre. After graduating her secondary school education in 2005 at the Van Maerlantlyceum in Eindhoven, she moved to Amsterdam. She studied clinical neuropsychology at the University of Amsterdam from 2005 to 2010. During her study, she worked as a day care worker at Unieke Kinderopvang in Amsterdam. During summer, she assisted in the daily care and activities of adults and children with epilepsy at the Epilepsy Center Kempenhaeghe in Heeze, which resulted in a growing interest in epilepsy. During the last year of her two-year master Health Care Psychology, she performed a clinical internship and a research internship. This research internship resulted in a first publication in which she contributed about the cognitive and behavioral findings in children with frontal lobe epilepsy. After graduating, she started working as a psychologist at the Department of Behavioral Sciences at Kempenhaeghe. In September 2013 , she started with the postgraduate program to become a registered mental-health psychologist in combination with her PhD-research. Currently, she is finishing the clinical part of her post-graduate program. In the future, she aspires to combine patient care with clinical research. 
List of publications 


\section{List of publications}

\section{In this thesis}

IJff DM, Aldenkamp AP. Comorbidities of treatment with antiepileptic drugs. In: Duchowny M, Cross JH, and Arzimanoglou A (Eds) Pediatric Epilepsy. New York: McGraw-Hill Professional;2012:424-36.

IJff DM, Aldenkamp AP. Cognitive side-effects of antiepileptic drugs in children. In: Dulac O, Lassonde M, Sarnat HB (Eds) Handbook of clinical neurology. Oxford: Elsevier Science;2013;111:707-18.

IJff DM, van Veenendaal TM, Majoie HJ, de Louw AJ, Jansen JF, Aldenkamp AP. Cognitive effects of lacosamide as adjunctive therapy in refractory epilepsy. Acta Neurol Scand. 2015;131:347-54.

IJff DM, Veenendaal TM, Debeij-van Hall MH, Jansen JFA, de Louw AJA, Majoie HJM, Aldenkamp AP. The cognitive profile of ethosuximide. Pediatr Drugs 2016;18:379-85.

IJff DM, Postulart D, Lambrechts DA, Majoie MH, de Kinderen RJ, Hendriksen JG, Evers $\mathrm{SM}$, Aldenkamp AP. Cognitive and behavioral impact of the ketogenic diet in children and adolescents with refractory epilepsy: a randomized controlled trial. Epilepsy Behav. 2016;17:153-7.

IJff DM, Veenendaal TM, Jansen JFA, Majoie HJM, Aldenkamp AP. Long-term impact of antiepileptic drug treatment on cognitive development. Submitted.

IJff DM, Kinderen R, Vader C, Majoie M, Aldenkamp A. Subjectively perceived sideeffects of antiepileptic drugs in chronic refractory epilepsy. Adv Pharmacoepidemiol Drug Saf. 2015;4:186.

IJff DM, Veenendaal TM, Jansen JFA, Backes WH, Hofman PA, de Louw AJA, Majoie HJM, Lazeron RH, Aldenkamp AP. Cognitive adverse effects of antiepileptic drug treatment; how to recognize who is at risk. Submitted.

IJff DM, Moll I, Tan IY, Majoie HJM, Aldenkamp AP. Effect of high risk chronic antiepileptic drug use on functional status; a ten year follow-up study using the Barthel Index. Submitted.

Veenendaal TM, IJff DM, Aldenkamp AP, Lazeron RH, Puts NAJ, Edden RAE, Hofman PA, de Louw AJA, Backes WH, Jansen JFA. Glutamate concentration vary with antiepileptic drug use and mental slowing. Epilepsy Behav. 2016;64:200-205. 
Veenendaal TM, IJff DM, Aldenkamp AP, Lazeron RH, Hofman PA, de Louw AJA, Backes WH, Jansen JFA. Chronic antiepileptic drug use and functional network efficiency. Submitted.

\section{Other publications}

Braakman HM, IJff DM, Vaessen MJ, Debeij-van Hall MH, Hofman PA, Backes WH, Vles JS, Aldenkamp AP. Cognitive and behavioural findings in children with frontal lobe epilepsy. Eur J Paediatr Neurol. 2012;16:707-15.

Bodde NM, van der Kruijs SJ, IJff DM, Lazeron RH, Vonck KE, Boon PA, Aldenkamp AP. Subgroup classification in patients with psychogenic non-epileptic seizures. Epilepsy Behav. 2013;26:279-89.

Halma E, de Louw AJ, Klinkenberg S, Aldenkamp AP, IJff DM, Majoie M. Behavioral sideeffects of levetiracetam in children with epilepsy: a systematic review. Seizure 2014;23:685-91.

Ebus SC, IJff DM, den Boer JT, van Hall MJ, Klinkenberg S, van der Does A, Boon PJ, Arends JB, Aldenkamp AP. Changes in the frequency of benign focal spikes accompany changes in central information processing speed: a prospective 2-year follow-up study. Epilepsy Behav. 2015;43:8-15.

van Veenendaal TM, IJff DM, Aldenkamp AP, Hofman PA, Vlooswijk MC, Rouhl RP, de Louw AJ, Backes WH, Jansen JF. Metabolic and functional MR biomarkers of antiepileptic drugs effectiveness: a review. Neurosci Biobehav Rev. 2015;59:92-9.

Grevers E, Breuer L, IJff DM, Aldenkamp AP. Mental slowing in relation to epilepsy and antiepileptic medication. Acta Neurol Scand. 2016;134:116-22. 